\title{
Dimensão fractal e métodos quantitativos aplicados ao estudo de comunidades do macrobentos marinhos
}

Tese apresentada ao Instituto Oceanográfico da Universidade de São Paulo, como parte dos requisitos para obtenção do título de Doutor em Ciências, área de Oceanografia Biológica.

Orientadora:

Prof $^{a}$. Dr ${ }^{\mathrm{a}}$. Ana Maria Setubal Pires Vanin

São Paulo 
Universidade de São Paulo

Instituto Oceanográfico

Dimensão fractal e métodos quantitativos aplicados ao estudo de comunidades do macrobentos marinhos

\section{Carina Waiteman Rodrigues}

Tese apresentada ao Instituto Oceanográfico da Universidade de São Paulo, como parte dos requisitos para obtenção do título de Doutor em Ciências, área de Oceanografia (Biológica).

Julgada em

Conceito

$\operatorname{Prof(a).~Dr(a).~}$

Conceito

$\operatorname{Prof}(\mathrm{a}) . \operatorname{Dr}(\mathrm{a})$

Conceito

$\operatorname{Prof}(\mathrm{a}) . \operatorname{Dr}(\mathrm{a})$.

Conceito

Prof(a). Dr(a)

Prof(a). Dr(a)

Conceito 
Aos meus pais, irmãos e meu marido

E aquele que está para chegar, Raul 


\section{AGRADECIMENTOS}

À Profa . Ana Maria Setubal Pires-Vanin, minha orientadora. Obrigada pela amizade, por ter acreditado no meu potencial durante todos esses anos e ter me dado crédito na realização deste doutorado.

Ao CNPq, pela concessão da bolsa de doutorado, sem a qual não seria possível desenvolver meu projeto.

Ao Instituto Oceanográfico da Universidade de São Paulo, e a todos os funcionários da Base Clarimundo de Jesus em Ubatuba, por terem possibilitado o desenvolvimento $e$ realização do meu projeto.

Um agradecimento especial à Sandra Bromberg, a Bromba, você para mim não é uma simples técnica de laboratório, você é um desenho animado, uma pessoa alegre e com uma sabedoria ímpar. Eu sinto e sentirei muita falta da nossa convivência, mas é reconfortante saber que em ti eu tenho uma verdadeira amiga. Muito obrigada por todos esses anos de conselhos, ajuda, amor e carinho.

Agradeço as minhas amigas Caia, Carolina Siliprandi e Betina Galerani. Sem a amizade de vocês, a vida no IO teria sido uma chatice, algo irritantemente tedioso. Amo vocês muito. Fico muito feliz de saber que o Raul terá tias tão loucas, malucas, mas extremamente amorosas como vocês gatas.

Aos meus amigos Luís Fabiano (Bica), Thaís, Pablo Muniz, Natalia Venturini, Vanessa Souto, Fábio, Paula Carpinteiro, Eduardo, Valéria Fabiane, Carlos Piriquito pelas risadas, pelos conselhos e pelo apoio nos momentos difíceis.

Um beijo especial para todos aqueles que ajudaram de maneira direta ou indireta na realização deste doutorado. Aos estagiários mais empolgados Stella Coelho e Tiago Carvalho, obrigada pela ajuda no campo e na eterna medição 
das algas. Aos amigos de longa ou pouca data Maurício Shimabukuro, Arthur Güth, Juliana Genistretti, Michele Quesada, Flávia Costa, Paulo Sumida, Valter, Guilherme Abuchahla. Caso eu tenha esquecido alguém, mil desculpas, não se deve confiar na cabeça de uma grávida.

Aos meus pais, Helio e Luzia, aos meus irmãos Erick e William. Vocês são meus exemplos de caráter e amor. Ao meu marido Thiago Henrique, te amo, você é meu melhor amigo, meu companheiro, minha cobaia na cozinha, alguém tão compreensivo e paciente comigo como você está para nascer. E ao meu filho (the unborn child), Raul, dezembro será mais alegre, te amo pequeno ser.

Atenciosamente,

Carina. 
SUMÁRIO

INTRODUÇÃOO 1

Capítulo 1 - "Avaliação do desempenho dos indicadores quantitativos da 11 estrutura de Sargassum filipendula sobre a epifauna bentônica"

\begin{tabular}{ll}
\hline Resumo & 11
\end{tabular}

$\begin{array}{ll}\text { Abstract } & 12\end{array}$

1. Introdução 13

2. Material \& Métodos 16

2.1. Área de Estudo 16

2.2. $\quad$ Trabalho de Campo 18

2.3. Laboratório 18

2.4. Análises Estatísticas 20

3. Resultados 21

3.1. Abióticos 21

3.2. Sargassum filipendula e Medidas Morfológicas 24

3.3. Comunidade e Densidade da Fauna 30

4. Discussão 34

Capítulo 2 - Dimensão fractal e medidas quantitativas: sua influência na
ocupação dos bancos de Sargassum filipendula pela macrofauna

Resumo

38

$\begin{array}{ll}\text { Abstract } & 39\end{array}$

1. Introdução 40

2. Material \& Métodos 43

2.1. Área de Estudo 43

2.2. Trabalho de Campo 43

2.3. Laboratório 44

2.4. Análises Estatísticas 47

3. Resultados 49

3.1. Quantidade e Complexidade do habitat do Sargassum filipend ula 49

3.2. Relação entre as medidas de complexidade do Sargassum filipendula e macrofauna total

3.3. Relação entre as medidas de complexidade do Sargassum filipendula e anfípodes

3.4. Abundância dos anfípodes, classes de tamanho e as medidas de complexidade 
Capítulo 3 - Colonização de anfípodes em Sargassum filipendula defaunado $e$ substratos artificiais na Praia do Lamberto, Ubatuba, sudeste do Brasil

Abstract

1. Introdução

2. Material \& Métodos $\quad 88$

2.1. Área de Estudo 88

2.2. Trabalho de campo $\quad 88$

2.3. Laboratório $\quad 89$

2.4. Análises Estatísticas $\quad 91$

3. Resultados 93

$\begin{array}{lr}\text { 4. Discussão } & 103\end{array}$

$\begin{array}{lr}\text { CONSIDERAÇÕES FINAIS } & 109\end{array}$

$\begin{array}{lc}\text { REFERÊNCIAS BIBLIOGRÁFICAS } & 111\end{array}$




\section{INDICE DE FIGURAS}

\section{INTRODUÇ̃̃O}

Figura 01 - (a) Desenho esquemático de um Sargassum com três ramos laterais; (b) aspecto dos receptáculos masculinos; (c) aspecto dos receptáculos femininos; (d) vesículas flutuadoras ou aerocistos; (e) aspecto do corte transversal do filoide na região do criptostomas. Fonte: Paula, 1988.

Figura 02 - Folha de samambaia considerada como objeto fractal onde é possível notar a auto-similaridade. Fonte: Barnsley, 1993.

Figura 03 - Metodologia do cálculo do logaritmo de Box-Counting pelos softwares. Fonte: Kraft et al., 1995.

\section{CAPÍTULO 1}

Figura 01 - Localização da área de estudo na Praia da Fortaleza, Enseada da Fortaleza, Ubatuba, São Paulo.

Figura 02 - Localização da área de estudo na Praia do Lamberto, Enseada do Flamengo, Ubatuba, São Paulo.

Figura 03 - Desenho esquemático para obtenção do Volume da Copa (VC), das frondes do Sargassum filipendula considerando-se a alga submersa em aquário, onde foram obtidos o comprimento (C), altura $(\mathrm{H})$ e largura $(\mathrm{L}) \mathrm{em} \mathrm{cm}$. Os cilindros representam como foi obtido o Volume do Talo (VT) de cada fronde por mês e praia.

Figura 04 - Imagem da fronde de Sargassum filipendula obtida através do programa ImageJ 1.51 para posterior cálculo da área superficial da macroalga (ASM).

Figura 05 - Precipitação média mensal, número de dias com chuva e temperaturas do ar máximas e mínimas no período de janeiro de 2012 a janeiro de 2013 em Ubatuba, São Paulo. Fonte: CPTEC, 2013.

Figura 06 - Material em suspensão $(\mathrm{g})$ e concentração de fosfato $(\mu \mathrm{M})$ nas amostras de água coletadas nas praias da Fortaleza e Lamberto, Ubatuba, São Paulo, durante o período de estudo.

Figura 07 - Concentração de nitrato e nitrito $(\mu \mathrm{M})$ das amostras de água coletadas nas praias da Fortaleza e Lamberto, Ubatuba, São Paulo, durante o período de amostragem.

Figura 08 - Número de ramos primários e secundários das frondes de Sargassum filipendula em cada mês nas praias da Fortaleza e Lamberto, Ubatuba, São Paulo. Barras com asterisco são significativamente diferentes, de acordo com o teste post-hoc Tukey HSD.

Figura 09 - Altura das frondes (cm) e Volume Intersticial (ml) do Sargassum filipendula em cada mês coletadas nas praias da Fortaleza e Lamberto, Ubatuba, São Paulo. Barras com asterisco são significativamente diferentes, de acordo com o teste post-hoc Tukey HSD.

Figura 10 - Valores médios de Pesos Seco Totais (g) das frondes de Sargassum filipendula (PST) coletadas em cada mês nas praias da Fortaleza e Lamberto, 
Ubatuba, São Paulo. Barras com asterisco são significativamente diferente, de acordo com o teste post-hoc Tukey HSD.

Figura 11 - Valores médios do Peso Seco (g) do Sargassum filipendula (PSS) e das algas epífitas (PSE) das frondes coletadas em cada mês nas praias da Fortaleza e Lamberto, Ubatuba, São Paulo. Barras com asterisco são significativamente diferentes, de acordo com o teste post-hoc Tukey HSD.

Figura 12 - Valores médios de Área Superficial do Sargassum filipendula e algas epífitas (ASM) coletadas em cada mês nas praias da Fortaleza e Lamberto, Ubatuba, São Paulo. Barras com asterisco são significativamente diferentes, de acordo com o teste post-hoc Tukey HSD.

Figura 13 - Porcentagem relativa (\%) dos principais grupos da macrofauna obtidos nas frondes de Sargassum filipendula das praias da Fortaleza e Lamberto, Ubatuba, São Paulo.

Figura 14 - Densidade da fauna obtida nas frondes de Sargassum filipendula em cada mês nas praias da Fortaleza e Lamberto, Ubatuba, São Paulo. A: Densidade por gramas; B: Densidade por $100 \mathrm{ml} \mathrm{e} \mathrm{C:} \mathrm{Densidade} \mathrm{por} 100 \mathrm{~cm}^{2}$. Barras com asterisco são significativamente diferentes, de acordo com o teste post-hoc Tukey HSD.

\section{CAPÍTULO 2}

Figura 01 - Modo de obtenção das diferentes escalas a partir da fronde inteira do Sargassum filipendula.

Figura 02 - Valores médios PST (g) e ASM $\left(\mathrm{cm}^{2}\right)$ das frondes de Sargassum filipendula coletadas mensalmente nas praias da Fortaleza e Lamberto, Ubatuba, São Paulo. Barras com asterisco são significativamente diferentes, de acordo com o teste post-hoc Tukey HSD.

Figura 03 - Valores médios do Peso Seco (g) do Sargassum filipendula (PSS) e das algas epífitas (PSE) das frondes coletadas mensalmente nas praias da Fortaleza e Lamberto, Ubatuba, São Paulo. Barras com asterisco são significativamente diferentes, de acordo com o teste post-hoc Tukey HSD.

Figura 04 - Valores médios das medidas fractais (Da e Dp) das frondes de Sargassum filipendula coletadas mensalmente nas praias da Fortaleza e Lamberto, Ubatuba, São Paulo. Barras com asterisco são significativamente diferentes, de acordo com o teste post-hoc Tukey HSD.

Figura 05 - Valores médios de Área Fractal (Da) e Perímetro Fractal (Dp) das frondes de Sargassum filipendula nas cinco escalas analisadas.

Figura 06 - Abundância média da macrofauna total obtida mensalmente nas praias da Fortaleza e Lamberto, Ubatuba, São Paulo. Barras com os mesmos asteriscos foram iguais, de acordo com o teste post-hoc Tukey HSD.

Figura 07 - Praia do Lamberto. Correlação de Spearman entre os valores de PST (g), PSS (g), PSE (g), ASM ( $\left.\mathrm{cm}^{2}\right)$ e Área Fractal (Da) e a abundância média da macrofauna total $(\mathrm{N})$ para cada período de coleta. Valores em logaritmo e gráficos com linha de regressão.

Figura 08 - Praia da Fortaleza. Correlação de Spearman entre os valores de PST (g), PSS (g), PSE (g), ASM ( $\left.\mathrm{cm}^{2}\right)$, Área Fractal (Da) e Perímetro Fractal (Dp) e 
a abundância média $(\mathrm{N})$ da macrofauna total para cada período de coleta. Valores em logaritmo e gráficos com linha de regressão.

Figura 09 - Correlação de Spearman entre os valores de PST (g), PSS (g), PSE (g) e Perímetro Fractal (Dp) e Riqueza (S) da macrofauna total para cada período de coleta nas praias da Fortaleza (A) e Lamberto (B). Valores em logaritmo e gráficos com linha de regressão.

Figura 10 - Resultados da análise de redundância à distância (dbRDA0. Os símbolos representam abundância da macrofauna total amostrado mensalmente nas praias da Fortaleza e do Lamberto. A distância entre os símbolos é baseada em uma matriz de similaridade de Bray-Curtis. Os vetores representam a direção e força as variáveis preditoras.

Figura 11 - Valores médios de abundância total de anfípodes nas praias da Fortaleza e Lamberto, Ubatuba, São Paulo. Barras com asterisco são significativamente diferentes, de acordo com o teste post-hoc Tukey HSD.

Figura 12 - Correlação de Spearman entre os valores de PST (g), PSS (g), PSE (g) e Da e a abundância média dos anfípodes (N) para cada período de coleta nas praias, Fortaleza (A) e Lamberto (B). Valores em logaritmo e gráficos com linha de regressão.

Figura 13 - Correlação de Spearman entre os valores de PSS (g), PSE (g) e ASM $\left(\mathrm{cm}^{2}\right)$ e a riqueza de espécies dos anfípodes (S) para cada período de coleta nas praias, Fortaleza (A) e Lamberto (B). Valores em logaritmo e gráficos com linha de regressão.

Figura 14 - Resultados da análise de redundância à distância (dbRDA). Os símbolos representam abundância dos anfípodes nos meses amostrados nas praias da Fortaleza e do Lamberto. A distância entre os símbolos é baseada em uma matriz de similaridade de Bray-Curtis. Os vetores representam a direção e força das variáveis preditoras.

Figura 15 - Praia do Lamberto. Correlação de Spearman entre as diferenças escalas da Área Fractal (Da) e os valores de abundância média dos anfípodes em cada classe de tamanho e meses do ano. Valores em logaritmo e gráficos com linha de regressão.

Figura 16 - Praia da Fortaleza. Correlação de Spearman entre as diferentes escalas das medidas fractais ( $\mathrm{Da}$ e $\mathrm{Dp}$ ) e os valores de abundância média dos anfípodes em cada classe de tamanho e meses do ano. Valores em logaritmo e gráficos com linha de regressão.

Figura 17 - Praia da Fortaleza. Correlação de Spearman entre as diferentes escalas das medidas fractais (Da e $\mathrm{Dp}$ ) e os valores médios de riqueza dos anfípodes em cada classe de tamanho (Classes I, II e III) e meses do ano. Valores de logaritmo e gráficos com linha de regressão.

Figura 18 - Praia do Lamberto. Correlação de Spearman entre as diferentes escalas das medidas fractais ( $\mathrm{Da}$ e $\mathrm{Dp}$ ) e os valores médios de riqueza dos anfípodes em cada classe de tamanho e meses do ano. Valores em logaritmo e gráficos com linha de regressão. 
Figura 01 - (A) Sargassum filipendula (Alga Natural) e (B) Alga Artificial (Trema Aquários®). Fotografia: Carina W. Rodrigues.

Figura 02 - Exemplos das imagens analisadas pelo software ImageJ 1.51: A Sargassum filipendula - Natural e B - Alga Artificial.

Figura 03 - Área Superficial (AS) do Sargassum filipendula (natural) e algas artificiais mímicas por $\mathrm{cm}^{2}$. Barras comos mesmos asteriscos foram iguais, de acordo com as comparações par a par do teste de Tukey HSD.

Figura 04 - Área Fractal (da) do Sargassum filipendula (natural) e algas artificiais mímicas. Barras com os mesmos asteriscos foram iguais, de acordo com as comparações par a par do teste de Tukey HSD.

Figura 05 - Perímetro Fractal (Dp) do Sargassum filipendula (natural) e algas artificiais mímicas. Barras com os mesmos asteriscos foram iguais, de acordo com a comparação par a par do teste de Tukey HSD.

Figura 06 - Valores médios de abundância, riqueza, diversidade e equitabilidade para cada tipo de substrato (natural e artificial) por dia.

Figura 07 - Correlação de Spearman entre as variáveis de complexidade das frondes de Sargassum filipendula e algas artificiais e abundância de anfípodes nos oito períodos amostrados.

Figura 08 - Correlação de Spearman entre as variáveis de complexidade das algas artificiais mímicas e a abundância de anfípodes nos oito períodos amostrados.

Figura 09 - Second-stage nMDS mostrando os três grupos identificados. Os números representam o dia de amostragem. 


\section{INDICE DE TABELAS}

\section{CAPÍTULO 1}

Tabela 01 - Datas de coleta, variação da maré, Temperatura $\left({ }^{\circ} \mathrm{C}\right)$ e Salinid ade da água para as praias da Fortaleza e Lamberto, Ubatuba, São Paulo.

Tabela 02 - Sumário das ANOVAs para as medidas de complexidade estrutural do Sargassum filipendula: Ramos Primários, Ramos Secundários, Altura das frondes e Volume Intersticial. ** $P<0.01$; ${ }^{\text {s }}$, significativo $\mathrm{e}^{\mathrm{ns}}$, não significativo.

Tabela 03-Sumário das ANOVAs para as medidas de complexidade estrutural do Sargassum filipendula.: Peso Seco (PST), Peso Seco S. filipendula (PSS), Peso Seco Epifítas (PSE) e Área Superficial da Macroalga (ASM). ** $P<0.01$; s, significativo e ${ }^{\text {ns }}$, não significativo.

Tabela 04 - Sumário das ANOVAs para os valores médios de abundância da fauna total $(\mathrm{N})$ e Número de Táxon. ** $P<0.01$; s, significativo e ${ }^{\mathrm{ns}}$, não significativo.

Tabela 05 - Sumário dos resultados das correlações de Spearman entre os valores de abundância média da macrofauna $(\mathrm{N})$ e número de táxon (Táxon) e as medidas quantitativas: PST: Peso seco total; PSS: Peso seco Sargassum filipendula (PSS); PSE: Peso seco Epífitas e ASM: Área Superficial da Macroalga. $* * P<0.01$.

Tabela 06 - Sumário das ANOVAs para os valores de densidade por gramas (indivíduos $/ \mathrm{g}$ ), densidade por $\mathrm{ml}$ (indivíduos $/ 100 \mathrm{ml}$ ) e densidade por $\mathrm{cm}^{2}$ (indivíduos $/ 100 \mathrm{~cm}^{2}$ ). $* * P<0.01 ;{ }^{\mathrm{s}}$, significativo $\mathrm{e}^{\mathrm{ns}}$, não significativo.

\section{CAPÍTULO 2}

Tabela 01 - Sumário das ANOVAs para as medidas de complexidade do Sargassum filipendula (PST, PSS, PSE, ASM, Da e Dp). ** $P<0.01$; , significativo $\mathrm{e}^{\mathrm{ns}}$, não significativo.

Tabela 02 - Sumário das ANOVAs para as medidas fractais: Área Fractal (Da) e Perímetro Fractal (Dp). ${ }^{*} P<0.05 \mathrm{e}^{* *} P<0.01$; , significativo e ns, não significativo.

Tabela 03 - Sumário das ANOVAs para as diferentes escalas das variáve is: Área Fractal (Da) e Perímetro Fractal (Dp). ** $P<0.01$; ${ }^{\text {ns }}$, não signific ativo.

Tabela 04 - Sumário das ANOVAs para os valores médios de abundância da fauna total $(\mathrm{N})$ e Número de Táxon. ** $P<0.01$; ${ }^{\mathrm{s}}$, significativo $\mathrm{e}^{\mathrm{ns}}$, não significativo.

Tabela 05 - Resultados do teste de regressão múltipla (DistLM) sobre o efeito das medidas de complexidade do Sargassum filipendula na abundância da macrofauna total. $* * P<0.01$.

Tabela 06 - Valores médios dos descritores de comunidade: Abundância (N); Riqueza (S) e Diversidade (H') para cada mês das praias da Fortaleza e Lamberto, Ubatuba, São Paulo.

Tabela 07 - Sumário das ANOVAs para os descritores de comunidade: Abundância (N), Riqueza (S) e Diversidade (H'). * $P<0.05$ e ** $P<0.01$; ' significativo $\mathrm{e}^{\text {ns }}$, não significativo 
Tabela 08 - Sumário do PERMANOVA para as espécies de anfípodes encontrados nas praias da Fortaleza e Lamberto, Ubatuba, São Paulo. ** $P<0.01$.

Tabela 09 - Resultados do teste de regressão múltipla (DistLM) sobre o efeito das medidas morfológicas das macroalgas na comunidade de anfípodes. *** $P<0.01$.

Tabela 10 - Resultado os valores médios de Abundância (N), Riqueza (S) e Diversidade (H') para cada classe/mês nas praias da Fortaleza e Lamberto, Ubatuba, São Paulo.

Tabela 11 - Sumário das ANOVAs para os valores dos descritores de comunidade Abundância (N), Riqueza (S) e Diversidade (H') obtido para cada classe de tamanho. I: Classe I; II: Classe II e III: Classe III. $* P<0.05$ e $* *$ 66 $P<0.01$; , significativo $\mathrm{e}^{\mathrm{ns}}$, não significativo.

Tabela 12 - Abundância e porcentagem de contribuição das principais espécies de anfípodes em cada classe de tamanho, nas praias da Fortaleza e do Lamberto, Ubatuba, São Paulo.

Tabela 13 - Sumário das ANOVAs para descritores de comunidade: abundância $(\mathrm{N})$, riqueza $(\mathrm{S})$ e diversidade $\left(\mathrm{H}^{\prime}\right)$ em relação às classes de tamanho. ${ }^{* *} P<0.01$; ', significativo $\mathrm{e}^{\mathrm{ns}}$, não significativo.

\section{CAPÍTULO 3}

Tabela 01 - Discriminação dos períodos de amostragem com os respectivos níveis de maré.

Tabela 02 - Resumo das ANOVAs para as medidas de complexidade do Sargassum filipendula e algas artificiais mímicas (área Superficial _ AS, Área Fractal - Da e Perímetro Fractal - Dp). ${ }^{* *}, P<0.01$; ${ }^{\mathrm{s}}$, significativo; ns, não significativo.

Tabela 03 - Espécies encontradas e seu respectivo grupo funcional.

Tabela 04 - Resumo das ANOVAs para os descritores e comunidade analisados (Abundância - N; Riqueza - S; Diversidade - H' e Equitabilidade - J)

Tabela 05 - Resultados da ANOSIM aplicada à interação entre período e grupos. $\mathrm{Sl}=$ nível de significância.

Tabela 06 - Resultados da análise SIMPER aplicada nos três grupos encontrado no second-stage nMDS, mostrando a abundância média (Ab.) e a porcentagem de contribuição de cada espécie. Contribuições maiores que 5\% estão em negrito. 


\section{INTRODUÇÃO}

\subsection{Macrófitas e Habitat}

Macrófitas são importantes produtoras primárias ao longo da costa ao redor do mundo, e invariavelmente atuam como hospedeiras para uma infinidade de organismos epífitos, vegetais ou animais, sésseis ou móveis (MASUNARI, 1987; HUANG et al., 2007; PEREIRA et al, 2010). Todas as macrófitas fornecem um habitat de duração variada, embora a maioria dos organismos tenha vida útil de aproximadamente um ano. Algumas podem viver apenas alguns meses, enquanto outras, como algas fucóides, gramas marinhas e kelps possam persistir por muitos anos. Adicionalmente, o período de renovação dos filoides e lâminas, é outro fator de variação, que flutua sempre dentro de uma escala, de semanas a meses. Assim, torna-se evidente que a composição e as taxas de colonização da epifauna nessa vegetação pode ser afetada pela longevidade das plantas (CHRISTIE et al., 2009).

Em costões rochosos, um dos fatores limitantes mais importantes para o estabelecimento dos organismos bentônicos é o espaço disponível no substrato (DAYTON, 1971). Por esta razão, a presença de macrófitas nesse ambiente as torna engenheiras ecológicas, uma vez que aumentam a heterogeneidade e complexidade da área disponível para a colonização (FERREIRO et al., 2011). Nos substratos consolidados, as macroalgas podem apresentar variação nas formas do talo, filoides e/ou lâminas; contudo, diferenças dentro de uma mesma espécie também são observadas, devido a variações nas taxas de crescimento, habilidade competitiva e estratégias contra herbivoria (STENECK \& DETHIER, 1994). Diferenças na qualidade estrutural do habitat poderão então afetar seu valor como refúgio contra predadores e a composição das espécies associadas (MONTEIRO et al., 2002).

Padrões de distribuição e abundância da epifauna diferem entre as macroalgas. Essas diferenças podem estar relacionadas tanto à variação no ambiente físico quanto à tolerância fisiológica dos animais (VIEJO, 1999). No entanto, a densidade da epifauna também difere entre as macroalgas que habitam um mesmo ambiente, como a zona entremarés ou uma área de forte exposição às ondas (TAYLOR \& COLE, 1994).

A arquitetura da macrófita, considerada como, sua forma e complexidade, pode influenciar fortemente a abundância e composição das espécies que the são associadas. Plantas com alta complexidade geralmente são selecionadas pelos organismos e para 
algumas espécies de animais, a presença de algas epífitas torna-se o fator determinante na colonização do habitat (STEWART et al., 2003; McABENDROTH et al., 2005). Habitats complexos podem prover mais nichos e micro-habitats para colonização dos organismos, acarretando maior abundância e diversidade de recursos ambientais e de refúgios contra predadores visuais, fatores estes que contribuem para aumentar $o$ número, biomassa e diversidade dos organismos e influenciar as interações biológicas locais (VIEJO,1999; FERREIRO et al., 2011).

Nos bancos de macroalgas, um dos principais problemas para se avaliar a variação na estrutura de comunidades do macrobentos vágil quando se considera as diversas escalas espaciais e temporais, é a influência resultante de mudanças na estrutura do habitat fornecido pela macroalga (EDGAR,1991; TILMAN, 1994). A macroalga Sargassum constitui habitat complexo que suporta uma fauna diversa e abundante. Mas, a interpretação das diferenças que possam haver na estrutura da fauna associada as algas crescendo em locais distintos, pode ser dificultada pela existência de variações na morfologia do Sargassum decorrentes das diferentes condições ambientais locais (SMITH et al., 1996; SMITH \& RULE, 2002).

\subsection{Sargassum como habitat}

O gênero Sargassum (Phaeophyta, Fucales) apresenta ampla distribuição na maioria das bacias oceânicas do mundo, com exceção das águas ao redor da Antártida (VELOSO \& SZÉCHY, 2008). Dentre os 49 gêneros que compõem a ordem Fucales, Sargassum é o mais representativo, com 354 espécies descritas (GUIRY \& GUIRY, 2016). Essas macroalgas podem exercer dominância sobre outras espécies nos ambientes em que ocorrem, principalmente no meso- ou infralitoral raso, embora algumas espécies já tenham sido descritas em ambientes situados a 200m de profundidade (PAULA, 1988; MAGRUDER, 1988).

A morfologia do Sargassum é complexa, sendo constituída por apressório, ramos primários e ramos secundários, estes últimos se individualizando a partir dos ramos primários e constituindo a maior parte do talo (Figura 01). O talo pode tornar-se bastante ramificado, diferenciando ramos cilíndricos e porções achatadas (COIMBRA, 2006).

Existem espécies de Sargassum que são anuais e espécies que vivem mais de um ano, denominadas perenes (SZÉCHY \& DE SÁ, 2008). Espécies perenes são 
representadas pela perda dos ramos, principalmente pela fragmentação dos ramos reprodutivos, após o período de liberação dos gametas, mas o talo não perde sua totalidade. As partes que persistem em espécies perenes são o apressório e os ramos principais, que, com o tempo irão aumentar gradativamente de dimensão (PAULA \& OLIVEIRA-FILHO, 1980; SZÉCHY et al., 2006).

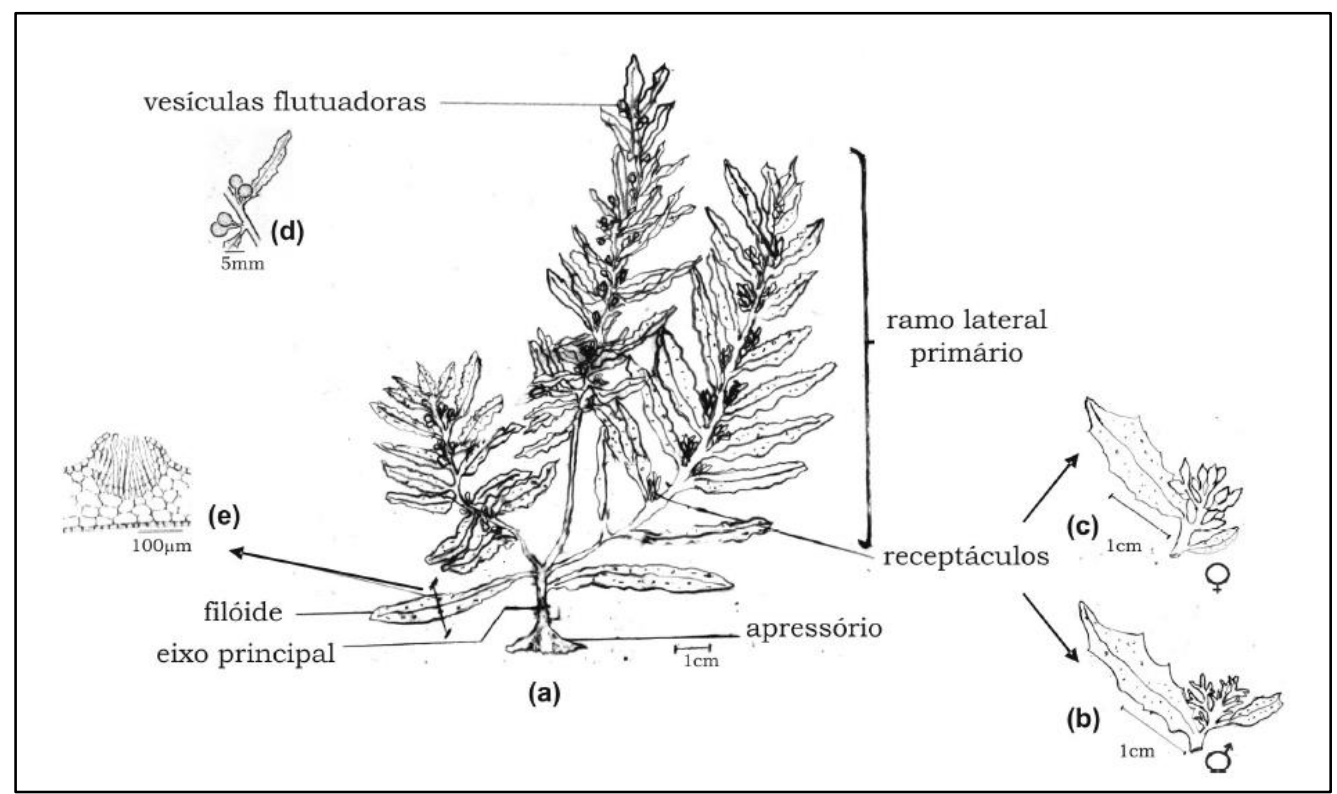

Figura 01 - (a) Desenho esquemático de um Sargassum com três ramos laterais; (b) aspecto dos receptáculos masculinos; (c) aspecto dos receptáculos femininos; (d) vesículas flutuadoras ou aerocistos; (e) aspecto do corte transversal do filoide na região do criptostomas. Fonte: Paula, 1988.

Densos bancos de Sargassum são comumente encontrados na costa brasileira, sendo frequentes desde do litoral do Estado do Maranhão até o Estado do Rio Grande do Sul, em costões rochosos de locais moderados e protegidos em relação ao embate de ondas (PAULA, 1988; SZÉCHY \& PAULA, 2000; ALMADA et al., 2008). Esses bancos são suscetíveis a mudanças sazonais na sua biomassa e/ou estado fisiológico em relação aos fatores abióticos, como luz, temperatura e nutriente; e bióticos, como herbivoria, competição e epifitismo (AIKINS \& KIKUCHI, 2001; NORDERHAUG et al., 2002). Variação temporal da abundância de Sargassum também é descrita para algumas espécies de diversos locais da costa brasileira e essas variações influenciam a distribuição e densidade dos organismos a elas associadas (LEITE \& TURRA, 2003; MUNIZ et al., 2003). 
Em relação às macroalgas epífitas, já foram descritas cerca de 80 espécies que podem estar associadas às espécies de Sargassum; porém, nem todas são epífitas obrigatórias (SZÉCHY \& PAULA, 1997; MUNIZ et al., 2003). Embora sua presença resulte no aumento de nichos e micro-habitats para os organismos epifaunais, seu crescimento pode causar efeitos negativos para o Sargassum, reduzindo diretamente a disponibilidade de luz e nutrientes, ou aumentando o arrasto da fronde sob condições intensas de hidrodinamismo. Neste caso ocorre na perda de tecido da macroalga (LEITE \& TURRA, 2003; JACOBUCCI et al., 2009b).

A ramificação da fronde do Sargassum com seus diferentes graus de epifitismo pode reter diferentes quantidades de sedimento, o que favorece a colonização de organismos epifaunais, podendo estes exibir alta densidade (VENEKEY et al., 2008; JACOBUCCI et al., 2009b). Neste universo, a presença dos organismos epifaunais herbívoros pode influenciar a dinâmica da biomassa tanto da macroalga hospedeira quanto da epífita, e essa influência pode ser negativa através do consumo direto da hospedeira, ou positiva através do consumo das epífitas.

As praias estudadas, praia da Fortaleza e Lamberto - Ubatuba, no presente trabalho possuem uma extensa cobertura de bancos de algas pardas do gênero Sargassum, sendo que para essas praias já foram descritas: S. cymosum, S. cymosum var. nanum, S. filipendula, S. filipendula var. laxum, S. filipendula var. montagnei, $S$. filipendula var. pinnatum, S. ramifolium e S. vulgare, S. vulgare var. foliossinum (PAULA \& OLIVEIRA-FILHO, 1982; PAULA, 1988; SZÉCHY \& PAULA, 2000; SZÉCHY \& PAULA, 2010). Os espécimes coletados no presente estudo em ambas as praias foram identificados como Sargassum filipendula.

\subsection{Macrofauna total e Amphipoda}

Os bancos de Sargassum muitas vezes abrigam altas abundâncias e diversidade de invertebrados da epifauna que exibiram uma variedade e habitats tróficos (TAYLOR \& COYLE, 1994). Pequenos crustáceos (anfípodes, isópodes e copépodes), gastrópodes e poliquetas são frequentemente abundantes, e podem ser uma importante fonte de alimento para peixes juvenis que também são abundantes em bancos de macroalgas (MUKAI, 1971). O Sargassum fornece a epifauna associada alimento, seja através da herbivoria sobre a própria macroalga ou sobre as suas epífitas, provocando a produção de detritos ou através da provisão de presas menores à epifauna carnívora. 
Apesar de moluscos, poliquetas e isópodes serem abundantes, a fauna fital é geralmente dominada por anfípodes (GUNNILL, 1985; JACOBUCCI \& LEITE, 2002; De-la-OSSA-CARRETERO et al., 2011). Esses pequenos crustáceos são extremamente comuns e amplamente distribuídos tanto em regiões tropicais quanto temperadas, normalmente vivem em grupos formando agregados de pequena escala, e estão associados a uma grande variedade de habitats, tais como macroalgas, ervas marinhas, esponjas, ascídias, equinodermos, moluscos e vertebrados (VADER, 1983; THIEL, 1999, 2002; GUERRA-GARCIA et al., 2014). Dessa grande variedade de habitats, são mais comumente encontrados em macroalgas, onde podem atingir densidades muito elevadas (WOODS, 2009).

Esses organismos constituem um dos grupos mais diversificados de crustáceos em relação ao estilo de vida, tipos tróficos e habitats (BIERNBAUM 1979; JACOBI, 1987; DE BROYER \& JAZDZEWSKI, 1996). Apresentam uma dieta bastante variada, alimentando-se de macroalgas, microalgas do perifiton, partículas em suspensão na coluna dá água e detritos (GUERRA-GARCIA et al., 2014). Muitas espécies podem modificar seu método de alimentação para utilizar diferentes recursos que se tornam disponíveis em determinada ocasião (HOWARD, 1982; KLUMPP et al., 1989). Vários estudos indicam que os anfípodes podem reduzir a cobertura de macro- e microepífitas sobre macrófitas (BRAWLEY \& FEI, 1987, DUFFY, 1990), estimulando em alguns casos o crescimento da macrófita pela redução da competição imposta pelas epífitas (HOWARD, 1982; D'ANTONIO, 1985; BRAWLEY \& FEI, 1987). Devido a sua abundância e riqueza de espécies, constituem importante ela de ligação entre a produção primária, secundária e os níveis tróficos superiores, tais como peixes, aves e mamíferos (GUERRA-GARCÍA et al., 2014).

Os anfípodes apresentam desenvolvimento direto, ou seja, as fêmeas carregam ovos e embriões em uma bolsa ventral (o marsúpio), da qual são liberados juvenis. Dessa forma, o estabelecimento das espécies não é limitado pelo alimento ou reprodução. Por esta razão, as espécies movem-se frequentemente entre os habitats e vivem camuflados, especialmente nas algas, para evitar predadores (PARKER et al., 2001; KLEY et al., 2009).

Padrões de distribuição e abundância dos anfípodes, e toda a epifauna, diferem entre as macroalgas. Essas diferenças podem estar relacionadas à variação no ambiente físico à tolerância fisiológica dos animais (VIEJO, 1999). No entanto, a densidade dos organismos também difere entre as macroalgas que habitam a mesma zona entre marés 
ou área de exposição às ondas (TAYLOR \& COYLE, 1994). Estes padrões de distribuição e abundância dos organismos muitas vezes é o resultado de uma seleção ativa do animal pela alga (HACKER \& STENECK, 1990; EDGAR, 1991; VIEJO, 1999). Se os organismos usam a macroalga como proteção, então a cor e arquitetura da alga são importantes para determinar a distribuição da fauna e sua escolha pela hospedeira (PAVIA et al., 1999; EILERTSEN et al., 2011).

\subsection{Métodos quantitativos e Metodologia Fractal}

As macroalgas apresentam uma alta variabilidade morfológica, complexidade e longevidade. A medida de complexidade do organismo formador de um habitat é uma tarefa importante que tem sido foco de muita pesquisa, pois, os organismos associados a essa macroalga não só são afetados pela quantidade de habitat disponível, mas também são influenciados pela morfologia ou disposição estrutural do habitat (HAUSER et al., 2006).

Inicialmente, vários estudos tentaram quantificar a complexidade estrutural das macrófitas, medindo a quantidade de habitat disponível como biomassa, volume ou área (TANIGUCHI et al., 2003; JACOBUCCI et al., 2009b) ou número e disposição dos ramos, comparando espécies de macroalgas com diferentes morfologias (HACKER \& STENECK, 1990; CHEMELLO \& MILAZZO, 2002). No entanto, levando em consideração apenas esses fatores, é difícil estimar o arranjo estrutural real que ocupa o espaço disponível, pois isso varia com a escala de medida (BRADBURY et al., 1984). Assim, era necessário encontrar maneiras de quantificar o arranjo estrutural, como por exemplo com o uso de medidas fractais.

A geometria clássica aborda o espaço tendo por base noções euclidianas de $n$ dimensões, examinando a natureza e as relações de figuras abstratas como pontos, linhas e polígonos. Esses objetos são conhecidos como sendo idealizações que não têm comprimento característico e nem tamanho absoluto (ASSIS et al., 2008).

Em 1967, o matemático francês Benoit Mandelbrot, desenvolveu uma nova metodologia na tentativa de suprir a dificuldade em se descrever formas complexas, ásperas, irregulares e por vezes ramificadas, encontradas na natureza, tais como linhas de costa, cadeias montanhosas e sistemas fluviais (MANDELBROT, 1967). Tal metodologia foi denominada de geometria fractal, palavra proveniente do latim fractus e frangere, que significa quebrar, fraturar (ASSIS et al., 2008). O fractal é um objeto semelhante a si mesmo em todas as escalas e que quando ampliado, representa um 
objeto semelhante ou exatamente igual a forma original. Um exemplo é dado através de uma folha de samambaia (Figura 02) (MANDELBROT, 1967 e 1983).

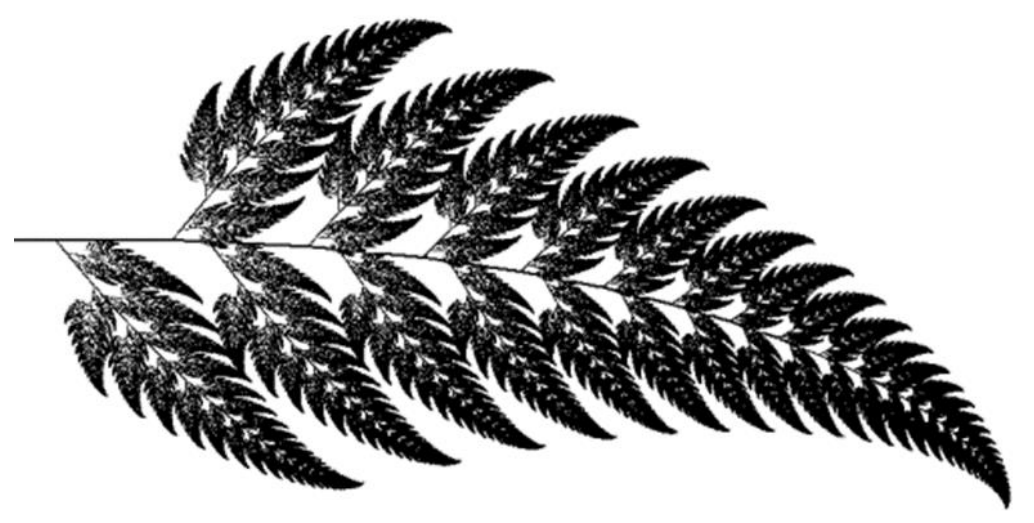

Figura 02 - Folha de samambaia considerada como um objeto fractal onde é possível notar a auto-similaridade. Fonte: Barnsley, 1993.

A dimensão de um objeto fractal é um valor fracionário, pois indica o grau de complexidade ou irregularidade que uma imagem possui, ou seja, o quanto do espaço físico ela ocupa. Sendo assim, quanto maior a irregularidade de uma forma, maior é a sua dimensão fractal (CESAR \& COSTA, 2000). Essa característica a torna uma ferramenta muito útil na comparação de duas formas fractais. Existem diversos métodos para o cálculo da dimensão fractal de uma determinada imagem digital. Softwares, como o ImageJ, Benoit 1.3 e Fractalyse, calculam a dimensão fractal baseado numa figura binária pela aplicação do algoritmo conhecido como Box-Couting Algorithm. Este método é muito utilizado devido a relativa facilidade de implementação computacional. O algoritmo para o cálculo dessa dimensão considera uma figura qualquer coberta por um conjunto de quadrados (de diferentes tamanhos), e calcula o número de quadrados necessários para cobrir toda a figura. Esta é representada por N(s), sendo "s" a escala, ou seja, número de vezes que o lado da imagem será dividido, e a dimensão fractal será o coeficiente angular do diagrama $\log (\mathrm{N}(\mathrm{s}) / \log (1 / \mathrm{s})$ (Figura 3) (KARPERIEN, 2007-2012). 

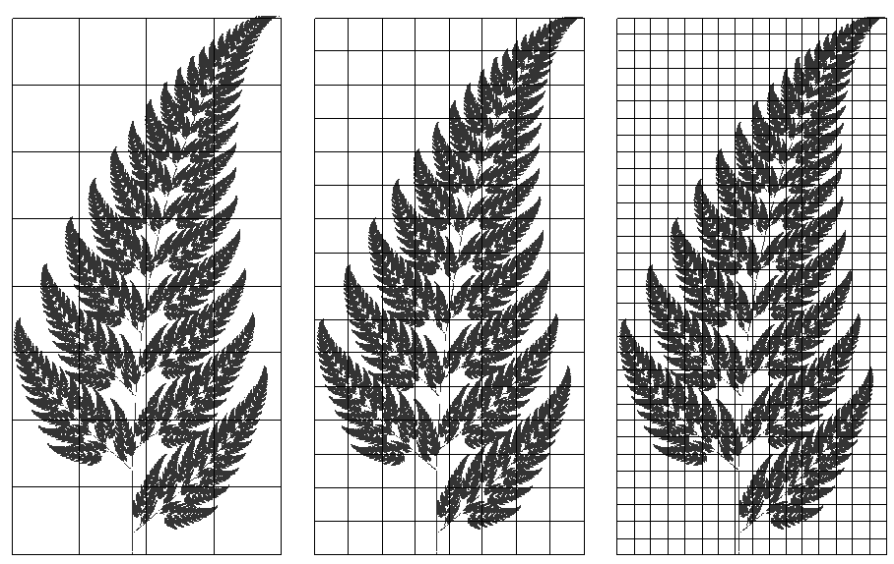

Figura 03 - Metodologia do cálculo do logaritmo de Box-Counting pelos diversos softwares existentes. Fonte: Kraft et al., 1995.

$\mathrm{O}$ advento dessa geometria permitiu descrever a complexidade do habitat e estabelecer um número simples para formas complexas que não poderiam ser calculados pela geometria euclidiana (BARNSLEY, 1993). A teoria do fractal foi disseminada rapidamente entre os ecólogos após a década de 80 , devido principalmente a facilidade desse modelo abranger fenômenos ecológicos de escala múltipla (THOMAZ \& CUNHA, 2010), mas também pela possibilidade de ser empregada em formas e/ou organismos vivos que não sejam considerados objetos fractais verdadeiros (McABENDROTH et al., 2005; CÚRDIA et al., 2005). Por esta razão, a dimensão fractal tem sido amplamente utilizada, pois fornece uma métrica precisa de complexidade e irregularidade de um determinado objeto (MORSE et al., 1985; GUNNARSSON, 1992; GEE \& WARWICK, 1994a, b).

A estratégia de medir o habitat espacial disponível usando geometria fractal tem um grande potencial em ecologia (SUGIHARA \& MAY, 1990), e a dimensão fractal (D) já foi usada para descrever, por exemplo, habitat em diferentes ecossistemas e em diferentes escalas espaciais, como em paisagens (SCHNEIDER, 2001), conjuntos de árvores (MORSE et al., 1985), zonas do litoral (McABENDROTH et al., 2005), em uma única fronde de macroalga, sendo artificiais (JEFFRIES, 1993) e naturais (THOMAZ et al., 2008).

A primeira investigação que usou geometria fractal para medir a complexidade de macrófitas em escalas pequenas (cm) foi realizada com plantas artificiais (JEFFRIES, 1993). Este autor trabalhou com estruturas plásticas imitando macroalgas e plantas submersas com diferentes dimensões fractais e usou sua complexidade como uma variável independente para explicar os atributos da comunidade de invertebrados. 
A descoberta foi uma relação positiva entre a dimensão fractal e a densidade de invertebrados e riqueza de táxons.

A maior parte das aplicações da geometria fractal em ecologia têm sido relacionadas com ligações entre a complexidade de uma planta e sua comunidade faunística. Esses estudos têm revelado uma associação entre altos valores de dimensão fractal a vegetação com a maior diversidade de comunidades animais (GEE \& WARWICK, 1994a) e/ ou maior abundância relativa de animais menores (MORSE et al., 1985; SHORROCK et al., 1991; GEE \& WARWICK, 1994b).

No Brasil, estudos com a comunidade de anfípodes e macroalgas começaram na década de 80, notadamente para as regiões Sudeste e Sul. Tais estudos utilizavam apenas a biomassa da macroalga (peso seco ou peso úmido) para mensurar a complexidade das macroalgas para evidenciar como essa variável influenciava a estruturação das referidas comunidades (WAKABARA et al., 1983; LEITE et al., 2007; CUNHA et al., 2008; JACOBUCCI et al., 2009a; JACOBUCCI et al., 2014). O uso da dimensão fractal como medida de complexidade morfológica em macroalgas é uma abordagem importante que tem sido foco de muita pesquisa no mundo todo (GEE \& WARWICK, 1994a, b; McABENDROTH et al., 2005; DIBBLE \& THOMAZ, 2009; FERREIRO et al., 2011). A maioria desses trabalhos avalia a influência da complexidade estrutural de diferentes tipos de substratos sobre a comunidade epifaunal total, sendo esses substratos representados por espécies diversas de macroalgas (HOOPER \& DAVENPORT, 2006; THOMAZ et al., 2008), substratos artificiais variados (JEFFRIES, 1993; HAUSER et al., 2006), havendo até mesmo comparações dentre espécies de macroalgas naturais e artificiais (DIBBLE \& THOMAZ, 2009). Dentre esses estudos poucos avaliaram a influência da complexidade estrutural em espécies do mesmo gênero sobre a comunidade dos anfípodes, organismos importantes no ambiente fital (AYALA \& MARTÍN, 2003; GUERRA-GARCÍA et al., 2009). Nenhum trabalho com dimensão fractal e ecologia do fital marinho foi publicado para $\mathrm{O}$ Brasil até o presente momento.

O presente estudo tem como objetivo geral avaliar a complexidade estrutural do habitat fornecido por dois bancos de Sargassum filipendula presentes em duas praias de Ubatuba, litoral norte do Estado de São Paulo, aplicando-se diferentes métodos para mensurar a complexidade do habitat do Sargassum, incluindo a dimensão fractal. Especificamente pretende-se responder se as diferenças na complexidade estrutural do Sargassum filipendula são fatores determinantes para a macrofauna e anfípodes. A 
variação dos atributos estruturais foi analisada em relação a dois fatores: a complexidade do habitat (peso seco, área superficial, dimensão fractal, entre outros) e período de tempo (meses ou dias). De modo geral, este estudo é inovador ao contribuir para o melhor entendimento da ecologia da macrofauna em bancos de Sargassum, trazendo uma abordagem ampla e focada no entendimento do efeito das várias escalas de dimensão espacial e temporal sobre a composição e distribuição da fauna.

A presente tese apresenta os seguintes capítulos que irão tratar de temas específicos:

- Capítulo 1 - "Avaliação do desempenho dos indicadores quantitativos da estrutura de Sargassum filipendula sobre a epifauna bentônica";

- Capítulo 2 - "Dimensão fractal e medidas quantitativas: sua influência na ocupação dos bancos de Sargassum filipendula pela macrofauna";

- Capítulo 3 - "Colonização de anfípodes em Sargassum filipendula defaunado e substratos artificiais na Praia do Lamberto, Ubatuba, sudeste do Brasil". 
CAPÍTUlO 1 - "Avaliação do desempenho dos indicadores quantitativos da estrutura de Sargassum filipendula sobre a epifauna bentônica"

\section{RESUMO}

A macroalga Sargassum C. Agardh é de reconhecida importância ecológica nos ecossistemas costeiros, particularmente nas comunidades de costões rochosos de regiões tropicais e temperadas quentes. Está amplamente distribuída na costa sudeste brasileira, sendo frequente em costões rochosos de locais moderados ou protegidos do embate de ondas. Nesses ambientes pode formar bancos densos e extensos, estruturalmente complexos, capaz de prover microhabitats variados para uma grande diversidade de organismos. Os bancos de Sargassum são suscetíveis a mudanças sazonais na sua biomas sa e/ou estado fisiológico relacionados a fatores abióticos e bióticos, sendo que essas variações podem influenciar drasticamente a distribuição e densidade dos organismos associados às algas. A complexidade desse substrato tem sido avaliada por meio de várias medidas, sendo quantitativas, como peso, as mais utilizadas. O presente trabalho tem como objetivo avaliar o desempenho de diferentes medidas quantitativas da complexidade estrutural de bancos de Sargassum filipendula $i$ ) no desenvolvimento temporal da complexidade estrutural da alga em dois ambientes hidrodinamicamente diferentes e ii) na composição e distribuição dos organismos epifaunais. Foram coletadas 15 frondes de $S$. filipendula por mês, durante 13 meses, nas praias da Fortaleza e do Lamberto, Ubatuba, SP. A fauna presente nessas frondes foi obtida através de lavagem e peneiramento contínuo. O período de amostragem caracterizou-se por ser atípico, apresentando altas temperaturas ao longo de todo o ano e um verão com baixa pluviometria. Este fato influenciou fortemente a variação sazonal do S. filipendula e epífitas associadas, ocasionando elevados valores de peso seco entre a primavera e verão. Os resultados das comparações das medidas analisadas mostraram que um único parâmetro não é representativo da complexidade estrutural da alga, uma vez que cada medida apresentou diferenças em relação à abundância e diversidade da fauna. Estes dois indicadores também mostraram correlação positiva com todos os parâmetros de complexidade do substrato. Houve diferença significativa entre as praias, e as frondes do Lamberto foram estruturalmente mais complexas, suportando a maior abundância. Contudo, foram as frondes do Fortaleza que exibiram os maiores valores de riqueza de grupos. Discute-se o emprego de mais uma de uma medida quantitativa para mensurar a complexidade estrutural do habitat.

Palavras chave: Sargassum filipendula, comunidade epifaunal, complexidade estrutural. 


\section{ABSTRACT}

The Sargassum C. Agardh macroalgae is of recognized ecological importance in coastal ecosystems, particularly in the rocky coastal communities of tropical and warm temperate regions. It is widely distributed on the southeast coast of Brazil, being frequent in rocky shores of moderate locations or protected from the impacts of waves. In these environments can form dense and extensive banks, structurally complex, capable of providing microhabitats varied for a great diversity of organisms. The Sargassum banks are susceptible to seasonal changes in their biomass and/or physiological status related to abiotic and biotic factors, and these variations can drastically influence the distribution and density of organisms associated with algae. The complexity of this substrate has been evaluated by means of several measures, being quantitative, as dry weight, the most used. The present work aims to evaluate the performance of different quantitative measures of the structural complexity of Sargassum filipendula banks $i$ ) in the temporal development of algae structural complexity in two hydrodynamically different environments and ii) in the composition and distribution of epifaunal organisms. Fifteen fronds of S. filipendula were collected per month, during 13 months, on the beaches of Fortaleza and Lamberto, Ubatuba, SP. The fauna present in these fronds was obtained through continuous washing and sieving. The sampling period was characterized by being atypical, presenting high temperatures throughout the year and a summer with low rainfall. This fact strongly influenced the seasonal variation of S. filipendula and associated epiphytes, causing high values of dry weight between spring and summer. The results of the comparisons of the measures analyzed showed that a single parameter is not representative of the structural complexity of the algae, since each measure presented differences in relation to the abundance and diversity of the fauna. These two indicators also showed a positive correlation with all parameters of substrate complexity. There was a significant difference between the beaches, and the Lambert fronds were structurally more complex, bearing the greatest abundance. However, it was the fronds of Fortaleza that exhibited the highest values of group richness. We discuss the use of one more of a quantitative measure to measure the structural complexity of the habitat.

Keywords: Sargassum, epifaunal community, structural complexity. 


\section{INTRODUÇÃO}

Macroalgas pardas da ordem Fucales, incluindo o gênero Sargassum, podem formar populações de porte variado que dominam especialmente locais protegidos da ação direta das ondas (PAULA \& OLIVEIRA, 1980). Crescem na região do meso- ou infralitoral do substrato consolidado existente, alcançando vários metros de profundidade (MENGE, 1976; SZÉCHY \& PAULA, 2000). Por serem organismos fotossintetizantes, são importantes como produtores primários da matéria orgânica, na produção de oxigênio e na ciclagem dos nutrientes (MASUNARI, 1987).

Tal como acontece com outros gêneros de Fucales, o crescimento e reprodução do Sargassum é altamente sazonal, tanto em regiões temperadas quanto tropicais e subtropicais (SZÉCHY et al., 2006). A ação de ondas e a interferência do homem no costão rochoso também contribuem para a existência de diferenças significativas na estrutura populacional dessa macroalga (NASSAR et al., 2002; THIBAUT et al., 2005). A comunidade é bastante sensível e responde rapidamente ao estresse mecânico causado pelo embate das ondas e alterações de temperatura, salinidade, teores de nutrientes, concentrações de poluentes e herbivoria (SZÉCHY, 1996; SZÉCHY \& PAULA, 1997; VIDOTTI \& ROLLEMBER, 2004; WELLS et al., 2007). Como resultado, os bancos de Sargassum podem sofrer alterações na sua abundância e biomassa ao longo do ano. Um menor desenvolvimento vegetativo das plantas está associado a regiões mais expostas, onde as macroalgas são tipicamente menores, mais ramificadas e com apressórios maiores para auxiliar na fixação. Em contraposição, em locais protegidos são mais abundantes em termos de biomassa, apesar de menos densas (PAULA \& OLIVEIRA-FILHO, 1982).

Invariavelmente, as macroalgas irão servir como hospedeiras para uma grande gama de organismos, pois funcionam como fontes diretas e/ou indiretas de alimento, local para fixação, berçário, refúgio contra predadores, dessecação e proteção contra deslocamento causado pela circulação da água (ORNELLAS \& COUTINHO, 1998; HAUSER et al., 2006). A epiflora e epifauna que utilizam o Sargassum como substrato também irão sofrer variações na sua abundância e biomassa em resposta às alterações do habitat do hospedeiro (JACOBUCCI et al., 2009b).

Em estudos sobre a estrutura das comunidades marinhas bentônicas, o epifitismo é uma variável muito importante, pois resulta numa maior diversidade específica e heterogeneidade de habitats (STEWART et al., 2003). A quantidade e tipos de algas epífitas, também podem variar sazonalmente, contribuindo, assim, para a diversidade local 
dos organismos da epifauna. O epifitismo pode causar efeitos deletérios para a macroalga hospedeira competindo por nutrientes, gases dissolvidos e reduzindo a luminosidade. Porém, às vezes o sombreamento gerado pelas epífitas pode servir como proteção temporária contra o excesso de luminosidade, temperatura e dessecação (FIGUEIREDO et al., 1997; FIGUEIREDO et al., 2000). Além disso, o grau de epifitismo elevado pode contribuir para o aumento da fragmentação da macroalga hospedeira, ocasionando até mesmo o desprendimento da macroalga do costão rochoso (AGUILAR-ROSAS \& GALUNDO, 1990).

A estrutura física do habitat gerado pelas macroalgas e suas epífitas pode influenciar fortemente a diversidade local, modificando as condições ambientais e influenciando uma variedade de processos biológicos (CHRISTIE et al., 2009). A menos que a variação do habitat (macroalga e epífitas) seja quantificado, nenhuma explicação para a variação na abundância, densidade e diversidade dos organismos epifaunais é válida. Além da quantificação do volume e/ou área disponível para a epifauna associada, o arranjo estrutural do habitat também é importante e irá influenciar a distribuição dos organismos epifaunais (SMITH \& RULE, 2002).

Vários estudos no mundo tentaram quantificar a complexidade estrutural da macroalga, através da medição da quantidade de habitat disponível, seja pela biomassa, volume intersticial, área superficial ou número e disposição dos ramos (HARROD \& HALL, 1962; COULL \& WELLS, 1983; HACKER \& STENECK, 1990; STONER \& LEWIS, 1985; ATTRILL et al., 2000; McABENDROTH et al., 2005). No litoral brasileiro, Sargassum é bem representado em número de espécies e estima-se que existam onze distribuídas desde o litoral do Estado do Maranhão até o Estado do Rio Grande do Sul (MAFRA \& CUNHA, 2002; COIMBRA, 2006). Muitos estudos mostraram a amplitude da variação sazonal das espécies de Sargassum presentes no litoral brasileiro e a relação positiva entre a complexidade estrutural da macroalga e suas epífitas com a diversidade de espécies da epifauna (JACOBUCCI et al., 2006; LEITE et al., 2007; PEREIRA et al., 2010). A maioria desses estudos considerou apenas a biomassa (em peso úmido ou seco) como fator influenciador. Contudo, a complexidade estrutural deve analisar características de pequena escala como o tamanho, forma e textura das frondes e espaços intersticiais fornecidos por elas e, principalmente, como os organismos percebem este habitat em diferentes escalas (JEFFRIES, 1993; GEE \& WARWICK, 1994b). Análises da complexidade estrutural utilizando apenas uma variável, no caso do Brasil, a biomassa, 
podem ser incompletas e conduzir a erros de interpretação, uma vez que frondes com valores elevados de biomassa não são seguramente os habitats mais complexos. Frondes com valores similares de biomassa podem apresentar valores dissimilares no tamanho e número de ramos, o que implica na alteração do arranjo da estrutura do habitat (GEE \& WARWICK, 1994b). Além disso, as medidas comumente utilizadas, principalmente a biomassa, são insatisfatórias no sentido de que não apresentam uma base matemática a partir da qual possam ser feitas previsões acerca das mudanças temporais da complexid ade do habitat e seu efeito sobre as comunidades, ou que permitam comparações com outros substratos (HACKER \& STENECK, 1990; GEE \& WARWICK, 1994b). No presente estudo utilizou-se uma série de medidas de complexidade estrutural das macroalgas, relacionando-as com a abundância dos organismos epifaunais.

Tendo em vista o exposto acima, o primeiro objetivo do presente estudo foi comparar o desempenho temporal de diferentes medidas quantitativas no desenvolvimento vegetativo de dois bancos de Sargassum filipendula. Para tal, foram utilizadas as seguintes medidas quantitativas: número de ramos, peso seco, volume intersticial e área superficial. A hipótese a ser testada é que o peso é uma medida insuficiente para analisar a complexidade estrutural de Sargassum filipendula e suas epífitas, independente da forma da alga.

O segundo objetivo desta pesquisa foi observar como a comunidade epifaunal responde a variação da complexidade estrutural do substrato ao longo do tempo, através da análise da estrutura da comunidade da epifauna. A hipótese a ser testada é que a abundância e diversidade da epifauna estão significativamente e positivamente relacionadas às medidas quantitativas do Sargassum filipendula, ou seja, com o aumento da complexidade estrutural do banco de alga ao longo do tempo. 


\section{MATERIAL \& MÉTODOS}

\section{1. Área de Estudo}

O presente estudo foi realizado em duas praias distintas quanto ao hidrodinamis mo, as praias da Fortaleza (Enseada da Fortaleza) e do Lamberto (Enseada do Flamengo), ambas localizadas no município de Ubatuba, litoral norte do Estado de São Paulo. Ubatuba é caracterizada principalmente por verões chuvosos e invernos secos e dessa forma a temperatura da água superficial de suas baías e enseadas varia de 21 a $31^{\circ} \mathrm{C}$ ao longo do ano (TARARAM \& WAKABARA, 1981; LEITE et al., 2007).

\subsubsection{Praia da Fortaleza - Enseada da Fortaleza}

O costão da Ponta da Praia da Fortaleza, localizado na Enseada da Fortaleza $\left(23^{\circ} 32^{\prime} \mathrm{S}, 45^{\circ} 10^{\prime} \mathrm{W}\right)$ é uma ponta rochosa com 40 metros de largura em sua porção mais estreita e que avança na direção sudeste-nordeste cerca de 500 metros para o mar. Essas características conferem à Ponta da Fortaleza acentuada exposição às ondas na sua face sudoeste e proteção na sua face noroeste (PAULA \& OLIVEIRA-FILHO, 1980). Esta última, onde foi realizado o presente estudo, pode ser considerada em sua maior extensão como moderadamente protegida e é constituída principalmente por blocos rochosos onde, de trechos em trechos, aparecem superfícies contínuas e uniformes (PAULA, 1978; JACOBUCCI et al., 2009a) (Figura 01). Com relação às características oceanográficas, a Enseada da Fortaleza apresenta valores médios anuais de temperatura da água do mar de $23,5^{\circ} \mathrm{C}\left(21\right.$ a $\left.28^{\circ} \mathrm{C}\right)$, salinidade de $34,4(32,4$ a 35,6$)$ e oxigênio dissolvido de $5,46 \mathrm{mg} / 1$ (4,20 a 6,33 mg/l) (NEGREIROS-FRANSOZO et al., 1991).

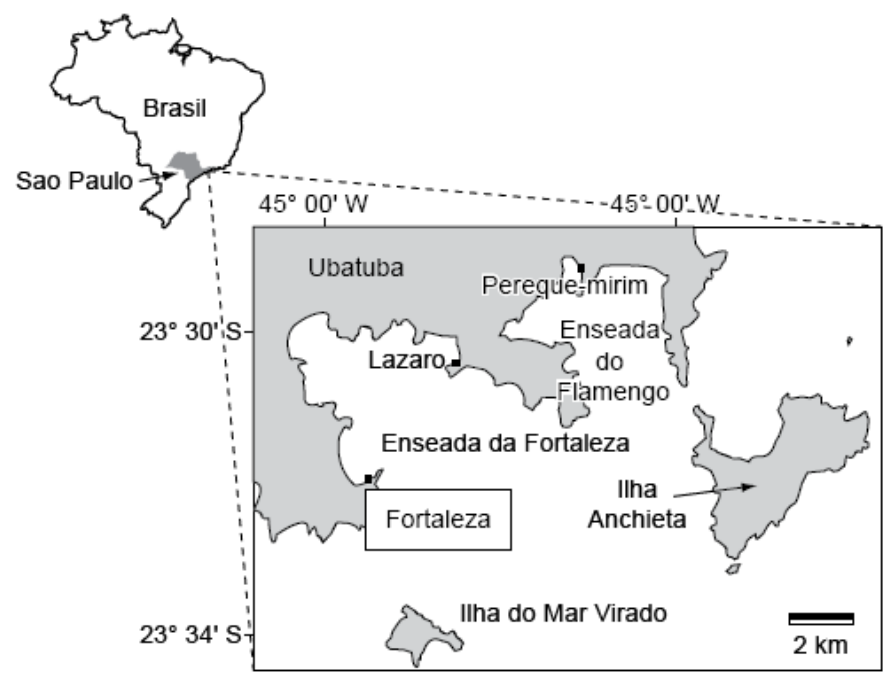

Figura 01 - Localização da área de estudo na Praia da Fortaleza, Enseada da Fortaleza, Ubatuba, São Paulo. 


\subsubsection{Praia do Lamberto - Enseada do Flamengo}

A Praia do Lamberto $\left(23^{\circ} 29^{\prime} 42^{\prime \prime} \mathrm{S}, 45^{\circ} 05^{\prime} \mathrm{W}\right)$, onde foi realizado o presente estudo, está situada na Enseada do Flamengo que apresenta profundidades máximas de $14 \mathrm{~m}$ e desta forma configura-se como uma enseada rasa. Esta é orientada na direção norte-sul, tendo ao fundo uma praia a nordeste denominada praia da Enseada e duas pequenas baías: Saco do Perequê-Mirim, situado a norte, e Saco da Ribeira, a nordeste (Figura 02) (SASSI \& KUTNER, 1982). A enseada é um ambiente semiconfinado, cujo padrão de circulação caracteriza-se por correntes vindas do Sul, que entram pelo seu lado ocidental. Essas correntes, após margearem a costa ocidental, bifurcam-se, indo parte para o Saco da Ribeira e parte para a costa oriental (DULEBA, 1994).

A água da enseada é oligotrófica e a salinidade e temperatura médias da água refletem normalmente valores encontrados nas das enseadas próximas, variando de 20 $30^{\circ} \mathrm{C}$ e 27.2 - 34.8 (CORBISIER, 1994). Diferentemente da Praia da Fortaleza, a Praia do Lamberto apresenta duas fontes de influência antropogênico. A primeira é a região do Saco da Ribeira, que apresenta um complexo de pequenas marinas e garagens de barcos; a segunda é o rio Perequê-Mirim (ALBERGARIA-BARBOSA et al., 2011; JACOBUCCI \& LEITE, 2014).

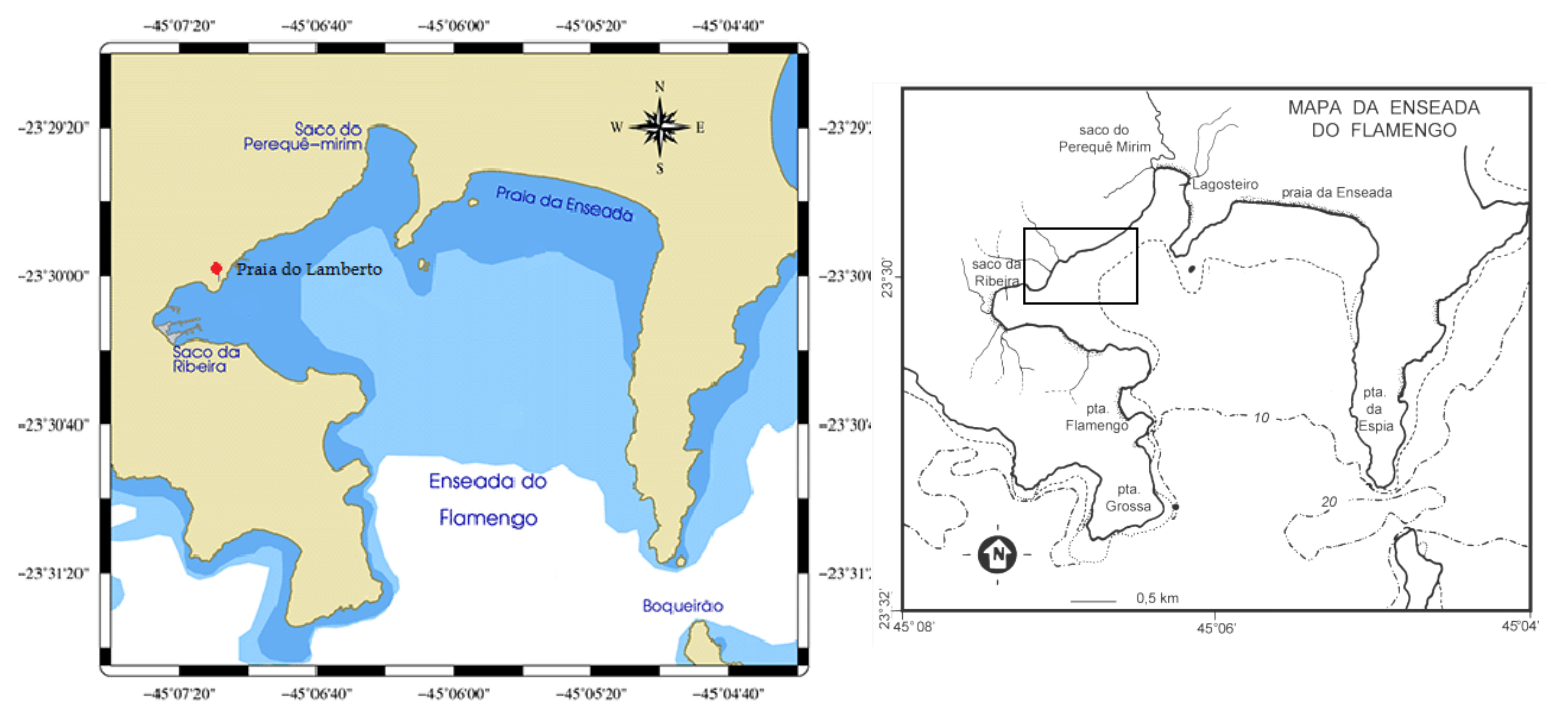

Figura 02 - Localização da área de estudo na Praia do Lamberto, Enseada do Flamengo, Ubatuba, São Paulo. 


\subsection{Trabalho de Campo}

Coletas mensais foram realizadas ao longo de treze meses, entre janeiro de 2012 a janeiro de 2013, nas praias da Fortaleza e do Lamberto. As macroalgas foram coletadas por meio de mergulho autônomo em uma área de $50 \mathrm{~m}$ de extensão, paralela ao costão rochoso e/ou píer. Em cada praia, mensalmente, foram coletadas aleatoriamente 15 frondes de Sargassum filipendula, durante a maré baixa diurna. Cada fronde foi coberta individualmente com saco de malha de $250 \mathrm{~mm}$ para retenção da macrofauna associada, inclusive indivíduos jovens. Todas as frondes foram retiradas do substrato com o auxílio de uma espátula, tendo-se o cuidado de manter o apressório junto da alga.

Os parâmetros ambientais, tais como temperatura superficial da água e salinidade, foram mensurados a cada mês. Três réplicas de água do mar (1 litro cada) foram coletadas para análise de material em suspensão, sendo que uma das amostras foi utilizada também para análise de nutrientes (fosfato, nitrato e nitrito). Os dados referentes à média pluviométrica de cada mês foram obtidos no próprio pluviógrafo eletrônico da Base Clarimundo de Jesus do IOUSP (Ubatuba-SP) e os valores mínimos e máximos mensais da temperatura do ar bem como o número de dias com chuva foram obtidos no site CPTEC/INMET.

\subsection{Laboratório}

Em laboratório, cada fronde foi lavada separadamente em um balde de água doce, sendo em seguida a solução do material peneirada em um jogo de peneiras com malhas de 2,0,1,0 e 0,5 mm. A lavagem e o peneiramento foram contínuos até que nenhum organis mo aparecesse mais na solução. As frondes do Sargassum filipendula e as algas epífitas associadas foram conservadas em formol $4 \%$ e a fauna em álcool $70 \%$. Os organismos foram triados e separados em grandes grupos taxonômicos.

No presente estudo a complexidade estrutural das frondes do $S$. filipendula e suas epífitas foram analisadas através de quatro tipos de medidas quantitativas, conforme descritas a seguir:

I) Número de ramos primários e ramos secundários - Em cada fronde foram contados os ramos primários e secundários, de acordo com PAULA (1988).

II) Volume Intersticial (ml) - baseado no método descrito por Hacker \&Steneck (1990) (Figura 03), foram calculados o Volume da Copa (VC) em ml, definido pela multiplicação entre a altura $(\mathrm{H})$, largura $(\mathrm{L})$ e comprimento $(\mathrm{C}) \mathrm{em} \mathrm{cm}$ de cada fronde 
submersa em água; Volume do Talo (VT) em $\mathrm{ml}$, definido como o volume de água deslocado quando a alga está submersa, em um local de volume conhecido; Volume Intersticial (VI) em ml, definido como o volume de água absorvido pelos espaços entre as copas das algas, determinado pela subtração do VT e VC. Com a medida do volume é possível determinar o número de organismos por $100 \mathrm{ml}$ de volume intersticial em cada fronde.
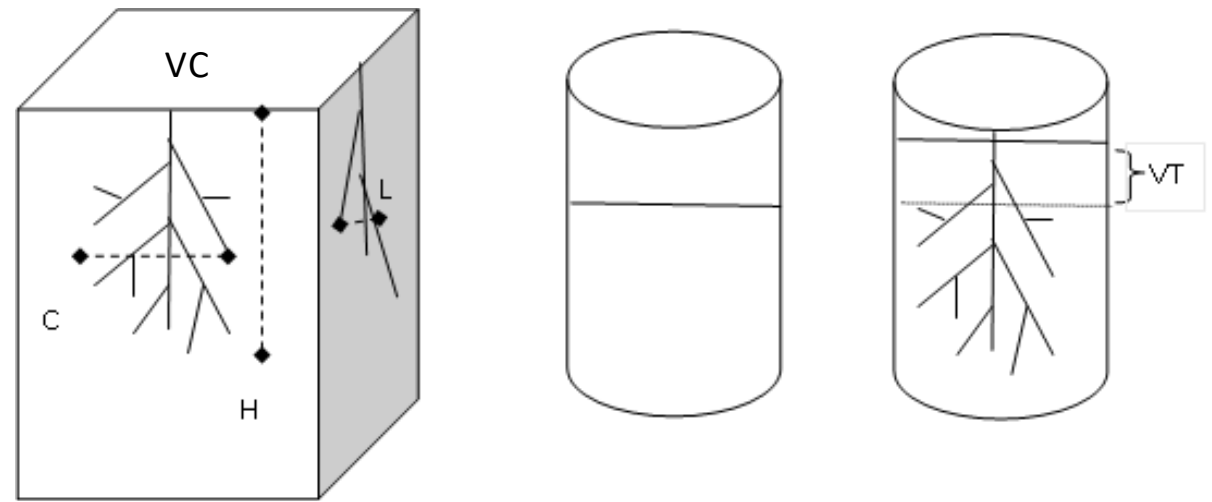

Figura 03 - Desenho esquemático para obtenção do Volume da Copa (VC), das frondes do Sargassum filipendula considerando-se a alga submersa em aquário, onde foram obtidos $\mathrm{o}$ comprimento $(\mathrm{C})$, altura $(\mathrm{H})$ e largura $(\mathrm{L}) \mathrm{em} \mathrm{cm}$. Os cilindros representam como foi obtido o Volume do Talo (VT) de cada fronde por mês e praia.

III) Área Superficial da Macroalga (ASM) via imagem $\left(\mathbf{c m}^{2}\right)$ - Todas as algas foram fotografadas e cada fotografia foi convertida em TIFF, depois transformadas em escala de cinza, produzindo uma imagem binária de preto e branco com pixel de comprimento de 0,03 mm, seguindo-se os processos descritos por McAbendroth et al. (2005). Essas imagens foram então analisadas pelo programa IMAGEJ 1.51 que calcula a área superficial da macroalga (ASM) (Figura 04).

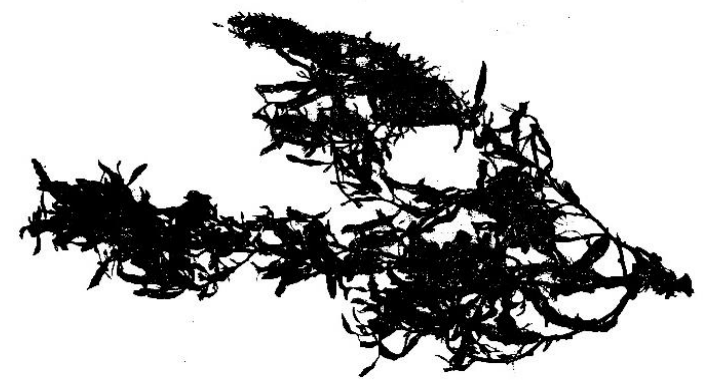

Figura 04 - Imagem da fronde de Sargassumfilipendula obtida através do programa ImageJ 1.51 para posterior cálculo da área superficial da macroalga (ASM).

IV) Peso Seco (g) -As algas epífitas presentes no S. filipendula foram cuidadosamente removidas com auxilio de pinças. Foram obtidos os pesos úmidos do $S$. filipendula e das epífitas separadamente. Em seguida, todas as algas foram colocadas em 
estufa por $72 \mathrm{~h}$ a $60^{\circ} \mathrm{C}$ para secagem. Após esse período, cada fronde foi pesada separadamente com o auxilio da balança analítica para obtenção dos pesos secos em gramas. Com a somatória do peso seco do S. filipendula (PSS) e do peso seco das algas epífitas (PSE) calculou-se o valor de peso seco total (PST).

\subsection{Análises Estatísticas}

Métodos não-paramétricos foram utilizados nas diversas análises efetuadas. Para se detectar diferenças nos valores de nutrientes (fosfato, nitrato e nitrito) e material em suspensão entre as amostras de água superficial das duas praias amostradas, empregouse o teste U de Mann-Whitney para amostras independentes.

Análises de Variância (ANOVAs) foram realizadas para testar possíveis diferenças significativas entre as frondes coletadas nas praias e meses amostrados e para todas as medidas quantitativas do Sargassum filipendula (número de ramos; altura das frondes; volume intersticial, pesos secos e área superficial), valores de abundância média dos organismos e número de táxons, além da densidade da fauna. Esta foi calculada com base no peso seco total, volume e área superficial da alga. Para essas análises, considerou-se sempre o mesmo modelo de duas vias, Two-way ANOVA, incluindo os fatores: Localização - Praia (Fixa com dois níveis: Fortaleza e Lamberto) e Período - Mês (Fixa com 13 níveis: Janeiro de 2012 a janeiro de 2013).

Antes de cada ANOVA o teste de Kolmogorov-Smirnov foi realizado para verificar a homogeneidade das variâncias. Se necessário, os dados foram transformados em $\log (10)$ para remover a heterogeneidade das variâncias. Quando isso não foi possível, o dado não transformado foi analisado e os resultados foram considerados robustos em nível de significância $P<0,01$ (UNDERWOOD, 1997). Na existência de diferenças significativas, foi realizado teste a posteriori de Tukey HSD para explorar essas diferenças entre os pares dos níveis do fator selecionado.

A correlação de Spearman é uma análise não paramétrica com a finalidade de determinar o grau de associação entre duas variáveis mensuradas, pelo menos, a nível ordinal e dispostas em postos ordenados em duas séries, $X$ e $Y$ (ZAR, 1999). Essa análise foi empregada para se observar possíveis correlações significativas entre os valores dos descritores abióticos (temperatura da água, salinidade, nutrientes, material em suspensão), e os valores das medidas quantitativas do Sargassum filipendula (volume intersticial, pesos secos e área superficial) e os valores de abundância média dos organismos, número de táxons e medidas de densidade. 


\section{RESULTADOS}

\subsection{Abióticos}

\subsubsection{Precipitação média mensal e temperatura do ar em Ubatuba.}

A precipitação média mensal para o período de amostragem (janeiro de 2012 a janeiro de 2013), os números de dias com chuvas para cada mês, bem como os valores médios mensais de temperatura do ar máxima e mínima estão apresentados na Figura 05.

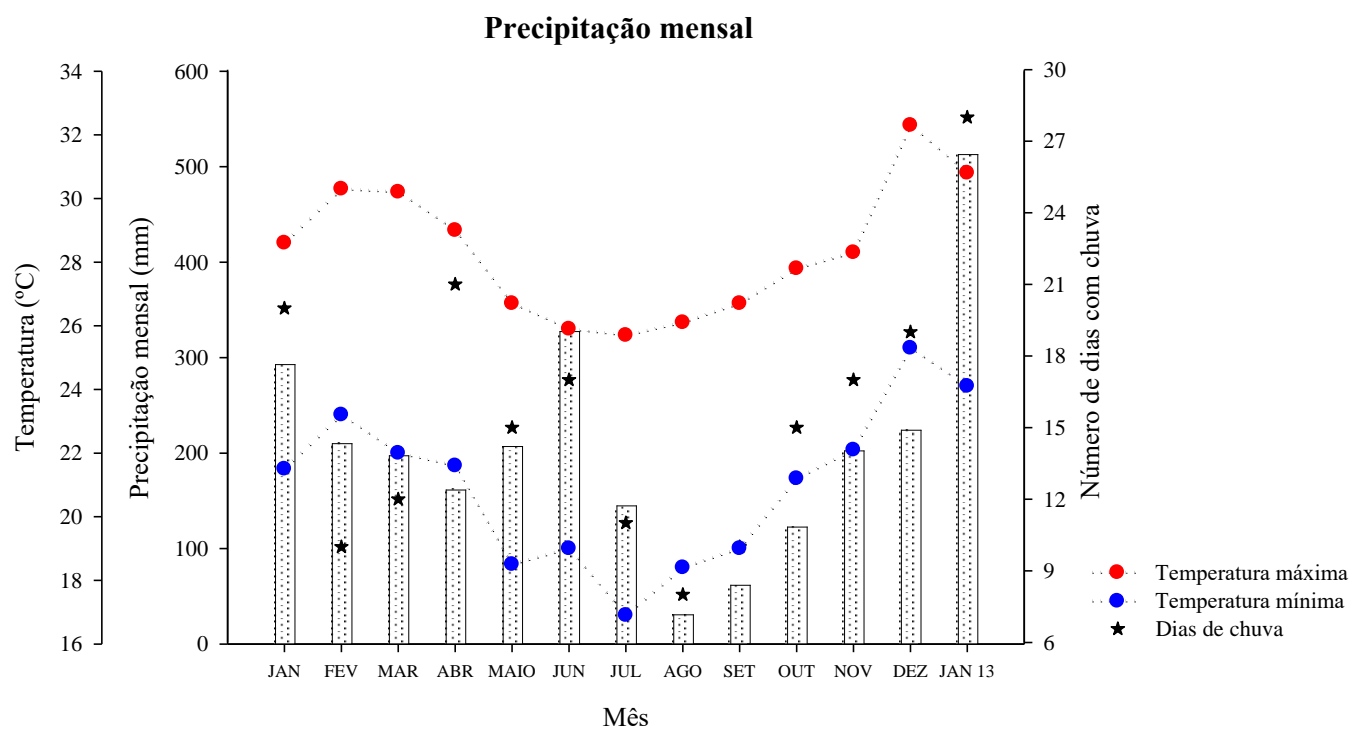

Figura 05 - Precipitação média mensal, número de dias com chuvas e temperaturas do ar máximas e mínimas no período de janeiro de 2012 a janeiro de 2013 em Ubatuba, São Paulo. Fonte: CPTEC, 2013.

Dois picos distintos de precipitação média foram observados no período estudado e ocorreram nos meses de junho $(328,2 \pm 19 \mathrm{~mm})$ e janeiro, especialmente em 2013 (513,5 $\pm 25 \mathrm{~mm}$ ) (Figura 05). Os demais meses apresentaram precipitação média abaixo do normal para a época. De fevereiro (principalmente na primeira quinzena) a maio as chuvas ocorreram abaixo da média histórica $(250 \mathrm{~mm})$ e o aumento de dias sem chuvas resultou em temperaturas mais elevadas. O mesmo foi observado entre agosto e outubro, que foi caracterizado pelo déficit de chuvas, resultado de um sistema de alta pressão anômalo na região, o que levou a um aumento nas temperaturas. Estas condições foram observadas até final do inverno e início da primavera. O aumento do calor e a elevada umidade no período causaram temporais seguidos por rajadas de vento. O mês de janeiro de 2013 foi caracterizado pela Zona de Convergência do Atlântico Sul (ZCAS) que favoreceu as 
precipitações e a ocorrência de temperaturas mais amenas, em comparação com o mês anterior.

\subsubsection{Temperatura superficial e Salinidade da água}

Durante os treze meses de amostragem, a temperatura superficial da água oscilou entre 21 a $25^{\circ} \mathrm{C}$ na Praia da Fortaleza e entre 19,5 a $26^{\circ} \mathrm{C}$ na Praia do Lamberto, sendo os maiores valores obtidos nos meses de fevereiro, março e abril e janeiro de 2013 (Tabela 01). A salinidade da água variou entre 33 e 36 na Praia da Fortaleza e 32 e 35 na Praia do Lamberto (Tabela 02). Não houve diferença significativa para os valores de temperatura superficial da água e salinidade entre as praias amostradas $(\mathrm{Z}(\mathrm{U})=0,18 ; \mathrm{p}=0,85 ; \mathrm{Z}(\mathrm{U})=$ 0,$89 ; \mathrm{p}=0,36$, respectivamente). Com base nos valores de T-S, podemos inferir que a massa de Água Costeira (AC) esteve presente nas duas enseadas durante a maior parte do estudo.

Tabela 01 - Datas de coleta, variação da maré, Temperatura $\left({ }^{\circ} \mathrm{C}\right)$ e Salinidade da água para as praias da Fortaleza e Lamberto, Ubatuba, São Paulo.

\begin{tabular}{cccccccccc}
\hline & \multicolumn{9}{c}{ Coletas Mensais } \\
\hline & & \multicolumn{9}{c}{ Fortaleza } & \multicolumn{4}{c}{ Lamberto } \\
& & Data & Maré & Temp $\left({ }^{\circ} \mathrm{C}\right)$ & Sal & Data & Maré & Temp $\left({ }^{\circ} \mathrm{C}\right)$ & Sal \\
\hline & JAN & 10 & 0.3 & 23.5 & 35 & 11 & 0.3 & 24 & 34 \\
& FEV & 8 & 0.2 & 25 & 34 & 7 & 0.2 & 25 & 32 \\
& MAR & 8 & 0.1 & 24 & 35 & 7 & 0.2 & 26 & 34 \\
& ABR & 10 & 0.2 & 25 & 33 & 9 & 0.1 & 25 & 34 \\
& MAIO & 8 & 0.1 & 23 & 35 & 9 & 0.1 & 23.5 & 35 \\
N & JUN & 20 & 0.0 & 21 & 34 & 21 & 0.0 & 21 & 34 \\
○ & JUL & 5 & -0.1 & 22 & 34 & 4 & -0.1 & 22 & 33 \\
& AGO & 31 & 0.0 & 21 & 34 & 29 & 0.0 & 19.5 & 34 \\
& SET & 13 & 0.1 & 21 & 35 & 12 & 0.2 & 21 & 35 \\
& OUT & 15 & 0.0 & 22 & 36 & 16 & 0.1 & 22 & 34 \\
& NOV & 12 & 0.1 & 22 & 34 & 11 & 0.1 & 21 & 34 \\
& DEZ & 12 & 0.3 & 24 & 33 & 11 & 0.3 & 24 & 33 \\
\hline 2013 & JAN & 10 & 0.3 & 25 & 33 & 9 & 0.4 & 26 & 34 \\
\hline
\end{tabular}

\subsubsection{Material em suspensão e nutrientes}

Os valores de material em suspensão das amostras de água coletadas tanto na Praia do Lamberto quanto na Fortaleza foram baixos, menores que 0,1g, exceto para os meses de março, maio e julho, quando foram $0,19 \pm 0,12 \mathrm{~g} ; 0,23 \pm 0,26 \mathrm{~g} \mathrm{e} 0,23 \pm 0,09 \mathrm{~g}$, respectivamente. Apesar de mais altos, esses valores apresentaram grande variação entre as réplicas (Figura 6). $\mathrm{O}$ teste $\mathrm{U}$ indicou não haver diferença significativa entre as amostras das duas praias $(\mathrm{Z}(\mathrm{U})=0,282 ; \mathrm{p}>0,05)$. 

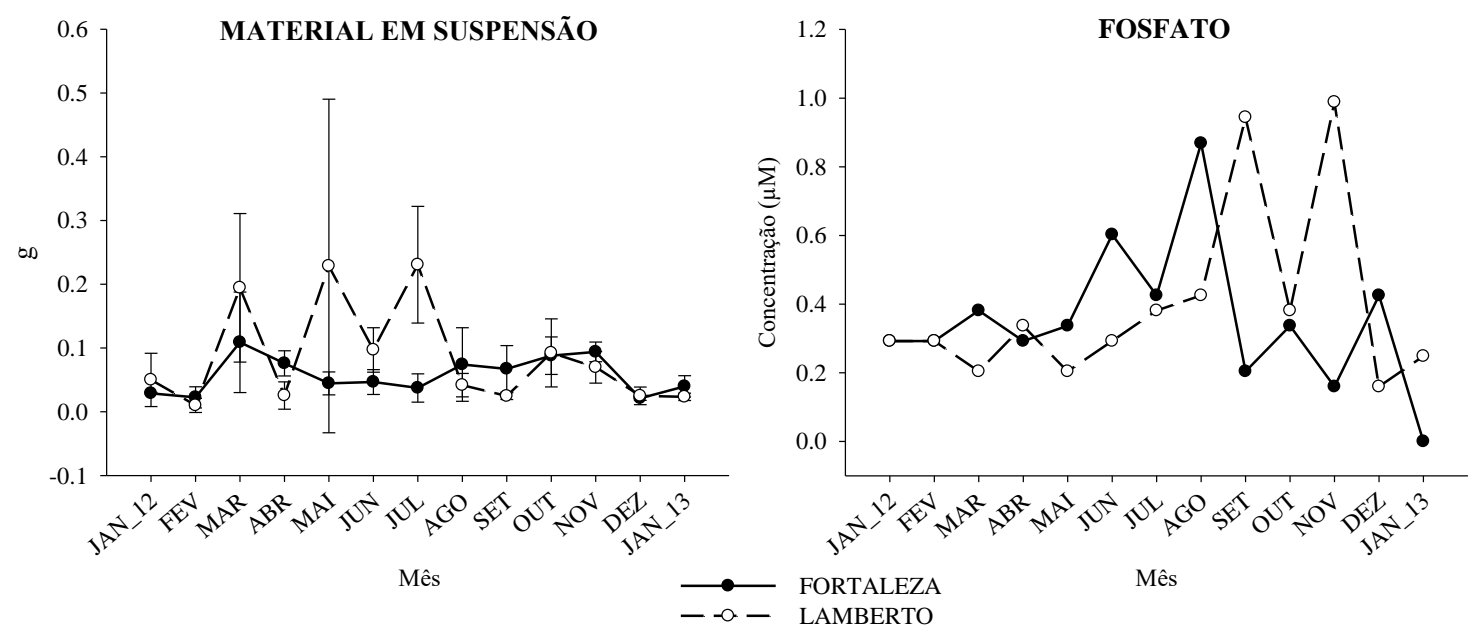

Figura 06 - Material em suspensão $(\mathrm{g})$ e concentração de fosfato $(\mu \mathrm{M})$ nas amostras de água coletadas nas praias da Fortaleza e Lamberto, Ubatuba, São Paulo, durante o período de estudo.

As concentrações de fosfato, nitrito e nitrato apresentaram grande variação ao longo do período amostrado, em ambas as praias. Os valores de fosfato indicaram dois grandes picos de concentração na Praia do Lamberto, setembro e novembro, e apenas um pico na Praia da Fortaleza, no mês de agosto (Figura 6). Segundo o Teste U não houve diferença significativa nos valores de fosfato nas amostras de água entre as praias $(Z(U)=0,076$; p>0,05). Apenas os valores de fosfato do Lamberto apresentaram correlação negativa com os valores de temperatura superficial da água ( $r s=-0,69 ; \mathrm{p}=0,009)$.

As concentrações de nitrito apresentaram maior flutuação na praia da Fortaleza em comparação ao Lamberto. Na Fortaleza os valores começaram a crescer a partir de abril, chegando ao ápice em setembro e outubro, a partir de quando tenderam a voltar aos níveis de base. Em contraposição, na Praia do Lamberto os níveis de base foram cerca de duas vezes mais elevados, mas os picos ocorreram mais cedo, em abril e maio, e também foram menores (Figura 7). Apesar do que foi apontado, os valores nas amostras de água das duas praias, quando comparados, não apresentaram diferenças significativas $(Z(U)=0,435$; $\mathrm{p}>0,05)$.

O nitrato das amostras apresentou concentrações e flutuação dos valores semelhantes nas duas praias. Na Fortaleza houve um pico forte em junho, enquanto no Lamberto ocorreu um período de valores mais elevados que foi de março a agosto (outono/inverno) (Figura 7). A aplicação do teste $U$ indicou não haver diferença significativa entre as amostras das praias $(Z(U)=0,769 ; p>0,05)$. Em relação aos fatores abióticos e os nutrientes, apenas para a Praia da Fortaleza foi obtida correlação negativa entre nitrito e temperatura superficial da água ( $r s=-0,79 ; p=0,001)$. 

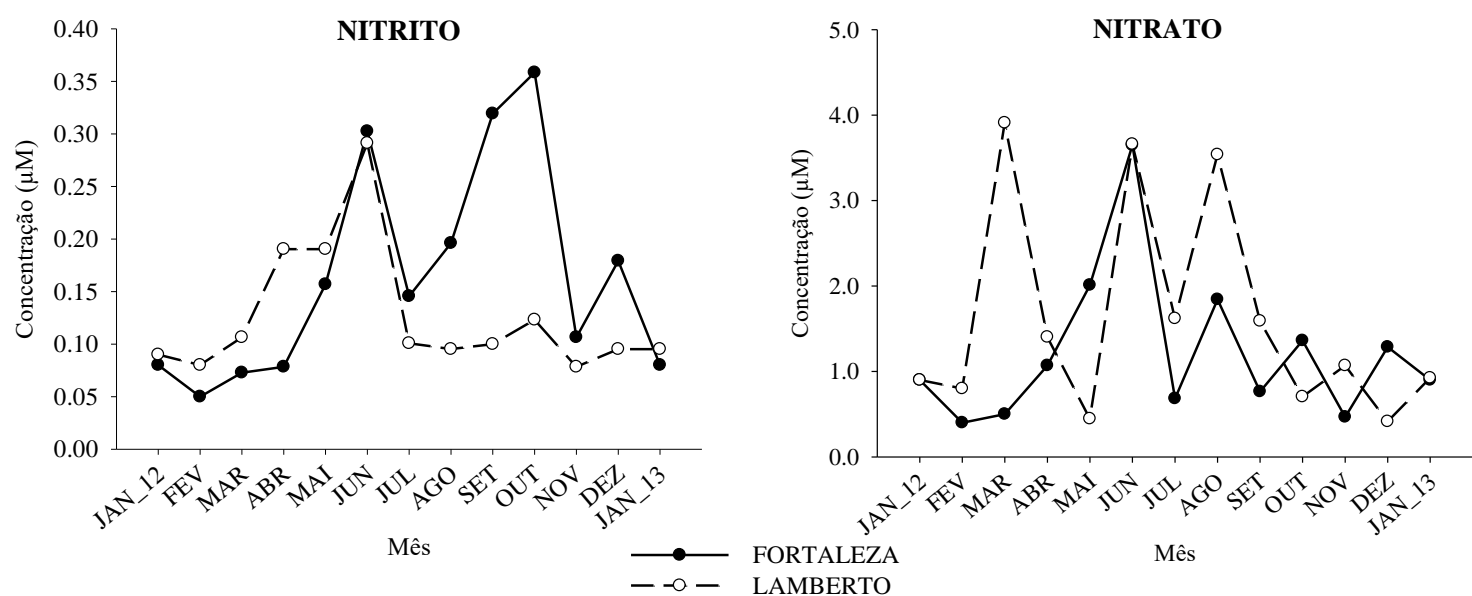

Figura 07 - Concentração de nitrato e nitrito $(\mu \mathrm{M})$ das amostras de água coletadas nas praias da Fortaleza e Lamberto, Ubatuba, São Paulo, durante o período de amostragem.

\subsection{Sargassum filipendula e Medidas Quantitativas}

Segundo as ANOVAs realizadas, as frondes de Sargassum filipendula exibiram diferenças significativas entre praias, meses e interação entre praia/ mês para as variáveis, ramos primários e ramos secundários, altura da fronde e volume intersticial (Tabela 02 e Figuras 8 e 9$)$.

Tabela 02 - Sumário das ANOVAs para as medidas de complexidade estrutural do Sargassum filipendula: Ramos Primários, Ramos Secundários, Altura das frondes e Volume Intersticial. ** $P<0.01$; ${ }^{\text {s }}$, significativo $\mathrm{e}^{\mathrm{ns}}$, não significativo.

\begin{tabular}{|c|c|c|c|c|c|c|c|c|c|}
\hline \multirow{2}{*}{ Fonte de variação } & \multirow{2}{*}{$d f$} & \multicolumn{2}{|c|}{$\operatorname{Ramos} 1^{\circ}$} & \multicolumn{2}{|c|}{$\operatorname{Ramos} 2^{\circ}$} & \multicolumn{2}{|c|}{ Altura } & \multicolumn{2}{|c|}{ Volume } \\
\hline & & MS & $\mathrm{F}$ & MS & $\mathrm{F}$ & MS & $\mathrm{F}$ & MS & $\mathrm{F}$ \\
\hline Praia & 1 & 716.67 & $140.18 * *$ & 9359.86 & $104.19 * *$ & 31237.21 & $443.56 * *$ & 4.36 & $49.18^{* *}$ \\
\hline Mês & 12 & 17.12 & $3.35^{* *}$ & 494.02 & $5.50^{* *}$ & 452.66 & $6.43^{* *}$ & 0.86 & $9.65^{* *}$ \\
\hline Praia*Mês & 12 & 11.45 & $2.24 * *$ & 319.82 & $3.56^{* *}$ & 265.11 & $3.77 * *$ & 0.54 & $6.14 * *$ \\
\hline Residual & 338 & 5.11 & & 89.83 & & 70.42 & & 0.09 & \\
\hline Total & 364 & & & & & & & & \\
\hline Kolmogorov-Smirnov & & \multicolumn{2}{|c|}{$0.156^{\mathrm{ns}}$} & \multicolumn{2}{|c|}{$0.085^{\mathrm{ns}}$} & \multicolumn{2}{|c|}{$0.089^{\mathrm{ns}}$} & \multicolumn{2}{|c|}{$0.055^{\mathrm{s}}$} \\
\hline Transformação & & \multicolumn{2}{|c|}{ Não } & \multicolumn{2}{|c|}{ Não } & \multicolumn{2}{|c|}{ Não } & \multicolumn{2}{|c|}{ Sim } \\
\hline
\end{tabular}




\section{FORTALEZA}
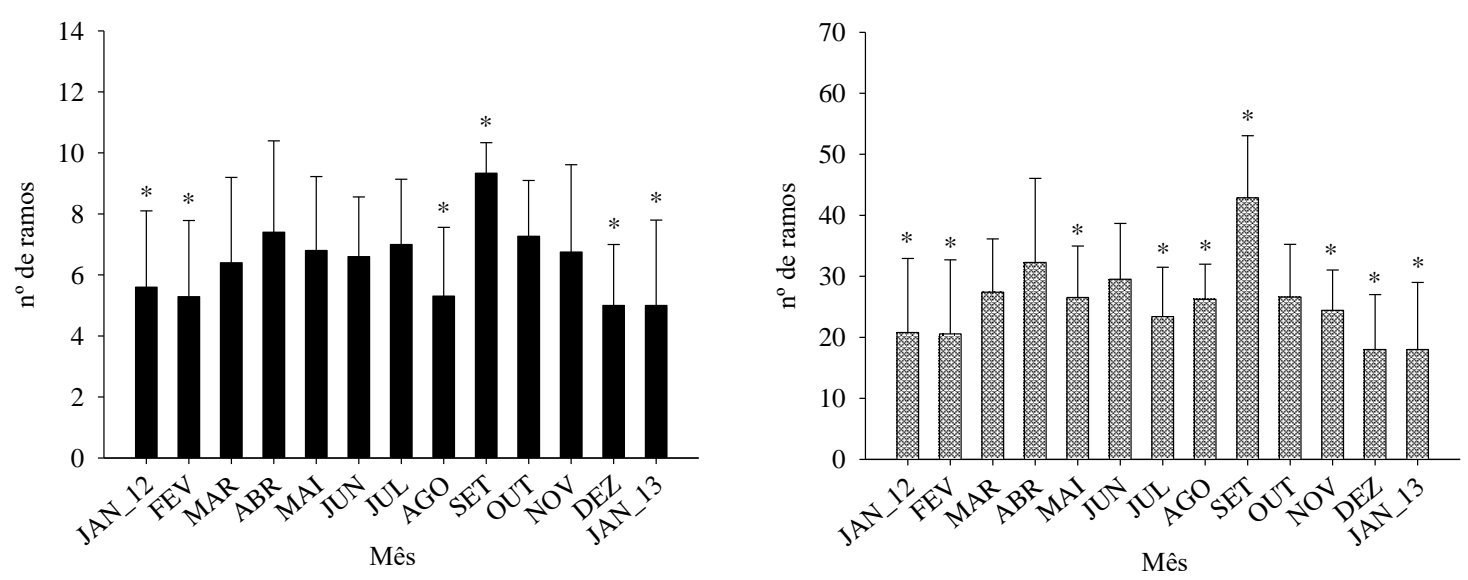

LAMBERTO
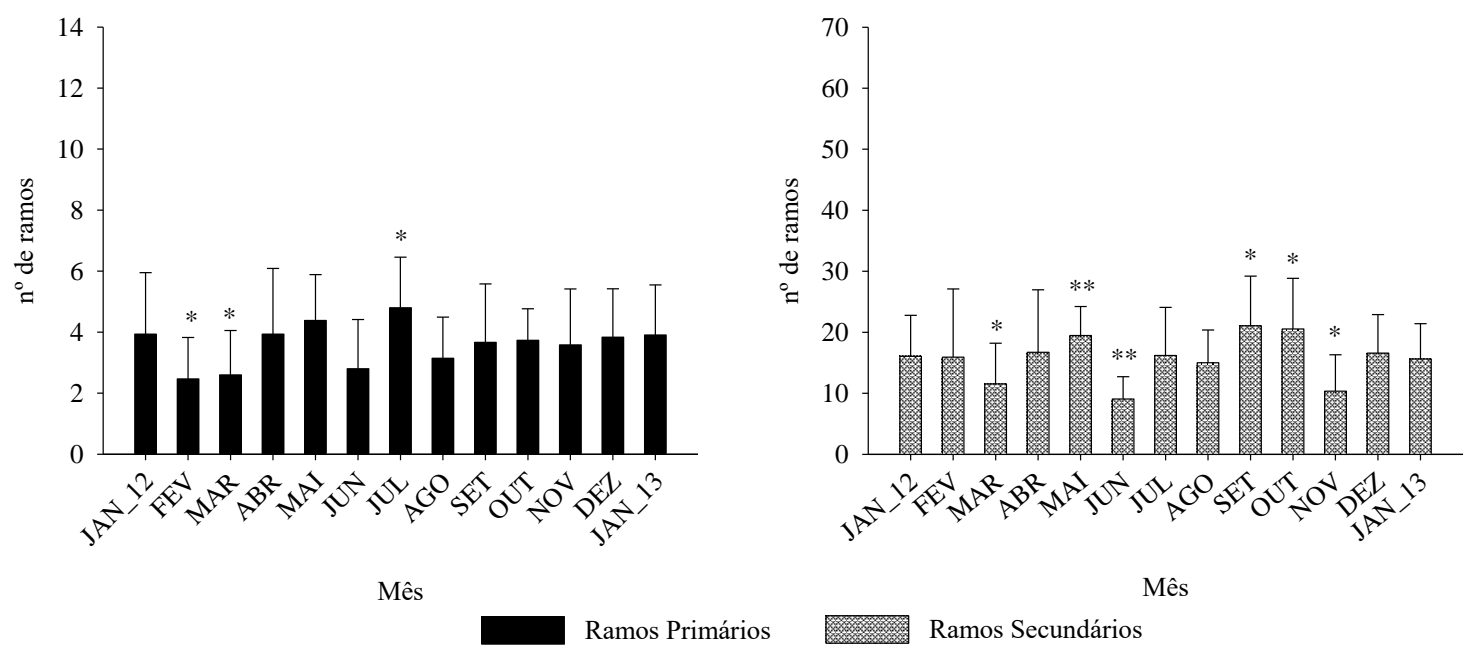

Figura 08 - Número de ramos primários e secundários das frondes de Sargassumfilipendula em cada mês nas praias da Fortaleza e Lamberto, Ubatuba, São Paulo. Barras com asterisco são significativamente diferentes, de acordo com o teste post-hoc Tukey HSD.

De modo geral, as frondes obtidas na Praia da Fortaleza foram mais ramificadas do que as obtidas na Praia do Lamberto (Figura 08). Independente da praia, houve variação na ramificação das frondes e, segundo comparações par a par, os maiores valores situaram-se na primavera (setembro) e foram significativamente diferentes dos menores obtidos no verão (Figura 08). Quanto à altura das frondes e volume intersticial, as frondes coletadas na Praia do Lamberto exibiram os maiores valores (Figura 09). Comparações par a par evidenciaram diferenças significativas entre os meses de verão e final de primavera (maiores valores) e inverno/primavera (menores valores) para as duas variáveis, a exceção ficou com o mês de setembro que mostrou um valor elevado para o volume intersticial (Figura 09). 

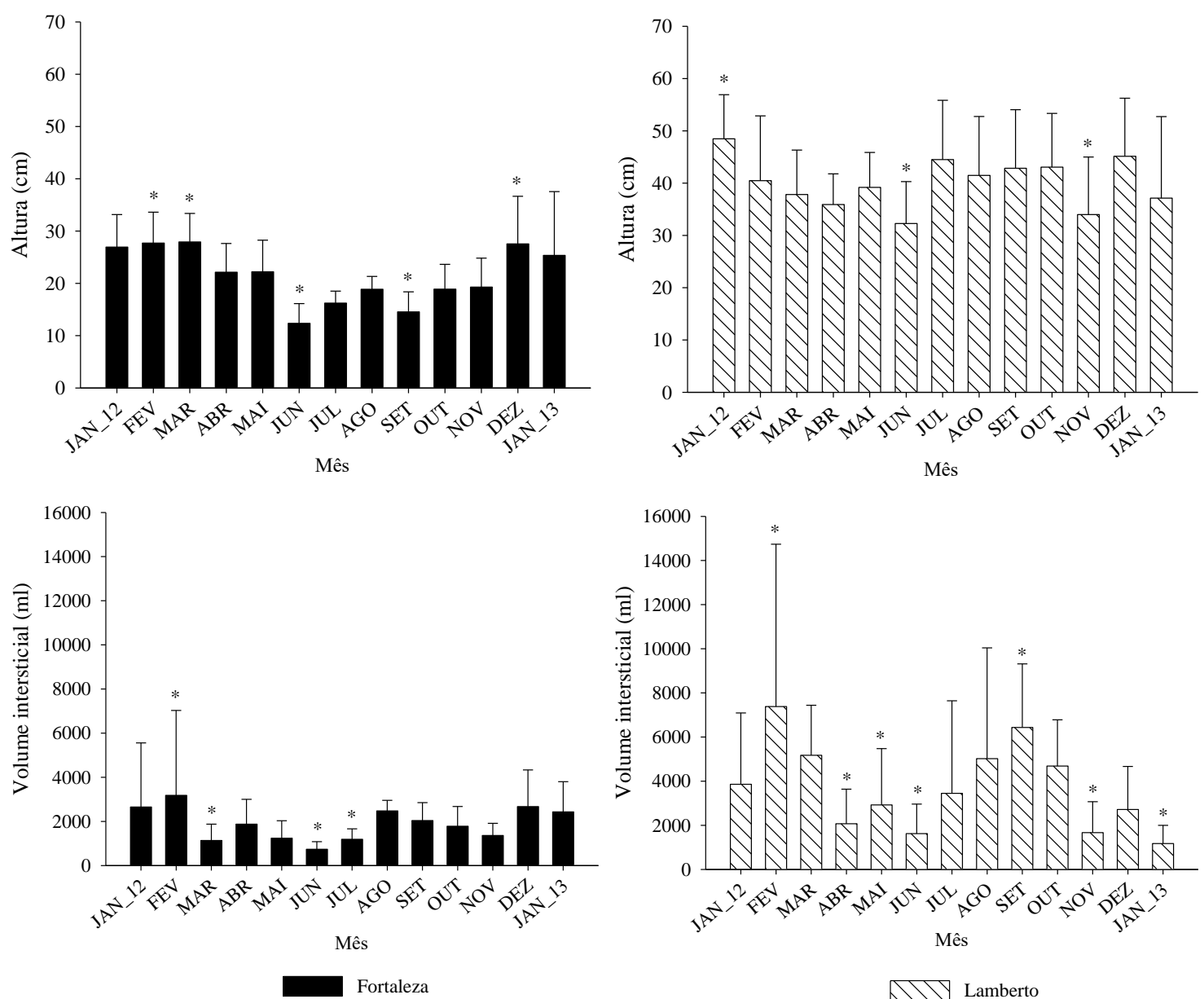

Figura 09- Altura das frondes (cm) e Volume intersticial (ml) do Sargassumfilipendula em cada mês coletadas nas praias da Fortaleza e Lamberto, Ubatuba, São Paulo. Barras com asterisco são significativamente diferentes, de acordo com o teste post-hoc Tukey HSD.

Segundo as ANOVAs existem diferenças significativas entre as praias e meses para todas as análises realizadas com o Peso Seco: Peso Seco Total (PST), Peso Seco do Sargassum filipendula (PSS) e Peso Seco das Epífitas (PSE), assim como para a Área Superficial da Macroalga (ASM). Ressaltamos ainda que houve diferença significativa nas interações praia/mês para PSE e ASM (Tabela 3).

Quanto ao Peso Seco Total (PST), a Praia do Lamberto exibiu o maior valor médio na comparação entre as praias (Lamberto: 6,7 \pm 2 g e Fortaleza: $5 \pm 2 \mathrm{~g}$ ). Ambos os locais apresentaram diferença significativa entre os meses e, segundo o Teste de Tukey HSD, houve diferença entre os maiores valores de PST no final da primavera e verão - dezembro e janeiro de 2013 (Fortaleza) e fevereiro/março (Lamberto) - e os menores valores no inverno, maio e junho (Fortaleza) e junho e agosto (Lamberto) (Figura 10). 
Tabela 03 - Sumário das ANOVAs para as medidas de complexidade estrutural de Sargassum filipendula: Peso Seco Total (PST), Peso Seco S. filipendula (PSS), Peso Seco Epífitas (PSE) e Área Superficial da Macroalga (ASM). ** $P<0.01$; ${ }^{\text {s }}$, significativo e ${ }^{\mathrm{ns}}$, não significativo.

\begin{tabular}{|c|c|c|c|c|c|c|c|c|c|}
\hline \multirow{2}{*}{ Fonte de variação } & \multirow{2}{*}{$d f$} & \multicolumn{2}{|c|}{ PST } & \multicolumn{2}{|c|}{ PSS } & \multicolumn{2}{|c|}{ PSE } & \multicolumn{2}{|c|}{ ASM } \\
\hline & & MS & $\mathrm{F}$ & MS & $\mathrm{F}$ & MS & $\mathrm{F}$ & MS & $\mathrm{F}$ \\
\hline Praia & 1 & 0.98 & $15.88^{* *}$ & 129.6 & $11.14^{* *}$ & 18.46 & $14.70 * *$ & 1.17 & $45.59 * *$ \\
\hline Mês & 12 & 0.45 & $7.31^{* *}$ & 75.45 & $6.48 * *$ & 12.49 & $9.94 * *$ & 0.27 & $10.65 * *$ \\
\hline Praia*Mês & 12 & 0.11 & 1.75 & 18.3 & 3.77 & 6.75 & $5.37 * *$ & 0.10 & $4.04 * *$ \\
\hline Residual & 338 & 0.06 & & 11.64 & & 1.26 & & 0.03 & \\
\hline Total & 364 & & & & & & & & \\
\hline Kolmogorov-Smirnov & & & & & & & & & \\
\hline Transformação & & & & & & & & & \\
\hline
\end{tabular}
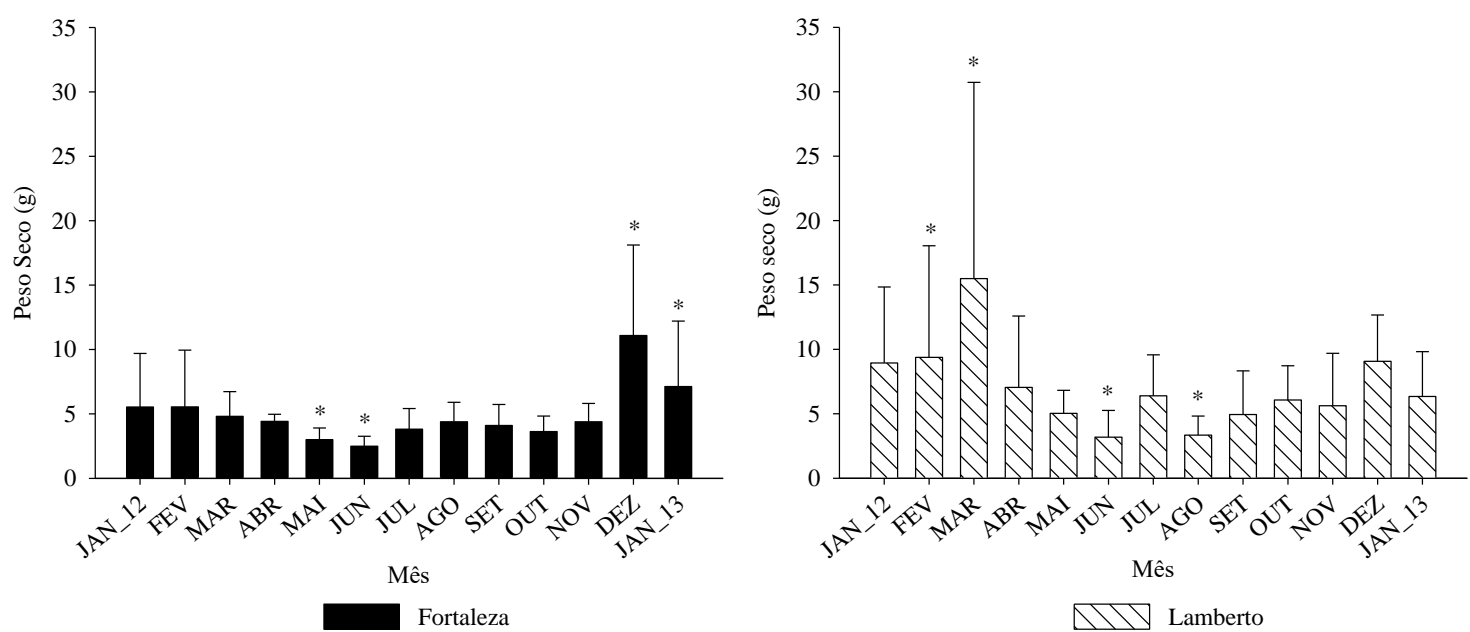

Figura 10 - Valores médios de Pesos Secos Totais (g) das frondes de Sargassumfilipendula (PST) coletadas em cada mês nas praias da Fortaleza e Lamberto, Ubatuba, São Paulo. Barras com asterisco são significativamente diferentes, de acordo com o teste post-hoc Tukey HSD.

As diferenças apontadas para PST permanecem ao se analisar separadamente os pesos secos do S. filipendula (PSS) e das epífitas (PSE), ou seja, a Praia do Lamberto foi significativamente diferente da Praia da Fortaleza por apresentar os maiores valores médios para o período amostrado (Lamberto: PST $=5,8 \pm 2 \mathrm{~g}$ e PSE $=0,8 \pm 1 \mathrm{~g}$; Fortaleza: PSS $=$ $4,6 \pm 2 \mathrm{~g}$ e PSE $=0,5 \pm 0,5 \mathrm{~g}$ ). A comparações par a par tornaram a apontar diferenças entre os meses, tanto para PSS quanto PSE, em ambas as praias (Figura 11). No geral, os meses de verão e final de primavera que apresentavam os maiores valores foram significativamente diferentes dos meses de inverno/primavera que apresentaram os menores valores.

Quanto à área superficial da macroalga (ASM), os dados mostraram diferença significativa entre as praias e, como as demais medidas apontaram, a Praia do Lamberto exibiu os maiores valores médios (Lamberto: $2561 \pm 620 \mathrm{~cm}^{2}$ e Fortaleza $=1965 \pm 520$ $\mathrm{cm}^{2}$ ) (Figura 12). 

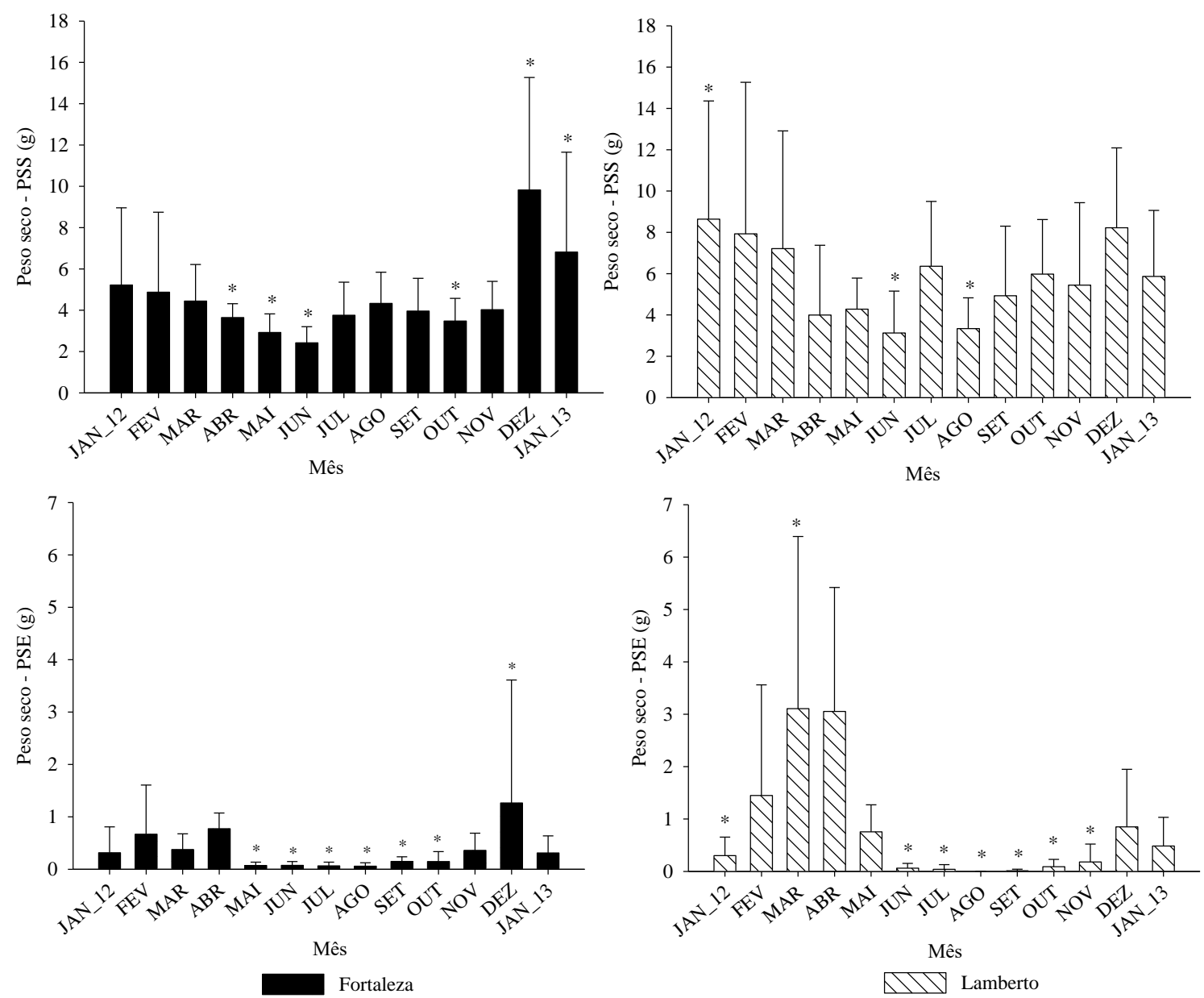

Figura 11 - Valores médios do Peso Seco (g) do Sargassum filipendula (PSS) e das algas epífitas (PSE) das frondes coletadas em cada mês nas praias da Fortaleza e Lamberto, Ubatuba, São Paulo. Barras com asterisco sãosignificativamente diferentes, de acordo com o teste post-hoc Tukey HSD.
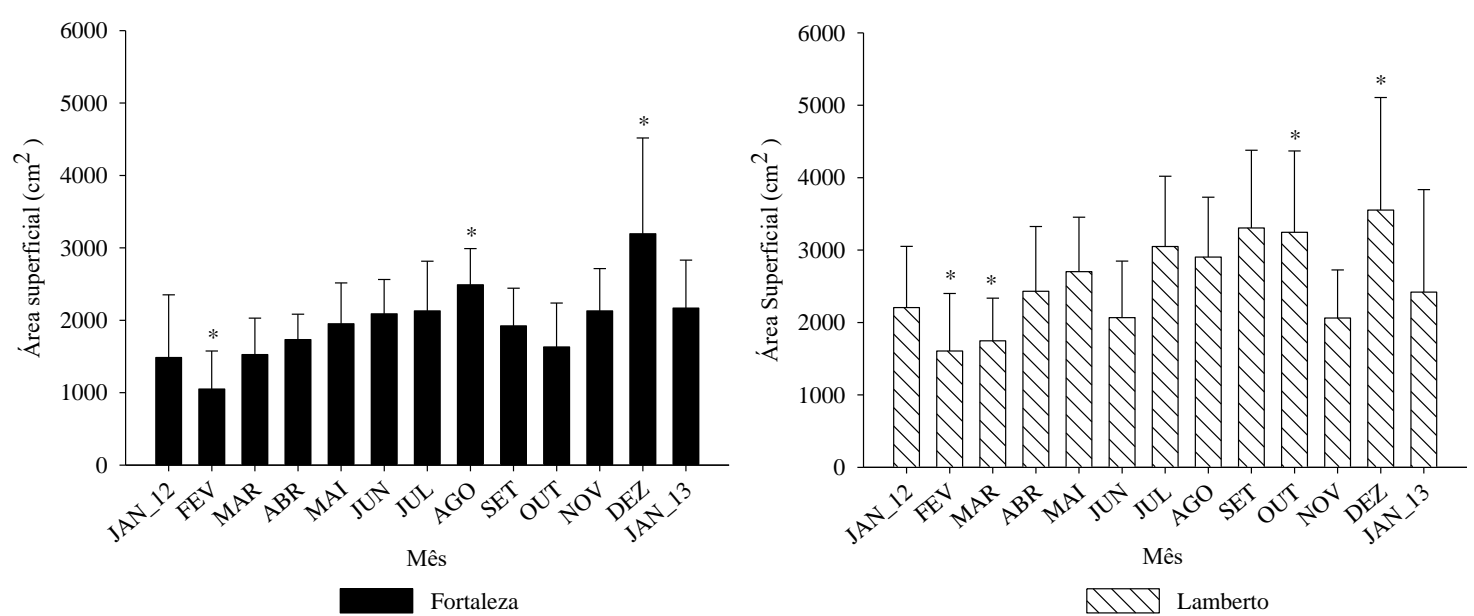

Figura 12 - Valores médios de Área Superficial do Sargassumfilipendula e algas epífitas (ASM) coletadas em cada mês nas praias da Fortaleza e Lamberto, Ubatuba, São Paulo. Barras com asterisco são significativamente diferentes, de acordo com o teste post-hoc Tukey HSD.

De modo geral, podemos observar um acréscimo nos valores ASM entre os meses para ambas as praias, principalmente no primeiro semestre. Segundo o teste de Tukey HSD, 
houve diferença significativa entre os meses amostrados em ambas as praias. Dezembro se destacou dos demais meses por exibir os maiores valores (Lamberto: $3552 \pm 1553 \mathrm{~cm}^{2} \mathrm{e}$ Fortaleza: $3195 \pm 1322 \mathrm{~cm}^{2}$ ), sendo também significativamente diferente de fevereiro que apresentou os menores valores (Lamberto: $1607 \pm 794 \mathrm{~cm}^{2}$ e Fortaleza: $1050 \pm 526 \mathrm{~cm}^{2}$ ) (Figura 12).

De acordo com a correlação de Spearman houve correlações positivas entre as medidas quantitativas empregadas no presente estudo e os fatores abióticos. As variáveis PST e PSE exibiram correlações positivas com a temperatura superficial em ambas as praias (PST: Fortaleza: rs $=0,72 ; p<0,01$ e Lamberto: 0,81; $p<0,01$ e PSE: Fortaleza: rs $=$ $0,71 ; p<0,05$ e Lamberto: 0,$86 ; p<0,01)$ e correlações negativas com nitrito das amostras de água coletadas na Praia da Fortaleza (PST: $r s=-0,60 ; p<0,05$ e PSE: $r s=-0,56 ; p<0,05$ ) e fosfato na Praia do Lamberto (PSE: $\mathrm{rs}=-0,68 ; p<0,01$ ).

ASM, para a Praia do Lamberto, esteve correlacionado positivamente com a temperatura superficial ( $\mathrm{rs}=0,63 ; p<0,05)$, material em suspensão ( $\mathrm{rs}=0,59 ; p<0,05) \mathrm{e}$ PSS ( $\mathrm{rs}=0.68 ; p<0,01$ ), e negativamente com o nitrato ( $\mathrm{rs}=0,64 ; p<0,01$ ). Não foram observadas correlações significativas entre ASM e as demais variáveis mensuradas para a Praia da Fortaleza

Correlações positivas significativas foram também obtidas entre as medidas quantitativas, principalmente Volume Intersticial, ASM, PST, PSS e PSE. Esses resultados corroboram o obtido com as comparações par a par entre meses efetuadas para cada medida de complexidade, mostrando, dessa forma um relacionamento forte entre elas. De modo geral, a Praia do Lamberto apresentou os maiores valores das medidas de complexidade, com exceção do número de ramos, indicando que as frondes dessa praia oferecem aos organismos epifaunais um habitat mais complexo. Os resultados apontam também para a existência de diferenças entre os meses, e principalmente entre as estações do ano para ambas as praias. Os meses de verão e final de primavera foram caracterizados por apresentar frondes mais complexas, com altos valores de Volume Intersticial, ASM e PST, em relação àquelas coletadas nos meses de inverno e início de primavera. 


\subsection{Comunidade e Densidade da Fauna}

Em relação a comunidade epifaunal, durante o período amostrado, as macroalgas coletadas na Praia da Fortaleza apresentaram um número maior de táxons (22) em oposição a 18 grupos verificados nas frondes amostradas na Praia do Lamberto. Entretanto, a maior abundância média foi observada nas frondes amostradas no Lamberto, $3148 \pm 394$ indivíduos, seguidos pela Fortaleza com $2795 \pm 372$ indivíduos. Os resultados obtidos pelas ANOVAs indicam que ocorreram diferenças significativas entre as praias e meses para os valores de abundância média e número de táxons. Entretanto foi observada significância apenas na interação praia/mês para a abundância média (Tabela 04).

Tabela 04 - Sumário das ANOVAs para os valores médios de abundância da fauna total $(\mathrm{N})$ e Número de Táxon. ** $P<0.01 ;{ }^{\mathrm{s}}$, significativo $\mathrm{e}^{\mathrm{ns}}$, não significativo.

\begin{tabular}{cccccc}
\hline \multirow{2}{*}{ Fonte de variação } & \multirow{2}{*}{$d f$} & \multicolumn{2}{c}{$\mathbf{N}$} & \multicolumn{2}{c}{ Táxon } \\
\cline { 3 - 6 } & & MS & F & MS & F \\
\hline Praia & 1 & 0.77 & $8.59^{* *}$ & 249.55 & $72.33^{* *}$ \\
Mês & 12 & 1.01 & $11.26^{* *}$ & 16.21 & $4.70^{* *}$ \\
Praia*Mês & 12 & 0.42 & $4.74^{* *}$ & 4.19 & 1.22 \\
Residual & 338 & 0.09 & & 3.45 & \\
Total & 364 & & & \multicolumn{2}{c}{$0.099^{\text {ns }}$} \\
Kolmogorov-Smirnov & \multicolumn{2}{c}{$0.041^{\text {s }}$} & \multicolumn{2}{c}{ Não } \\
Transformação & \multicolumn{2}{c}{ Sim }
\end{tabular}

Os grupos mais abundantes foram semelhantes nas frondes coletadas nas duas praias. Os crustáceos foram os dominantes, sendo representados principalmente por Brachyura e Caridea, e as ordens de Peracarida - Amphipoda, Isopoda e Tanaidacea. Dentre os crustáceos, Amphipoda foi mais abundante, representando cerca de 58\% (Fortaleza) e 46\% (Lamberto) de toda a macrofauna (Figura 13). Gastropoda também se destacou pela sua abundância nas frondes coletadas nas duas praias, no Lamberto (Figura 13). 

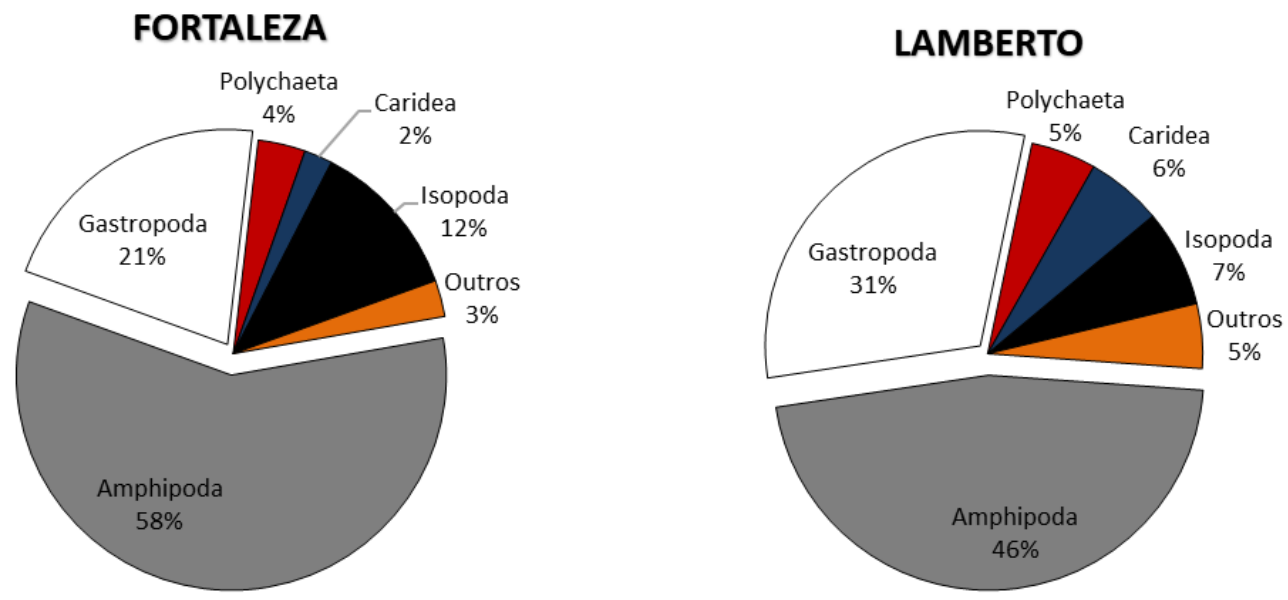

Figura 13 - Porcentagem relativa (\%) dos principais grupos da macrofauna obtidos nas frondes de Sargassumfilipendula das praias da Fortaleza e Lamberto, Ubatuba, São Paulo.

A correlação de Spearman apontou correlações positivas e significativas entre os dados de abundância média da macrofauna total com os valores das medidas quantitativas do S. filipendula em ambas as praias (Tabela 05). Os valores do número de táxon foram correlacionados positivamente com os valores de volume intersticial e pesos secos (PST, PSS e PSE) na Praia da Fortaleza e com os valores de PSE na Praia do Lamberto (Tabela 05). Além das medidas quantitativas, os valores de abundância da macrofauna total também correlacionaram positivamente com os valores de temperatura da água em ambas as praias (Fortaleza: rs $=0,80 ; p<0,01$ e Lamberto: rs $=0,65 ; p<0,01$ ) e negativamente com os valores de nitrito ( $\mathrm{rs}=-0,67 ; p<0,01)$.

Tabela 05 - Sumário dos resultados das correlações de Spearman entre os valores de abundância média da macrofauna $(\mathrm{N})$ e número de táxon (Táxon) e as medidas quantitativas. PST: Peso seco total: PSS: Peso seco Sargassumfilipendula; PSE: Peso seco Epífitas e ASM: Área Superficial da Macroalga. ** $P<0.01$

\begin{tabular}{ccccc}
\hline & \multicolumn{2}{c}{ FORTALEZA } & \multicolumn{2}{c}{ LAMBERTO } \\
\cline { 2 - 5 } & $\mathbf{N}$ & Táxon & $\mathbf{N}$ & Táxon \\
\hline Volume & $0.46^{* *}$ & $0.19^{* *}$ & $0.21^{* *}$ & - \\
PST & $0.66^{* *}$ & $0.26^{* *}$ & $0.50^{* *}$ & - \\
PSS & $0.62^{* *}$ & $0.24^{* *}$ & $0.37^{* *}$ & - \\
PSE & $0.55^{* *}$ & $0.31^{* *}$ & $0.54^{* *}$ & $0.20^{* *}$ \\
ASM & $0.22^{* *}$ & - & $0.20^{* *}$ & - \\
\hline
\end{tabular}

Com base nas medidas de complexidade das frondes de macroalgas (PST, volume intersticial e ASM) mensuradas, obteve-se os dados de densidade por gramas 
(indivíduos/gramas), densidade por $\mathrm{ml}$ (indivíduos /100ml) e densidade por $\mathrm{cm}^{2}$ (indivíduos $/ 100 \mathrm{~cm}^{2}$ ).

Segundo as ANOVAs, todas as medidas de densidade exibiram diferença significativa entre os meses e na interação praia/mês (Tabela 06). Apenas a densidade por $\mathrm{ml}$, ou seja, a densidade baseada na medida de volume intersticial apresentou diferença significativa entre as praias.

Tabela 06 - Sumário das ANOVAs para os valores de densidade por gramas (indivíduos/g), densidade por $\mathrm{ml}$ (indivíduos $/ 100 \mathrm{ml}$ ) e densidade por $\mathrm{cm}^{2}$ (indivíduos $/ 100 \mathrm{~cm}^{2}$ ). $\quad * * P<0.01$; ${ }^{\mathrm{s}}$, significativo $\mathrm{e}^{\mathrm{ns}}$, não significativo.

\begin{tabular}{|c|c|c|c|c|c|c|c|}
\hline \multirow[t]{2}{*}{ Fonte de variação } & \multirow[t]{2}{*}{$d f$} & \multicolumn{2}{|c|}{$\begin{array}{l}\text { Densidade } \\
\text { (ind/g) }\end{array}$} & \multicolumn{2}{|c|}{$\begin{array}{l}\text { Densidade } \\
\text { (ind/100ml) }\end{array}$} & \multicolumn{2}{|c|}{$\begin{array}{c}\text { Densidade } \\
\left(\text { ind } / 100 \mathrm{~cm}^{2}\right)\end{array}$} \\
\hline & & MS & $\mathrm{F}$ & MS & $\mathrm{F}$ & MS & $\mathrm{F}$ \\
\hline Praia & 1 & 0.017 & 0.235 & 1.53 & $13.46^{* *}$ & 0.03 & 0.34 \\
\hline Mês & 12 & 0.347 & $4.78^{* *}$ & 1.26 & $11.12^{* *}$ & 1.70 & $23.92 * *$ \\
\hline Praia*Mês & 12 & 0.274 & $3.77 * *$ & 0.54 & $4.74 * *$ & 0.34 & $6.14 * *$ \\
\hline Residual & 338 & 0.073 & & 0.11 & & 0.07 & \\
\hline Total & 364 & & & & & & \\
\hline Kolmogorov-Smirnov & & \multicolumn{2}{|c|}{$0.067^{\mathrm{ns}}$} & \multicolumn{2}{|c|}{$0.027^{\mathrm{s}}$} & \multicolumn{2}{|c|}{$0.029^{\mathrm{s}}$} \\
\hline Transformação & & \multicolumn{2}{|c|}{ Sim } & \multicolumn{2}{|c|}{ Sim } & \multicolumn{2}{|c|}{ Sim } \\
\hline
\end{tabular}

Os valores médios para as medidas de densidade encontram-se na Figura 14. Na Praia da Fortaleza, independente da medida de densidade utilizada, as comparações par a par exibiram o mesmo padrão, onde os meses de verão apresentaram os valores mais elevados e estes foram significativamente diferentes dos valores inferiores presentes nos meses de inverno/primavera.

Entretanto, na Praia do Lamberto, as medidas de densidade apresentaram padrões diferentes (Figura 14). Pelo teste de Tukey HSD, as densidades por gramas e por ml exibiram padrões similares entre os meses, com valores elevados no outono (abril de 2012) e estes foram significativamente diferentes dos valores baixos obtidos no início do verão (dezembro) e inverno/primavera (agosto e setembro) (Figura 14). Apesar dos valores de densidade por $\mathrm{cm}^{2}$ exibirem uma flutuação similar as demais densidades, segundo a comparação par a par, o mês que apresentou o maior valor foi fevereiro, fato antes não observado pelas demais medidas de densidade. E este mês em conjunto com abril foram significativamente diferentes dos meses de inverno/primavera (Figura 14). 
$\mathbf{A}$

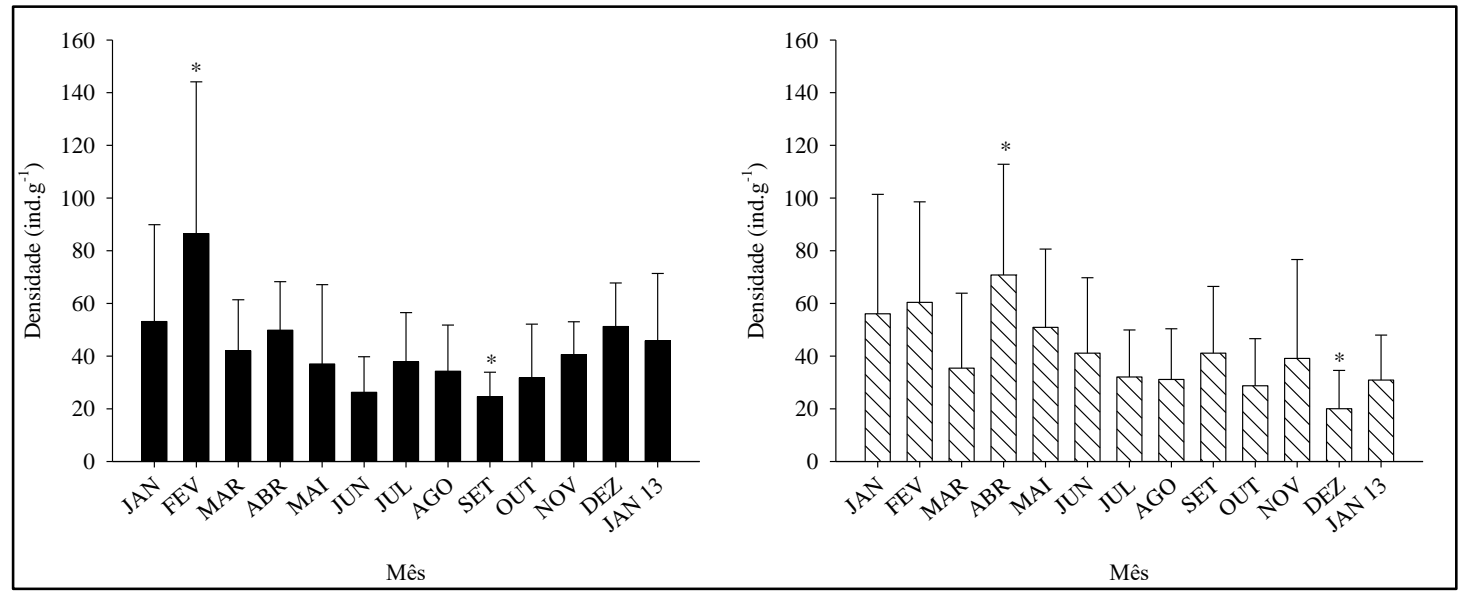

B
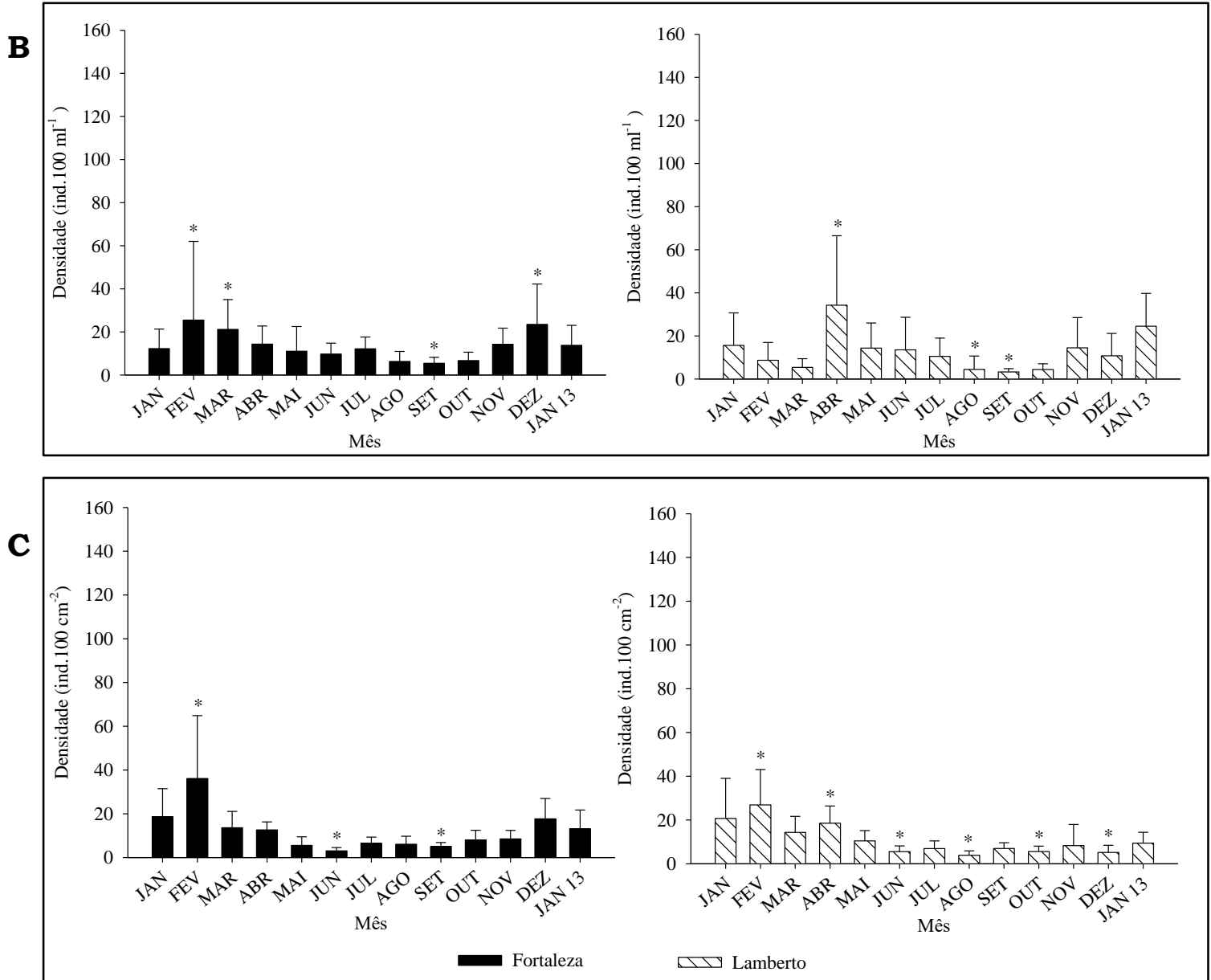

Figura 14 - Densidade da fauna obtida nas frondes de Sargassumfilipendula em cada mês nas praias da Fortaleza e Lamberto, Ubatuba, São Paulo. A: Densidade por gramas; B: Densidade por $100 \mathrm{ml}$ e C: Densidade por $100 \mathrm{~cm}^{2}$. Barras com asterisco são significativamente diferentes, de acordo com o teste post-hoc Tukey HSD. 


\section{DISCUSSÃO}

O primeiro objetivo deste trabalho foi explorar as diferenças nas medidas quantitativas e avaliar qual delas melhor demonstraria a variação sazonal do Sargassum filipendula. Os resultados indicaram que a utilização de apenas uma medida de quantitati va, como por exemplo o peso seco total (PST), acaba não sendo suficiente para se entender de forma ampla a influência da estrutura da macroalga sobre a epifauna. Cada medida empregada conseguiu demonstrar algum dos níveis de complexidade quantitativa do habitat Sargassum, e essas medidas, no seu conjunto, ofereceram um quadro mais completo do ambiente disponibilizado pela alga. Além disso, o estudo comparativo efetuado entre as várias medidas permitirá também que sejam feitas comparações entre bancos de Sargassum filipendula aqui estudados e aqueles de outras partes do mundo. Além disso, as medidas utilizadas neste capítulo para avaliar a complexidade estrutural são consideradas, por alguns autores, como medidas de quantificação de habitat, sendo que uma grande quantidade de peso, área ou volume do habitat necessariamente não significaria um habitat mais complexo (GEE \& WARWICK, 1994b; ATTRILL et al., 2000; TANIGUCHI et al., 2003; VEIGA et al., 2014).

O segundo objetivo do presente estudo foi explorar diferenças na abundância e riqueza dos grupos da epifauna com base nas medidas mensuradas. Partimos da hipótese inicial em que a abundância e riqueza dos grupos epifaunais estariam correlacionados positivamente com as medidas quantitativas do Sargassum filipendula.

A partir dos dados provenientes das medidas quantitativas utilizadas neste capítulo, podemos inferir que o Sargassum filipendula presente na Praia do Lamberto pode ser considerado um habitat mais complexo do que aquele obtido na Praia da Fortaleza. Isto se deve ao fato que as frondes do Lamberto apresentaram os maiores valores para todas as medidas quantitativas (peso seco, volume intersticial, área superficial, etc), com exceção do número de ramos. Na literatura encontra-se amplamente descrita a existência de uma relação positiva entre complexidade estrutural das macrófitas e abundância e riqueza da fauna associada (CHEMELLO \& MILAZZO, 2002; CROOKS, 2002; BOUMA et al., 2009; SUEIRO et al., 2011). Ainda assim, essa relação nem sempre foi observada e, portanto, o assunto merece uma maior investigação (HAGERMAN, 1966; CYR \& DOWNING, 1988; RUSSO, 1990; CREMONA et al., 2008; HANSEN et al., 2010). Quantificar a complexidade de um habitat é algo árduo, porque temos principalmente que identificar o que é estruturalmente relevante para um conjunto de organismos, e também 
as medidas que deverão ser utilizadas para quantificar o habitat. Deve-se aqui considerar que estas medidas não levam em consideração a escala do habitat e a forma como este é percebido pelos organismos (GEE \& WARWICK, 1994b; TANIGUCHI et al., 2003). No presente estudo, de fato, os valores de abundância da fauna presentes nas frondes da Praia do Lamberto superaram aqueles obtidos para a Praia da Fortaleza, e correlações positivas entre as medidas de quantitativas e abundância total foram observados nas duas praias. Diferentemente dos valores elevados de riqueza (número de táxons) obtidos na Praia da Fortaleza e não na Praia do Lamberto (com frondes mais complexas) como esperado. Por esta razão, a hipótese levantada inicialmente foi parcialmente confirmada pelos nossos resultados, uma vez que apenas os valores de abundância da fauna responderam positivamente ao aumento das medidas quantitativas do S. filipendula. Com isto, conseguimos evidenciar que as medidas quantitativas do habitat podem influenciar a fauna presente nas frondes, mas apenas uma delas não é suficiente para caracterizar os grupos presentes, em termos de abundância e riqueza.

O clima de Ubatuba é conhecido como tropical litorâneo úmido ou tropical atlântico, com chuvas bem distribuídas ao longo do ano, sem estação seca e inverno rigoroso, possuindo temperaturas acima de $18^{\circ} \mathrm{C}$ (TARARAM \& WAKABARA, 1981; LEITE et al., 2007). Segundo informações adquiridas no CPTEC, o ano de 2012 foi considerado um ano atípico, sendo caracterizado por chuvas abaixo do normal e aumento de temperatura com temporais e rajadas de vento entre o inverno e primavera. Este perfil atípico não foi observado apenas em Ubatuba, mas também na maior parte do Brasil (CPTEC, 2016 - www.clima1.cptec.inpe.br) e repetido no mundo todo ao longo do ano, sendo observados fenômenos meteorológicos e climáticos extremos, desde ondas de calor e frio, secas, incêndios e inundações. Destaca-se, por exemplo, na Europa a ocorrência da pior onda de frio nos últimos 25 anos e a primavera nos EUA, que foi considerada como a mais quente registrada (WMO - www.wmo.int). Por esta razão, podemos considerar o período analisado no presente estudo como um ano anormal dentre os outros reportados anteriormente para a região de Ubatuba.

Uma série de fatores abióticos e bióticos podem influenciar as variações temporais dos bancos de Sargassum e dentre eles destacam-se: temperatura, irradiância, nutrientes, ação de ondas, epifitismo e herbivoria (SZÉCHY et al., 2006). No presente estudo, podemos notar a forte influência da temperatura sobre o banco de Sargassum filipendula em ambas as praias amostradas. 
Os maiores valores de PST e altura média das frondes de S. filipendula foram relacionados com os meses de verão e final de primavera, especialmente dezembro e janeiro de 2013, que exibiram os maiores valores de temperatura do ar e média pluviometria mensal. A temperatura influencia positivamente os processos metabólicos da macroalga, como a fotossíntese e respiração, auxiliando assim o desenvolvimento vegetativo do Sargassum (SZÉCHY et al., 2006; VELOSO \& SZÉCHY, 2008). No presente estudo, os valores de temperatura superficial da água foram correlacionados positivamente aos de PST e PSE em ambas as praias e negativamente com as concentrações de fosfato (Lamberto) e nitrito (Fortaleza). Os dados obtidos corroboram com os de estudos efetuados na costa sudeste do Brasil, sendo que a maior parte deles relaciona os altos valores de peso seco aos meses de verão/final de primavera e os mais baixos aos meses de outono/inverno, também durante o período de amostragem não foram observados valores de temperatura superficial da água acima de $30^{\circ} \mathrm{C}$ que ocasionariam a inibição do crescimento das frondes, principalmente entre o final da primavera e verão (PAULA \& OLIVEIRA FILHO, 1980; GODOY \& COUTINHO, 2002; AMADO FILHO et al., 2003; REIS et al., 2003; NISHIHIARA et al., 2005; SZÉCHY et al., 2006).

Segundo Széchy et al. (2006), o aumento da pluviosidade está relacionado principalmente ao aumento da concentração de nutrientes no ecossistema aquático, contribuindo para isso o incremento de material proveniente da lixiviação de material terrestre adjacente ao ecossistema aquático, e/ou aumento do input de material orgânico trazido pelos rios. A influência da pluviosidade foi notada principalmente em junho, o segundo mês a exibir o maior valor pluviométrico da série avaliada, que mostrou um pico de nutrientes, especialmente os nitrogenados, nas amostras de água das duas praias. No mês seguinte, após o pico, houve um aumento na altura das frondes e nos valores de PST, sendo que os valores médios para esse mês foram semelhantes aos obtidos no verão.

O alto grau de epifitismo já foi associado ao declínio da biomassa de populações de Sargassum devido à redução da luminosidade, competição por nutrientes e gases dissolvidos e pelo arrastamento da macroalga hospedeira (LEITE \& TURRA, 2003; JACOBUCCI et al., 2009b). Dessa maneira, muitos estudos associaram o menor peso seco do Sargassum (PSS) ao maior peso seco de algas epífitas (PSE) (ANG Jr, 1985; LEITE \& TURRA, 2003), fato esse observado na Praia do Lamberto, onde o valor máximo de PSE foi relacionado com o declínio de PSS. Contudo, essa influência não foi notada na Praia da Fortaleza, onde os maiores valores de PSS amostrados no verão, coincidiram com os 
maiores valores de PSE, corroborando os dados encontrados para outras regiões brasileiras como, por exemplo, a Baía de Sepetiba, RJ (REIS et al., 2003; SZÉCHY \& de SÁ, 2008). Independente da influência do PSE sob PSS, o aumento significativo de PSE observado entre o final de primavera e verão em ambas as praias, já foi descrito em outros estudos para a região de Ubatuba, e esteve relacionada ao maior número de ramos maduros e senescentes do Sargassum (PAULA \& OLIVEIRA-FILHO, 1980; JACOBUCCI et al., 2009b). Outro fator importante, é que com o aumento de PSE, ocorre um aumento na complexidade estrutural do habitat oferecido pelo Sargassum a fauna associada.

A fauna associada ao Sargassum filipendula invariavelmente irá refletir as mudanças sazonais sofridas pelo habitat, o que pode ser aferido principalmente pela densidade da fauna. No presente estudo, ao analisar três medidas quantitativas diferentes (volume intersticial, PST e ASM) notamos que cada uma influi de forma diferente sobre este fator. Apenas uma das medidas apresentou resposta similar a abundância média da macrofauna total, e assim apontar uma diferença significativa entre as praias, e na Praia do Lamberto duas dessas medidas exibiram padrões diferentes entre os meses. Torna-se claro, então, que ao analisar a macroalga com auxílio de apenas uma variável proporciona uma visão deturpada ou até mesmo respostas errôneas da influência exercida pelo substrato sobre a fauna, uma vez que cada medida quantitativa avalia a complexidade estrutural da macroalga de perspectiva diferente e que cada organismo por exibir formas e estruturas físicas próprias irão utilizar o habitat criado pelo Sargassum de maneira diferente.

Dessa forma, em conclusão, recomenda-se utilizar um conjunto de medidas e não apenas uma, para tentar elucidar se existe uma diferença real entre elas e assim analisar e tentar interpretar como os organismos aproveitam esse habitat ofertado pelo Sargassum e epífitas associadas. 
CAPÍTULO 2 - "Dimensão fractal e medidas quantitativas: sua influência na ocupação dos bancos de Sargassum filipendula pela macrofauna"

\section{RESUMO}

Habitats com Sargassum abrigam uma maior abundância e diversidade epifaunal do que aqueles sem vegetação. No entanto, as algas, geralmente mostram alta variabilidade com diferenças em tamanho, complexidade e longevidade o que pode vir a afetar as comunidades epifaunais associadas. O objetivo do presente estudo foi avaliar as diferenças existentes no habitat formado pelas frondes de $S$. filipendula em duas praias com hidrodinâmicas diferentes, e a influência da complexidade desse habitat na estruturação da comunidade de anfípodes, organismos abundantes no fital. Para fornecer uma visão abrangente da estrutura do Sargassum foram utilizados: peso seco (PST), peso seco do Sargassum (PSS), peso seco das epífitas (PSE) e área superficial da macroalga (ASM) como medidas quantitativas e a dimensão fractal, representada pela área fractal (Da) e perímetro fractal (Dp), como medida morfológica. Embora a dimensão fractal tenha sido empregada com sucesso para mensuração da morfologia de diversos ambientes, esta é a primeira vez que é usada no Brasil para avaliação da complexidade estrutural de macroalgas marinhas. Foram coletadas 15 frondes de S. filipendula por mês, durante 13 meses, nas praias da Fortaleza e Lamberto, ambas localizadas no município de Ubatuba. De modo geral, ocorreram diferenças nas medidas quantitativas e morfológicas do S. filipendula entre as praias e meses amostrados, sendo a maior complexidade estrutural do habitat obtida nos meses de verão na Praia do Lamberto. No total, foram identificados 3.082 anfípodes identificados em 32 espécies. Todas as medidas de complexidade foram correlacionadas aos descritores de comunidade. Segundo a análise DistLM, a maioria das medidas de complexidade influenciaram na estruturação da macrofauna e anfipodes; porém, aquelas relativas à quantidade de habitat foram mais expressivas do que morfológicas. Ficou evidenciada a importância de se analisar medidas quantitativas aliadas à dimensão fractal para o entendimento da estruturação da comunidade de anfípodes. A dimensão fractal consegue gerar dados das diferentes dimensões do habitat fornecido pela macroalga e, consequentemente, permite conhecer como este é percebido pelos organismos.

Palavras-chave: Amphipoda, complexidade, dimensão fractal, peso seco. 


\section{ABSTRACT}

Sargassum habitats harbor greater epifaunal abundances and diversity than those without vegetation and diversity than those without vegetation. However, algae usually show high variability with differences in size, complexity and longevity which may affect the associated epifaunal communities. The objective of the present study was to evaluate the differences in the habitat formed by the fronds of S. filipendula on two beaches with different hydrodynamics, and the influence of the complexity of this habitat on the structuring of the amphipods community, phytal abundant organisms. To provide a comprehensive overview of Sargassum's structure, we used: total dry weight (PST), Sargassum dry weight (PSS), epiphytes dry weight (PSE) and macroalgal surface are (ASM) as quantitative measures and the fractal dimension, represented by fractal area (Da) and fractal perimeter (Dp), as morphological measure. Although the fractal dimension has been used successfully to measure the morphology of several environments, this is the first time it is used in Brazil to evaluate the structural complexity of marine macroalgae. Fifteen fronds of S. filipendula were collected per month, during 13 months, at Fortaleza and Lamberto beaches, both located in Ubatuba. In general, there were differences in the quantitative and morphological measures of S. filipendula between beaches and months sampled, with the greatest structural complexity of the habitat obtained during the summer months at Lamberto Beach. In total 3,082 amphipods were identified in 32 species. All measures of complexity were correlated to community descriptors. According to the DistLM analysis, most measures of complexity influe nced the structuring of macrofauna and amphipods; however, those related to the amount of habitat were more expressive than morphological. It was evidenced the importance of analyzing quantitative measures allied to the fractal dimension for understanding the structuring of amphipod community. The fractal dimension can generate data of the different dimensions of the habitat provided by the macroalga and, consequently, allows to know how this is perceived by the organisms.

Keywords: Amphipod, complexity, fractal dimension, dry weight. 


\section{INTRODUÇÃO}

A complexidade do habitat tem sido considerada um dos fatores determinantes da diversidade biológica e como a estrutura física desse habitat influencia os organismos tem sido uma questão central na ecologia (TANIGUCHI et al., 2003; TOKESHI \& ARAKAKI, 2012). Estudos realizados mostraram a existência de uma relação positiva entre a complexidade morfológica das macroalgas e a abundância e diversidade dos organis mos associados (HAUSER et al., 2006; HOOPER \& DAVENPORT, 2006). Os bancos de Sargassum e algas epífitas são altamente sazonais e sensíveis a fatores abióticos, como temperatura, embates de ondas e concentração de nutrientes e poluentes. Essas alterações ambientais invariavelmente acarretam variação na abundância e diversidade da macrofauna associada (SZÉCHY \& PAULA, 1997; WELLS et al., 2007). Estudos apontam que uma alta complexidade morfológica geralmente resulta no aumento de organismos epifaunais ocasionado por fatores como redução da predação, perturbação física e aumento do alimento disponível e número de nichos diferentes (ORAV-KOTTA \& KOTTA, 2004; WILLIS et al., 2005).

Segundo Gee e Warwik (1994a) a fauna associada será influenciada não só pela variação do peso seco e área do habitat, mas também pelo arranjo estrutural do próprio habitat. No capítulo anterior descrevemos estudos que quantificaram a complexidade estrutural das macroalgas através da medida da quantidade de habitat disponível (peso seco, volume e área superficial) ou do número e disposição dos ramos (HACKER \& STENECK, 1990; CHEMELLO \& MILAZZO, 2002; LEITE \& TURRA, 2003). No entanto, com apenas esses fatores, torna-se difícil estimar o arranjo estrutural real que a macroalga apresenta e os espaços entre os ramos disponíveis para a epifauna, uma vez que este varia de acordo com a escala medida (BRADBURY et al., 1984). Além disso, uma maior quantidade de habitat não indica necessariamente uma maior complexidade (GEE \& WARWICK, 1994a, b; ATTRILL et al., 2000; TANIGUCHI et al., 2003).

Uma das formas para se calcular o arranjo estrutural é com o uso da dimensão fractal (GEE \& WARWICK, 1994b). A dimensão fractal é o melhor indicador da complexidade do habitat porque fornece uma expressão numérica fácil de calcular, indica o grau de rugosidade da superfície, independente da natureza do habitat e estima esse habitat em várias escalas. Fornecendo assim, a ideia de percepção do habitat por parte dos organismos (JEFFRIES, 1993; GEE \& WARWICK, 1994b; McABENDROTH et al., 2005). 
A complexidade estrutural também afeta significativamente a distribuição do tamanho corporal dos organismos associados ao habitat. Em geral, habitats mais complexos, por apresentarem muitos espaços pequenos entre os ramos, conseguem suportar densidades mais elevadas e uma maior diversidade de animais de pequeno porte, enquanto que habitats simplificados possuem grandes espaços entre os ramos e suportam comparativamente, um maior número de organismos maiores (JEFFRIES, 1993; McABENDROTH et al., 2005; THOMAZ et al., 2008).

O papel das macrófitas como estruturas físicas que aumentam a complexidade do habitat tem sido amplamente reconhecido. Porém, raramente essas macrófitas são medidas e avaliadas de forma padronizada, dificultando assim as comparações entre os estudos (BECK, 1998). As macroalgas não são objetos verdadeiramente fractais; contudo, o uso da dimensão fractal provou ser um modo adequado para estimar a sua complexidade estrutural (GEE \& WARWICK, 1994a; DAVENPORT et al., 1999; HALLEY et al., 2004; McABENDROTH et al., 2005; CÚRDIA et al., 2015). Existem vários métodos usados para a determinação da dimensão fractal, mas a fotografia digital é o mais popular, principalmente devido ao crescente avanço das tecnologias usadas nas câmeras digita is (FROST et al., 2005). A disponibilidade de programas específicos para calcular a dimensão fractal a partir da análise de imagens também contribui para ampla utilização de métodos fotográficos, tais como Fractalyse, Fractop e Image J.

Apesar da importância potencial das macroalgas na estruturação do ambiente litorâneo e a possibilidade de mensuração da complexidade com o emprego da dimensão fractal, poucas investigações têm usado esse método para identificar a complexidade existente em macroalgas marinhas. A maioria dos estudos utiliza a comunidade epifaunal como um todo (VEIGA et al., 2014; TORRES et al., 2015). Os principais estudos no Brasil com dimensão fractal e macroalgas foram feitos em ambientes de água doce (DIBBLE et al., 2006; THOMAZ et al., 2008; DIBBLE \& THOMAZ, 2009; THOMAZ \& CUNHA, 2010), sendo inexistentes trabalhos para o ambiente marinho. No presente estudo optou-se por avaliar a relação da complexidade do habitat e sua influência na comunidade de anfípodes, uma vez que esses organismos são dominantes no fital.

O objetivo principal do presente estudo foi explorar as diferenças nas medidas de complexidade (quantidade e morfologia do habitat) do Sargassum filipendula obtido em duas praias com hidrodinâmicas diferentes. Também procuramos avaliar o papel das medidas de complexidade do Sargassum filipendula na abundância, riqueza e diversidade das espécies de anfípodes associadas. 
Com base no exposto, as seguintes hipóteses serão investigadas:

i. Há diferenças nas medidas de complexidade (quantitativas e morfológicas) das macroalgas entre as praias investigadas e entre os meses de coleta;

ii. Há diferença na abundância (número de indivíduos) e riqueza (número de táxons) da macrofauna total entre praias e meses estudados; as diferenças estarão significativamente correlacionadas às medidas de complexidade da macroalga;

iii. Há diferença na abundância (número de indivíduos), riqueza e diversidade de anfípodes entre praias e meses estudados; as diferenças estarão significativamente correlacionadas às medidas complexidade das macroalgas;

iv. Há um aumento no número de indivíduos e de espécies de pequeno porte com o aumento do perímetro fractal (Dp). 


\section{MATERIAL E MÉTODOS}

\section{1. Área de Estudo}

O presente estudo foi realizado em duas praias distintas: a Praia do Lamberto (Enseada do Flamengo) e Praia da Fortaleza (Enseada da Fortaleza), ambas situadas no munícipio de Ubatuba, litoral norte de São Paulo.

A praia da Fortaleza é mais afastada do centro urbano da cidade de Ubatuba, e por esta razão apresenta baixa ação antropogênica, fator comum em outras praias da região. Esta localização é formada por um estreito trecho rochoso que corre na direção sudestenordeste, mostrando dois lados com diferentes graus de exposição à ação de ondas (PAULA \& OLIVEIRA-FILHO, 1980). A costa da rocha onde as amostras foram coletadas tem cerca de $2,5 \mathrm{~m}$ de profundidade, o que pode ser considerado moderadamente protegido da ação de ondas, de acordo com o critério utilizado por Széchy \& Paula (2000). Com relação as características oceanográficas, a Enseada da Fortaleza apresenta valores médios anuais de temperatura da água do mar de $23,5^{\circ} \mathrm{C}(21$ a $\left.28^{\circ} \mathrm{C}\right)$ e salinidade de $34,4(32,4$ a 35,6$)$.

A praia do Lamberto é uma praia rasa, apresentando $5 \mathrm{~m}$ de profundidade no seu ponto mais profundo, e os locais estudados situam-se no nível $-0,3$, na franja do infralitoral. A água da enseada é oligotrófica e a salinidade e temperatura médias da água refletem normalmente aquelas das enseadas próximas, variando de 27.2 - 34.8 e 20-30 ${ }^{\circ} \mathrm{C}$, respectivamente (CORBISIER, 1994).

Para mais detalhes sobre os locais de coleta vide "Capítulo 1".

\subsection{Trabalho de Campo}

Durante treze meses, janeiro de 2012 a janeiro de 2013, foram realizadas coletas mensais nas praias da Fortaleza e Lamberto. Em cada praia local coletadas aleatoriamente 15 frondes de Sargassum filipendula por mergulho autônomo e durante a baixa maré. Cada fronde foi coberta individualmente com saco de malha de $250 \mathrm{~mm}$ para retenção da macrofauna, incluindo os jovens.

Para maiores de detalhes da amostragem vide "Capítulo 1". 


\subsection{Laboratório}

Em laboratório, a solução resultante da lavagem e peneiramento de cada fronde/mês, foi triada e os anfípodes separados e contados. Deve-se notar que para cada fronde o material foi separado utilizando-se um jogo de peneiras de 2,0 mm, 1,0 mm e 0,5 mm. Dessa maneira, os organismos foram separados em três Classes de Tamanho, a saber: Classe I-organismos maiores que 2,0 mm; Classe II - entre 1,9 mm a 1,0 mm e Classe III - entre 0,9 mm a 0,5 mm. Os anfípodes foram identificados sob microscópio estereoscópico, pela aluna até o menor nível taxonômico possível.

Para caracterizar a complexidade de cada fronde foram utilizadas sete variáveis: Peso Seco Total da macroalga (PST), Peso Seco do S. filipendula (PSS), Peso Seco das Epífitas (PSE) e Área Superficial da Macroalga (ASM), usadas como medidas quantitativas, e a dimensão fractal mensuradas pela Área Fractal (Da) e Perímetro Fractal (Dp), usadas como medidas morfológicas do habitat. O método utilizado para obter os valores de PST, PSS, PSE e ASM encontram-se explicados em detalhe no Capítulo 1 (item 2.3. Laboratório).

A análise da dimensão fractal foi feita posteriormente às medidas de quantidade de habitat, utilizando as mesmas imagens obtidas para a Área Superficial da Macroalga ASM. A dimensão fractal foi avaliada com duas medidas - Área fractal (Da) e Perímetro fractal ou lacunaridade (Dp). Da é uma medida do contorno da macroalga, ou o grau de circunvoluções de suas bordas, e assim, valores mais altos indicam mais divisões em escalas menores. Já Dp é uma medida dos espaços entre as ramificações, e os valores mais altos indicam grandes espaços vazios entre os ramos (McABENDROTH et al., 2005). Da e Dp fornecem informações diferentes sobre a natureza da complexidade estrutural associada a cada alga. O Da indica a mudança da área superficial em diferentes escalas, enquanto que Dp se relaciona com a natureza das lacunas existentes entre os ramos das algas. Ambas as medidas parecem ser potencialmente significativas para a epifauna que vive sobre ou entre os ramos da alga.

Escolheu-se calcular $\mathrm{Da}$ e Dp em cinco escalas diferentes - a fronde de $S$. filipendula como um todo e em quatro escalas menores para mostrar o detalhamento da fronde. As escalas a partir da fronde inteira foram feitas nas seguintes resoluções espaciais: quadrados de $100 \mathrm{~cm}^{2}, 25 \mathrm{~cm}^{2}, 9 \mathrm{~cm}^{2}$ e $1 \mathrm{~cm}^{2}$ (Figura 01). Procurou-se com isto investigar se há importância biológica que possa ser evidenciada em algum desses detalhamentos, uma vez que essas escalas podem mostrar como o habitat é percebido 
pelos organismos que vivem sobre ou entre os ramos da macroalga. Com base nas imagens obtidas, as medidas de Da e Dp foram codificadas da seguinte forma:

$$
\begin{gathered}
100 \mathbf{c m}^{2}: \text { Da-100 e Dp-100 } \\
25 \text { cm}^{2}: \text { Da-25 e Dp-25 } \\
9 \text { cm}^{2}: \text { Da-9 e Dp-9 e } \\
1 \text { cm }^{2}: \text { Da- } 1 \text { e Dp- } 1 .
\end{gathered}
$$

Para a análise fractal foi utilizado o método "Box-counting", no plugin FracLac do programa ImageJ 1.51, um dos métodos mais utilizados. Em linhas gerais, esse método consiste em dividir a imagem em quadrados e contar quantos quadrados contêm a forma analisada. Dessa forma, o ImageJ pode quantificar a dimensão fractal da área (Da) e do perímetro (Dp). Uma série de tamanhos de grade variando de 5 a 2000 pixels de largura (nas cinco escalas analisadas) foram utilizados para estimar a Da e o Dp de cada fotografia, em cada escala. As parcelas de $\log 10$ das estimativas da Da e Dp contra a escala de medida (tamanho da grade) foram então construídas dentro do ImageJ para cada fotografia, cujos gradientes fornecem estimativas alternativas da dimensão fractal da planta. O resultado foi de dez estimativas de D, sendo 5 de Da e 5 de Dp em cada alga, derivadas da escala de ampliação da fotografia (McABENDROTH et al., 2005; MORMUL et al., 2011). 
\begin{tabular}{l|l|l} 
Cap. 2 - Dimensão fractal e medidas quantitativas: sua influência na ocupação dos bancos de & 46
\end{tabular} Sargassum filipendula pela macrofauna

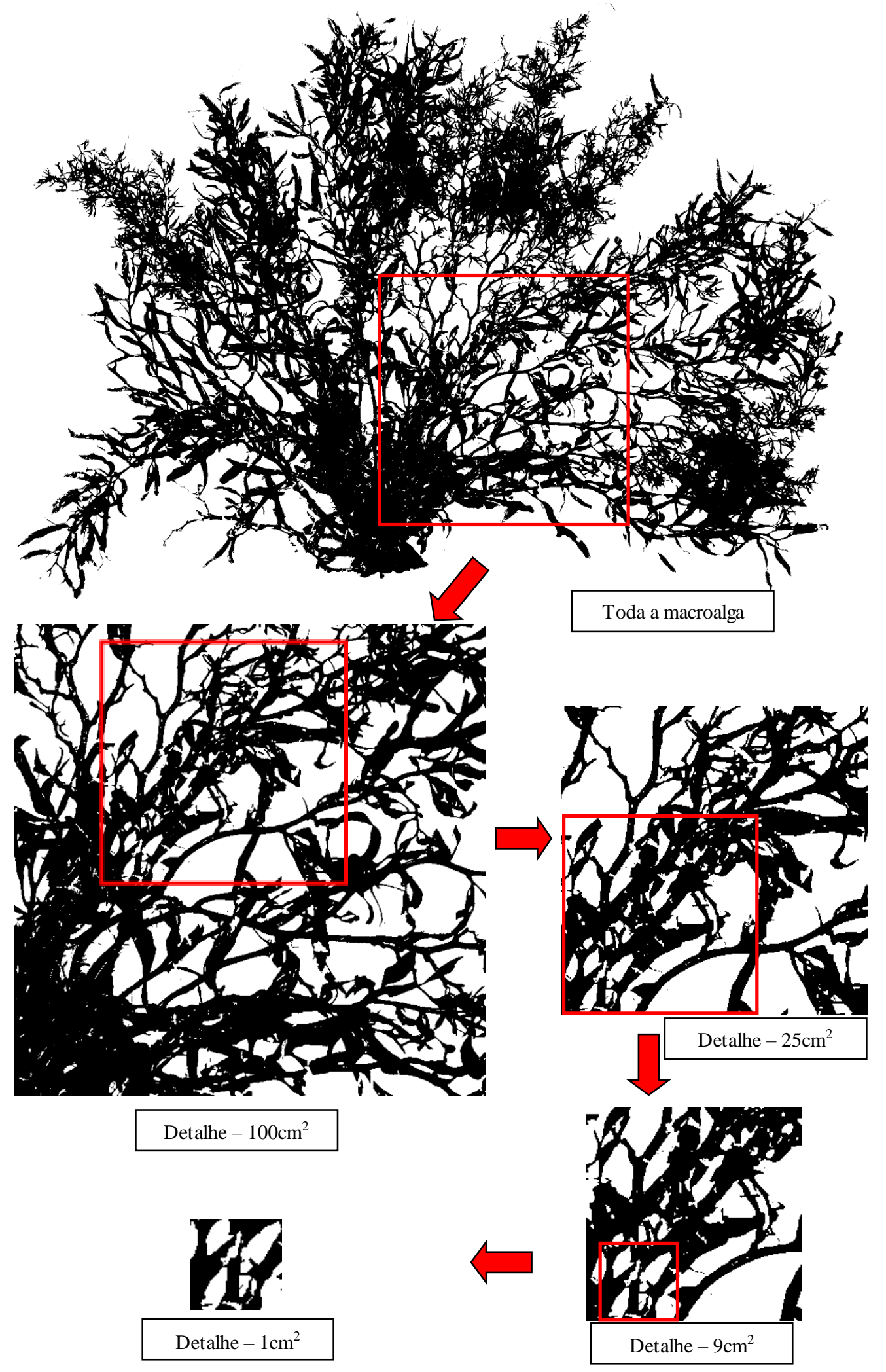

Figura 01 - Modo de obtenção das diferentes escalas a partir da fronde inteira do Sargassum filipendula. 


\subsection{Análises Estatísticas}

Análises de variância (ANOVAs) foram realizadas para testar as diferenças entre as praias quanto a quantidade de habitat (Peso Seco Total - PST, Peso Seco do $S$. filipendula - PSS, Peso Seco das Epífitas - PSE e Área Superficial da Macroalga - ASM), quanto a morfologia do habitat (Área Fractal - Da e Perímetro Fractal - Dp) nas frondes de S. filipendula em todas as escalas analisadas, e nos descritores de comunidade tanto da macrofauna total, abundância $(\mathrm{N})$ e riqueza ou número de táxons $(\mathrm{S})$ e dos anfípodes, abundância $(\mathrm{N})$, riqueza $(\mathrm{S})$ e diversidade (H').

Para essas análises considerou-se um modelo de duas vias incluindo os fatores: Localização - Praia (Fixa com dois níveis: Fortaleza e Lamberto) e Período - Mês (Fixa com 13 níveis: janeiro de 2012 a janeiro de 2013). Com o intuito de comparar as diferentes escalas espaciais empregadas avaliou-se um segundo modelo de duas vias com os fatores: Localização - Praia (Fixa com dois níveis: Fortaleza e Lamberto) e Escalas (Fixa com 5 níveis: Da ou Dp e suas quatro escalas de medidas: $100 \mathrm{~cm}^{2}, 25 \mathrm{~cm}^{2}, 9 \mathrm{~cm}^{2}$ e $1 \mathrm{~cm}^{2}$ ).

ANOVAs também foram utilizados para avaliar diferenças entre as abundâncias, riqueza e diversidade de espécies de anfípodes entre as classes de tamanho (Classes I, II e III). Para essas análises considerou-se um modelo de duas vias incluindo os dois fatores expostos acima (Localização e Período) somado ao fator Classe de Tamanho (Fixa com 3 níveis: Classe I, Classe II e Classe III).

Antes de cada ANOVA, o teste de Kolmogorov-Smirnov foi realizado para verificar a homogeneidade das variâncias. Quando necessário, os dados foram transformados em $\log (10)$ para remover a heterogeneidade das variâncias. Quando isso não foi possível, o dado não transformado foi analisado e os resultados foram considerados robustos quando o nível de significância alcançou $P<0,01$ (UNDERWOOD, 1997). Em caso de diferença significativa foi realizado o teste $a$ posteriori de Tukey HSD para explorar as diferenças entre todos os pares dos níveis do fator selecionado.

A análise de variância multivariada por permutação (PERMANOVA) foi empregada para verificar toda a estrutura da amostra. Esta análise foi baseada em dissimilaridades de Bray-Curtis não transformadas (ANDERSON, 2001). O modelo seguido foi o mesmo do caso da ANOVA descrito acima para N e S. Sempre que a PERMANOVA mostrou diferenças significativas $(P<0,05)$, foi feita uma comparação entre pares (999 permutações) para explorar essas diferenças (ANDERSON, 2001). 
A fim de estudar a relação entre as respostas das variáveis univariadas (isto é, $\mathrm{N}$, $\mathrm{S}$ e $\mathrm{H}^{\prime}$ ) e as medidas de complexidade das macroalgas (PST, PSS, PSE, ASM, Da e Dp), foram feitas análises de correlação de Spearman. A correlação de Spearman foi empregada para se observar possíveis correlações significativas entre: valores dos descritores quantitativos (PST, PSS, PSE e Área Superficial); valores dos descritores morfológicos (Da e Dp e suas escalas); valores de abundância, riqueza da macrofauna total; e valores de abundância, riqueza e diversidade de espécies das anfípodes (total e para cada classe de tamanho). Os dados nos gráficos de correlação foram logaritmizados - log (10), e uma linha de regressão foi incluída parar facilitar a visualização.

Para avaliar o efeito entre o conjunto de medidas de complexidade das algas sobre a estrutura da comunidade da macrofauna total e dos anfípodes aplicou-se o modelo linear sobre a matriz de distância (DistLM) em PERMANOVA, uma vez que as variáveis preditoras nem sempre são independentes entre si e sim parcialmente correlacionadas entre si. Para isso foram criadas duas matrizes, uma para as medidas de complexidade transformadas pela Distância Euclidiana, e outra com base na dissimilaridade de BrayCurtis, tendo os dados de abundância dos grupos e das espécies dos anfípodes transformados em raiz dupla. O procedimento utilizado foi de passo-a-passo, com 999 permutações. Esta análise é particularmente adequada a uma matriz de dados ecológicos que contenham grande número de zeros e sem distribuição normal (ANDERSON et al., 2008), que é o caso de nossos dados.

A análise de Similaridade Porcentual (SIMPER) consiste em calcular a dissimilaridade dentro e entre grupos pré-determinados. Por ser uma análise de caráter exploratório, determina a dissimilaridade média entre todos os pares de amostras e entre grupos e depois desdobra esta média na contribuição isolada de cada táxon para a dissimilaridade média (CLARKE \& WARWICK, 1994). No presente estudo esta análise foi aplicada em dois momentos, primeiro para determinar quais as espécies que mais contribuíam na dissimilaridade entre as praias amostradas e para avaliar quais espécies eram mais representativas entre as classes de tamanho e praia. 


\section{RESULTADOS}

\subsection{Quantidade e Morfologia do habitat do Sargassum filipendula}

Os valores de Peso Seco Total (PST), Peso Seco do S. filipendula (PSS), Peso Seco das Epífitas (PSE), Área Superficial da Macroalga (ASM) e medidas fractais (Dp e Da) do Sargassum filipendula variaram consideravelmente entre as praias e meses amostrados (Figuras 02, 03 e 04). Segundo as ANOVAs ocorreram diferenças significativas entre as praias e meses para todas as medidas de complexidade do $S$. filipendula (Tabela 01). Houve ainda significância nas interações praia/mês para PSE, ASM, Da e Dp, embora não houvesse para PST e PSS (Tabela 01). Como já descrito no capítulo anterior, a praia do Lamberto exibiu os maiores valores tanto de PST, PSS e PSE quanto ASM, e pela comparação par a par os meses de verão (fevereiro e março) e final de primavera (dezembro) apresentaram os maiores valores independente da medida analisada. Já os meses de inverno/ primavera (Fortaleza - PST, PSS e PSE) e verão (ASM) exibiram os menores valores (Figura 02 e 03).
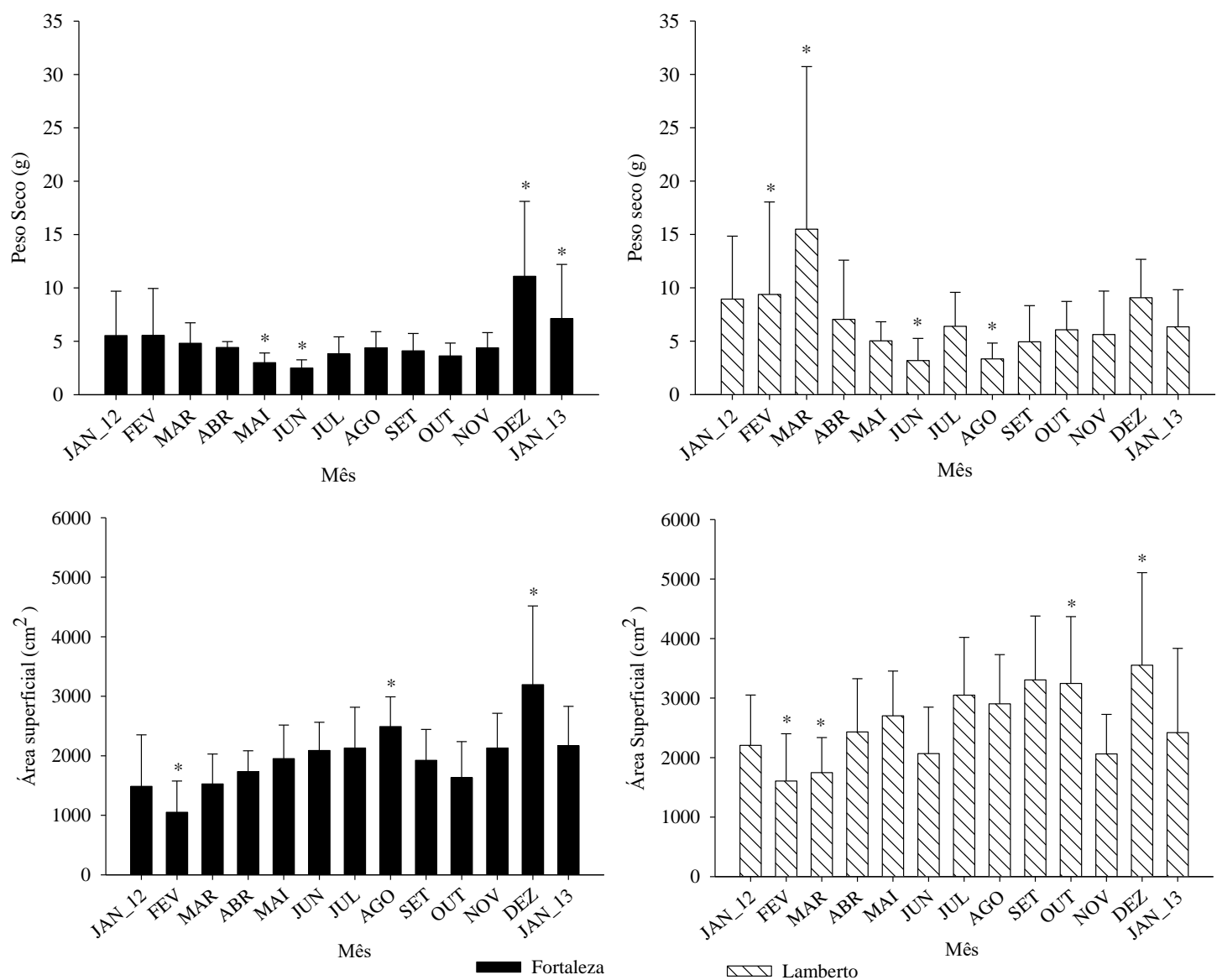

Figura 02- Valores médios PST (g) e ASM $\left(\mathrm{cm}^{2}\right)$ das frondes de Sargassumfilipendula coletadas mensalmente nas praias da Fortaleza e Lamberto, Ubatuba, São Paulo. Barras com asterisco são significativamente diferentes, de acordo com o teste post-hoc de Tukey HSD. 
Tabela 01 - Sumário das ANOVAs para as medidas de complexidade do Sargassum filipendula (PST, PSS, PSE, ASM, Da e Dp). ** $P<0.01$; ${ }^{\text {s }}$, significativo $e^{\text {ns }}$, não significativo.

\begin{tabular}{|c|c|c|c|c|c|c|c|c|c|c|c|c|c|}
\hline \multirow{2}{*}{ Fonte de variação } & \multirow{2}{*}{$d f$} & \multicolumn{2}{|c|}{ PST } & \multicolumn{2}{|c|}{ PSS } & \multicolumn{2}{|c|}{ PSE } & \multicolumn{2}{|c|}{ ASM } & \multicolumn{2}{|c|}{ Da } & \multicolumn{2}{|c|}{ Dp } \\
\hline & & MS & $\mathrm{F}$ & MS & $\mathrm{F}$ & MS & $\mathrm{F}$ & MS & $\mathrm{F}$ & MS & $\mathrm{F}$ & MS & $\mathrm{F}$ \\
\hline Praia & 1 & 0.98 & $15.88^{* *}$ & 126.6 & $11.14^{* *}$ & 18.46 & $14.70^{* *}$ & 1.17 & $45.59^{* *}$ & 0.02 & $10.38^{* *}$ & 0.21 & $19.07 * *$ \\
\hline Mês & 12 & 0.45 & $7.31 * *$ & 75.45 & $6.48^{* *}$ & 12.49 & $9.94 * *$ & 0.27 & $10.65^{* *}$ & 0.02 & $8.7 * *$ & 0.12 & $10.72 * *$ \\
\hline Praia*Mês & 12 & 0.11 & 1.75 & 18.3 & 1.75 & 6.75 & $5.37 * *$ & 0.1 & $4.04 * *$ & 0.008 & $3.49 * *$ & 0.08 & $7.2 * *$ \\
\hline Residual & 338 & 0.06 & & 11.64 & & 1.26 & & 0.03 & & 0.002 & & 0.01 & \\
\hline Total & 364 & & & & & & & & & & & & \\
\hline Kolmogorov-Smirnov & & \multicolumn{2}{|c|}{$0.047^{\mathrm{s}}$} & \multicolumn{2}{|c|}{$0.158^{\mathrm{ns}}$} & \multicolumn{2}{|c|}{$0.334^{\mathrm{ns}}$} & \multicolumn{2}{|c|}{$0.099^{\mathrm{ns}}$} & \multicolumn{2}{|c|}{$0.030^{\mathrm{s}}$} & \multicolumn{2}{|c|}{$0.093^{\mathrm{ns}}$} \\
\hline Transformação & & \multicolumn{2}{|c|}{ Sim } & \multicolumn{2}{|c|}{ Não } & \multicolumn{2}{|c|}{ Não } & \multicolumn{2}{|c|}{ Sim } & \multicolumn{2}{|c|}{ Não } & \multicolumn{2}{|c|}{ Não } \\
\hline
\end{tabular}
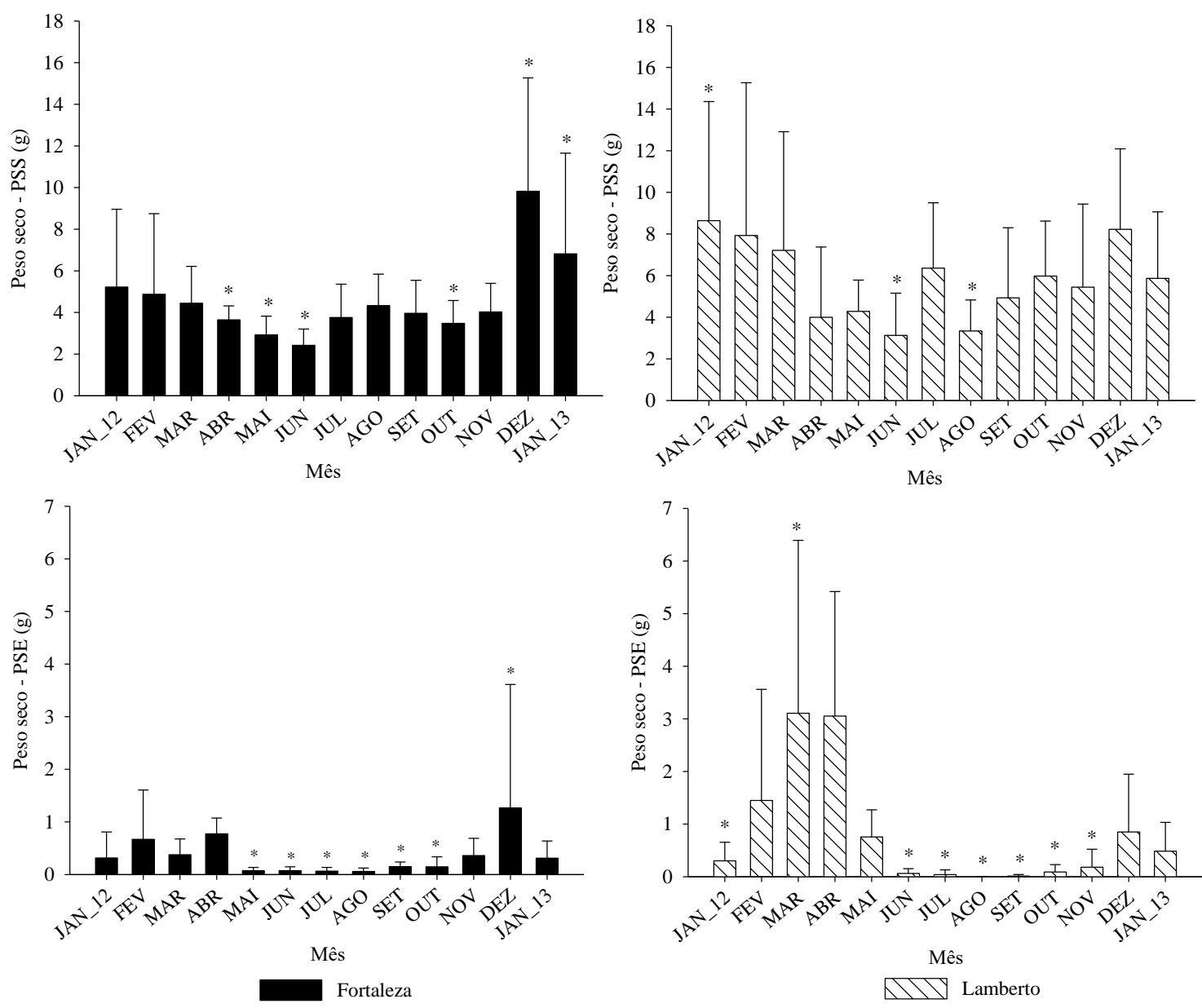

Figura 03 - Valores médios do Peso Seco (g) do Sargassumfilipendula (PSS) e das algas epífitas (PSE) das frondes coletadas mensalmente nas praias da Fortaleza e Lamberto, Ubatuba, São Paulo. Barras com asterisco são significativamente diferentes, de acordo com o teste post-hoc Tukey HSD. 

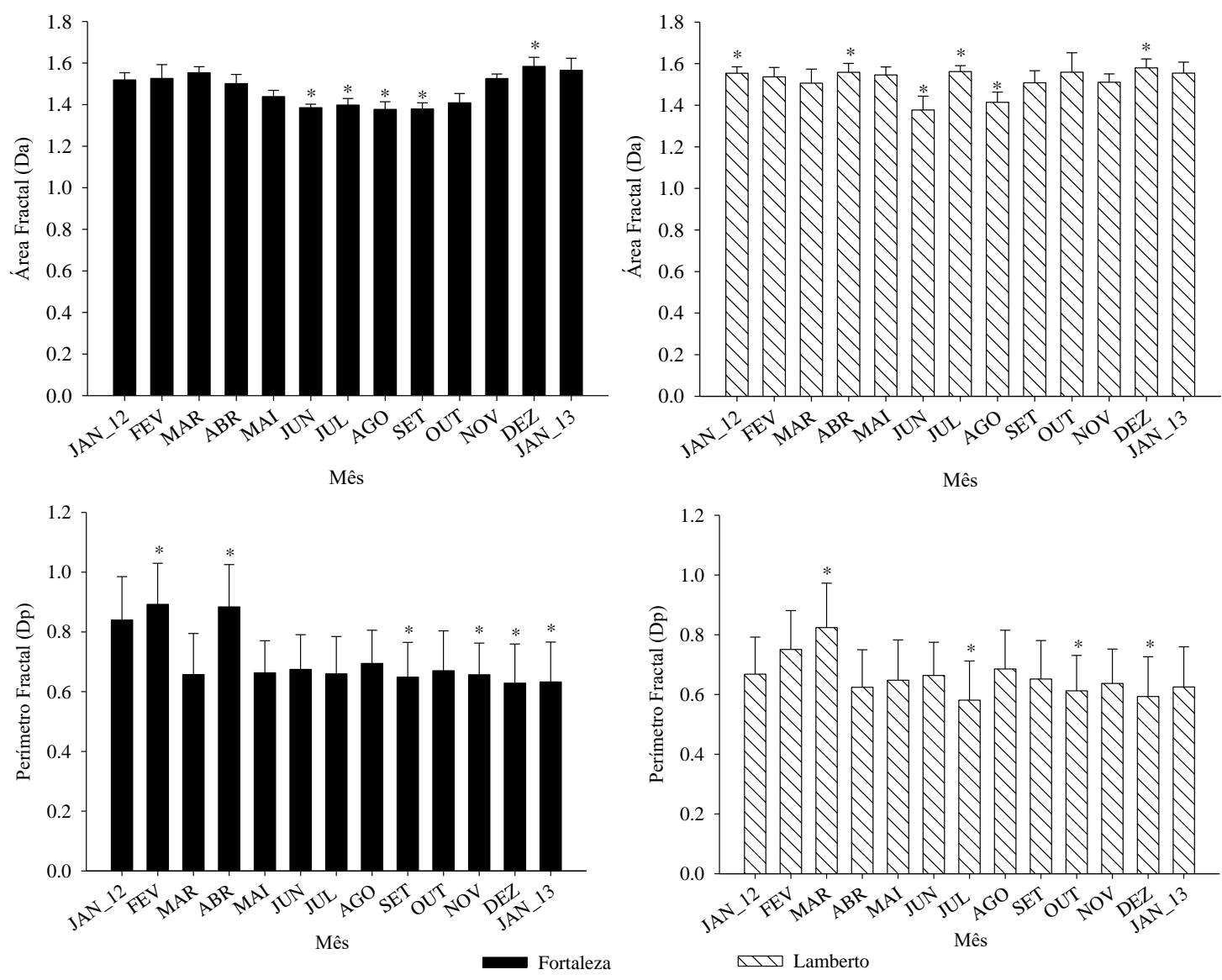

Figura 04- Valores médios das medidas fractais (Da e Dp) das frondes de Sargassumfilipendula coletadas mensalmente nas praias da Fortaleza e Lamberto, Ubatuba, São Paulo. Barras com asterisco são significativamente diferentes, de acordo com o teste post-hoc de Tukey HSD.

Os valores de Da na Praia da Fortaleza variaram 1,58 \pm 0,04 em dezembro a 1,38 $\pm 0,04$ e 1,38 \pm 0,07 em agosto e setembro, respectivamente (Figura 04). No Lamberto, a variação foi semelhante à da Fortaleza, e o maior valor obtido foi em dezembro $(1,58 \pm$ $0,04)$ e o menor em junho $(1,38 \pm 0,04)$ (Figura 04). As comparações par a par entre os meses de cada praia evidenciaram diferença entre os períodos de verão/final de primavera e inverno. Os valores de Dp na Fortaleza variaram de 0,89 $\pm 0,14$ em fevereiro a 0,63 \pm 0,13 em dezembro e janeiro de 2013 (ambos com o mesmo valor) (Figura 04). No Lamberto foram de 0,82 \pm 0,15 em março para 0,58 \pm 0,13 em julho (Figura 04). Em ambas as praias, as comparações a posteriori pelo Tukey HSD demonstraram diferenças entre os primeiros meses de 2012 e os restantes, que, por sua vez, foram mais homogêneos. Adicionalmente, verificou-se que na Fortaleza fevereiro e abril se destacaram significativamente dos demais, enquanto que no Lamberto, o destaque ficou para março (Figura 04).

A análise conjunta das comparações a posteriori e dos resultados da correlação de Spearman mostram que houve um importante grau de variação entre os meses do ano, 
para todos os descritores de complexidade do S. filipendula, e alguns padrões puderam ser observados. De modo geral, os maiores valores das medidas quantitativas (PST, PSS, PSE e ASM) foram correlacionados positivamente aos maiores valores de Da, em ambas as praias (dezembro) (Figuras 02,03 e 04). A variável Dp se comportou similarmente nas duas praias, correlacionando-se negativamente com ASM (Fortaleza: fevereiro; Lamberto: fevereiro e dezembro). Os valores de Dp se correlacionaram positivamente com os de PST e negativamente com os de PSS apenas para a Praia do Lamberto, principalmente em março (Figuras 02, 03 e 04).

Quanto às quatro escalas de medidas fractais, os maiores valores de $\mathrm{Da}$, independente da escala ou praia observada, foram obtidos nos meses de verão: fevereiro, março e dezembro (Figura 05). Quando analisamos individualmente cada escala pela ANOVA (Tabela 02), notamos que em todas os valores de Da (Da-100, Da-25, Da-9 e Da-1) apresentaram diferenças significativas entre os meses (Da-100: $F=3$,95; Da-25: $F$ $=3,53$; Da-9: $\mathrm{F}=9,61$ e Da-1: $\mathrm{F}=6,43$ - todos com $p<0,01$ ); porém, em nenhuma delas ocorreu diferença significativa entre as praias. Apenas a escala Da-1 apresentou uma interação significativa entre praia/mês $(\mathrm{F}=2,06 ; p<0,05)$ (Tabela 02$)$.

Os valores para $\mathrm{Dp}$ em todas as escalas foram maiores nos primeiros meses de 2012, independente da praia, enquanto que nos demais períodos não houve variação significativa (Figura 05). Segundo as ANOVAs, houve diferenças significativas entre as praias para as escalas Dp-100 $(\mathrm{F}=10,57 ; p<0,01)$ e Dp-1 $(\mathrm{F}=11,66 ; p<0,01)$. Ocorreram também diferenças significativas entre os meses para Dp-9 $(\mathrm{F}=1,99 ; p<0,05)$ e Dp-1 (F $=2,84 ; p<0,01)$. Apenas Dp-9 apresentou significância na interação praia/mês $(\mathrm{F}=2,84$; $p<0,01$ ) (Tabela 02). 

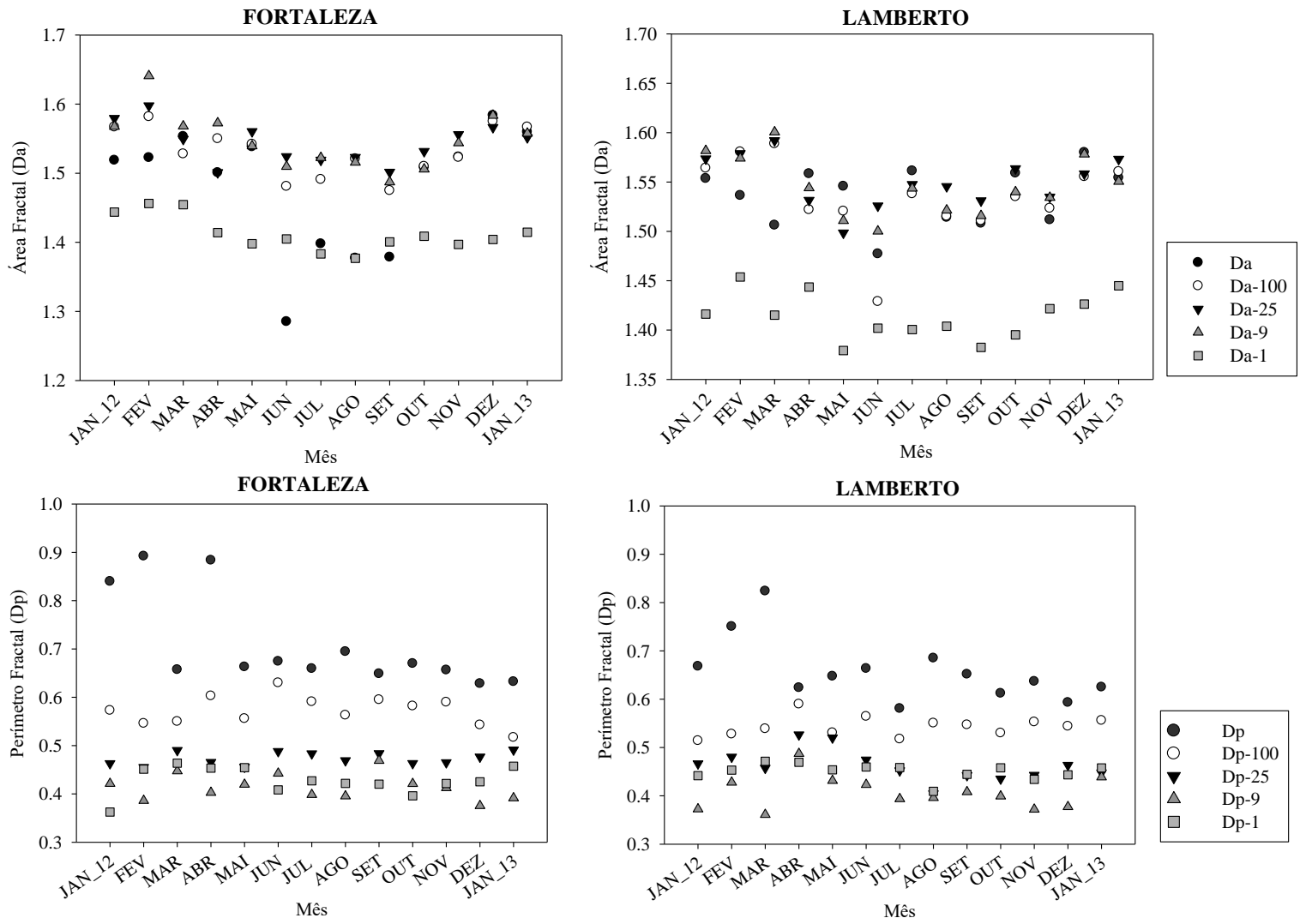

Figura 05 - Valores médios de Área Fractal (Da) e Perímetro Fractal (Dp) das frondes de Sargassum filipendula das cinco escalas analisadas.

Tabela 02 - Sumário das ANOVAs para as medidas fractais: Área Fractal (Da) e Perímetro Fractal (Dp). $* P<0.05 \mathrm{e}^{* *} P<0.01 ;{ }^{\mathrm{s}}$, significativo $\mathrm{e}^{\mathrm{ns}}$, não significativo.

\begin{tabular}{|c|c|c|c|c|c|c|c|c|c|}
\hline \multirow{2}{*}{ Fonte de variação } & \multirow{2}{*}{$d f$} & \multicolumn{2}{|c|}{ Da-100 } & \multicolumn{2}{|c|}{ Da-25 } & \multicolumn{2}{|c|}{ Da-9 } & \multicolumn{2}{|c|}{ Da-1 } \\
\hline & & MS & $\mathrm{F}$ & MS & $\mathrm{F}$ & MS & $\mathrm{F}$ & MS & $F$ \\
\hline Praia & 1 & 3.22E-05 & 0.03 & 0.004 & 0.812 & 2.70E-04 & 0.082 & 4.04E-04 & 0.206 \\
\hline Mês & 12 & 0.004 & $3.95^{* * *}$ & 0.017 & $3.53 * *$ & 0.03 & $9.61 * *$ & 0.013 & $6.43^{* *}$ \\
\hline Praia*Mês & 12 & 0.001 & 1.10 & 0.006 & 1.26 & 0.006 & 1.85 & 0.004 & $2.06^{*}$ \\
\hline Residual & 338 & 0.001 & & 0.005 & & 0.003 & & 0.002 & \\
\hline Total & 364 & & & & & & & & \\
\hline \multirow{2}{*}{\multicolumn{2}{|c|}{$\begin{array}{l}\text { Kolmogorov-Smirnov } \\
\text { Transformação }\end{array}$}} & \multirow{2}{*}{\multicolumn{2}{|c|}{$\begin{array}{c}0.204^{\mathrm{ns}} \\
\mathrm{Sim}\end{array}$}} & \multicolumn{2}{|c|}{$0.107^{\mathrm{ns}}$} & \multicolumn{2}{|c|}{$0.037^{\mathrm{s}}$} & \multicolumn{2}{|c|}{$0.043^{\mathrm{s}}$} \\
\hline & & & & & & $\mathrm{N}$ & & $\mathrm{N}$ & \\
\hline \multirow{2}{*}{ Fonte de variação } & \multirow{2}{*}{$d f$} & \multicolumn{2}{|c|}{ Dp-100 } & \multicolumn{2}{|c|}{ Dp-25 } & \multicolumn{2}{|c|}{ Dp-9 } & \multicolumn{2}{|c|}{ Dp-1 } \\
\hline & & MS & $\mathrm{F}$ & MS & $\mathrm{F}$ & MS & $\mathrm{F}$ & MS & $\mathrm{F}$ \\
\hline Praia & 1 & 0.073 & $10.57 * *$ & 0.01 & 1.238 & 0.04 & 0.785 & 0.04 & $11.66 * *$ \\
\hline Mês & 12 & 0.012 & 1.733 & 0.007 & 0.94 & 0.011 & $1.99 *$ & 0.01 & $2.84 * *$ \\
\hline Praia*Mês & 12 & 0.006 & 0.941 & 0.011 & 1.389 & 0.016 & $2.84 * *$ & 0.005 & 1.44 \\
\hline Residual & 338 & 0.007 & & 0.008 & & 0.006 & & 0.004 & \\
\hline Total & 364 & & & & & & & & \\
\hline Kolmogorov-Smirnov & & \multicolumn{2}{|c|}{$0.058^{\text {ns }}$} & \multicolumn{2}{|c|}{$0.072^{\mathrm{ns}}$} & \multicolumn{2}{|c|}{$0.054^{\mathrm{s}}$} & \multicolumn{2}{|c|}{$0.058^{\mathrm{ns}}$} \\
\hline Transformação & & \multicolumn{2}{|c|}{ Não } & \multicolumn{2}{|c|}{ Não } & \multicolumn{2}{|c|}{ Não } & \multicolumn{2}{|c|}{ Não } \\
\hline
\end{tabular}


Segundo a ANOVA, houve diferença entre as escalas para Da $(F=280,56$; $p<0,01)$ e comparações a posteriori pelo teste de Tukey HSD mostraram que Da-1 é significantemente diferente das demais escalas (Figura 05 e Tabela 03). Ainda, segundo a ANOVA, não foi obtido diferenças significativas entre as praias e entre a interação praia/escala (Tabela 03). Para as escalas de Dp, a ANOVA indicou diferenças significativas entre as praias $(\mathrm{F}=12,48 ; p<0,01)$, entre as escalas $(\mathrm{F}=540,42 ; p<0,01) \mathrm{e}$ na interação praia/escala $(\mathrm{F}=8,02 ; p<0,01)$. Comparações par a par pelo teste de Tukey HSD mostraram que os valores foram maiores na Fortaleza e os valores de Dp e Dp-100 são significativamente diferentes em relação aos das demais escalas (Figura 04).

Tabela 03 - Sumário das ANOVAs para as diferentes escalas das variáveis: Área Fractal(Da) e Perímetro Fractal (Dp). ** $P<0.01$; ns, não significativo.

\begin{tabular}{|c|c|c|c|c|c|}
\hline \multirow{2}{*}{ Fonte de variação } & \multirow{2}{*}{ df } & \multicolumn{2}{|c|}{ Escalas de $\mathrm{Da}$} & \multicolumn{2}{|c|}{ Escalas de Dp } \\
\hline & & MS & $F$ & MS & $\mathrm{F}$ \\
\hline Praia & 1 & 0.02 & 3.51 & 0.1 & $12.48^{* * *}$ \\
\hline Escala & 4 & 1.16 & $280.56^{* *}$ & 4.51 & $540.42 * *$ \\
\hline Praia*Escala & 4 & 0.005 & 1.10 & 0.07 & $8.02 * *$ \\
\hline Residual & 1810 & 0.004 & & 0.01 & \\
\hline Total & 1820 & & & & \\
\hline Kolmogorov-Smirnov & & \multicolumn{2}{|c|}{$0.061^{\mathrm{ns}}$} & \multicolumn{2}{|c|}{$0.079^{\mathrm{ns}}$} \\
\hline Transformação & & \multicolumn{2}{|c|}{ Não } & \multicolumn{2}{|c|}{ Não } \\
\hline
\end{tabular}

\subsection{Relação entre as medidas de complexidade do Sargassum filipendula $e$} macrofauna total

A macrofauna amostrada na praia do Lamberto foi significativamente mais abundante em relação à Fortaleza, mas esta apresentou maior diversidade (Tabela 04). Diferenças significativas entre os meses para abundância e riqueza (número de táxons) foram observadas no teste par a par e os altos valores estiveram relacionados aos meses de verão e final de primavera, especialmente fevereiro e dezembro. Este período foi significativamente diferente daqueles do inverno/primavera, quando ocorreram valores mínimos (junho, agosto e setembro) (Figura 06).

Na Praia do Lamberto observou-se correlações positivas entre PST, PSS, ASM e Da e a abundância, e correlação positiva entre PSS e PSE com a riqueza (Figuras 07 e 09). Na Praia da Fortaleza ocorreu um número maior de correlações positivas, entre a 
abundância média da macrofauna total e todas as variáveis medidas para o Sargassum filipendula e entre riqueza e PST, PSS, PSE e Dp (Figuras 08 e 09).

Tabela 04 - Sumário das ANOVAs para os valores médios de abundância da fauna total $(\mathrm{N})$ e Número de Táxons. ** $P<0.01$; ${ }^{\text {s }}$, significativo $\mathrm{e}^{\text {ns }}$, não significativo.

\begin{tabular}{cccccc}
\hline \multirow{2}{*}{ Fonte de variação } & \multirow{2}{*}{$d f$} & \multicolumn{2}{c}{$\mathbf{N}$} & \multicolumn{2}{c}{ Táxon } \\
\cline { 3 - 6 } & & MS & $\mathrm{F}$ & MS & $\mathrm{F}$ \\
\hline Praia & 1 & 0.77 & $8.59^{* *}$ & 249.55 & $72.33^{* *}$ \\
Mês & 12 & 1.01 & $11.26^{* *}$ & 16.21 & $4.70^{* *}$ \\
Praia*Mês & 12 & 0.42 & $4.74^{* *}$ & 4.19 & 1.22 \\
Residual & 338 & 0.09 & & 3.45 & \\
Total & 364 & & & & \\
Kolmogorov-Smirnov & \multicolumn{2}{c}{$0.041^{\mathrm{s}}$} & \multicolumn{2}{c}{$0.099^{\text {ns }}$} \\
Transformação & \multicolumn{2}{c}{ Sim } & \multicolumn{2}{c}{ Não } \\
\hline
\end{tabular}
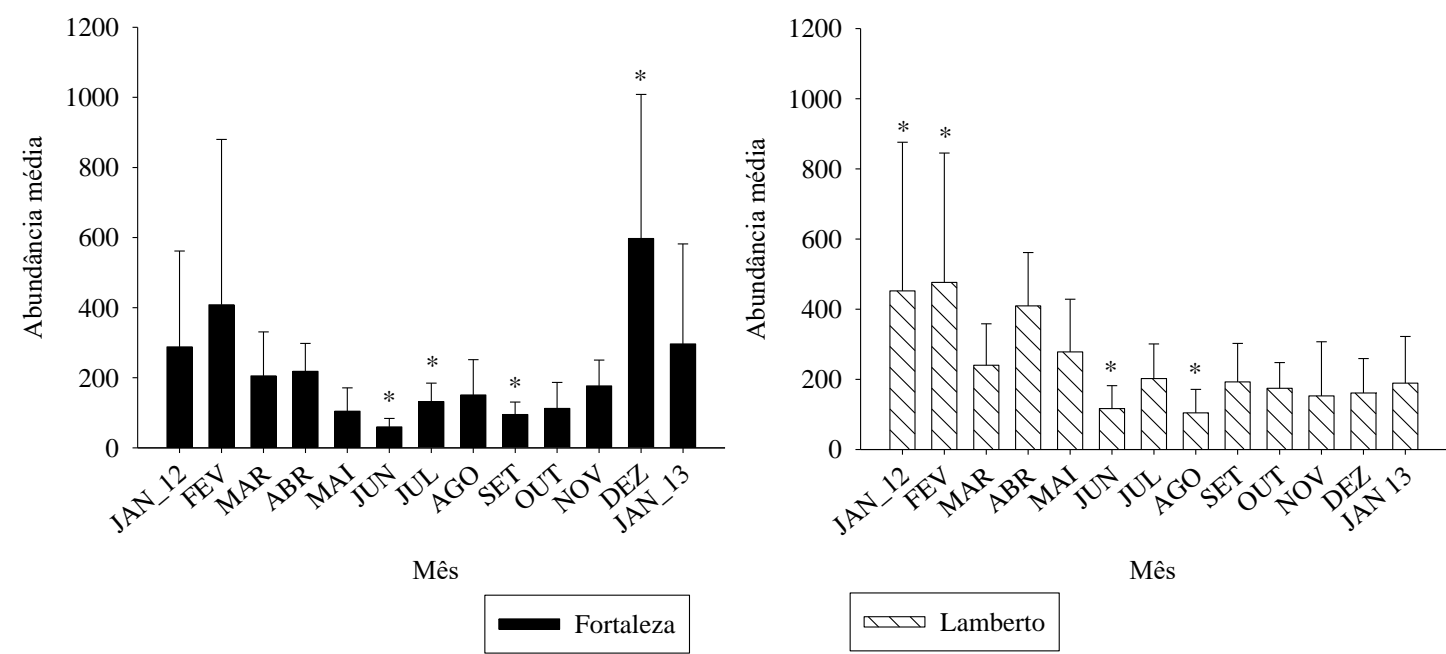

Figura 06 - Abundância média da macrofauna total obtida mensalmente nas praias da Fortaleza e Lamberto, Ubatuba, São Paulo. Barras com os mesmos asteriscos foram iguais, de acordo com o teste post-hoc Tukey HSD. 

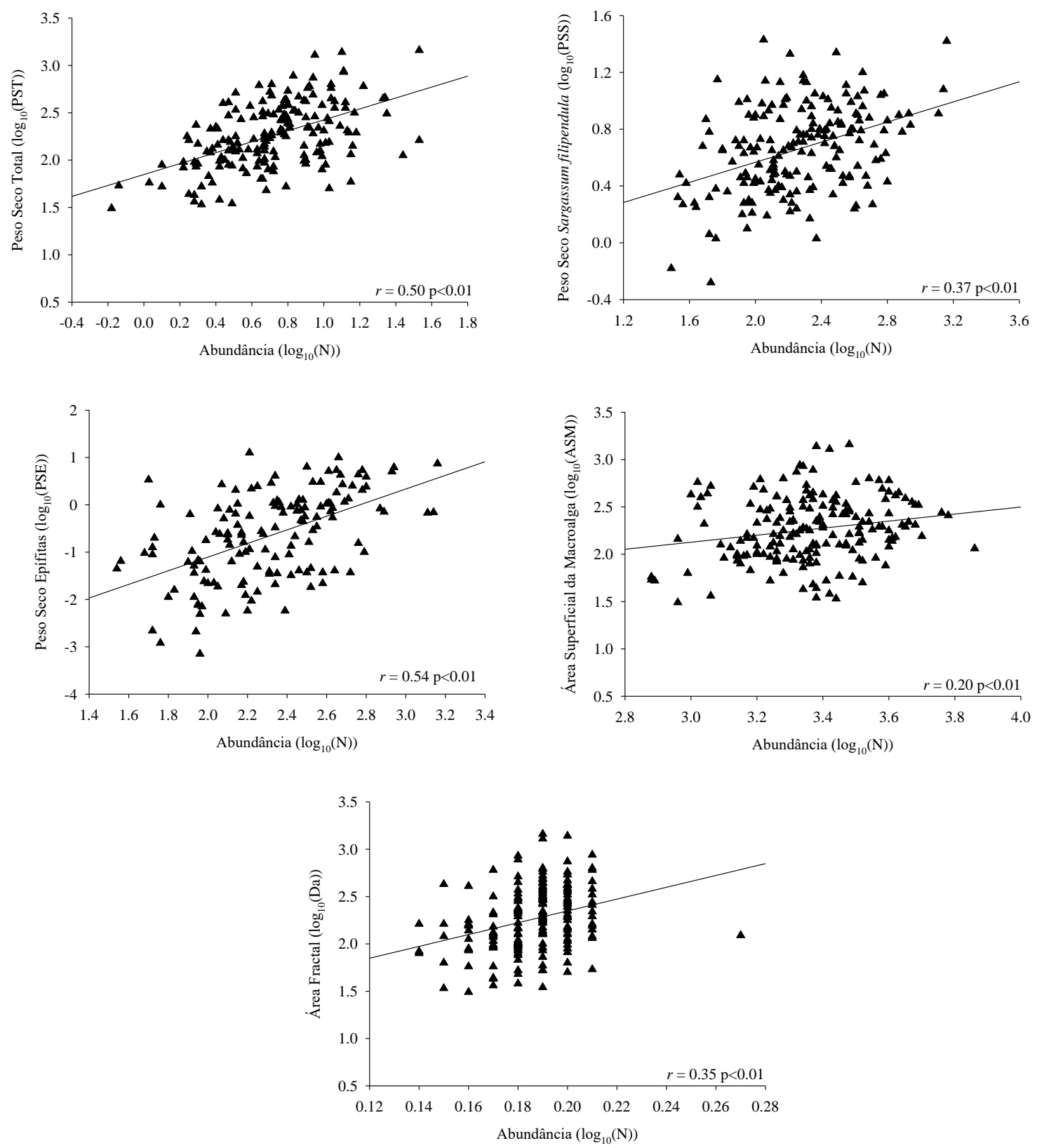

Figura 07 - Praia do Lamberto. Correlação de Spearman entre os valores de PST (g), PSS (g), $\operatorname{PSE}(\mathrm{g}), \operatorname{ASM}\left(\mathrm{cm}^{2}\right)$ e Área Fractal (Da) e a abundância média da macrofauna total $(\mathrm{N})$ para cada período de coleta. Valores em logaritmo e gráficos com linha de regressão. 

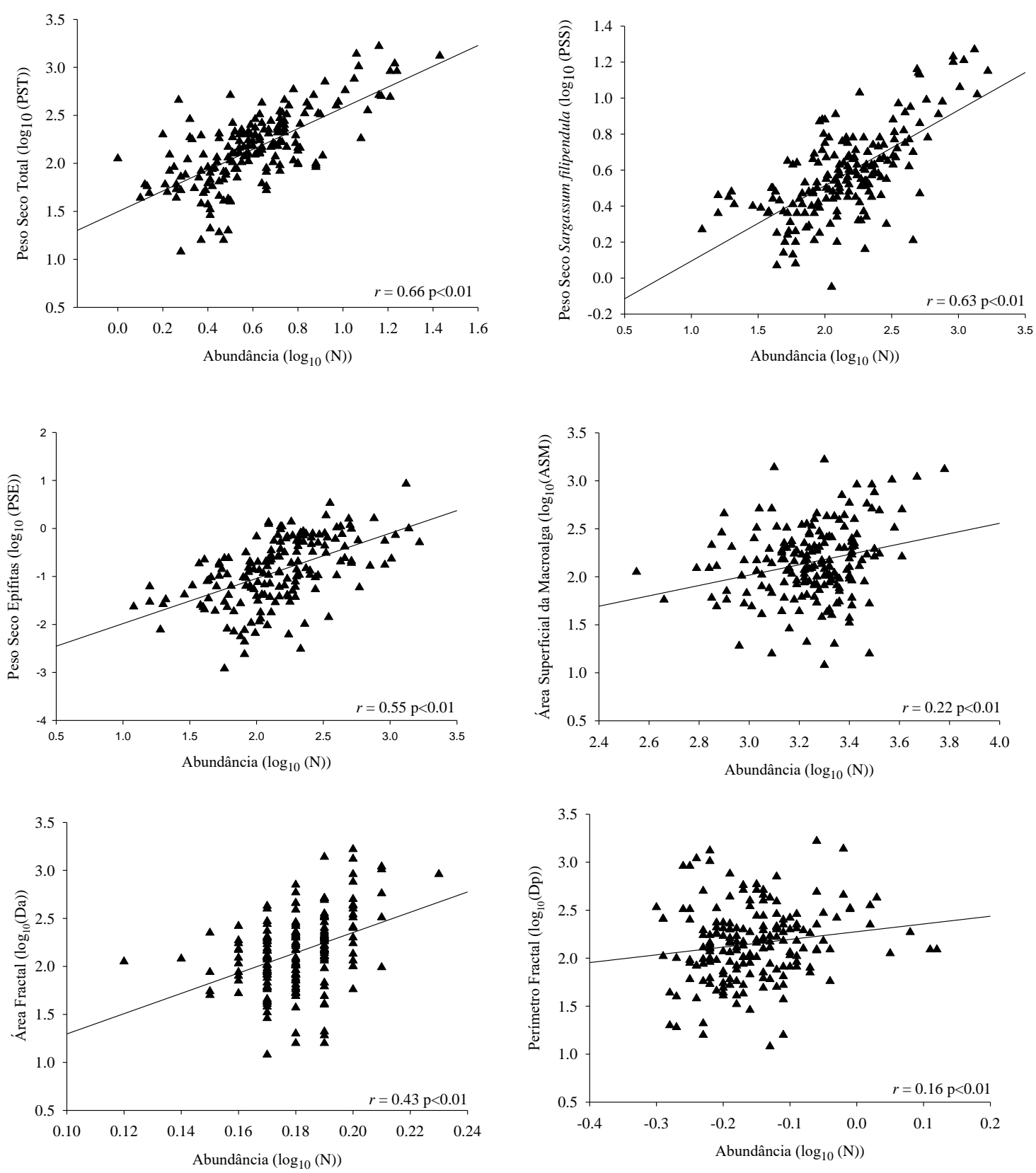

Figura 08 - Praia da Fortaleza. Correlação de Spearman entre os valores de PST (g), PSS (g), PSE (g), ASM $\left(\mathrm{cm}^{2}\right)$, Área Fractal (Da) e Perímetro Fractal (Dp) e a abundância média (N) da macrofauna total para cada período de coleta. Valores em logaritmo e gráficos com linha de regressão. 
A

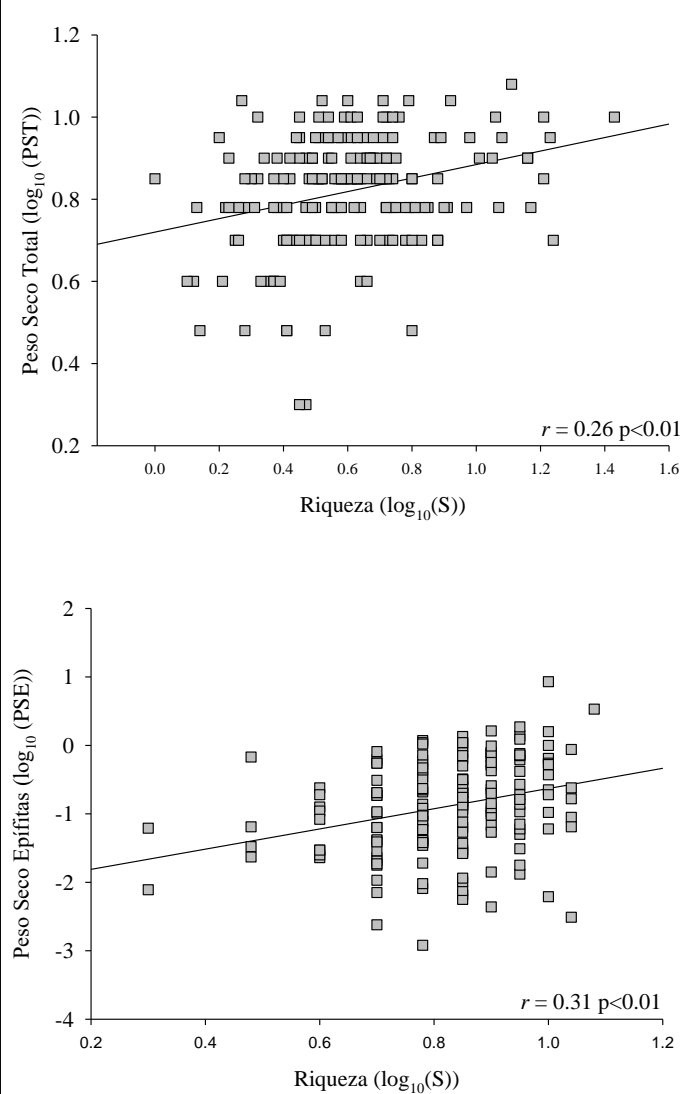

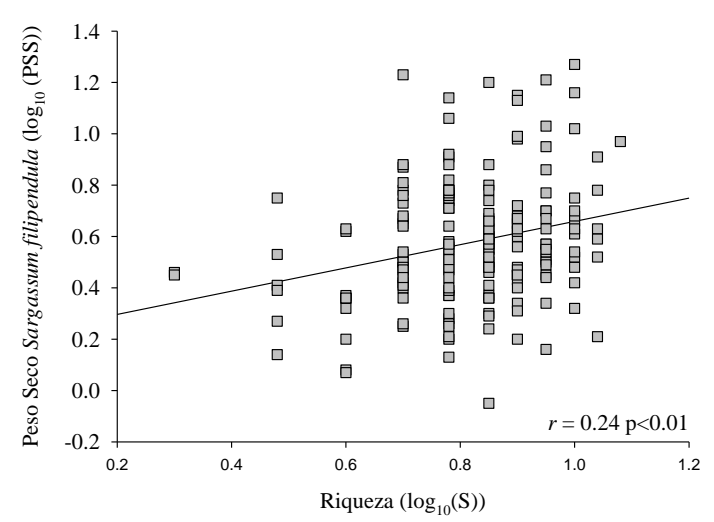

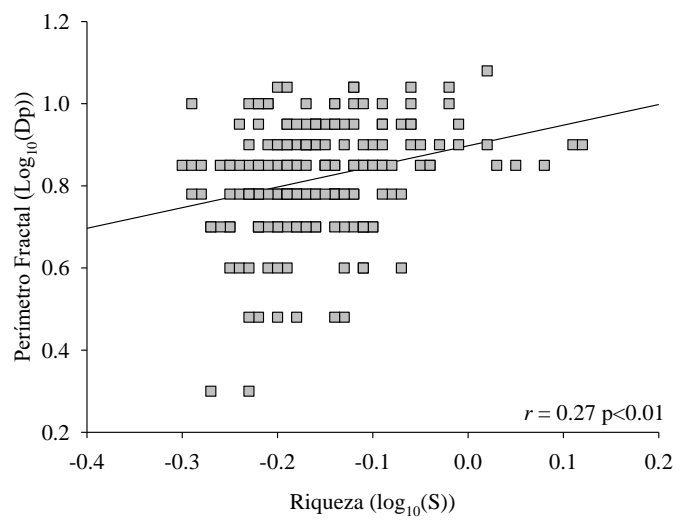

B

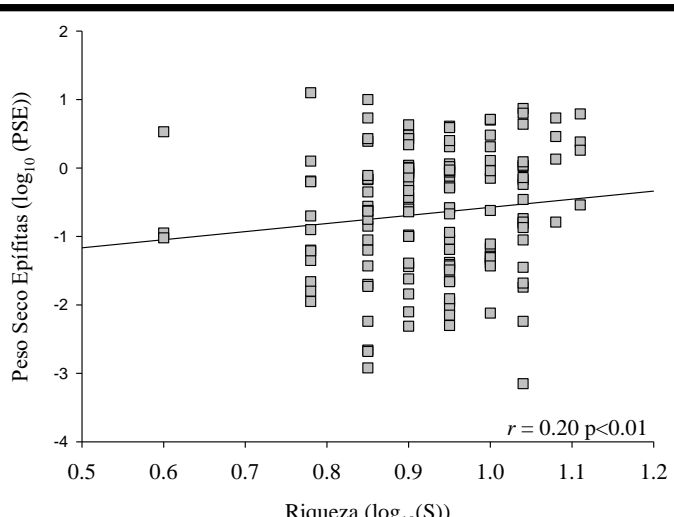

Figura 09 - Correlação de Spearman entre os valores de PST (g), PSS (g), PSE (g) e Perímetro Fractal (Dp) e Riqueza (S) da macrofauna total para cada período de coleta nas praias da Fortaleza (A) e Lamberto (B). Valores em logaritmo e gráficos com linha de regressão.

Para averiguar quais variáveis do Sargassum filipendula mais influenciaram a distribuição da macrofauna total nas praias, utilizamos o teste de regressão múltipla, DistLM. Os resultados mostraram que a maioria das variáveis conseguem influenciar a estrutura da macrofauna, porém essa influência é pequena (Tabela 05). A medida quantitativa- PST em conjunto com as medidas morfológicas Da e Dp, foram as variá ve is que mais influenciam a macrofauna. Esse resultado pode ser corroborado pela análise de redundância baseada em distância, dbRDA (Figura 10). 
Tabela 05 - Resultados do teste de regressão múltipla (DistLM) sobre o efeito das medidas de complexidade do Sargassumfilipendula na abundância da macrofauna total. ** $P<0.01$.

\begin{tabular}{cccc}
\hline VARIÁ VEIS & Pseudo-F & Prob. & $\boldsymbol{R}^{2}$ cumul. \\
\hline PST & 35.72 & $0.089^{* *}$ & 0.089 \\
Da & 6.46 & $0.016^{* *}$ & 0.106 \\
Dp & 7.28 & $0.018^{* *}$ & 0.124 \\
ASM & 5.73 & $0.014^{* *}$ & 0.140 \\
PSE & 3.80 & $0.009^{*}$ & 0.146 \\
PSS & 1.43 & 0.004 & 0.150 \\
\hline
\end{tabular}

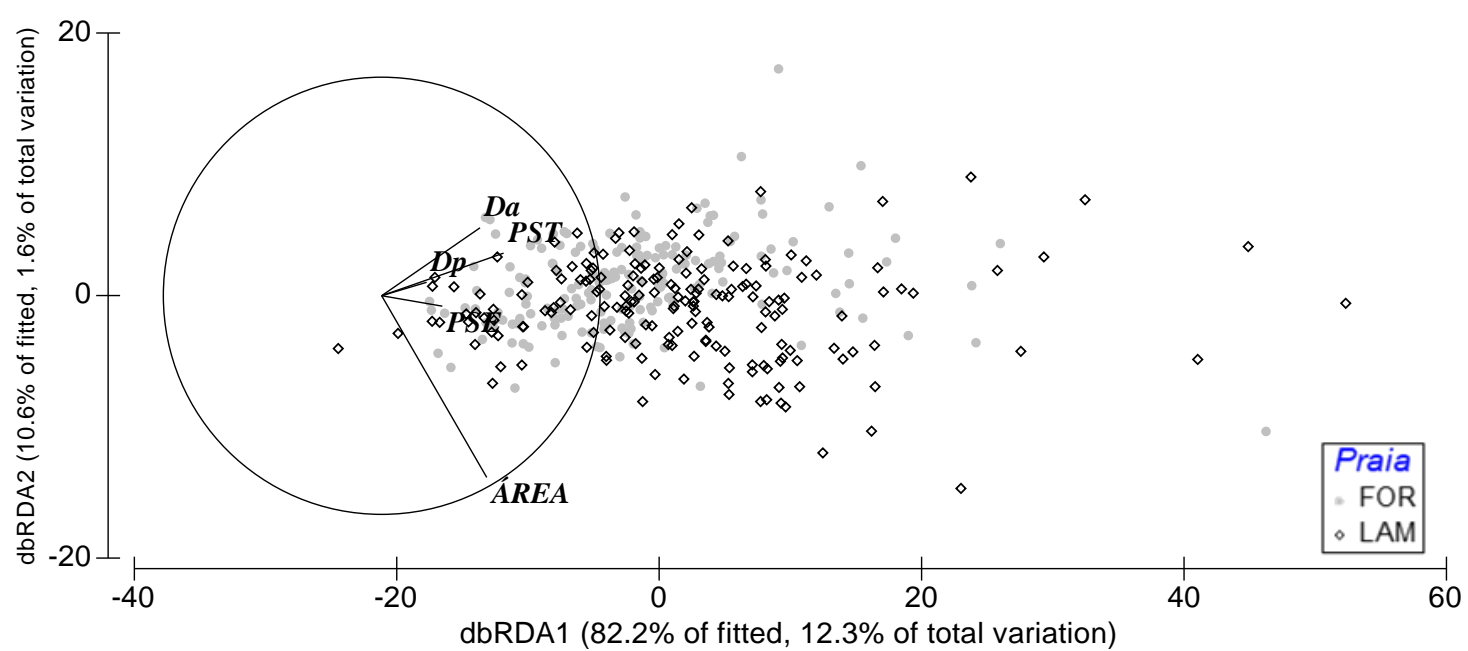

Figura 10 - Resultados da análise de redundância à distância (dbRDA). Os símbolos representam abundância da macrofauna total amostrada mensalmente nas praias da Fortaleza e do Lamberto. A distância entre os símbolos é baseada emuma matriz de similaridade de Bray-Curtis. Os vetores representam a direção e força das variáveis preditoras.

\subsection{Relação entre as medidas de complexidade do Sargassum filipendula $e$} anfipodes

Entre o período de 13 meses de amostragem foram obtidos 3.082 anfípodes nas duas praias estudadas, sendo que estes organismos foram separados em 32 espécies. A relação das espécies encontra-se no Anexo I e no Anexo II aquelas que mais contribuíram em cada mês e praia. Segundo o SIMPER foram dez as espécies mais abundantes: Sunamphitoe pelagica, Hyale niger, Caprella scaura, Ampithoe ramondi, Cymadusa filosa, Apohyale media, Ericthonius punctatus, Photis longicaudata, Aora spnicornis e Apolochus neapolitanus.

Os valores médios referentes aos descritores de comunidade estão apresentados na tabela 06. As ANOVAs não indicaram diferenças significativas entre as duas praias quanto aos valores médios de abundância e riqueza de espécies $(\mathrm{N}: \mathrm{F}=0,21 p>0,05 ; \mathrm{S}$ : $\mathrm{F}=2,34 p>0,05$ ); porém os valores médios de diversidade foram significativamente 
diferentes entre as praias $(\mathrm{F}=5,55 ; p<0,05)$ (Tabela 07). Segundo as mesmas análises, ocorreram diferenças significativas entre os meses e entre a interação praia/mês para todos os descritores de comunidade (Tabela 07).

Tabela 06- Valores médios dos descritores de comunidade: Abundância (N); Riqueza (S) e Diversidade (H') para cada mês nas praias da Fortaleza e Lamberto, Ubatuba, São Paulo.

\begin{tabular}{ccccccc}
\hline & \multicolumn{3}{c}{ FORTALEZA } & \multicolumn{3}{c}{ LAMBERTO } \\
\cline { 2 - 7 } $\mathbf{N}$ & $\mathbf{S}$ & $\mathbf{H}^{\prime}(\operatorname{loge})$ & $\mathbf{N}$ & $\mathbf{S}$ & H'$^{\prime}(\operatorname{loge})$ \\
\hline JAN_12 & $223 \pm 211.54$ & $8 \pm 2.70$ & $1.37 \pm 0.39$ & $331 \pm 364.42$ & $7 \pm 1.84$ & $1.15 \pm 0.20$ \\
FEV & $332 \pm 423.22$ & $11 \pm 3.03$ & $1.59 \pm 0.30$ & $281 \pm 217.44$ & $8 \pm 1.85$ & $1.33 \pm 0.33$ \\
MAR & $152 \pm 92.77$ & $9 \pm 3.36$ & $1.42 \pm 0.37$ & $88 \pm 50.16$ & $7 \pm 1.97$ & $1.30 \pm 0.25$ \\
ABR & $98 \pm 83.72$ & $9 \pm 3.07$ & $1.48 \pm 0.31$ & $132 \pm 67.00$ & $9 \pm 2.23$ & $1.64 \pm 0.14$ \\
MAI & $34 \pm 28.6$ & $5 \pm 1.57$ & $1.25 \pm 0.23$ & $59 \pm 33.34$ & $8 \pm 2.29$ & $1.59 \pm 0.30$ \\
JUN & $30 \pm 17.11$ & $5 \pm 1.60$ & $1.15 \pm 0.39$ & $19 \pm 10.68$ & $6 \pm 2.05$ & $1.50 \pm 0.33$ \\
JUL & $52 \pm 28.84$ & $7 \pm 2.25$ & $1.36 \pm 0.29$ & $54 \pm 29.37$ & $8 \pm 1.71$ & $1.58 \pm 0.32$ \\
AGO & $60 \pm 65.27$ & $7 \pm 1.91$ & $1.37 \pm 0.18$ & $48 \pm 39.78$ & $7 \pm 2.21$ & $1.28 \pm 0.39$ \\
SET & $33 \pm 16.45$ & $7 \pm 2.98$ & $1.44 \pm 0.42$ & $101 \pm 80.60$ & $8 \pm 1.82$ & $1.26 \pm 0.46$ \\
OUT & $45 \pm 25.73$ & $7 \pm 2.20$ & $1.34 \pm 0.29$ & $52 \pm 24.55$ & $9 \pm 2.02$ & $1.72 \pm 0.28$ \\
NOV & $78 \pm 49.92$ & $9 \pm 2.97$ & $1.58 \pm 0.38$ & $94 \pm 143.12$ & $9 \pm 1.72$ & $1.71 \pm 0.35$ \\
DEZ & $285 \pm 232.96$ & $8 \pm 2.15$ & $1.35 \pm 0.24$ & $64 \pm 34.75$ & $8 \pm 1.83$ & $1.67 \pm 0.26$ \\
JAN_13 & $219 \pm 213.95$ & $7 \pm 1.81$ & $1.17 \pm 0.36$ & $116 \pm 88.69$ & $7 \pm 2.51$ & $1.19 \pm 0.37$ \\
\hline
\end{tabular}

Tabela 07 - Sumário das ANOVAs para os descritores de comunidade: Abundância (N), Riqueza (S) e Diversidade (H'). * $P<0,05$; ** $P<0.01$; ' , significativo $e^{\text {ns }}$, não significativo.

\begin{tabular}{cccccccc}
\hline \multirow{2}{*}{ Fonte de variação } & \multirow{2}{*}{$d f$} & \multicolumn{2}{c}{$\mathrm{N}$} & \multicolumn{2}{c}{$\mathrm{S}$} & \multicolumn{2}{c}{$\mathrm{H}^{\prime}$} \\
\cline { 3 - 8 } & & $\mathrm{MS}$ & $\mathrm{F}$ & $\mathrm{MS}$ & $\mathrm{F}$ & $\mathrm{MS}$ & $\mathrm{F}$ \\
\hline Praia & 1 & 0.03 & 0.21 & 0.04 & 2.34 & 0.575 & $5.55^{*}$ \\
Mês & 12 & 2.34 & $18.51^{*}$ & 0.12 & $6.09 * *$ & 0.44 & $4.24^{* *}$ \\
Praia*Mês & 12 & 0.41 & $3.24 *$ & 0.05 & $2.62^{* *}$ & 0.396 & $3.82^{* *}$ \\
Residual & 338 & 0.13 & & 0.02 & & 0.10 & \\
Total & 364 & & & & & & \\
Kolmogorov-Smirnov & & \multicolumn{2}{c}{$0.047^{\mathrm{s}}$} & $0.123^{\text {ns }}$ & $0.045^{\text {s }}$ \\
Transformação & \multicolumn{2}{c}{ Sim } & \multicolumn{2}{c}{ Sim } & Não \\
\hline
\end{tabular}

De modo geral, os meses de verão e final de primavera apresentaram os maiores valores de todos os descritores em oposição aos meses de outono/inverno. As comparações a posteriori pelo teste de Tukey HSD comprovaram que, independente do descritor analisado, existem diferenças significativas entre fevereiro e dezembro e os meses de inverno (junho, julho e agosto) (Tabela 06).

Segundo os resultados do PERMANOVA houve uma diferença significativa entre as praias (Pseudo-F $=116,42 ; p<0,01$ ) e os meses (Pseudo- $\mathrm{F}=10,7 ; p<0,01$ ) para a comunidade de anfípodes, assim como na interação entre praia/mês (Pseudo- $F=6,45$; $p<0,01$ ) (Tabela 08). 
Tabe la 08- Sumário do PERMANOVA para as espécies de anfípodes encontrados nas praias da Fortaleza e Lamberto, Ubatuba, São Paulo. ** $P<0.01$.

\begin{tabular}{ccccc}
\hline \multirow{2}{*}{ Fonte de variação } & \multirow{2}{*}{$d f$} & \multicolumn{3}{c}{ AMPHIPODA } \\
\cline { 3 - 5 } & & MS & Pseudo-F & Unique Perms \\
\hline Praia & 1 & 137760 & $116.42^{* *}$ & 999 \\
Mês & 12 & 12661 & $10.7^{* *}$ & 998 \\
Praia*Mês & 12 & 7633.2 & $6.451^{* *}$ & 998 \\
Residual & 338 & 1183.3 & & \\
Total & 363 & & & \\
\hline
\end{tabular}

Com base na figura 11, observou-se que apesar das duas praias apresentarem um padrão similar na distribuição da abundância entre os meses, Fortaleza destacou-se pelo maior valor médio (For: $126 \pm 105$ indivíduos e Lam: $111 \pm 93$ indivíduos). As comparações par a par indicaram diferenças significativas entre os meses de verão/final de primavera e inverno em ambas as praias, em especial entre fevereiro e junho (For: $t=$ $3,03$; $p<0,001$ e Lam: $t=3,29 ; p<0,001)$. Nos meses de verão e final de primavera ocorre um incremento variável na complexidade do habitat, para cada fronde considerada, o que fica evidente pela grande variância observada na distribuição dos dados.
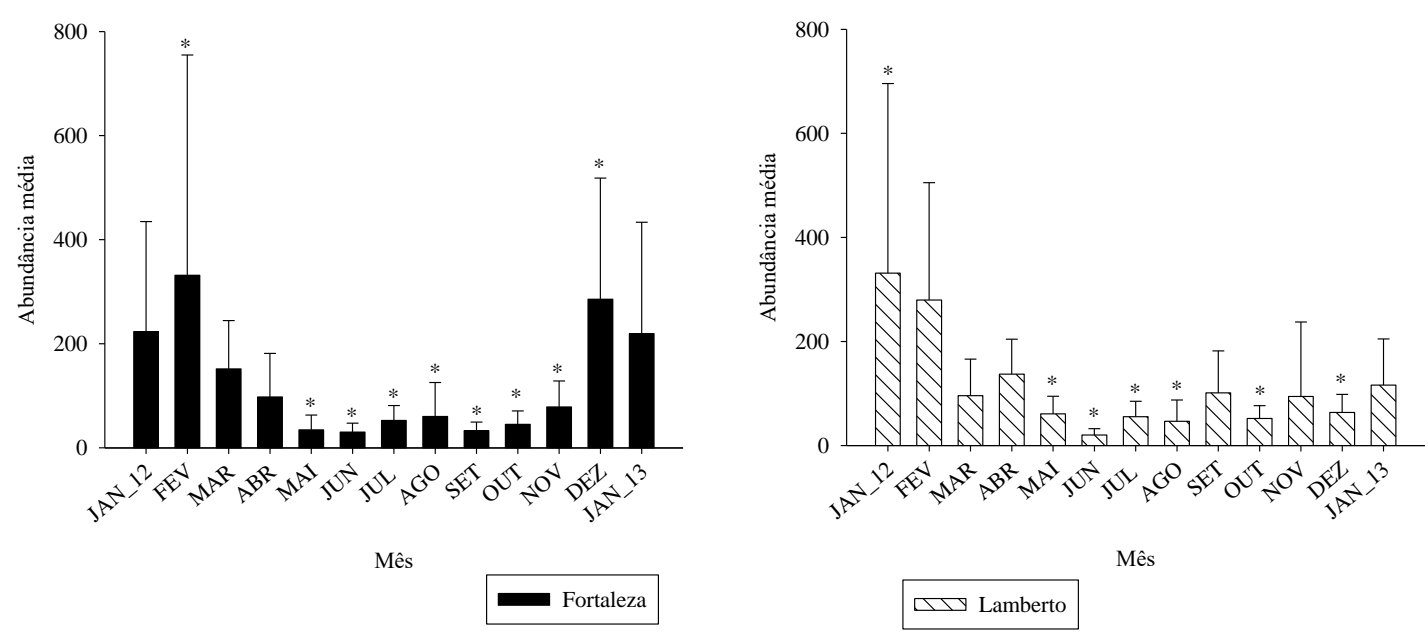

Figura 11 - Valores médios de abundância total de anfípodes nas praias da Fortaleza e Lamberto, Ubatuba, São Paulo. Barras com asterisco são significativamente diferentes, de acordo com o teste post-hoc Tukey HSD.

A correlação de Spearman apontou relação positiva e significativa entre os dados de abundância média e riqueza de espécies e os valores de PST, PSS, PSE e Da, para ambas as praias (Figura 12). Riqueza apresentou correlações positivas com os valores de PSE em ambas as praias e PSS apenas para a Praia da Fortaleza e ASM para a Praia do Lamberto (Figura 13). 
A

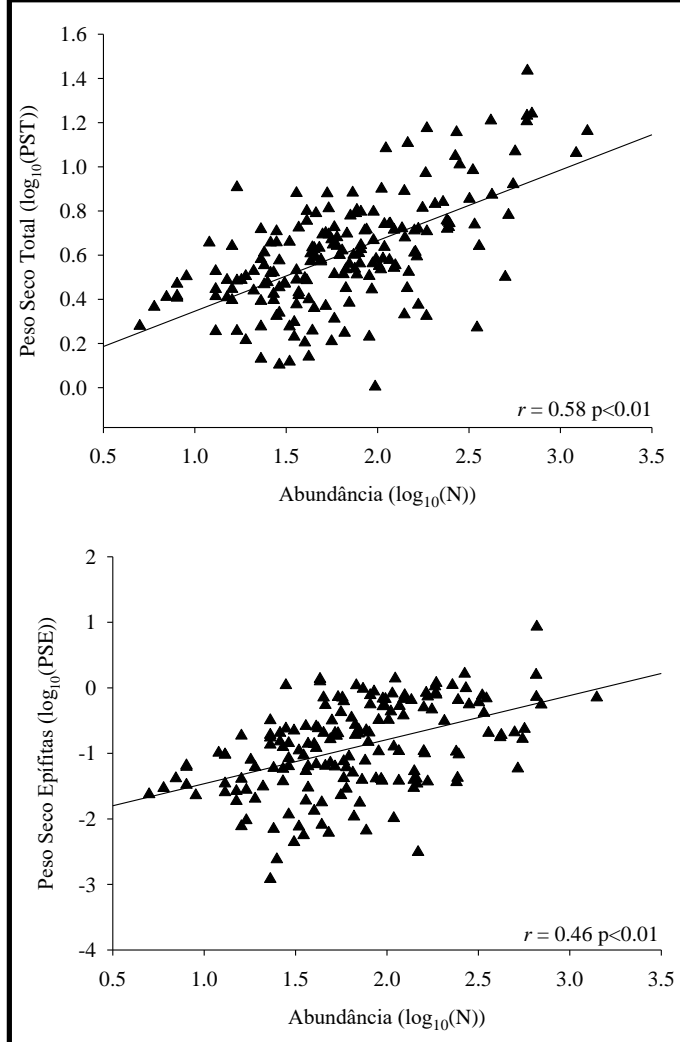

B
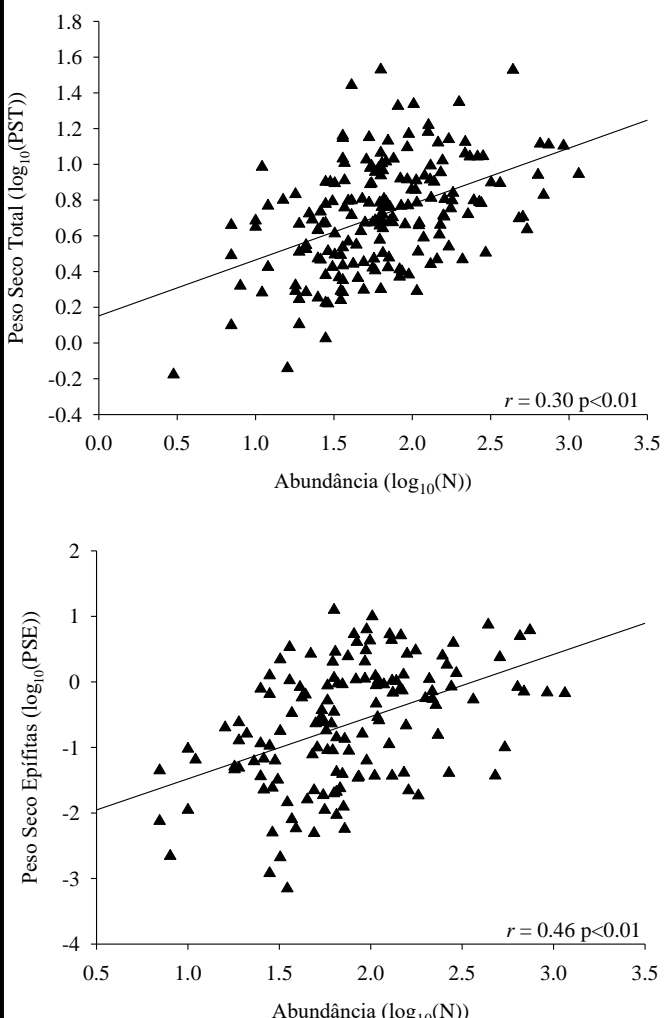
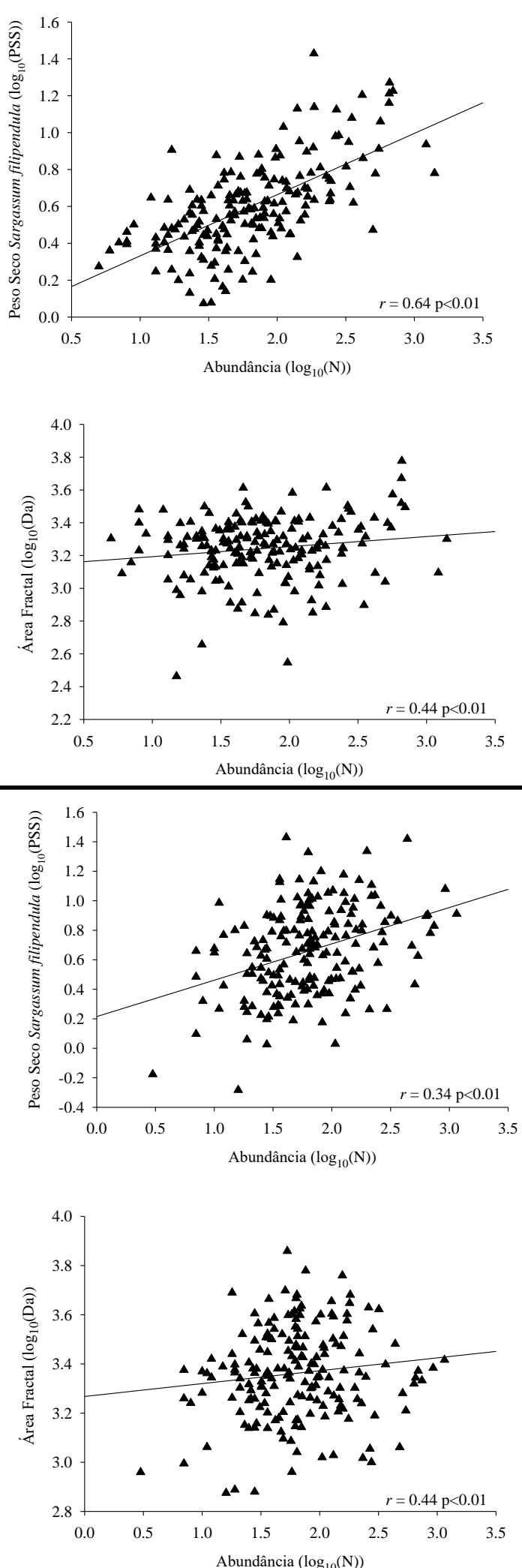

Figura 12 - Correlação de Spearman entre os valores de PST (g), PSS (g), PSE (g) e Da e a abundância média dos anfípodes (N) para cada período de coleta nas praias, Fortaleza (A) e Lamberto (B). Valores em logaritmo e gráficos com linha de regressão. 


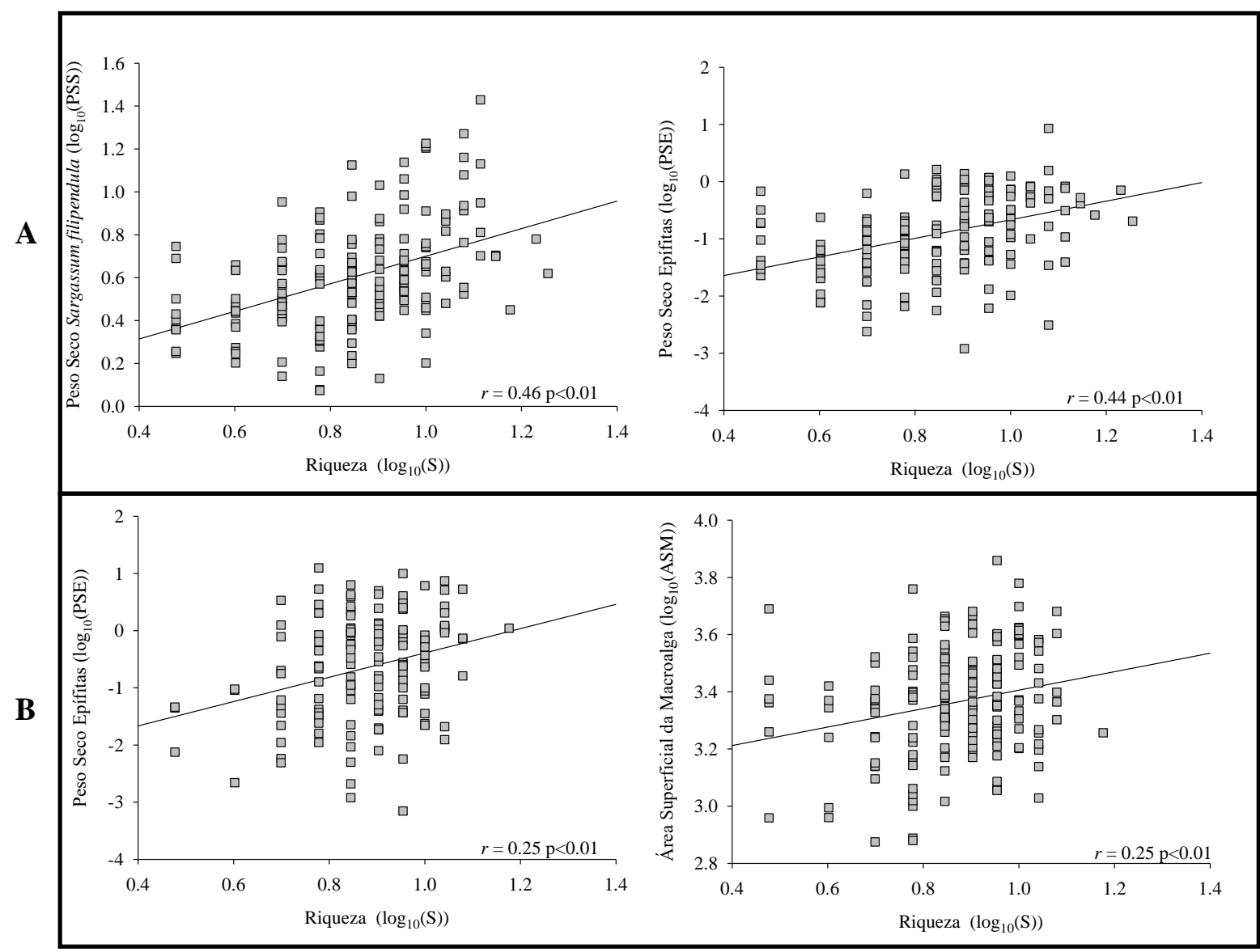

Figura 13 - Correlação de Spearman entre os valores de PSS (g), PSE $(\mathrm{g})$ e ASM $\left(\mathrm{cm}^{2}\right)$ e a riqueza de espécies dos anfípodes (S) para cada período de coleta nas praias, Fortaleza (A) e Lamberto (B). Valores em logaritmo e gráficos com linha de regressão.

O efeito potencial das medidas de complexidade (quantidade e morfológica do habitat) das frondes de Sargassum filipendula sobre a estrutura da comunidade de anfípodes foi testado pela DistLM e visualizado pela análise de redundância baseada em distância (dbRDA) (Tabela 09 e Figura 14). Foi visto que a proporção das variáveis na estrutura da comunidade de anfípodes entre as frondes de Sargassum filipendula estudadas e praias foi significativa, mas relativamente baixa e que os valores de PST, Dp e Da mostraram-se mais influentes na estruturação da comunidade dos anfípodes.

Tabela 09 - Resultados do teste de regressão múltipla (DistLM) sobre o efeito das medidas morfológicas das macroalgas na comunidade de anfípodes. $* * P<0.01$.

\begin{tabular}{cccc}
\hline VARIÁVEIS & Pseudo-F & Prob. & $\boldsymbol{R}^{2}$ cumul. \\
\hline PST & 17.24 & $0.045^{* *}$ & 0.045 \\
Dp & 5.80 & $0.015^{* *}$ & 0.060 \\
Da & 6.73 & $0.017^{* *}$ & 0.078 \\
PSE & 5.68 & $0.014^{* *}$ & 0.092 \\
ASM & 3.40 & $0.008^{* *}$ & 0.100 \\
PSS & 1.44 & 0.003 & 0.104 \\
\hline
\end{tabular}




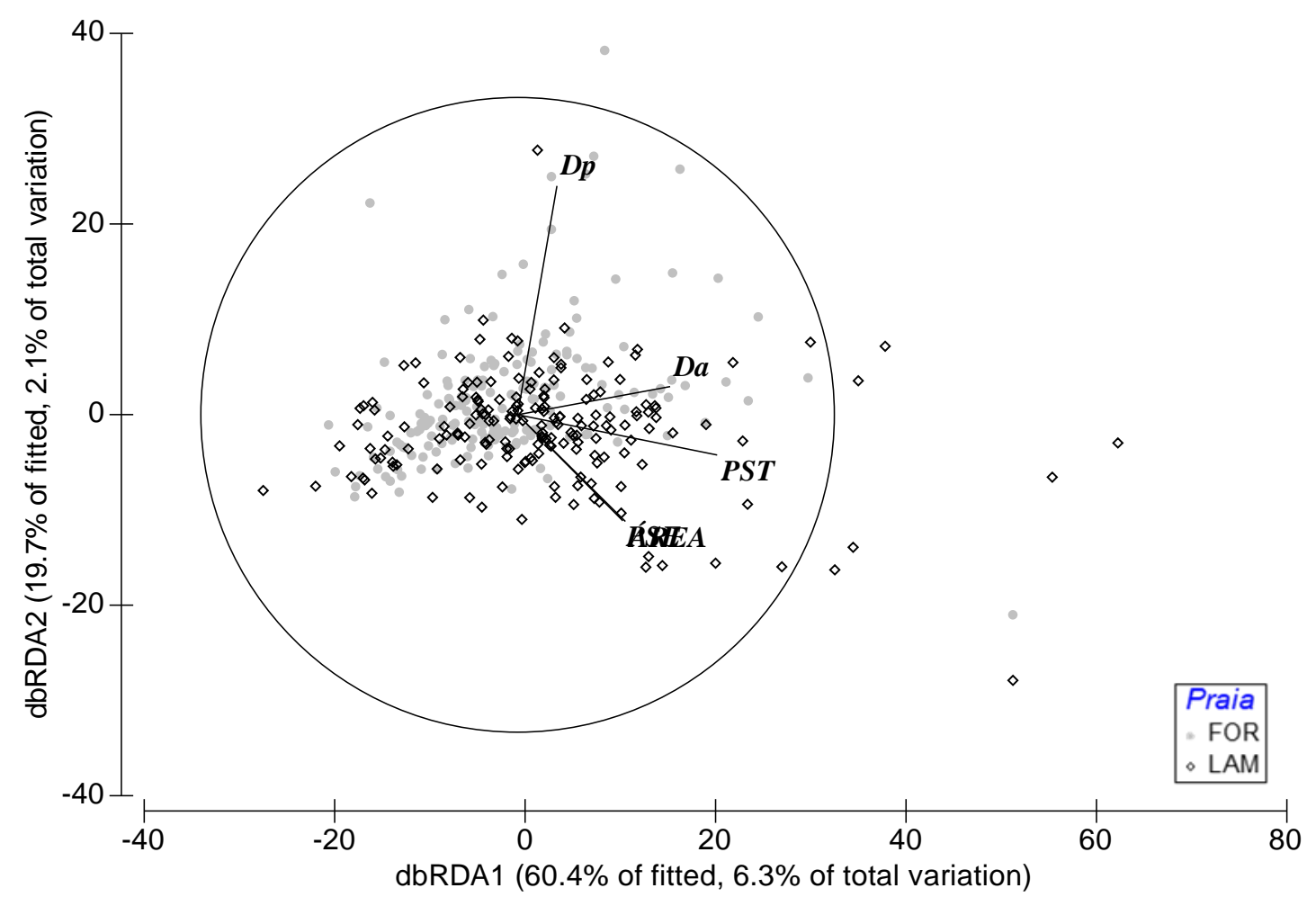

Figura 14- Resultados da análise de redundância à distância (dbRDA). Os símbolos representam abundância dos anfípodes nos meses amostrados nas praias da Fortaleza e do Lamberto. A distância entre os símbolos é baseada em uma matriz de similaridade de Bray-Curtis. Os vetores representam a direção e força das variáveis preditoras.

\subsection{Abundância dos anfípodes, classes de tamanho e as medidas de}

\section{complexidade}

A abundância dos anfípodes nas duas praias amostradas, foi também avaliada segundo o tamanho dos exemplares, classificados em três grupos: Classe I (>2,0 mm), Classe II $(1,9-1,0 \mathrm{~mm})$ e Classe III $(0,9-0,5 \mathrm{~mm})$. Dessa maneira, foi possível comparar a abundância, riqueza e diversidade das espécies de anfípodes de cada classe de tamanho com as medidas fractais, em todas as escalas. Na tabela 10, são apresentados os valores médios obtidos em cada classe de tamanho para os descritores abundância, riqueza e diversidade. 
Tabela 10 - Resultado os valores médios de Abundância (N), Riqueza (S) e Diversidade (H') para cada classe/mês nas praias da Fortaleza e Lamberto, Ubatuba, São Paulo.

\begin{tabular}{|c|c|c|c|c|c|c|c|c|c|}
\hline \multirow{3}{*}{ MÊS } & \multicolumn{9}{|c|}{ FORTALEZA } \\
\hline & \multicolumn{3}{|c|}{ Classe I } & \multicolumn{3}{|c|}{ Classe II } & \multicolumn{3}{|c|}{ Classe III } \\
\hline & $\mathbf{N}$ & $\mathbf{S}$ & $\mathbf{H}^{\prime}(\log \mathrm{e})$ & $\mathbf{N}$ & $\mathbf{S}$ & $\mathbf{H}^{\prime}(\log \mathrm{e})$ & $\mathbf{N}$ & $\mathbf{S}$ & $\mathbf{H}^{\prime}(\log \mathrm{e})$ \\
\hline JAN_12 & $8 \pm 9.3$ & $2 \pm 1.1$ & $0.48 \pm 0.4$ & $57 \pm 52.5$ & $4 \pm 1.5$ & $1.03 \pm 0.3$ & $155 \pm 156.7$ & $6 \pm 2.8$ & $1.26 \pm 0.4$ \\
\hline FEV & $15 \pm 13.2$ & $4 \pm 1.9$ & $0.96 \pm 0.4$ & $51 \pm 47$ & $6 \pm 2.4$ & $1.32 \pm 0.5$ & $266 \pm 381.3$ & $10 \pm 3.1$ & $1.49 \pm 0.5$ \\
\hline MAR & $3 \pm 3.2$ & $2 \pm 1.1$ & $0.50 \pm 0.4$ & $32 \pm 23.8$ & $4 \pm 1.2$ & $0.88 \pm 0.3$ & $116 \pm 74.1$ & $8 \pm 3$ & $1.30 \pm 0.4$ \\
\hline ABR & $8 \pm 8.8$ & $2 \pm 1.8$ & $0.65 \pm 0.5$ & $26 \pm 40.9$ & $5 \pm 2.6$ & $1.16 \pm 0.4$ & $64 \pm 40.5$ & $7 \pm 2.4$ & $1.33 \pm 0.4$ \\
\hline MAI & $3 \pm 3$ & $2 \pm 0.9$ & $0.43 \pm 0.4$ & $7 \pm 12.2$ & $2 \pm 1.0$ & $0.46 \pm 0.4$ & $25 \pm 18.8$ & $4 \pm 2$ & $0.93 \pm 0.4$ \\
\hline JUN & $3 \pm 2.2$ & $1 \pm 0.5$ & $0.19 \pm 0.3$ & $6 \pm 5.3$ & $2 \pm 1.1$ & $0.48 \pm 0.4$ & $21 \pm 12.4$ & $4 \pm 1.3$ & $1.09 \pm 0.4$ \\
\hline JUL & $3 \pm 2.9$ & $1 \pm 1.0$ & $0.28 \pm 0.4$ & $13 \pm 7.9$ & $4 \pm 1.7$ & $0.90 \pm 0.5$ & $36 \pm 21.5$ & $6 \pm 1.9$ & $1.24 \pm 0.3$ \\
\hline AGO & $4 \pm 4.7$ & $1 \pm 0.6$ & $0.13 \pm 0.2$ & $9 \pm 6$ & $4 \pm 1.3$ & $1.08 \pm 0.3$ & $47 \pm 57.3$ & $5 \pm 1.9$ & $1.18 \pm 0.2$ \\
\hline SET & $5 \pm 6$ & $2 \pm 1.3$ & $0.50 \pm 0.5$ & $9 \pm 7.8$ & $3 \pm 1.3$ & $0.82 \pm 0.4$ & $19 \pm 8.2$ & $6 \pm 3$ & $1.41 \pm 0.5$ \\
\hline OUT & $5 \pm 2.6$ & $2 \pm 1.2$ & $0.42 \pm 0.5$ & $9 \pm 3.1$ & $3 \pm 1.0$ & $0.99 \pm 0.4$ & $31 \pm 25.3$ & $5 \pm 2$ & $1.24 \pm 0.3$ \\
\hline NOV & $10 \pm 6.7$ & $3 \pm 1.2$ & $0.73 \pm 0.4$ & $13 \pm 9.9$ & $5 \pm 2.1$ & $1.22 \pm 0.5$ & $56 \pm 38.5$ & $8 \pm 2.7$ & $1.53 \pm 0.4$ \\
\hline DEZ & $88 \pm 111.4$ & $5 \pm 2.3$ & $0.92 \pm 0.5$ & $53 \pm 14.1$ & $6 \pm 1.6$ & $1.22 \pm 0.2$ & $143 \pm 100.2$ & $7 \pm 1.5$ & $1.35 \pm 0.3$ \\
\hline \multirow[t]{2}{*}{ JAN_13 } & $141 \pm 150.9$ & $4 \pm 1.5$ & $0.56 \pm 0.4$ & $47 \pm 43.3$ & $5 \pm 1.3$ & $1.28 \pm 0.3$ & $38 \pm 36.7$ & $6 \pm 2.3$ & $1.40 \pm 0.5$ \\
\hline & \multicolumn{9}{|c|}{ LAMBERTO } \\
\hline JAN_12 & $73 \pm 103.8$ & $3 \pm 1.4$ & $0.45 \pm 0.3$ & $105 \pm 109.6$ & $5 \pm 1.8$ & $0.93 \pm 0.3$ & $144 \pm 207$ & $6 \pm 2$ & $1.09 \pm 0.4$ \\
\hline FEV & $62 \pm 56.9$ & $3 \pm 1.4$ & $0.68 \pm 0.4$ & $77 \pm 63.8$ & $6 \pm 1.8$ & $1.13 \pm 0.3$ & $141 \pm 132$ & $7 \pm 2.3$ & $1.29 \pm 0.5$ \\
\hline MAR & $12 \pm 10.5$ & $2 \pm 1.2$ & $0.38 \pm 0.4$ & $23 \pm 15.9$ & $4 \pm 1.8$ & $1.11 \pm 0.4$ & $48 \pm 33.5$ & $6 \pm 1.7$ & $1.19 \pm 0.3$ \\
\hline ABR & $17 \pm 15.1$ & $3 \pm 1.6$ & $0.69 \pm 0.5$ & $36 \pm 21.2$ & $6 \pm 1.5$ & $1.28 \pm 0.2$ & $79 \pm 47.2$ & $8 \pm 1.5$ & $1.49 \pm 0.2$ \\
\hline MAI & $5 \pm 3.7$ & $2 \pm 1.1$ & $0.56 \pm 0.5$ & $14 \pm 9.8$ & $4 \pm 1.6$ & $1.21 \pm 0.4$ & $40 \pm 25.2$ & $7 \pm 2.2$ & $1.38 \pm 0.5$ \\
\hline JUN & $2 \pm 2.2$ & $1 \pm 1.0$ & $0.20 \pm 0.4$ & $4 \pm 4$ & $3 \pm 1.5$ & $0.76 \pm 0.5$ & $14 \pm 8.2$ & $5 \pm 1.5$ & $1.36 \pm 0.3$ \\
\hline JUL & $3 \pm 3.2$ & $2 \pm 1.2$ & $0.47 \pm 0.4$ & $14 \pm 10.7$ & $4 \pm 1.6$ & $1.00 \pm 0.4$ & $37 \pm 20.5$ & $6 \pm 2.2$ & $1.37 \pm 0.4$ \\
\hline AGO & $10 \pm 14.7$ & $2 \pm 1.7$ & $0.40 \pm 0.5$ & $15 \pm 17$ & $3 \pm 1.6$ & $0.41 \pm 0.3$ & $24 \pm 13.3$ & $6 \pm 1.8$ & $1.37 \pm 0.3$ \\
\hline SET & $14 \pm 12.3$ & $3 \pm 1.7$ & $0.79 \pm 0.6$ & $25 \pm 29$ & $4 \pm 1.5$ & $0.74 \pm 0.4$ & $63 \pm 56.3$ & $7 \pm 2.1$ & $1.27 \pm 0.4$ \\
\hline OUT & $8 \pm 4.6$ & $3 \pm 1.6$ & $1.02 \pm 0.5$ & $14 \pm 8.4$ & $4 \pm 1.8$ & $1.12 \pm 0.5$ & $30 \pm 15.5$ & $7 \pm 2.1$ & $1.50 \pm 0.4$ \\
\hline NOV & $9 \pm 4.3$ & $4 \pm 1.1$ & $1.12 \pm 0.4$ & $17 \pm 18.7$ & $5 \pm 2.2$ & $1.30 \pm 0.5$ & $68 \pm 123.7$ & $7 \pm 2$ & $1.52 \pm 0.4$ \\
\hline DEZ & $15 \pm 16.9$ & $4 \pm 1.2$ & $1.01 \pm 0.3$ & $19 \pm 10.8$ & $5 \pm 1.7$ & $1.21 \pm 0.5$ & $31 \pm 13.3$ & $7 \pm 1.7$ & $1.58 \pm 0.2$ \\
\hline JAN_13 & $49 \pm 45.9$ & $5 \pm 1.9$ & $0.94 \pm 0.3$ & $39 \pm 35$ & $5 \pm 1.6$ & $0.91 \pm 0.5$ & $29 \pm 23.9$ & $5 \pm 2.1$ & $1.06 \pm 0.2$ \\
\hline
\end{tabular}

Segundo as ANOVAs houve diferenças significativas entre as praias e os meses para os descritores de comunidade em cada classe de tamanho (Tabela 11). Diferenças significativas foram obtidas entre as praias para a Classe II (N) e Classe I (S). Todas as classes apresentaram diferenças significativas entre os meses, independente do descritor. Para a Classe I, apenas os valores médios de riqueza e diversidade não exibiram diferenças significativas na interação praia/mês. A significância na interação praia/mês foi observada em todas as classes de tamanho para os valores de abundância, e nas Classes II e III para os valores de riqueza e diversidade (Tabela 11). 
Tabela 11 - Sumário das ANOVAs para os valores dos descritores de comunidade Abundância (N), Riqueza (S) e Diversidade (H') obtidos para cada classe de tamanho. I: Classe I; II: Classe II e III: Classe III. * $P<0.05 \mathrm{e}^{* *} P<0.01$; ${ }^{\mathrm{s}}$, significativo $\mathrm{e}^{\text {ns }}$, não significativo.

\begin{tabular}{|c|c|c|c|c|c|c|c|}
\hline \multirow{2}{*}{ Fonte de variação } & \multirow{2}{*}{$d f$} & \multicolumn{2}{|c|}{$\mathbf{N}-\mathbf{I}$} & \multicolumn{2}{|c|}{$\mathbf{N}-\mathbf{I I}$} & \multicolumn{2}{|c|}{ N - III } \\
\hline & & MS & $\mathrm{F}$ & MS & $\mathrm{F}$ & MS & $\mathrm{F}$ \\
\hline Praia & 1 & 1.07 & 5.19 & 0.72 & $4.68 *$ & 0.372 & 2.36 \\
\hline Mês & 12 & 3.47 & $16.77 * *$ & 2.85 & $18.52 * *$ & 2.04 & $12.98 * *$ \\
\hline Praia*Mês & 12 & 0.75 & $3.60 * *$ & 0.36 & $2.36^{*}$ & 0.47 & $2.97 * *$ \\
\hline Residual & 338 & 0.21 & & 0.15 & & 0.16 & \\
\hline Total & 364 & & & & & & \\
\hline \multirow{2}{*}{\multicolumn{2}{|c|}{$\begin{array}{l}\text { Kolmogorov-Smirnov } \\
\text { Transformação }\end{array}$}} & \multicolumn{2}{|c|}{$0.077^{\mathrm{ns}}$} & \multicolumn{2}{|c|}{$0.042^{\mathrm{s}}$} & \multicolumn{2}{|c|}{$0.048^{\mathrm{s}}$} \\
\hline & & \multicolumn{2}{|c|}{ Sim } & \multicolumn{2}{|c|}{ Sim } & \multicolumn{2}{|c|}{ Sim } \\
\hline \multirow{2}{*}{ Fonte de variação } & \multirow{2}{*}{$d f$} & \multicolumn{2}{|c|}{ S- I } & \multicolumn{2}{|c|}{ S - II } & \multicolumn{2}{|c|}{ S - III } \\
\hline & & MS & $\mathrm{F}$ & MS & $\mathrm{F}$ & MS & $\mathrm{F}$ \\
\hline Praia & 1 & 0.45 & $8.57 * *$ & 0.16 & 4.25 & 0.02 & 0.59 \\
\hline Mês & 12 & 0.51 & $10.85^{* * *}$ & 0.42 & $10.90 * *$ & 0.16 & $5.86 * *$ \\
\hline Praia*Mês & 12 & 0.08 & 1.73 & 0.12 & $3.18 * *$ & 0.07 & $2.47 * *$ \\
\hline Residual & 338 & 0.05 & & 0.04 & & 0.03 & \\
\hline Total & 364 & & & & & & \\
\hline \multicolumn{2}{|l|}{ Kolmogorov-Smirnov } & \multicolumn{2}{|c|}{$0.171^{\mathrm{ns}}$} & \multicolumn{2}{|c|}{$0.163^{\text {ns }}$} & \multicolumn{2}{|c|}{$0.140^{\mathrm{ns}}$} \\
\hline Transformação & & \multicolumn{2}{|c|}{ Sim } & \multicolumn{2}{|c|}{ Sim } & \multicolumn{2}{|c|}{ Sim } \\
\hline \multirow{2}{*}{ Fonte de variação } & \multirow{2}{*}{$d f$} & \multicolumn{2}{|c|}{ H- I } & \multicolumn{2}{|c|}{ H- II } & \multicolumn{2}{|c|}{ H - III } \\
\hline & & MS & $\mathrm{F}$ & MS & $\mathrm{F}$ & MS & $\mathrm{F}$ \\
\hline Praia & 1 & 0.15 & 4.56 & 0.04 & 0.24 & 0.29 & 2.2 \\
\hline Mês & 12 & 0.10 & $2.95 * *$ & 1.18 & $7.32 * *$ & 0.34 & $2.50 * *$ \\
\hline Praia*Mês & 12 & 0.07 & 2.18 & 0.79 & $4.88^{* *}$ & 0.37 & $2.72 * *$ \\
\hline Residual & 338 & 0.03 & & 0.16 & & 0.13 & \\
\hline Total & 364 & & & & & & \\
\hline \multicolumn{2}{|l|}{ Kolmogorov-Smirnov } & \multicolumn{2}{|c|}{$0.097^{\mathrm{ns}}$} & \multicolumn{2}{|c|}{$0.048^{\mathrm{s}}$} & & \\
\hline Transformação & & & & & & & \\
\hline
\end{tabular}

A análise SIMPER feita para cada classe de tamanho indicou haver uma comunidade estruturada de forma diferente em cada praia, com valores crescentes dos descritores de acordo com o decréscimo das classes de tamanho (Tabelas 10 e 12). Na Classe I, em ambas as praias, apenas cinco espécies destacaram-se como principais: Sunamphitoe pelagica, Caprella scaura, Hyale niger, Ampithoe ramondi e Cymadusa filosa. A abundância aumenta e a composição das espécies muda na Classe II, em ambas as praias, em especial na Praia do Lamberto. Essa classe ainda pode ser considerada como de transição entre às Classes I e III, uma vez que contém espécies das outras duas classes (Tabela 12). A Classe III foi a que apresentou as maiores abundâncias de espécies de 
pequeno porte, como Apolochus neapolitanus, Photis longicaudata e Stenothoe valida e indivíduos jovens de Sunamphitoe pelagica, Caprella scaura e Cymadusa filosa.

ANOVAs comparativas entre os valores dos descritores foram empregados para identificar diferenças entre as praias, meses e classes de tamanho. Os resultados mostraram diferenças significativas entre os meses, classes e as interações praia/mês e mês/classe, para todos os descritores (Tabela 13). Ainda, foram observadas diferenças significativas entre as praias para os valores de riqueza e diferenças na interação praia/mês para os valores de abundância e diversidade. Apenas a diversidade exibiu diferença significativa na interação praia/mês/classe (Tabela 13). Segundo o teste a posteriori de Tukey HSD, no verão e final da primavera situam-se os maiores valores dos descritores em todas as classes, destacando-se fevereiro (em ambas as praias) e dezembro (apenas na Fortaleza). O contrário ocorreu no outono/inverno, especialmente maio (Fortaleza) e junho (ambas as praias) (Tabelas 10 e 13). Os resultados também mostraram que na Classe III situou-se o pico de todos os descritores, independente da praia, corroborando assim os resultados obtidos pela análise SIMPER. 
Tabela 12- Abundância e porcentagem de contribuição das principais espécies de anfípodes em cada classe de tamanho, nas praias da Fortaleza e do Lamberto, Ubatuba, São Paulo.

\begin{tabular}{|c|c|c|c|c|c|c|c|c|c|c|c|c|c|c|c|c|c|c|c|c|c|c|c|c|c|c|}
\hline \multirow{2}{*}{$\begin{array}{c}\text { Classe I } \\
\text { Espécies }\end{array}$} & \multicolumn{26}{|c|}{ PRAIA DA FORTALEZA } \\
\hline & \multicolumn{2}{|c|}{$\begin{array}{c}\text { JAN_12 } \\
\text { Avv_Abund Cont }\end{array}$} & \multicolumn{2}{|c|}{$\begin{array}{l}\text { FEV } \\
\text { bund C }\end{array}$} & \multicolumn{2}{|c|}{$\begin{array}{l}\text { MAR } \\
\text { bunc Con }\end{array}$} & \multicolumn{2}{|c|}{$\begin{array}{l}\mathrm{ABR} \\
\text { unic } \mathrm{Co}\end{array}$} & \multicolumn{2}{|c|}{$\begin{array}{c}\text { MAI } \\
\text { bunc Cor }\end{array}$} & \multicolumn{2}{|c|}{$\begin{array}{l}\text { JUN } \\
\text { unc Cont }\end{array}$} & \multicolumn{2}{|c|}{$\begin{array}{c}\text { JUL } \\
\text { Abunc Con }\end{array}$} & \multicolumn{2}{|c|}{$\begin{array}{c}\text { AGO } \\
\text { Abunc Cont }\end{array}$} & \multicolumn{2}{|c|}{$\begin{array}{c}\text { SET } \\
\text { Abunc Cor }\end{array}$} & \multicolumn{2}{|c|}{$\begin{array}{c}\text { OUT } \\
\text { Abunc Co }\end{array}$} & 1 & $\mathbf{V}$ & & EZ & JAI & -13 \\
\hline$\overline{\text { Sunamphitoe pelagica }}$ & 2.13 & 35.59 & 3.50 & 44.61 & 0.60 & 4.87 & 2.40 & 45.68 & 1.47 & 51.43 & 2.80 & 98.67 & 2.00 & 80.37 & 3.92 & 98.56 & 2.27 & 69.16 & 3.47 & 88.74 & 3.42 & 66.68 & 8.67 & 23.97 & 15.09 & 7.70 \\
\hline Caprella scaura & & & 2.64 & 3.04 & 0.13 & 0.00 & - & & & & 0.07 & 0.00 & 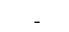 & - & - & - & & - & & & & - & 65.33 & 59.26 & 115.73 & 87.58 \\
\hline Ampithoe ramondi & 1.93 & 48.64 & 3.00 & 18.18 & 1.13 & 44.33 & 2.07 & 45.68 & 0.73 & 21.48 & 0.07 & 0.00 & 0.47 & 13.44 & 0.23 & 1.44 & 0.33 & 4.41 & 0.20 & 0.26 & 1.42 & 15.89 & 0.75 & 2.03 & 2.91 & 0.89 \\
\hline Hyale niger & 3.47 & 15.14 & 4.07 & 31.08 & 1.33 & 50.80 & 1.47 & 2.99 & 0.93 & 27.09 & 0.27 & 1.33 & 0.40 & 6.19 & 0.08 & 0.00 & 2.07 & 25.66 & 0.80 & 10.50 & 1.00 & 9.37 & 1.83 & 0.85 & 0.36 & 0.29 \\
\hline Classe II & & & & & & & & & & & & & & & & & & & & & & & & & & \\
\hline Sunamphitoe pelagica & 13.87 & 38.14 & 11.57 & 46.35 & 5.20 & 23.41 & 7.13 & 67.13 & 1.60 & 67.50 & 3.47 & 76.42 & 6.13 & 72.85 & 3.46 & 66.12 & 3.87 & 71.04 & 4.13 & 62.80 & 3.33 & 49.42 & 13.08 & 25.49 & 12.27 & 30.12 \\
\hline Hyale niger & 30.33 & 51.68 & 18.93 & 30.80 & 21.93 & 71.61 & 10.80 & 6.40 & 4.07 & 28.28 & 1.47 & 22.43 & 4.33 & 23.80 & 1.46 & 20.67 & 3.87 & 27.36 & 2.60 & 31.51 & 3.08 & 32.53 & 1.25 & 1.29 & 3.73 & 3.56 \\
\hline Caprella scaura & 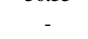 & - & 1.43 & 0.10 & 0.07 & 0.00 & 0.07 & 0.00 & - & & & - & 0.07 & 0.00 & 0.08 & 0.00 & & - & 0.13 & 0.00 & & - & 21.00 & 32.64 & 15.91 & 41.39 \\
\hline Aora spnicornis & & - & 1.93 & 0.72 & 0.13 & 0.00 & 1.20 & 3.77 & - & - & 0.07 & 0.00 & 0.20 & 0.19 & 0.38 & 0.99 & 0.07 & 0.00 & 0.07 & 0.00 & 0.08 & 0.00 & 12.25 & 30.74 & 7.55 & 15.63 \\
\hline Ampithoe ramondi & 3.27 & 4.48 & 5.79 & 9.95 & 1.20 & 2.32 & 1.80 & 18.86 & 0.47 & 1.46 & 0.07 & 0.00 & 0.33 & 0.93 & 0.31 & 2.25 & 0.13 & 0.37 & 0.13 & 0.21 & 0.25 & 0.75 & 0.92 & 2.08 & 2.27 & 1.37 \\
\hline Classe III & & & & & & & & & & & & & & & & & & & & & & & & & & \\
\hline Apolochus neapolitanus & 51.67 & 13.92 & 94.43 & 49.01 & 44.13 & 20.68 & 27.87 & 50.91 & 11.47 & 65.58 & 1.00 & 2.69 & 7.00 & 19.83 & 27.38 & 45.56 & 2.47 & 13.07 & 11.40 & 11.39 & 12.67 & 15.35 & 9.75 & 7.87 & 4.09 & 5.85 \\
\hline Sunamphitoe pelagica & 24.73 & 29.26 & 26.21 & 26.05 & 8.47 & 11.68 & 12.87 & 35.10 & 2.00 & 9.17 & 8.47 & 58.33 & 11.80 & 49.61 & 6.15 & 30.04 & 5.00 & 41.34 & 7.73 & 48.50 & 12.92 & 38.11 & 39.75 & 31.96 & 6.82 & 15.99 \\
\hline Apohyale media & 3.07 & 1.59 & 50.50 & 1.55 & 31.93 & 36.15 & 0.67 & 0.07 & 4.47 & 14.01 & 4.53 & 19.74 & 1.73 & 2.60 & 3.00 & 15.74 & 1.67 & 6.43 & 3.73 & 19.28 & 10.58 & 24.82 & 0.08 & 0.00 & - & - \\
\hline Hyale niger & 40.53 & 32.51 & 15.79 & 4.04 & 13.67 & 23.21 & 7.13 & 2.99 & 2.93 & 7.54 & 2.47 & 9.78 & 5.27 & 9.85 & 0.08 & 0.00 & 2.67 & 18.02 & 2.40 & 6.77 & 3.17 & 4.31 & 1.08 & 0.22 & 1.00 & 1.32 \\
\hline Stenothoe valida & 28.33 & 21.43 & 33.07 & 9.84 & 10.47 & 4.73 & 3.47 & 0.75 & 1.60 & 1.91 & 2.13 & 4.29 & 7.60 & 15.68 & 7.46 & 5.65 & 1.93 & 10.97 & 3.47 & 7.43 & 7.67 & 6.82 & 0.25 & 0.00 & 0.09 & 0.00 \\
\hline Aora spnicornis & 0.20 & 0.00 & 5.14 & 0.64 & 0.80 & 0.25 & 2.07 & 2.92 & & & 0.07 & 0.00 & 0.13 & 0.06 & 0.46 & 0.18 & 0.40 & 0.35 & 0.13 & 0.04 & 0.67 & 0.45 & 64.33 & 43.00 & 13.00 & 32.56 \\
\hline Cymadusa filosa & 0.13 & 0.03 & 6.43 & 1.87 & 0.20 & 0.05 & 0.67 & 0.30 & 0.13 & 0.11 & 0.33 & 0.29 & 0.07 & 0.00 & 0.08 & 0.00 & 1.20 & 0.00 & 0.13 & 0.00 & 1.92 & 4.06 & 5.00 & 4.42 & 6.45 & 19.47 \\
\hline Caprella scaura & & & 0.36 & 0.01 & 0.07 & 0.00 & & & 0.13 & 0.00 & 0.07 & 0.00 & 0.07 & 0.00 & & & & & & & 0.08 & 0.00 & 17.92 & 9.76 & 3.82 & 23.36 \\
\hline Classe I & & & & & & & & & & & & PRAI & ADO I & AMBE & RTO & & & & & & & & & & & \\
\hline Hyale niger & 2.47 & 1.31 & 16.93 & 17.44 & 0.13 & 0.00 & 3.27 & 9.42 & 2.31 & 73.53 & 0.40 & 18.40 & 1.07 & 51.73 & 6.64 & 91.24 & 9.73 & 74.00 & 1.07 & 29.09 & 1.00 & 5.39 & 2.92 & 7.48 & 31.91 & 49.66 \\
\hline Caprella scaura & 64.20 & 85.31 & 34.73 & 64.84 & 3.73 & 17. & 5.67 & 11.61 & 0.31 & 1.70 & 0.20 & 1.75 & 0.67 & 37.27 & 0.36 & 0.00 & 0.67 & 2.97 & & & 2.42 & 30.90 & 6.25 & 49.74 & 6.73 & 34.82 \\
\hline Cymadusa filosa & 5.20 & 11.47 & 9.33 & 17.62 & 7.33 & 82.47 & 6.60 & 75.90 & 0.77 & 13.64 & 0.53 & 11.41 & 0.93 & 10.35 & 0.71 & 3.7 & 1.40 & 10.14 & 2.13 & 37.59 & 2.17 & 26.99 & 2.25 & 18.78 & 6.00 & 9.18 \\
\hline Sunamphitoe pelagica & 0.67 & 1.90 & & & 0.20 & 0.31 & 0.87 & 2.44 & 1.38 & 11.13 & 0.47 & 68.45 & & & 0.64 & 3.73 & 1.00 & 9.14 & 1.33 & 20.35 & 2.42 & 36.05 & 2.83 & 22.48 & 3.27 & 5.96 \\
\hline Classe II & & & & & & & & & & & & & & & & & & & & & & & & & & \\
\hline Hyale niger & 47 & 22.32 & 29.47 & 24.30 & 3.93 & 15 & 16.00 & 39.2 & 6. & 58 & 1.40 & 28.79 & 6.07 & 44.60 & 13.07 & 98.28 & 19.73 & 85.05 & 5.00 & 41.76 & 2.83 & 7.88 & 6.42 & 26.96 & 30.00 & 69.73 \\
\hline Caprella & 57.07 & 50.01 & 29.40 & 46.14 & 5.13 & & 1.93 & 6.12 & 0. & 0. & 0.33 & 5.96 & 1.33 & 18.60 & & & 0.33 & 0.47 & 0.07 & 0. & 2.42 & 19.78 & 5.00 & 39.81 & 1.82 & 9.89 \\
\hline Cymadusa filosa & 14.47 & 23.67 & 7.93 & 21.18 & 8.27 & 42.41 & 10.07 & 34.67 & 2. & 9.3 & 0.47 & 23.16 & 1.07 & 13.15 & 0.21 & 0.20 & 0.53 & 1.71 & 2.13 & 21.94 & 2.42 & 22.97 & 1.75 & 5.29 & 4.00 & 12.69 \\
\hline Sunamphitoe pelagica & 1.80 & 3.05 & 0.73 & 0.33 & 0.47 & 3 & 4.33 & 11.70 & 1. & 17.28 & 0.93 & 30.92 & 0.80 & 6.16 & 0.36 & & 0.60 & 1.16 & 1.73 & 16.66 & 1.67 & 18.50 & 3.42 & 21.01 & 1.09 & 4.78 \\
\hline Bateac & 0.3 & 0.06 & 4.20 & 2. & 0.33 & 0.2 & 0.20 & 0.17 & 0.08 & 0.00 & 0.20 & 4.64 & 0.60 & 4.25 & 0.21 & 0.06 & 2.20 & 10.45 & 1.20 & 2.48 & 3.33 & 8.16 & 0.83 & 3.20 & 0.91 & 2.20 \\
\hline Ericthonius punctatus & 0.07 & 0.00 & 2.27 & 3.65 & 4.20 & 22.12 & 1.47 & 6.11 & 0.08 & 0.00 & 0.20 & 2.91 & 0.73 & 2.67 & 0.07 & 0.00 & & & 0.07 & 0.00 & 0.17 & 0.00 & 0.17 & 0.00 & 0.45 & 0.59 \\
\hline Shoemakerella cubensis & 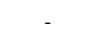 & - & - & - & - & - & 0.13 & 0.04 & 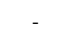 & - & 0.07 & 0.00 & 0.53 & 5.67 & 0.21 & 0.25 & 0.2 & 0.47 & 1.53 & 6.25 & 1.25 & 13.50 & 0.50 & 1.41 & 0.09 & 0.00 \\
\hline Aora spnicornis & & t & - & 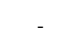 & - & . & - & & . & . & & 0.00 & 年 & - & 0.21 & 0.25 & 0.40 & 0.31 & 1.67 & 8.70 & 1.58 & 5.65 & 1.08 & 2.32 & 0.18 & 0.00 \\
\hline Photis longicaudata & 0.13 & 0.02 & 0.40 & 0.32 & 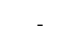 & & 0.13 & 0.04 & 1.69 & 11.41 & 0.13 & 0.00 & 0.60 & 3.29 & 0.07 & 0.00 & 0.07 & 0.00 & & & & & & & 0.18 & 0.12 \\
\hline Classe III & & & & & & & & & & & & & & & & & & & & & & & & & & \\
\hline Hyale niger & 86.73 & 28 & 25.87 & 12 & 3.47 & 3. & 12.33 & 11.72 & 2. & 8. & 1.27 & 13.08 & 4. & 15.83 & 7.14 & 44.32 & 18.20 & 32.04 & 2.27 & 5.7 & 0.83 & 1.63 & 3.25 & 15.35 & 10.36 & 41.90 \\
\hline Cymadusa fil & & 38. & 30.47 & 41 & 10 & 38 & & 25 & 2. & 6. & 1.8 & 6. & & 8. & 0. & 1. & 1.80 & 5. & 4.53 & & 7.33 & 34.34 & 3.08 & 13.71 & 5.82 & 23.95 \\
\hline Batea catharinensis & 3.73 & 3.25 & 49.87 & 19.46 & 0.53 & 0.4 & 1.07 & 0.58 & 0.23 & 0. & 1.27 & 10.92 & 10.67 & 28.12 & 1.0 & 1. & 23.33 & 27.82 & 7.67 & 19.79 & 42.00 & 17.90 & 6.58 & 25.63 & 8.45 & 25.61 \\
\hline Pho & 1.6 & 0. & 5.47 & 4.3 & 8. & 7.3. & 27.73 & 43.54 & 9. & 33.15 & 2 & 22.80 & 6.00 & 27.67 & 1. & & 1.33 & 3. & 0.93 & -1 & 1.00 & 1.45 & 0.25 & 0 & 1.36 & 4.90 \\
\hline Apohyale media & 1.6 & 0. & 7.8 & 2. & 0.1 & 0 & 4 & 1. & 13.00 & 31.73 & 0.93 & 5.7 & 3. & 7.40 & 7. & 35.66 & 13.87 & 24.38 & 2.13 & 6. & 3.92 & 7.23 & 0.58 & 0.14 & $x^{2}+2$ & m \\
\hline Sunamphitoe pelagi & 8.47 & 3.10 & 2.13 & 0.95 & 1.07 & 2.86 & 8.07 & 5.77 & 3.31 & 9.94 & 1.67 & 14.13 & 1.13 & 0.79 & 0.93 & 2.63 & 1.60 & 2.18 & 4.13 & 17.75 & 4.17 & 18.87 & 4.83 & 17.24 & 0.55 & 1.16 \\
\hline Ericthonius punct & 0.20 & 0.13 & 5.27 & 4.62 & 19.40 & 41.08 & $9.2-3 x-30$ & 10.11 & 0. & 0. & 1 & 22. & 0. & 3. & 0.29 & 0.45 & & & 0.2 & 0. & 0.08 & 0.00 & 0.92 & 1.19 & 1.09 & 1.05 \\
\hline Caprella scaura & 22.47 & 23.87 & 12.33 & 12.47 & 3.0 & 4.9 & 0 & 0. & 0.0 & 0. & 0 & 0. & 1 & 3. & 0.2. & 0.1 & 0. & 1. & 0.1 & 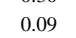 & 1.75 & 3.68 & 0.92 & 89 & 09 & 0.00 \\
\hline Apolochus neapolitanus & 0.13 & 0.00 & - & 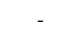 & 0.07 & 0.00 & 0.07 & 0.00 & 6.92 & 8.27 & 0.73 & 5.74 & 2.13 & 2.84 & 2.57 & 3.08 & 0.33 & 0.3 & 2.67 & 3.60 & 1.00 & 0.02 & 2.83 & 6.41 & 0.13 & 0.09 \\
\hline Aora spnicornis & & & & & & & 0.20 & 0.00 & & & & 0.00 & 0.07 & 0.00 & 0.07 & 0.00 & 0.47 & 0.74 & 3.73 & $\begin{array}{c}5.00 \\
16.23\end{array}$ & 3.58 & 8.42 & 2.67 & 5.67 & 0.09 & 0.00 \\
\hline
\end{tabular}


Tabela 13 - Sumário das ANOVAs para os descritores de comunidade: abundância $(\mathrm{N})$, riqueza (S) e diversidade $\left(\mathrm{H}^{\prime}\right)$ em relação as classes de tamanho. $* * P<0.01$; ${ }^{\mathrm{s}}$, significativo ${ }^{\mathrm{ns}}$, não significativo.

\begin{tabular}{|c|c|c|c|c|c|c|c|}
\hline \multirow{2}{*}{ Fonte de variação } & \multirow{2}{*}{$d f$} & \multicolumn{2}{|c|}{$\mathbf{N}$} & \multicolumn{2}{|c|}{$\mathbf{S}$} & \multicolumn{2}{|c|}{$\mathbf{H}^{\prime}$} \\
\hline & & MS & $\mathrm{F}$ & MS & $\mathrm{F}$ & MS & $\mathrm{F}$ \\
\hline Praia & 1 & 0.56 & 3.27 & 0.46 & $12.30 * *$ & 0.11 & 4.12 \\
\hline Mês & 12 & 6.59 & $38.35 * *$ & 0.85 & $22.68 * *$ & 0.2 & $7.28 * *$ \\
\hline Classe & 2 & 42.43 & $246.77 * *$ & 14.89 & $396.60 * *$ & 1.19 & $43.74 * *$ \\
\hline Praia*Mês & 12 & 1.03 & $6.00 * *$ & 0.16 & $4.31 * *$ & 0.09 & $3.37 * *$ \\
\hline Praia*Classe & 2 & 0.82 & $4.79 * *$ & 0.07 & 1.83 & 2.66 & $97.77^{* *}$ \\
\hline Mês*Classe & 24 & 0.89 & $5.17 * *$ & 0.13 & $3.35 * *$ & 0.06 & $2.31 * *$ \\
\hline Praia*Mês*Classe & 24 & 0.27 & 1.55 & 0.05 & 1.41 & 0.05 & $1.88^{* * *}$ \\
\hline Residual & 986 & 0.17 & & 0.04 & & 0.03 & \\
\hline Total & 1064 & & & & & & \\
\hline Kolmogorov-Smirnov & & \multicolumn{2}{|c|}{$0.030^{\mathrm{ns}}$} & $0.130^{\mathrm{ns}}$ & & \multicolumn{2}{|c|}{$0.110^{\mathrm{ns}}$} \\
\hline Transformação & & \multicolumn{2}{|c|}{ Sim } & Sim & & \multicolumn{2}{|c|}{ Sim } \\
\hline
\end{tabular}

Apesar das praias estudadas apresentarem composição similar de espécies, a Praia da Fortaleza exibiu maior diversidade e alta dominância, diferentemente do encontrado para a Praia do Lamberto. Esse padrão se repetiu em todas as classes de tamanho (Tabelas 10, 12 e 13). A abundância e diversidade destacadamente altas encontradas na Fortaleza ocorreram principalmente nos meses de verão e final de primavera, em oposição aos do outono/inverno.

Correlações de Spearman foram empregadas para demonstrar a relação entre as diferentes escalas analisadas no presente estudo e abundâncias e riquezas de cada classe de tamanho, ou seja, se com base no tamanho os organismos respondem as diferente escalas das medidas fractais (Figuras 15 a 18).

Na praia do Lamberto, os valores de abundância média para cada classe de tamanho foram correlacionados positivamente aos valores de área fractal (Da), independente da escala considerada. Entretanto, não houve correlação alguma com as escalas utilizadas para o perímetro fractal (Dp) (Figura 15). Na praia da Fortaleza, os dados de abundância média para todas as classes de tamanho foram positivamente correlacionados às escalas de Da-100 e Da-9 (Figura 16), enquanto que as abundâncias das Classes II e III foram com o Da-25. Para o perímetro fractal (Dp) ocorreram apenas correlações negativas, de forma que a abundância média da Classe III relacionou-se com Dp-100 e Dp-9 e a Classe II com Dp-9 (Figura 16). 
Quanto aos valores médios de riqueza, na praia da Fortaleza houve correlações positivas entre as três classes de tamanho e duas escalas de Da (Da-100 e Da-9) (Figura 17). As demais escalas das medidas fractais apresentaram correlação com uma ou duas classes: Da-25 e Classe I; Da-1 e Classes II e III; Dp-100 e Classes I e II e Dp-9 e Classes II e III (Figura 16). Na praia do Lamberto apenas quatro das escalas de medidas fractais apresentaram correlações positivas com os valores médios de riqueza (Figura 18), Da100, Da-9, Da-1 e Dp-1. Para essas variáveis a Classe II sempre exibiu uma correlação positiva. Além disso, houve correlações positivas entre a Classe I com de Da-100 e a Classe III com Da-9 (Figura 18).
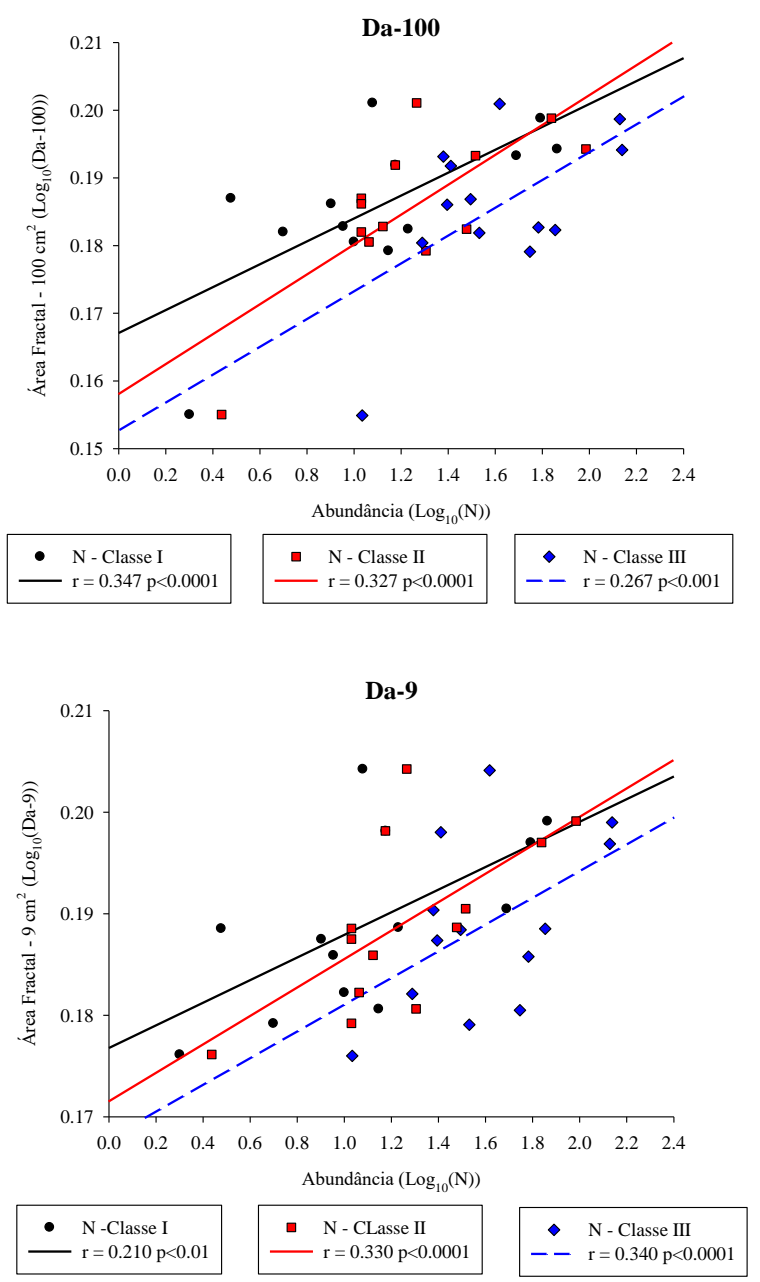
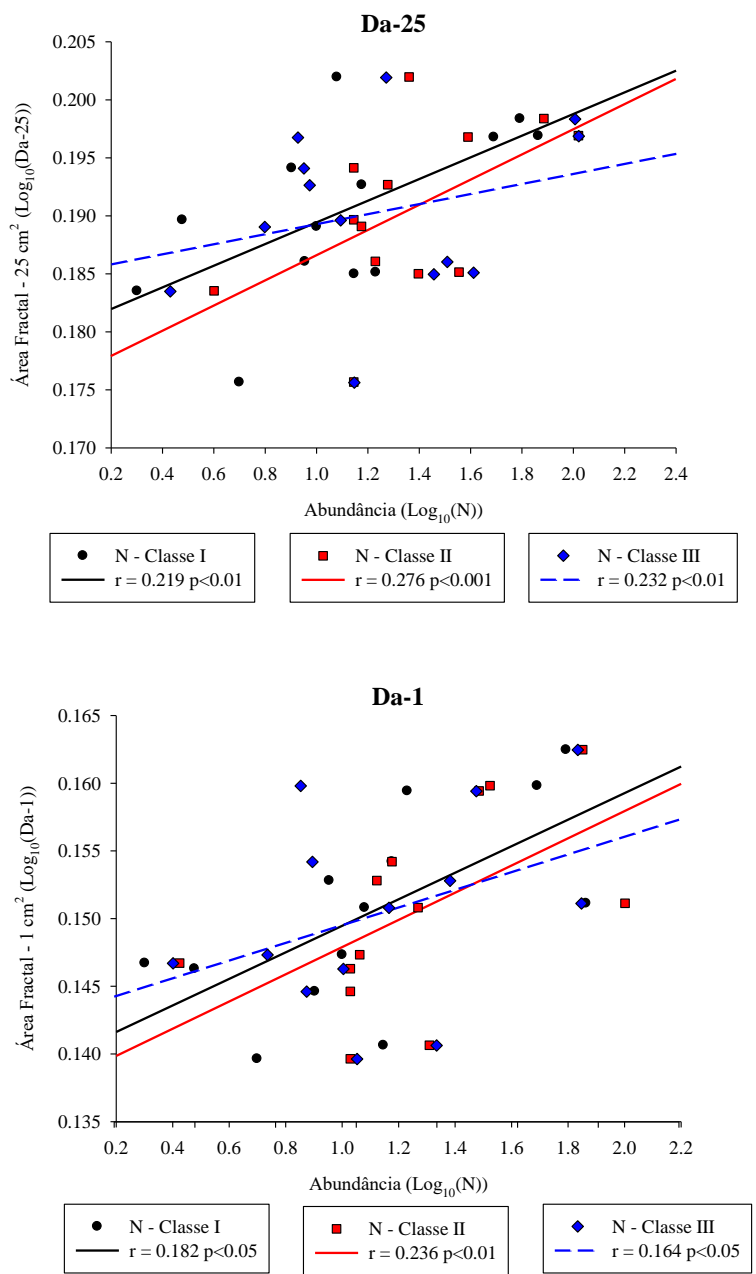

Figura 15 - Praia do Lamberto. Correlação de Spearman entre as diferentes escalas da Área Fractal(Da) e os valores de abundância média dos anfípodes em cada classe de tamanho e meses do ano. Valores em logaritmo e gráficos com linha de regressão.

Os resultados acima demonstram que em ambas as praias, os organismos presentes em cada classe de tamanho conseguem notar e perceber as mudanças na morfologia do $S$. filipendula em diferentes escalas. Tanto a abundância quanto a riqueza de espécies responderam positivamente ao acréscimo na complexidade morfológica apontada por Da, 
comprovando a eficiência dessa medida em qualquer escala utilizada. Além disso, a relação negativa apontada na maioria dos resultados para Dp, ou seja, a representação da tamanho e quantidade dos espaços entre os ramos, demonstra a influência dessa medida principalmente nas Classes II e III que são compostas principalmente por espécies de pequeno porte.
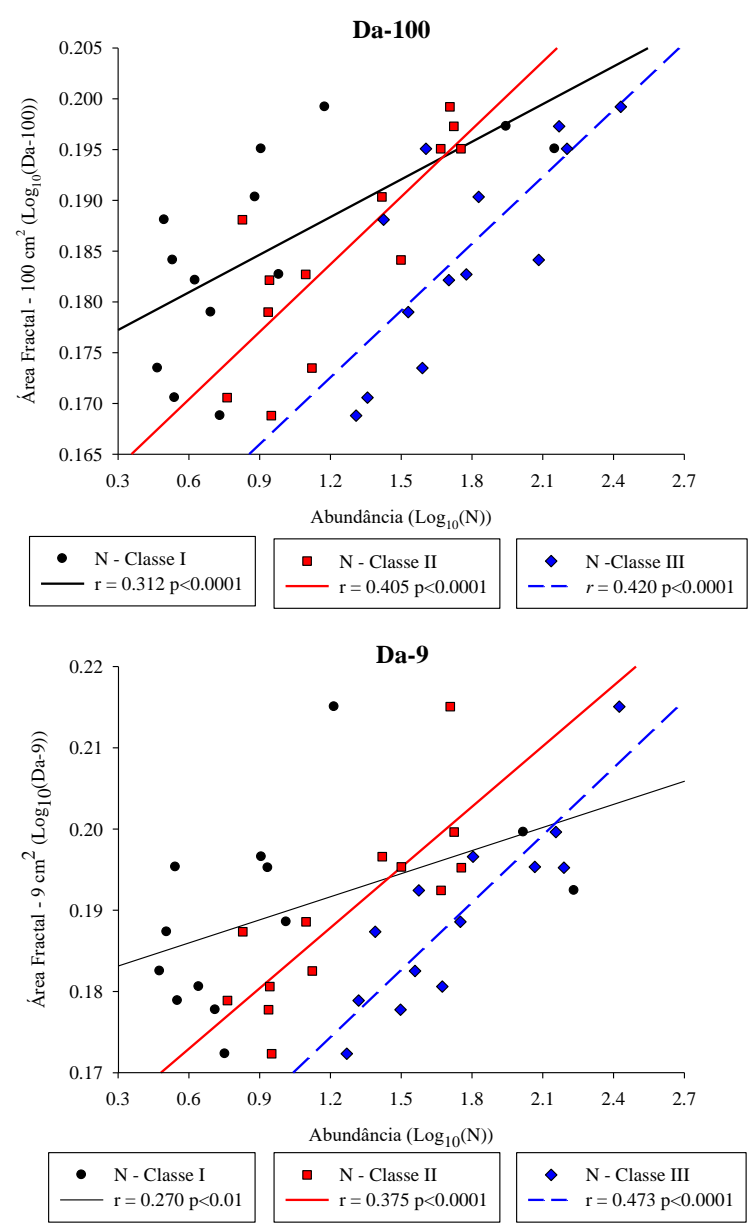

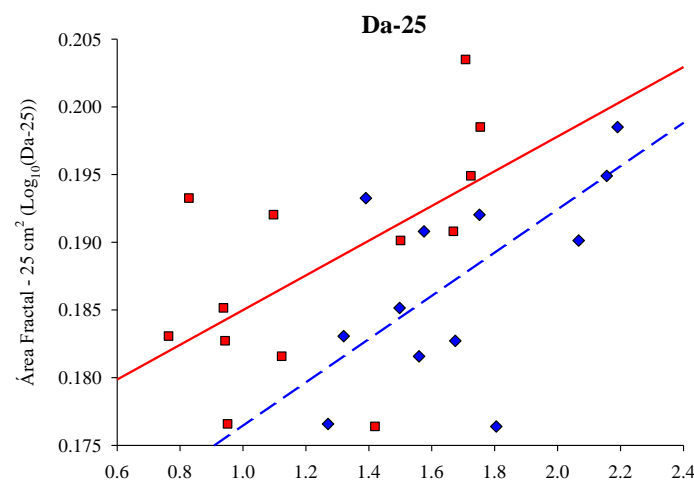

Abundância $\left(\log _{10}(\mathrm{~N})\right)$

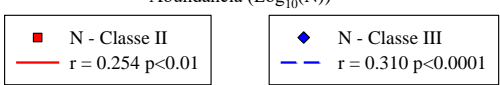

Dp-100

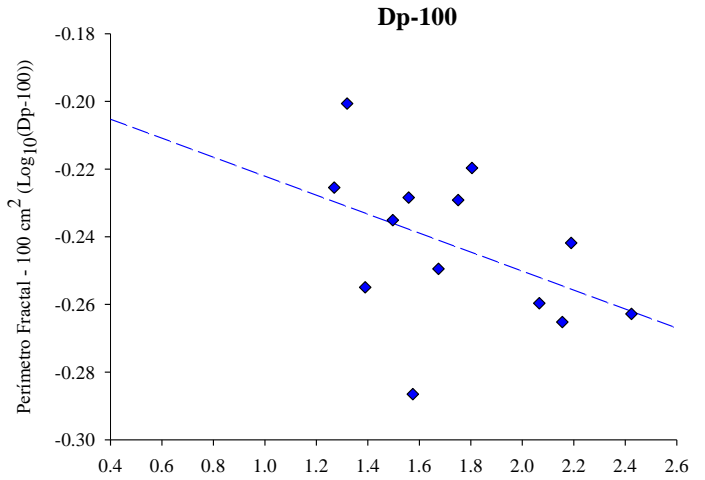

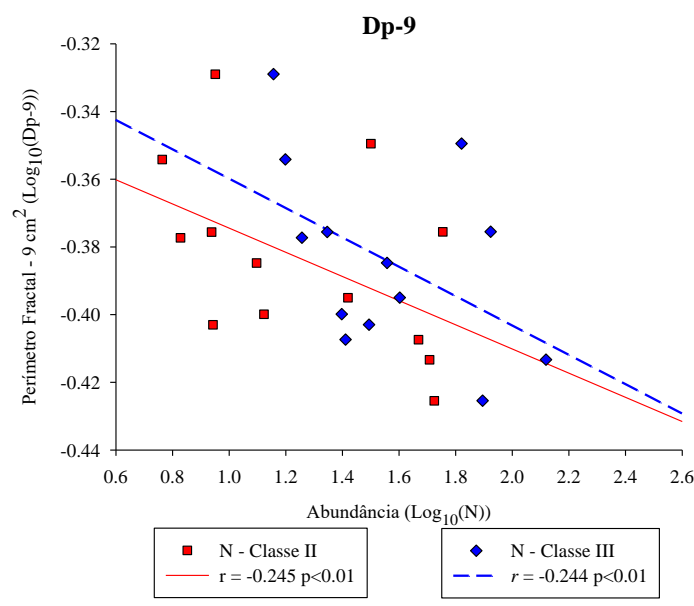

Figura 16 - Praia da Fortaleza. Correlação de Spearman entre as diferentes escalas das medidas fractais (Da e Dp) e os valores de abundância média dos anfípodes em cada classe de tamanho e meses do ano. Valores em logaritmo e gráficos com linha de regressão. 

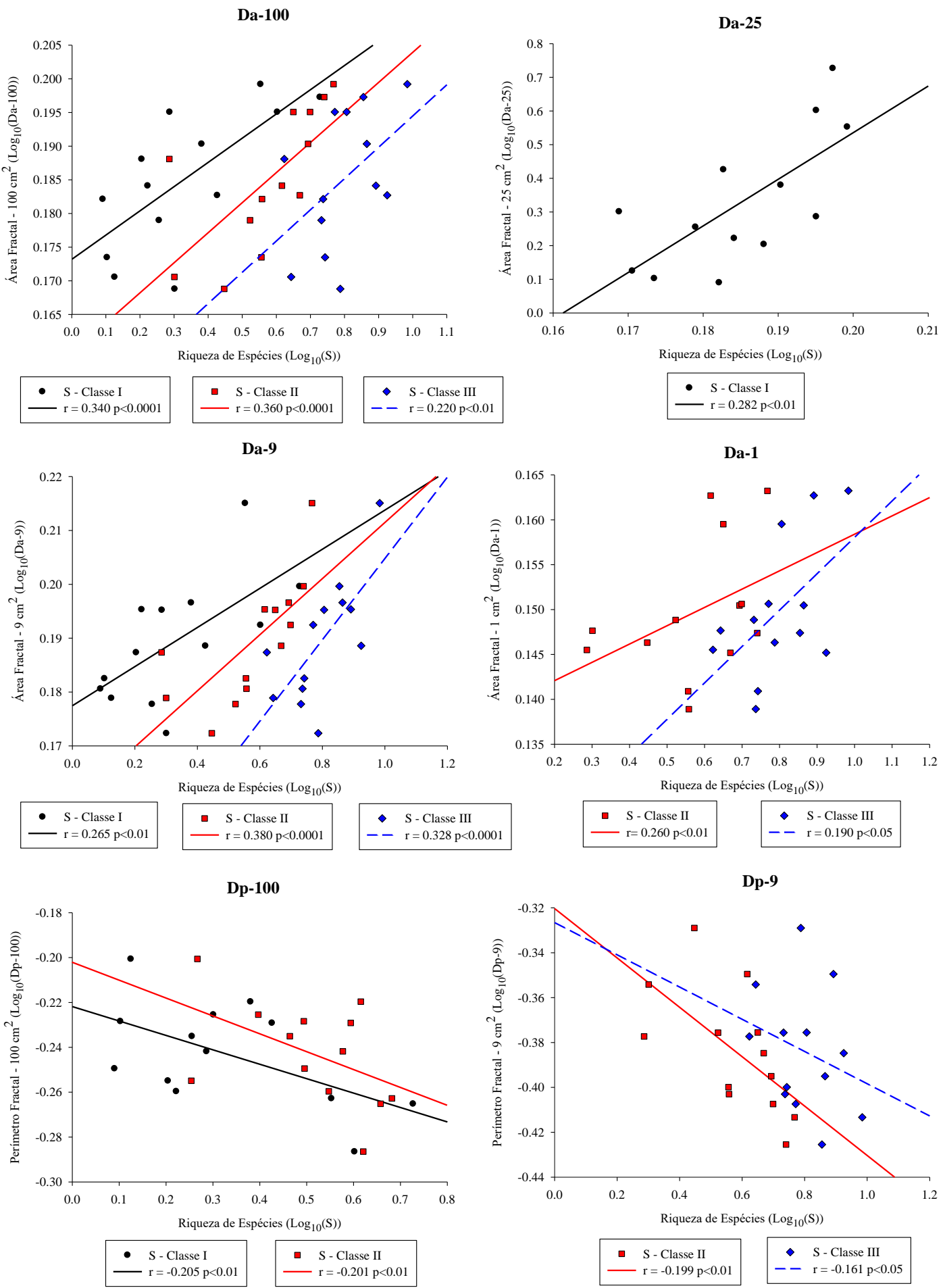

Figura 17 - Praia da Fortaleza. Correlação de Spearman entre as diferentes escalas das medidas fractais (Da e Dp) e os valores médios de riqueza dos anfípodes em cada classe de tamanho (Classes I, II e III) e meses do ano. Valores em logaritmo e gráficos com linha de regressão. 

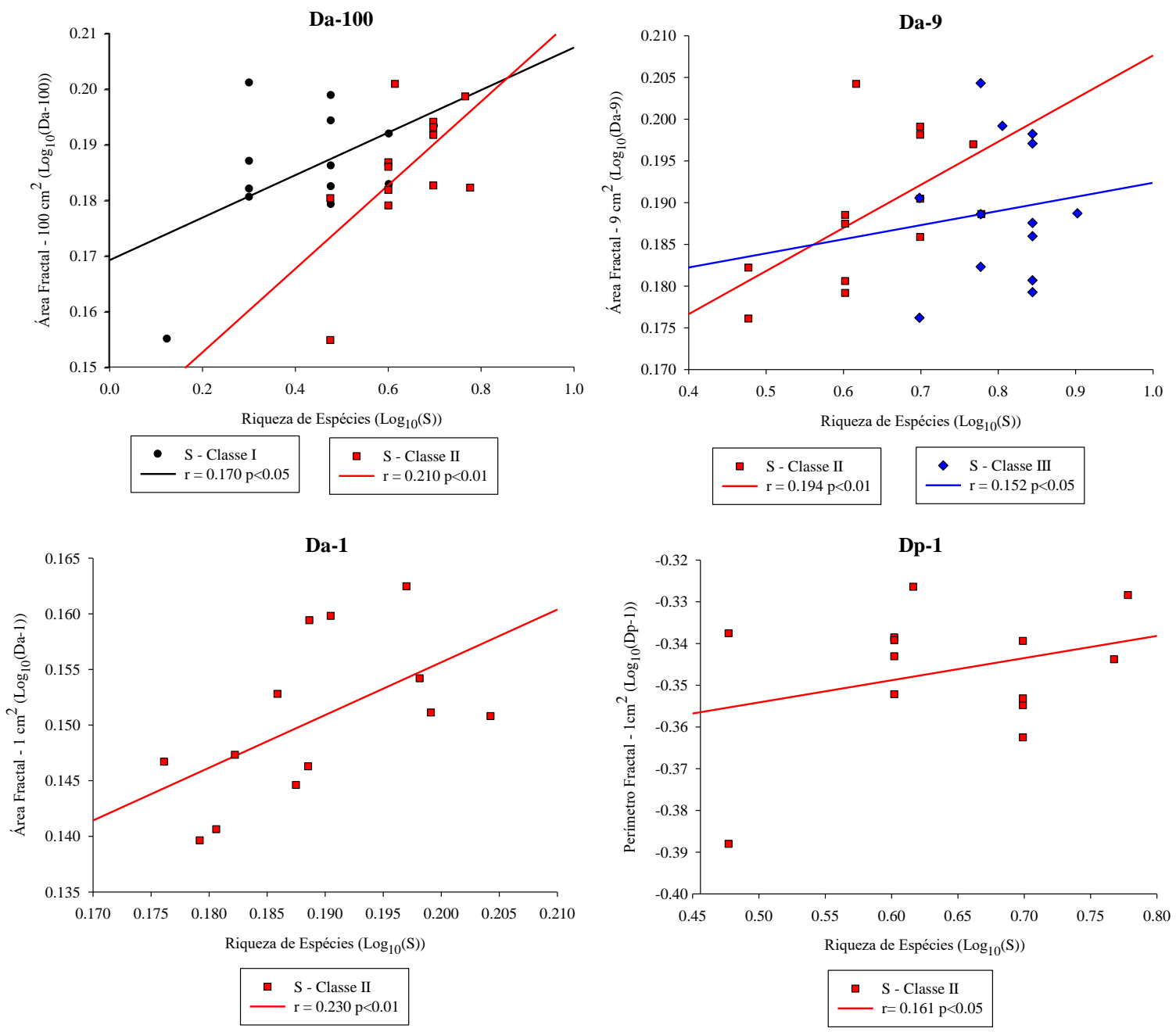

Figura 18 - Praia do Lamberto. Correlação de Spearman entre as diferentes escalas das medidas fractais (Da e Dp) e os valores médios de riqueza dos em cada classe de tamanho e meses do ano. Valores em logaritmo e gráficos com linha de regressão. 


\section{DISCUSSÃO}

O primeiro passo para explorar a relação entre a complexidade do Sargassum filipendula e a macrofauna total e os anfípodes associados foi obter medidas adequadas que incluem a quantidade de espaço disponível e como ele está estruturado. Afim de entender essa relação, aplicamos para o S. filipendula medidas de complexidade relativas à quantidade de habitat, Peso Seco Total (PST), Peso Seco do S. filipendula (PSS), Peso Seco das Epífitas (PSE) e Área Superficial da Macroalga (ASM), e medidas fractais relativas à morfologia do habitat, Área Fractal (Da) e Perímetro Fractal (Dp).

A primeira hipótese levantada, de que as frondes de Sargassum filipendula apresentariam diferenças significativas nas suas medidas de complexidade tanto em relação a sua localização (Fortaleza e Lamberto) quanto ao período (Mês), pode ser aceita, uma vez que isso foi demonstrado pelas variáveis relativas à quantidade e morfologia estrutural do ambiente disponível à ocupação dos animais. Somado a isso, observamos correlações positivas/negativas entre essas medidas, mostrando a existência de interação entre elas. Um outro fator importante evidenciado neste trabalho foi que as diferenças na complexidade da macroalga ocorrem mesmo quando se analisa exemplares diversos da mesma espécie e essas diferenças existem devido ao ciclo de desenvolvimento das plantas, ou seja, crescimento, reprodução, senescência e abscisão dos ramos laterais primários, processos que ocorrem durante todo o ano (PAULA \& OLIVEIRA-FILHO, 1980; PAULA, 1988; VELOSO \& SZÉCHY, 2008). Nossos resultados também indicam que os maiores valores das medidas de complexidade estiveram relacionados com início do verão e o final da primavera. Esses dados estão de acordo com Paula \& Oliveira-Filho (1980), realizado na Ponta da Fortaleza. Os autores relataram que os maiores valores de massa seca da Sargassum cymosum foram obtidos no final da primavera (dezembro) e menores no início do outono (abril). Outro fator que deve ser acrescentado é que o declínio da complexidade do S. filipendula observado após o verão, pôde ser reconhecido em campo, devido a diminuição do vigor das algas, ocasionado pela mudança de coloração ou pelo aumento no número de ramos férteis senescentes.

A maioria dos estudos realizados em bancos de Sargassum no Brasil considerou apenas o peso seco como medida de quantidade de habitat (LEITE \& TURRA, 2003; TANAKA \& LEITE, 2003; JACOBUCCI et al., 2009a, b; JACOBUCCI et al., 2011) não tratando do aspecto ligado à estrutura do substrato vegetal. As sete medidas aplicadas no 
presente estudo parecem não ser redundantes, podemos tomar como exemplo os meses com alto valor de PST/ASM que não apresentaram necessariamente valores elevados/baixos de Da ou Dp (GEE \& WARWICK, 1994b; ATTRILL et al., 2000; TANIGUCHI et al., 2003). Dessa forma, o esforço em empregar diversas metodologias para se mensurar a complexidade, ao invés de utilizar apenas um índice de quantidade, nos garantiu avaliar a real estrutura oferecida pelo S. filipendula, evitando assim em análises errôneas. Por esta razão, a complexidade da macroalga parece ser resultado de diferentes propriedades e, portanto, diferentes medidas morfológicas combinadas com aquelas de quantidade de habitat deveriam ser incluídas para caracterizá-lo e avaliá-lo adequadamente (GEE \& WARWICK, 1994b).

O segundo e o terceiro objetivos consistem em explorar diferenças entre os valores dos descritores de comunidade entre as praias e meses, e se essas diferenças estariam relacionadas às medidas de quantidade e morfologia do habitat. Estas hipóteses foram baseadas na teoria de que habitats mais complexos possuem maior número de nichos disponíveis aos organismos, e assim, o aumento da complexidade acarretaria em um aumento da abundância e diversidade dos organismos associados a macroalga (McABENDROTH et al., 2005; HAUSER et al., 2006; FERREIRO et al., 2011; 2013).

Primeiramente se analisarmos o conjunto da macrofauna como um todo observamos que a teoria de complexidade pode ser parcialmente comprovada, sendo que houve diferença significativa entre as praias e a praia com as frondes mais complexas, Lamberto, apresentou os maiores valores de abundância. Porém, os maiores valores de riqueza (número de táxons) foram observados na Praia da Fortaleza. Os resultados obtidos para a abundância de macrofauna estão de acordo com estudos anteriores realizados no hemisfério norte, com diversas espécies de macroalgas, e utilizando dimensão fractal (GEE \& WARWICK, 1994b; HAUSER et al., 2006).

Os dados da comunidade de anfípodes também responderam a terceira hipótese de modo parcial. Apesar da comprovada diferença de complexidade do S. filipendula entre as praias, os nossos resultados não apresentaram diferença significativa para a abundância e riqueza dos anfípodes entre as praias. Apesar disso, a variação sazonal sobre a complexidade estrutural do $S$. filipendula em cada praia foi o suficiente para influenciar os descritores, e assim, obtivemos diferenças significativas entre a abundância, riqueza e 
diversidade de espécies de anfípodes mensalmente em cada praia, com altas abundâncias no verão e final da primavera, e menores entre o outono e inverno.

Dessa maneira, ao analisarmos a influência das medidas de complexidade (quantidade e morfologia), observamos que os descritores (macrofauna e anfípodes) foram correlacionados positivamente com todas as medidas. Assim, podemos aceitar que existe uma influência das medidas de complexidade sobre a macrofauna total e também sobre os anfípodes, seja sazonalmente ou pelo tipo de praia. Os resultados das correlações foram confirmados por aqueles obtidos com outras análises, tais como PERMANOVA e técnicas univariadas, conferindo-lhes robustez. A questão que deve então ser observada é o nível de influência dessas medidas na estrutura da comunidade. Apesar das medidas morfológicas apresentarem uma influência sobre a comunidade (macrofauna ou anfípodes), foram as medidas quantitativas, especialmente PST, que melhor correlacionaram com abundância e riqueza, tanto para a macrofauna quanto para os anfípodes. A baixa porcentagem de variabilidade explicada pelas medidas fractais (Da e Dp) sugere que a morfologia da macroalga não é o principal fator determinante na estruturação da comunidade seja da macrofauna total como dos anfípodes, e que outros fatores biológicos/abióticos poderiam desempenhar um papel mais importante. De forma semelhante aos nossos resultados Attrill et al. (2000) mostraram que a abundância e diversidade de organismos foi afetada somente pela quantidade de habitat não pela morfologia das gramas marinhas, Zostera marina. Fortes correlações também foram reportadas entre a biomassa de Sargassum cymosum e abundância total de anfípodes em estudos anteriores realizados no Brasil, porém medidas fractais não foram empregadas (LEITE \& TURRA, 2003; LEITE et al., 2007; JACOBUCCI et al., 2009b).

No presente estudo, as espécies de anfípodes identificadas no S. filipendula estão de acordo com as espécies normalmente obtidas para as praias de Ubatuba (LEITE et al., 2007; JACOBUCCI et al., 2009b). Apesar da alta diversidade de guilda, os detritívoros foram os anfípodes dominantes durante todo o período estudado, seguido pelos herbívoros, sendo que a maioria dos grupos funcionais foi representada por espécies tubícolas, principalmente na Praia do Lamberto. As altas abundâncias dos anfípodes foram correlacionados positivamente com as medidas quantitativas (PST, PSS e PSE) e medida morfológica (Da), acredita-se que a presença de algas epífitas, aqui representado como PSE, entre o verão e final da primavera ocasionou em um incremento na 
complexidade do habitat oferecido pelo Sargassum, sendo o oposto observado para o outono/inverno. De acordo com alguns especialistas, a maioria das espécies de anfípodes não se alimentam diretamente das macroalgas hospedeiras e sim dos detritos acumulados em suas frondes, e com o aumento da complexidade estrutural do Sargassum, ocorreria um aumento nos detritos presentes nas frondes (GUERRA-GARCÍA et al., 2014). Além disso, devido ao baixo hidrodinamismo característico na Praia do Lamberto, podemos inferir que a dominância de espécies tubícolas nessa área se deve a um maior acúmulo de detritos nas frondes, principalmente no período de chuvas (verão).

Além da dominância de espécies detritívoras, destacamos também a dominância durante o ano inteiro em ambas as praias de espécies tubícolas herbívoras da família Ampithoidae, Sunamphitoe pelagica e Cymadusa filosa. A dominância dessas espécies já foi descrita por outros autores em bancos de Sargassum para a região de Ubatuba (JACOBUCCI \& LEITE, 2014; MACHADO et al., 2017). De acordo com esses autores, essas espécies tendem a se alimentar preferencialmente da alga hospedeira, Sargassum, ao invés das algas epífitas. Devido a sua dieta, a abundância dessas espécies está vinculada com o peso seco do Sargassum, fato observado no presente estudo, onde observamos altas abundâncias de $S$. pelagica e $C$. filosa no verão e final de primavera e baixas entre o outono e inverno. Outra espécie herbívora que destacamos é Hyale niger, presente nas duas praias, porém, esta espécie ao contrário das espécies de Ampithoidae, alimenta-se de algas epífitas (POORE, 1994), e por esta razão sua abundância estaria relacionada ao PSE, fato esse também observado no presente estudo.

A quarta hipótese focou em avaliar a relação entre tamanho corporal e abundância dos anfípodes, baseado na variação do espaço disponível em diferentes dimensões do substrato algal e estas dimensões foram estudadas em quatro escalas de medidas fractais. Previa-se que ocorreria um aumento na abundância de anfípodes pelo aumento nos valores de Da, e que espécies pequenas seriam mais abundantes em frondes que apresentassem valores baixos de Perímetro Fractal (Dp), uma vez que essa medida está relacionada ao número de espaços ou lacunas entre os ramos do S. filipendula, e o seu aumento indicaria grandes espaços entre os ramos.

Muitos estudos sugeriram que a diminuição do Dp levaria a um aumento na variedade de lacunas, tanto grandes quanto pequenas; porém ocorreria um maior número de espaços pequenos e estes seriam limitados ao uso por parte das espécies pequenas 
(McABENDROTH et al., 2005). Por esta razão, a diminuição do Dp acarretaria em um aumento na densidade de espécies de pequeno porte, que conseguiriam se movimentar e aproveitar os recursos presentes entre os pequenos espaços com maior facilidade do que as espécies maiores (JEFFRIES, 1993; THOMAZ et al., 2008; VEIGA et al., 2014). Nossos resultados mostraram, em ambas as praias, a existência de correlações positivas entre Da e a abundância/riqueza de anfípodes, independente da classe de tamanho analisada, comprovando assim a influência da área fractal (Da) sobre a comunidade de anfípodes. Além disso, foi observada correlação negativa entre o perímetro fractal (Dp) e abundância e riqueza de anfípodes, principalmente da Classe III, significando que o aumento no número de espaços intersticiais pequenos resultou no aumento da densidade e diversidade de espécies de pequeno porte, Apolochus neapolitanus e Photis longicaudata, além de espécies juvenis de Sunamphitoe pelagica e Cymadusa filosa. Contudo, esses últimos resultados só foram observados na Praia da Fortaleza e por esta razão nossa quarta hipótese foi parcialmente confirmada.

O uso de diferentes escalas no presente estudo foi de avaliar se os valores de dimensão se modificavam significativamente entre as escalas e de avaliar se os organismos (divididos em classes de tamanho) eram influenciados significativamente pelas diferentes escalas do habitat ofertado pelo Sargassum. Com base nos resultados, destacamos uma eficiência na utilização das escalas, primeiro porque elas foram diferentes entre si e dessa maneira podemos mensurar com segurança os habitats percebidos pelas espécies de anfípodes em diferentes classes de tamanho.

Poucos estudos avaliaram a morfologia de habitats naturais em diferentes escalas espaciais com a dimensão fractal (MORSE et al., 1985; GEE \&WARWICK, 1994b; McABENDROTH et al., 2005; DIBBLE et al., 2006; WARFE et al., 2008; DIBBLE \& THOMAZ, 2009), de acordo com esses autores, as escalas empregadas foram independentes entre elas e essas escalas conseguiram comprovar uma influência sobre a macrofauna. Apesar dos resultados obtidos por esses autores serem semelhantes aos obtidos no presente estudo, não é possível a comparação entre eles, devido ao uso de diferentes técnicas para obtenção das imagens, escalas aplicadas e cálculo da dimensão. A padronização das técnicas de determinação deste parâmetro torna-se, pois, necessária para o avanço do conhecimento sobre aplicação da dimensão fractal em estudos de ecologia marinha (FROST et al., 2005; KOSTYLEV et al., 2005). 
No presente estudo, ao analisar a comunidade da macrofauna total em grandes grupos e a comunidade dos anfípodes em nível de espécie, levantamos a questão sobre a suficiência taxonômica, ou seja, se níveis taxonômicos diferentes exibem os mesmos resultados diante a influência das medidas de complexidade do Sargassum. Uma das vantagens em se obter resultados similares entre níveis taxonômicos diferentes seria a redução de tempo e custo em programas de monitoramento ambiental pela utilização de organismos em filos, gêneros ou mesmo famílias (MUNIZ \& PIRES-VANIN, 2005). De acordo com os resultados, a macrofauna e os anfípodes apresentaram correlações significativas entre todas as variáveis medidas, porém essas respostas foram diferentes. No caso da macrofauna houve uma clara influência do habitat mais complexo, presente na Praia do Lamberto, na abundância dos organismos, e o mesmo não foi obtido para os anfipodes. Assim, notamos que houve uma perda de informação entre esses dois níveis taxonômicos, mais investigações devem ser feitas para se analisar se a resposta obtida para a macrofauna total se mantém quando analisamos os gêneros e famílias.

Em conclusão ao presente estudo frisamos a necessidade de se empregar a dimensão fractal como medida complementar às metodologias já utilizadas para uma análise da complexidade das macroalgas, uma vez que ela mensura a estrutura real do habitat proporcionado pela macroalga da forma ou nível em que é percebido pelos pequenos organismos. Faz-se necessário ainda analisar a influência dessa complexidade não só sobre a macrofauna total, mas também sobre grupos e espécies, para que se tenha consistência do papel dessas medidas na revelação de um habitat tridimensional. Além disso, lembramos que quantificar e identificar como os organismos interagem com o ambiente é o primeiro passo para se entender os padrões de ocupação do meio, onde os espaços em suas diversas dimensões desempenham importante papel. Dessa forma, fica patente a importância das medidas que revelam a complexidade estrutural serem realizadas em diferentes escalas. 
Anexo I - Listagem das espécies encontradas nas praias da Fortaleza e Lamberto, Ubatuba, São Paulo.

\begin{tabular}{|c|c|c|}
\hline Família & Espécies & Grupo Funcional \\
\hline \multirow[t]{2}{*}{ Amphilochidae } & Apolochus neapolitanus & Detritívoro / Carnívoro \\
\hline & Hourtonius wakabarae & Detritívoro / Carnívoro \\
\hline Atylidae & Nototropis minikoi & Detritívoro \\
\hline Bateidae & Batea catharinensis & Detritívoro \\
\hline Leucothoidae & Leucothoe spinicarpa & Detritívoro / Carnívoro \\
\hline Stenothoidae & Stenothoe valida & Detritívoro / Carnívoro \\
\hline \multirow[t]{2}{*}{ Lysianassidae } & Shoemakerella cubensis & Detritívoro / Carnívoro \\
\hline & Lysisanassa brasiliensis & Detritívoro / Carnívoro \\
\hline Oedicerotidae & Monoculodes sp. & Detritívoro \\
\hline \multirow[t]{6}{*}{ Caprellidae } & Caprella danilevskii & Detritívoro \\
\hline & Capprella dilatata & Detritívoro \\
\hline & Caprela equilibra & Detritívoro \\
\hline & Caprella penantis & Detritívoro \\
\hline & Caprella scaura & Detritívoro \\
\hline & Paracaprella pusilla & Detritívoro \\
\hline Podoceridae & Podocerus brasiliensis & Detritívoro \\
\hline \multirow[t]{2}{*}{ Aoridae } & Aora spinicornis & Detritívoro \\
\hline & Bemlos sp. & Detritívoro \\
\hline \multirow[t]{3}{*}{ Ampithoidae } & Ampithoe ramondi & Herbívoro / Detritívorc \\
\hline & Cymadusa filosa & Herbívoro / Detritívoro \\
\hline & Sunamphitoe pelagica & Herbívoro / Detritívorc \\
\hline Corophiidae & Laticorophium baconi & Detritívoro \\
\hline \multirow[t]{3}{*}{ Ischyroceridae } & Jassa falcata & Detritívoro \\
\hline & Jassa marmorata & Detritívoro \\
\hline & Ericthonius punctatus & Detritívoro \\
\hline \multirow[t]{2}{*}{ Photidae } & Gammaropsis thompsoni & Detritívoro \\
\hline & Photis longicaudata & Detritívoro \\
\hline \multirow[t]{3}{*}{ Maeridae } & Elasmopus brasiliensis & Herbívoro / Detritívoro \\
\hline & Elasmopus pectenicrus & Herbívoro / Detritívoro \\
\hline & Maera sp. & Herbívoro / Detritívorc \\
\hline Melitidae & Dulichiella anisochir & Herbívoro \\
\hline \multirow[t]{2}{*}{ Hyalidae } & Apohyale media & Herbívoro \\
\hline & Hyale niger & Herbívoro \\
\hline
\end{tabular}


Anexo II - Resultado completo da análise SIMPER e as espécies que contribuíram na abundância em cada malha para as praias da Fortaleza e Lamberto (respectivamente), Ubatuba, São Paulo.

\begin{tabular}{|c|c|c|c|c|c|c|c|c|c|c|c|c|c|c|c|c|c|c|c|c|c|c|c|c|c|c|}
\hline \multirow{2}{*}{ Espécies } & \multicolumn{2}{|c|}{ JAN_12 } & \multicolumn{2}{|c|}{ FEV } & \multicolumn{2}{|c|}{ MAR } & \multicolumn{2}{|c|}{ ABR } & \multicolumn{2}{|c|}{ MAI } & \multicolumn{2}{|c|}{ JUN } & \multicolumn{2}{|c|}{ JUL } & \multicolumn{2}{|c|}{ AGO } & \multicolumn{2}{|c|}{ SET } & \multicolumn{2}{|c|}{ OUT } & \multicolumn{2}{|c|}{ NOV } & \multicolumn{2}{|c|}{ DEZ } & \multicolumn{2}{|c|}{ JAN_13 } \\
\hline & Ab. & Cont $\%$ & Ab. & Cont $\%$ & Ab. & Cont $\%$ & Ab. & Cont $\%$ & Ab. & Cont $\%$ & Ab. & Cont $\%$ & Ab. & Cont \% & Ab. & Cont $\%$ & Ab. & Cont $\%$ & Ab. & Cont $\%$ & Ab. & Cont $\%$ & Ab. & Cont $\%$ & Ab. & Cont $\%$ \\
\hline Sunamphitoe pelagica & 5.91 & 28.60 & 6.01 & 23.65 & 3.62 & 18.48 & 4.62 & 31.28 & 2.06 & 29.37 & 3.50 & 55.96 & 4.26 & 42.02 & 3.45 & 33.82 & 3.14 & 42.33 & 3.81 & 41.37 & 4.24 & 29.93 & 6.93 & 23.93 & 4.92 & 19.15 \\
\hline Hyale niger & 7.49 & 31.89 & 5.00 & 14.01 & 5.79 & 29.02 & 2.72 & 5.96 & 2.04 & 19.90 & 1.55 & 14.85 & 2.66 & 16.91 & 0.97 & 6.79 & 2.28 & 19.20 & 2.15 & 19.27 & 2.29 & 11.53 & 1.52 & 3.34 & 1.62 & 4.43 \\
\hline Amphilocus neapolitanus & 4.96 & 10.37 & 8.06 & 25.60 & 4.91 & 10.83 & 4.90 & 29.09 & 2.80 & 26.56 & 0.54 & 2.79 & 2.16 & 13.57 & 4.34 & 29.38 & 1.15 & 8.46 & 2.22 & 7.00 & 2.87 & 12.59 & 2.82 & 8.55 & 1.81 & 4.64 \\
\hline Apohyale media & 1.29 & 2.48 & 3.02 & 2.94 & 5.19 & 24.75 & 0.49 & 0.44 & 1.60 & 10.90 & 1.64 & 16.93 & 0.86 & 2.76 & 1.51 & 12.76 & 0.88 & 4.90 & 1.68 & 14.50 & 3.36 & 18.84 & 0.08 & 0.00 & - & \\
\hline Stenothoe valida & 4.88 & 17.12 & 4.40 & 10.81 & 2.43 & 5.16 & 1.06 & 1.59 & 0.68 & 2.37 & 0.80 & 2.66 & 2.31 & 15.42 & 1.92 & 7.51 & 1.11 & 8.96 & 1.53 & 8.34 & 2.07 & 6.14 & 0.14 & 0.00 & 0.09 & 0.00 \\
\hline Ampithoe ramondi & 1.86 & 5.61 & 3.56 & 7.87 & 1.55 & 3.90 & 2.24 & 14.77 & 1.11 & 9.85 & 0.23 & 0.63 & 0.70 & 2.98 & 0.65 & 3.25 & 0.75 & 6.16 & 0.46 & 1.46 & 1.37 & 6.02 & 1.76 & 6.00 & 1.76 & 3.74 \\
\hline Caprella scaura & - & & 1.00 & 0.47 & 0.23 & 0.12 & 0.07 & 0.00 & 0.09 & 0.00 & 0.13 & 0.22 & 0.13 & 0.20 & 0.08 & 0.00 & - & & 0.09 & 0.00 & 0.08 & 0.00 & 8.38 & 22.06 & 9.86 & 40.79 \\
\hline Aora spinicornis & 0.12 & 0.00 & 1.44 & 1.88 & 0.52 & 0.56 & 1.42 & 6.12 & - & - & 0.09 & 0.00 & 0.29 & 0.60 & 0.54 & 1.20 & 0.30 & 0.43 & 0.20 & 0.24 & - & - & 8.28 & 24.83 & 4.16 & 13.55 \\
\hline Cymadusa filosa & 0.49 & 1.01 & 2.47 & 4.83 & 0.36 & 0.28 & 0.73 & 2.18 & 0.20 & 0.61 & 0.34 & 0.78 & 0.07 & 0.00 & 0.08 & 0.00 & 0.38 & 0.13 & 0.16 & 0.08 & 1.44 & 7.17 & 2.92 & 8.55 & 3.41 & 13.33 \\
\hline Paracaprella pusilla & 0.50 & 0.65 & 0.37 & 0.27 & 0.55 & 0.59 & 0.23 & 0.00 & 0.20 & 0.09 & 0.44 & 2.25 & 0.68 & 3.15 & 0.67 & 2.66 & $0 . \overline{78}$ & 5.22 & 0.95 & 5.10 & 1.20 & 2.91 & & & & \\
\hline Elasmopus pectenicrus & 0.20 & 0.11 & 0.47 & 0.29 & 0.46 & 1.00 & 1.10 & 3.03 & 0.18 & 0.14 & 0.16 & 0.15 & 0.23 & 0.30 & 0.34 & 0.97 & 0.20 & 0.40 & 0.23 & 0.38 & 0.56 & 1.75 & 0.94 & 1.92 & 0.31 & 0.31 \\
\hline Batea catharinensis & 0.98 & 0.51 & 2.23 & 2.79 & - & - & 0.71 & 1.49 & 0.07 & 0.00 & 0.44 & 2.17 & 0.59 & 1.35 & 0.26 & 0.15 & 0.07 & 0.00 & - & - & 0.41 & 0.26 & 0.49 & 0.39 & 0.18 & 0.06 \\
\hline Laticorophium baconi & 0.81 & 1.45 & 1.32 & 2.37 & 1.04 & 2.75 & 0.34 & 0.37 & 0.07 & 0.00 & & . & 0.07 & 0.00 & 0.15 & 0.09 & 0.27 & 0.71 & 0.20 & 0.32 & 0.25 & 0.32 & - & - & - & \\
\hline Shoemakerella cubensis & 0.19 & 0.06 & 0.75 & 1.58 & 0.23 & 0.12 & 0.67 & 2.61 & - & - & 0.07 & 0.00 & 0.13 & 0.09 & 0.15 & 0.13 & 0.16 & 0.11 & 0.43 & 1.62 & 0.52 & 1.45 & 0.57 & 0.37 & 0.09 & 0.00 \\
\hline Ericthonius punctatus & 0.07 & 0.00 & 0.51 & 0.14 & 0.94 & 2.07 & 0.92 & 0.78 & 0.13 & 0.21 & - & - & 0.07 & 0.00 & & - & - & 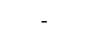 & - & - & - & & 0.08 & 0.00 & - & - \\
\hline Caprella danilevskii & - & - & - & - & - & - & - & - & - & - & - & - & 0.07 & 0.00 & 0.45 & 1.30 & 0.48 & 1.48 & 0.23 & 0.24 & 0.42 & 0.31 & 0.17 & 0.05 & - & - \\
\hline Leucothoe spinicarpa & 0.07 & 0.00 & 0.20 & 0.07 & 0.07 & 0.00 & 0.28 & 0.20 & - & - & - & - & 0.35 & 0.38 & 0.08 & 0.00 & 0.27 & 0.40 & 0.13 & 0.09 & 0.26 & 0.10 & - & - & - & - \\
\hline Caprella equilibra & 0.07 & 0.00 & 0.27 & 0.14 & 0.27 & 0.27 & 0.07 & 0.00 & - & 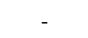 & 0.13 & 0.15 & 0.16 & 0.09 & 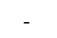 & - & 0.12 & 0.00 & - & - & - & - & 0.12 & 0.00 & - & - \\
\hline Jassa marmorata & 0.13 & 0.03 & 0.29 & 0.14 & 0.07 & 0.00 & 0.09 & 0.00 & - & - & - & - & - & - & 0.08 & 0.00 & 0.27 & 0.74 & - & - & - & - & - & - & - & - \\
\hline Elasmopus brasiliensis & - & - & 0.39 & 0.15 & 0.13 & 0.04 & - & - & - & - & 0.23 & 0.48 & 0.16 & 0.17 & - & - & 0.07 & 0.00 & - & - & - & - & - & - & - & - \\
\hline Caprella penantis & 0.16 & 0.04 & - & - & 0.07 & 0.00 & - & - & - & - & - & - & 0.07 & 0.00 & - & - & 0.23 & 0.37 & 0.09 & 0.00 & 0.08 & 0.00 & - & - & - & - \\
\hline Caprella dilatata & 0.07 & 0.00 & - & - & 0.13 & 0.06 & 0.39 & 0.06 & - & - & - & - & - & - & - & - & 0.07 & 0.00 & - & - & - & - & - & - & - & - \\
\hline Nototropis minikoi & - & - & 0.17 & 0.00 & - & & - & - & - & - & - & - & - & - & - & - & - & 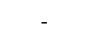 & - & - & 0.08 & 0.00 & 0.08 & 0.00 & 0.13 & 0.00 \\
\hline Photis longicaudata & - & - & 0.07 & 0.00 & 0.07 & 0.00 & 0.07 & 0.00 & - & - & 0.07 & 0.00 & 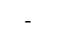 & 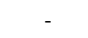 & 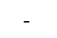 & 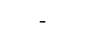 & - & - & - & 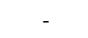 & - & - & - & - & 0.13 & 0.00 \\
\hline Lysianassa brasiliensis & - & 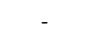 & - & - & - & . & 0.23 & 0.03 & - & - & 0.07 & 0.00 & - & - & - & - & - & - & - & - & - & - & - & - & - & - \\
\hline Jassa falcata & 0.24 & 0.06 & - & - & - & - & - & - & - & - & - & - & - & - & - & - & - & - & - & - & - & - & - & - & - & - \\
\hline Gammaropsis thompsoni & 0.13 & 0.04 & - & - & - & - & - & - & - & - & - & - & - & 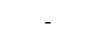 & 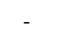 & - & 0.07 & 0.00 & - & - & - & - & - & - & - & - \\
\hline Hourtonius wakabarae & 0.20 & 0.00 & - & - & - & - & - & - & - & - & - & - & - & - & - & - & - & - & - & - & - & - & - & - & - & - \\
\hline Bemlos sp. & - & - & - & - & - & - & - & - & - & - & - & - & - & - & - & - & - & - & - & - & - & - & 0.17 & 0.00 & - & - \\
\hline Dulichiella anisochir & - & - & 0.10 & 0.00 & - & - & - & - & - & - & - & - & - & - & - & - & - & - & - & - & - & - & - & - & - & - \\
\hline Podocerus brasiliensis & - & - & - & - & - & - & - & - & - & - & - & - & - & - & - & - & - & - & - & - & 0.08 & 0.00 & - & - & - & - \\
\hline Maera $s p$. & - & - & - & - & - & 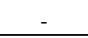 & - & - & - & 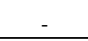 & 0.07 & 0.00 & - & 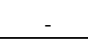 & - & - & - & - & - & - & - & - & - & - & - & - \\
\hline
\end{tabular}




\section{Anexo II - continuação}

\begin{tabular}{|c|c|c|c|c|c|c|c|c|c|c|c|c|c|c|c|c|c|c|c|c|c|c|c|c|c|c|}
\hline \multirow{2}{*}{ Espécies } & \multicolumn{2}{|c|}{ JAN_12 } & \multicolumn{2}{|c|}{ FEV } & \multicolumn{2}{|c|}{ MAR } & \multicolumn{2}{|c|}{ ABR } & \multicolumn{2}{|c|}{ MAI } & \multicolumn{2}{|c|}{ JUN } & \multicolumn{2}{|c|}{ JUL } & \multicolumn{2}{|c|}{ AGO } & \multicolumn{2}{|c|}{ SET } & \multicolumn{2}{|c|}{ OUT } & \multicolumn{2}{|c|}{ NOV } & \multicolumn{2}{|c|}{ DEZ } & \multicolumn{2}{|c|}{ JAN_13 } \\
\hline & Ab. & Cont $\%$ & Ab. & Cont $\%$ & Ab. & Cont \% & Ab. & Cont $\%$ & Ab. & Cont $\%$ & Ab. & Cont $\%$ & Ab. & Cont $\%$ & Ab. & Cont $\%$ & Ab. & Cont $\%$ & Ab. & Cont \% & Ab. & Cont $\%$ & Ab. & Cont $\%$ & Ab. & Cont \% \\
\hline Hyale niger & 8.08 & 21.69 & 6.68 & 16.45 & 2.19 & 10.81 & 4.95 & 19.02 & 3.15 & 25.50 & 1.20 & 12.40 & 2.94 & 23.67 & 4.67 & 49.02 & 6.06 & 37.01 & 2.61 & 18.99 & 1.69 & 8.23 & 2.99 & 18.66 & 7.38 & 35.68 \\
\hline Cymadusa filosa & 6.18 & 28.19 & 6.41 & 26.44 & 4.58 & 28.88 & 5.14 & 25.54 & 1.86 & 10.29 & 1.16 & 11.44 & 1.96 & 11.69 & 0.87 & 4.57 & 1.68 & 9.59 & 2.74 & 19.71 & 3.31 & 23.82 & 2.32 & 12.60 & 3.44 & 16.40 \\
\hline Caprella scaura & 9.27 & 29.52 & 7.55 & 25.29 & 2.47 & 9.08 & 2.23 & 7.20 & 0.40 & 1.00 & 0.48 & 2.95 & 1.50 & 11.13 & 0.16 & 0.00 & 0.97 & 4.15 & 0.43 & 0.86 & 2.26 & 12.75 & 3.29 & 22.61 & 2.81 & 20.73 \\
\hline Sunamphitoe pelagica & 2.02 & 8.59 & 1.13 & 2.62 & 1.04 & 6.10 & 2.91 & 8.59 & 2.28 & 16.23 & 1.41 & 23.55 & 0.74 & 2.88 & 1.06 & 6.11 & 1.39 & 6.34 & 2.38 & 16.07 & 2.71 & 19.43 & 2.85 & 16.52 & 2.09 & 12.73 \\
\hline Batea catharinensis & 1.66 & 4.31 & 5.06 & 11.83 & 0.61 & 1.11 & 0.66 & 1.00 & 0.31 & 0.98 & 0.82 & 8.42 & 2.50 & 14.37 & 0.69 & 2.30 & 3.89 & 18.33 & 2.30 & 11.59 & 4.05 & 12.14 & 2.26 & 11.14 & 2.45 & 9.35 \\
\hline Photis longicaudata & 1.10 & 2.00 & 1.96 & 5.14 & 2.49 & 12.23 & 4.76 & 19.66 & 3.03 & 21.51 & 1.29 & 14.61 & 2.20 & 17.60 & 1.09 & 6.71 & 0.87 & 3.48 & 0.56 & 1.29 & 0.62 & 1.26 & 0.25 & 0.41 & 0.94 & 3.00 \\
\hline Apohyale media & 0.97 & 1.41 & 2.13 & 3.34 & 0.20 & 0.19 & 1.12 & 1.56 & 3.04 & 16.00 & 0.56 & 4.19 & 1.45 & 5.18 & 2.43 & 22.47 & 2.96 & 13.25 & 1.01 & 4.04 & 1.60 & 6.00 & 0.37 & 0.39 & - & - \\
\hline Ericthonius punctatus & 0.29 & 0.43 & 2.22 & 6.32 & 4.66 & 29.33 & 3.02 & 12.18 & 0.48 & 0.63 & 1.03 & 17.91 & 0.93 & 5.98 & 0.34 & 0.78 & - & - & 0.27 & 0.59 & 0.20 & 0.14 & 0.64 & 1.64 & 0.71 & 1.08 \\
\hline Aora spinicornis & - & $=$ & - & $=$ & $=$ & - & 0.12 & 0.00 & - & $=$ & 0.07 & 0.00 & 0.07 & 0.00 & 0.07 & 0.00 & 0.51 & 0.90 & 2.08 & 12.25 & 1.74 & 7.28 & 1.44 & 4.81 & 0.38 & 0.34 \\
\hline Shoemakerella cubensis & 0.07 & 0.00 & 0.18 & 0.04 & - & - & 0.38 & 0.31 & 0.08 & 0.00 & 0.07 & 0.00 & 0.84 & 3.26 & 0.76 & 3.89 & 1.04 & 5.52 & 1.45 & 6.67 & 1.39 & 6.52 & 1.20 & 5.88 & 0.16 & 0.00 \\
\hline Ampithoe ramondi & 1.35 & 3.18 & 0.81 & 2.09 & 0.44 & 0.50 & 0.91 & 2.14 & 0.73 & 1.32 & 0.13 & 0.20 & 0.59 & 1.63 & 0.29 & 0.83 & 0.07 & 0.00 & 0.93 & 4.68 & 0.64 & 1.56 & 0.54 & 1.20 & 0.27 & 0.28 \\
\hline Amphilocus neapolitanus & 0.16 & 0.04 & - & - & 0.07 & 0.00 & 0.07 & 0.00 & 1.78 & 4.96 & 0.42 & 1.96 & 0.74 & 1.82 & 0.90 & 2.55 & 0.38 & 0.78 & 1.00 & 2.38 & 0.39 & 0.10 & 1.17 & 3.41 & 0.18 & 0.08 \\
\hline Elasmopus pectenicrus & 0.21 & 0.05 & 0.16 & 0.06 & 0.58 & 0.80 & 0.56 & 1.56 & - & - & 0.29 & 1.21 & 0.16 & 0.14 & 0.50 & 0.61 & 0.38 & 0.47 & 0.23 & 0.28 & 0.20 & 0.19 & 0.45 & 0.59 & 0.27 & 0.32 \\
\hline Leucothoe spinicarpa & - & - & 0.07 & 0.00 & 0.34 & 0.48 & 0.34 & 0.31 & 0.13 & 0.00 & 0.20 & 0.59 & 0.13 & 0.16 & 0.07 & 0.00 & 0.13 & 0.08 & 0.29 & 0.51 & 0.28 & 0.56 & 0.24 & 0.14 & - & - \\
\hline Laticorophium baconi & 0.20 & 0.19 & 0.40 & 0.38 & 0.27 & 0.48 & 0.13 & 0.06 & 0.31 & 0.51 & 0.07 & 0.00 & 0.09 & 0.00 & - & - & - & - & 0.09 & 0.00 & 0.08 & 0.00 & - & - & 0.09 & 0.00 \\
\hline Stenothoe valida & 0.23 & 0.34 & 0.21 & 0.00 & - & - & 0.07 & 0.00 & 0.08 & 0.00 & 0.13 & 0.31 & 0.18 & 0.10 & 0.07 & 0.00 & 0.07 & 0.00 & 0.18 & 0.09 & 0.08 & 0.00 & - & - & - & - \\
\hline Elasmopus brasiliensis & - & - & - & - & - & - & 0.30 & 0.17 & 0.31 & 0.51 & - & - & - & - & 0.07 & 0.00 & - & - & - & - & - & - & - & - & - & - \\
\hline Paracaprella pusilla & 0.13 & 0.06 & 0.07 & 0.00 & - & - & 0.07 & 0.00 & 0.08 & 0.00 & 0.26 & 0.27 & 0.23 & 0.39 & - & - & - & - & 0.09 & 0.00 & - & - & - & - & - & - \\
\hline Nototropis minikoi & - & - & 0.09 & 0.00 & - & - & 0.61 & 0.64 & - & - & - & - & - & - & - & - & - & - & - & - & - & - & - & - & - & - \\
\hline Dulichiella anisochir & - & - & - & - & - & - & 0.16 & 0.06 & 0.23 & 0.27 & 0.07 & 0.00 & - & - & - & - & 0.07 & 0.00 & - & - & - & - & - & - & - & - \\
\hline Lysianassa brasiliensis & - & - & - & - & - & - & 0.07 & 0.00 & - & 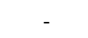 & - & - & 0.07 & 0.00 & - & - & 0.16 & 0.09 & - & - & 0.12 & 0.00 & - & - & 0.09 & 0.00 \\
\hline Caprella dilatata & - & - & - & - & - & - & 0.07 & 0.00 & 0.08 & 0.00 & - & - & - & - & 0.17 & 0.15 & - & - & - & - & - & - & - & - & - & - \\
\hline Podocerus brasiliensis & 0.07 & 0.00 & - & - & - & - & - & - & 0.15 & 0.15 & - & - & 0.07 & 0.00 & - & - & - & - & - & - & - & - & - & - & - & - \\
\hline Hourtonius wakabarae & 0.09 & 0.00 & - & - & - & - & - & - & - & - & 0.25 & 0.00 & - & - & - & - & - & - & - & - & - & - & - & - & - & - \\
\hline Monoculodes sp. & 0.07 & 0.00 & - & - & - & - & 0.12 & 0.00 & - & - & - & - & - & - & - & - & - & - & - & - & - & - & - & - & - & - \\
\hline Caprella equilibra & - & - & 0.07 & 0.00 & - & - & 0.07 & 0.00 & - & - & - & - & - & - & - & - & - & - & - & - & - & - & - & - & - & - \\
\hline Jassa marmorata & - & - & 0.07 & 0.00 & - & - & - & - & - & - & - & - & 0.07 & 0.00 & - & - & - & - & - & - & - & - & - & - & - & - \\
\hline Caprella danilevskii & - & - & - & - & - & - & - & - & - & - & - & - & - & - & - & - & - & - & - & - & 0.08 & 0.00 & - & - & - & - \\
\hline Gammaropsis thompsoni & - & - & - & - & - & - & - & - & - & - & - & - & - & - & 0.07 & 0.00 & - & - & - & - & - & - & - & - & - & - \\
\hline Jassa falcata & - & - & - & - & - & - & - & - & - & - & - & - & - & - & 0.07 & 0.00 & - & - & - & - & - & - & - & - & - & - \\
\hline
\end{tabular}


CAPÍTUlO 3 - “Colonização de anfípodes em Sargassum filipendula defaunado e substratos artificiais na Praia do Lamberto, Ubatuba, sudeste do Brasil"

\section{RESUMO}

Um aumento no número de estruturas artificiais que substituem o habitat natural, principalmente em áreas rochosas, tornou-se evidente. A principal questão sobre essas estruturas artificiais é se elas substituem adequadamente o habitat natural. $\mathrm{O}$ uso de habitats artificias é comumente aplicado para vários ambientes aquáticos, embora não haja consenso sobre a real resposta da epifauna e nem sobre se sustentam a mesma comunidade da área circundante. O objetivo principal deste estudo é avaliar se um substrato artificial representado por algas plásticas mímicas pode substituir o habitat natural de Sargassum usando anfípodes como ferramenta biológica. Um experimento de curto período (90 dias) foi aplicado para comparar a comunidade de anfípodes presente no Sargassum filipendula defaunado e substratos artificiais na praia do Lamberto, Ubatuba, costa sudeste do Brasil. Para avaliar a variação na complexidade do habitat durante o experimento, a área superficial e a dimensão fractal foram calculadas para ambos os substratos. Os anfípodes foram identificados em nível de espécie e classificados de acordo com seu modo de vida, como tubícolas, vida livre, inquilino e para o grupo trófico como suspensívoros, detritívoros, herbívoro e comensais. Os gamarídeos tubícolas foram os dominantes em ambos os substratos e representados principalmente por Ericthonius punctatus, Cymadusa filosa e Ampithoe ramondi. Um atraso na colonização dos substratos artificiais em relação ao S. filipendula foi observado nos seis primeiros dias do experimento, provavelmente como resposta à ausência de biofilme nos substratos artificiais. Ambos os substratos mostraram um aumento na abundância e número de espécies e foram significativamente correlacionados com a área e o perímetro fractal. Além disso, após o $15^{\circ}$ dia, ambos os substratos apresentaram abundância e composição de espécies semelhantes. Nossos resultados mostram que as algas plásticas mímicas utilizadas podem efetivamente substituir o habitat natural para a comunidade analisada, considerando-se as abordagens estrutural e funcional.

Palavras-chave: Sargassum filipendula, Amphipoda, artificial, dimensão fractal, Brasil. 


\begin{abstract}
An increase in the number of artificial structures replacing natural habitats, mainly in rocky shore areas, has recently become evident. The main question regarding these artificial structures is whether they replace the natural habitat adequately. The use of artificial habitats commonly occurs in various aquatic environments, though there is no consensus as to the real response of epifauna to them or whether they sustain the same community as the surrounding area. The main purpose of this study is to evaluate whether an artificial substrate represented by mimic plastic algae can replace the natural habitat of Sargassum using amphipods as a biological tool. A short period experiment (90 days) was applied to compare the amphipod community present on both defaunated Sargassum filipendula and an artificial substrate at Lamberto Beach, Ubatuba, on the southeastern Brazilian coast. To evaluate the variation in habitat complexity during the experiment, the superficial area and fractal dimension were calculated for both substrates. Amphipods were identified to species level and classified according to their life style as tube-dwellers, free-living or nestlers and to their feeding group: suspension-feeders, detritivores, herbivores and commensals. Gammarid tube-dwellers were dominant on both substrates, and were represented mostly by Ericthonius punctatus, Cymadusa filosa and Ampithoe ramondi. A delay in the colonization of the artificial substrates in relation to S. filipendula was observed on the $1^{\text {st }}, 2^{\text {nd }}, 3^{\text {rd }}$ and $6^{\text {th }}$ days of the experiment, probably as a response to the absence of biofilm on the former. Both substrates showed an increase in abundance and number of species and these were significantly correlated to fractal area and fractal perimeter. Further, after the $15^{\text {th }}$ day both substrates presented similar abundance and species composition. Our results show that the mimic plastic algae used can effectively replace the natural habitat for the community analyzed, considering both the structural and functional approaches.
\end{abstract}

Keywords: Sargassum filipendula, Amphipoda, artificial, fractal dimension, Brazil. 


\section{INTRODUÇÃO}

Os substratos artificiais são comumente utilizados em vários sistemas aquáticos, tanto marinhos como de água doce (CHRISTIE et al., 2007; CACABELOS et al., 2010; WETZEL et al., 2014). Este amplo uso de substratos artificiais para fins experimentais e outros está mais relacionado ao baixo nível de variação entre as replicações, uma vez que o habitat ou substrato artificial fornece uma padronização do tamanho e composição do substrato natural, reduzindo a variabilidade biológica associada (GIBBONS et al., 1993; GODOY \& COUTINHO, 2002). Além disso, são fáceis de manipular e o tempo inicial de colonização pode ser estabelecido (GEE \& WARWICK, 1996). Demonstrou-se que os organismos epifaunais podem colonizar substratos artificiais rapidamente (ATILLA et al., 2005). A epifauna pode ser atraída para os habitats artificiais por características físicas e tróficas, da mesma maneira que são atraídos por habitats naturais.

Os sistemas costeiros naturais continuam a ser destruídos e substituídos por construções humanas que incluem quebra-mares, pontes, pontões, cais e paredes de pedra (ZINTZEN et al., 2008; GARCÍA-GÓMEZ et al., 2011). Em muitos casos, substratos artificiais podem substituir os ambientes naturais, atraindo e mantendo os organis mos associados. O uso de estruturas artificiais, no entanto, levanta questões sobre se as comunidades a elas associadas são comparáveis ou não com aquelas dos naturais. Alguns estudos indicaram que essas estruturas podem alojar diferentes comunidades em relação aos habitats naturais das proximidades (SMITH \& RULE, 2002; BACCHIOCCHI \& AIROLDI, 2003), enquanto outros sugeriram que os habitats artificiais poderiam ser considerados bons análogos dos naturais. Além disso, os substratos artificiais podem ser utilizados em amostragens bentônicas e/ou programas de monitoramento para a investigação de efeitos naturais e antropogênicos sobre comunidades de invertebrados (EDGAR, 1991; RULE \& SMITH, 2005).

Os anfípodes são conhecidos por responder à modificação do habitat (SANCHEZJEREZ et al., 2000) e são rápidos colonizadores (BEERMANN, 2014). São importantes produtores secundários e apresentam diversas estratégias de alimentação: pastagem, filtração e captação de detritos, predação e necrofagia (macrofagia ou microfagia) (SARVALA \& UITTO, 1991). Algumas espécies exibem alta especificidade de habitat, enquanto que outras toleram uma variedade de alterações resultantes de poluição, invasão por espécies exóticas ou qualquer outro distúrbio. Além disso, os anfípodes são 
comumente associados às algas marinhas (GUERRA-GARCÍA et al., 2014), onde dominado em número e algumas espécies são bons indicadores de impactos ambientais (SANCHEZ-JEREZ et al., 2000).

A complexidade do habitat foi considerada um dos determinantes da diversidade biológica e saber como a estrutura física desse habitat influencia os organismos tornouse uma questão central da ecologia (TANIGUCHI et al., 2003; TOKESHI \& ARAKAKI, 2012). Estudos realizados têm sugerido uma forte relação entre a complexidade das macroalgas e a abundância e diversidade dos organismos associados (HAUSER et al., 2006; HOOPER \& DAVENPORT, 2006). Os bancos de Sargassum sustentam grande diversidade de algas epífitas e ambos são altamente sazonais e sensíveis a fatores abióticos, como temperatura, embate das ondas e concentração de nutrientes e poluentes (SZÉCHY \& PAULA, 2000; WELLS et al., 2007). Esses fatores acrescentam complexidade ao ambiente, que por sua vez tem relação intrínseca com o desenvolvimento do substrato vegetal. Adicionalmente, estudos têm relatado que uma alta complexidade poderia resultar no aumento de organismos epifaunais por redução da predação, distúrbios físicos, aumento do alimento disponível e do número de nichos diferentes (ORAV-KOTTA \& KOTTA, 2004; WILLIS et al., 2005).

No entanto, apesar do amplo uso de substratos artificiais para investigar as comunidades epifaunais, poucos estudos experimentais compararam substratos artificia is aos naturais (TANIGUCHI et al., 2003; WARFE \& BARMUTA, 2006) e um menor número ainda utilizou medidas de dimensão fractal para avaliar a variação temporal da complexidade estrutural do habitat durante o experimento (DIBBLE \& THOMAZ, 2009; HANSEN et al., 2010; HANSEN et al., 2011). Contudo, estudos com esse foco poderiam facilitar a compreensão do efeito relativo do substrato na abundância, diversidade e funcionalidade das espécies no seu ambiente. No presente trabalho, discutimos o relacionamento de algas e anfípodes, focando especificamente na seleção de habitat (natural ou artificial) e no desenvolvimento da comunidade desses crustáceos por um curto período de 90 dias. Duas hipóteses foram levantadas. A primeira hipótese é que plantas artificiais podem substituir o habitat natural de Sargassum filipendula para a comunidade de anfípodes e, portanto, espera-se que a abundância e a diversidade das espécies sejam iguais em ambos os tipos de substratos. A segunda hipótese levantada é que um aumento na complexidade do substrato ao longo do tempo influenciaria 
fortemente a abundância e a diversidade das espécies. Sendo assim, é esperado que a abundância e diversidade sejam mais elevadas no final do experimento. 


\section{MATERIAL \& MÉTODOS}

\section{1.Área de Estudo}

O experimento foi realizado na Praia do Lamberto, semi abrigada e subtropical, situada na Enseada do Flamengo, Ubatuba, São Paulo, Brasil (23²9’42’S, 4505'O), entre janeiro e maio de 2014, num total de 90 dias. A área está sujeita a verões chuvosos e invernos secos, e a temperatura da água superficial varia entre 21 e $31^{\circ} \mathrm{C}$ ao longo do ano (TARARAM \& WAKABARA, 1981; LEITE et al., 2007). Próximo desse local está a Praia do Saco da Ribeira, que apresenta um complexo de pequenas marinas e armazéns, e a desembocadura do Rio Perequê-Mirim, sendo estes as principais fontes de influência antropogênica para a região (ALBERGARIA-BARBOSA et al., 2011; STRADIOTTO, 2013; JACOBUCCI \& LEITE, 2014).

\subsection{Trabalho de campo}

A macroalga Sargassum foi a escolha do habitat natural, porque mostra a morfologia de maior complexidade entre as Fucales (SZÉCHY \& PAULA, 2000). Além disso, em regiões tropicais e subtropicais, Sargassum pode formar bancos densos, e na costa dos estados de São Paulo e Rio de Janeiro representa o habitat mais importante (SZÉCHY \& PAULA, 2000). O local do experimento possui extensa cobertura de Sargassum e para essa localidade já foram descritas as espécies: Sargassum filipendula, S. filipendula var. laxum, S. filipendula var. pinnatum, S. vulgare e S. vulgare var. foliossinum (PAULA \&OLIVEIRA-FILHO, 1982; PAULA, 1988; SZÉCHY \& PAULA, 2000; SZÉCHY \& PAULA, 2010). No presente estudo, os exemplares de Sargassum foram identificados como Sargassum filipendula C. Agardh 1824.

Antes do procedimento de defaunação, 50 espécimes de Sargassum filipendula foram coletados aleatoriamente de matacões. Cada fronde foi lavada em três baldes consecutivos com água doce por pelo menos 3 minutos. Este procedimento é um método não destrutivo e eficiente, que remove aproximadamente $95 \%$ da fauna total presente nas frondes (HOLMLUND et al., 1990). Posteriormente, todas as algas epífitas presentes nas frondes do $S$. filipendula foram cuidadosamente removidas, usando-se uma pinça. Apenas as algas saudáveis foram utilizadas. As algas naturais defaunadas e os substratos artific ia is plásticos mímicos (Trema Áquarios®) foram colocados juntos no experimento (Figura 01). 


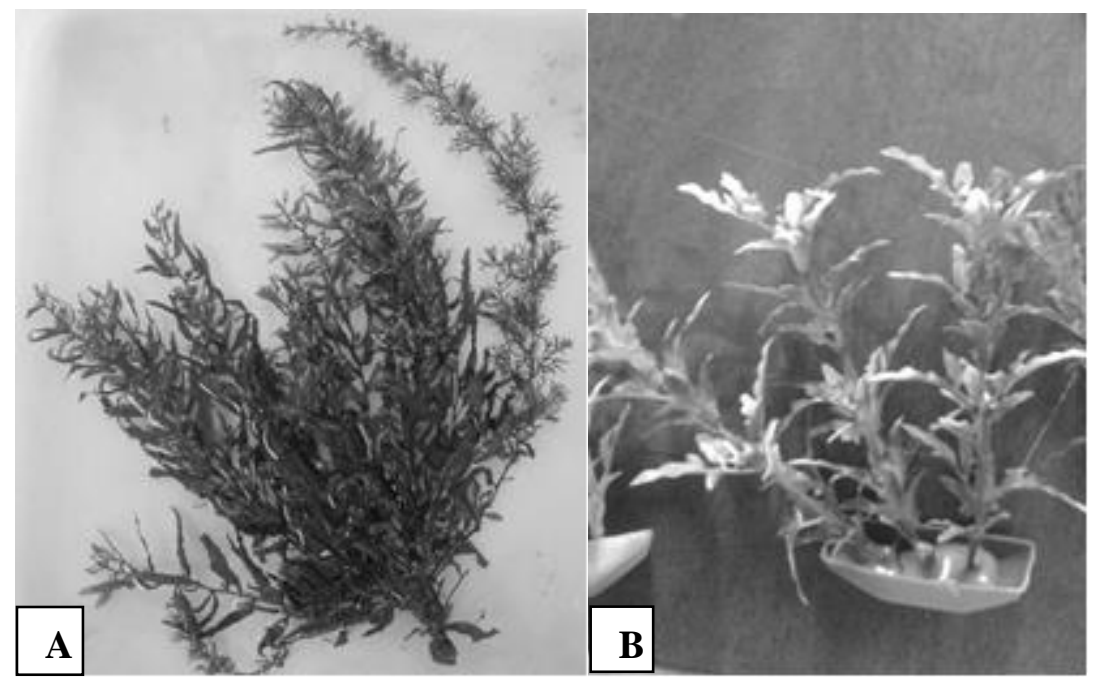

Figura 01 - (A) Sargassum filipendula (Alga Natural) e (B) Alga Artificial (Trema Aquários®). Fotografia: Carina W. Rodrigues.

O Sargassum defaunado e o substrato artificial foram presos a um cabo em intervalos regulares e de maneira intercalada. Todos os substratos ficaram $0,5 \mathrm{~m}$ equidistantes. Todo o sistema foi colocado em um semicírculo, a uma distância de um metro dos matacões presentes na praia do Lamberto e a um metro do fundo marinho. As boias de meia água e amarras foram posicionadas de forma intercalada para que todas as algas permanecessem imersas na mesma profundidade, independente das condições de maré.

Dentro do desenho amostral empregado procurou-se observar a colonização dos anfípodes nos dois tipos de substrato ao longo de um período de 90 dias (Tabela 01). Em cada um dos oito períodos de amostragem foram coletadas cinco réplicas de cada substrato (natural e artificial) com o auxilio de um saco com malha de $250 \mathrm{~mm}$, para minimizar perdas da fauna.

Tabela 01 - Discriminação dos períodos de amostragem com os respectivos níveis de maré.

\begin{tabular}{ccc}
\hline PERÍODO & DIA & MARÉ \\
\hline $0^{\circ}$ & $14 / 1$ & 0.3 \\
$1^{\circ}$ & $15 / 1$ & 0.3 \\
$2^{\text {o }}$ & $16 / 1$ & 0.3 \\
$3^{\text {o }}$ & $17 / 1$ & 0.2 \\
$6^{\circ}$ & $20 / 1$ & 0.4 \\
$15^{\circ}$ & $29 / 1$ & 0.3 \\
$30^{\circ}$ & $13 / 2$ & 0.3 \\
$45^{\circ}$ & $28 / 2$ & 0.2 \\
$90^{\circ}$ & $14 / 4$ & 0.1 \\
\hline
\end{tabular}




\subsection{Laboratório}

Em laboratório, cada réplica foi lavada separadamente em um balde contendo água doce. O soluto foi então peneirado através de peneira com malha de 0,5 mm para recuperar os macroinvertebrados. A lavagem e o peneiramento foram contínuos até que nenhum organismo pudesse ser encontrado no soluto. Todos os espécimes de anfípodes foram identificados ao nível taxonômico mais baixo possível, contados e armazenados em etanol $70 \%$.

A influência dos tipos de substratos na densidade dos anfípodes foi estimada pela mensuração da Área Superficial (AS) e pela dimensão fractal. Imagens digitais de cada planta foi analisada pelo de software ImageJ 1.51 para o cálculo da AS $\left(\mathrm{cm}^{2}\right)$. Para obter a imagem digital adequada para o software, cada réplica (natural e artificial) foi imersa em água sob um vidro e mantida uma régua para escala (Figura 02).

Para calcular as dimensões fractais (D) das algas naturais e artificiais, foram utilizadas as mesmas imagens digitais da AS. Então, o ImageJ analisou a estrutura fractal de cada imagem pelo algoritmo "Box counting". Este é análogo ao método de grade de Sugihara e May (1990) e pode quantificar a dimensão fractal da área (Da) e do perímetro (Dp). Análises fractais baseadas em área e perímetro fornecem diferenças sutis sobre a natureza da complexidade de cada alga. A área fractal (Da) é uma estimativa da ocupação da área, ou seja, uma medida do contorno da macroalga, ou o grau de circunvoluções de suas bordas, enquanto que o perímetro fractal é uma estimativa da complexidade da borda, relacionando a natureza das lacunas entre os ramos das algas (naturais ou artificiais) (McABENDROTH et al., 2005).

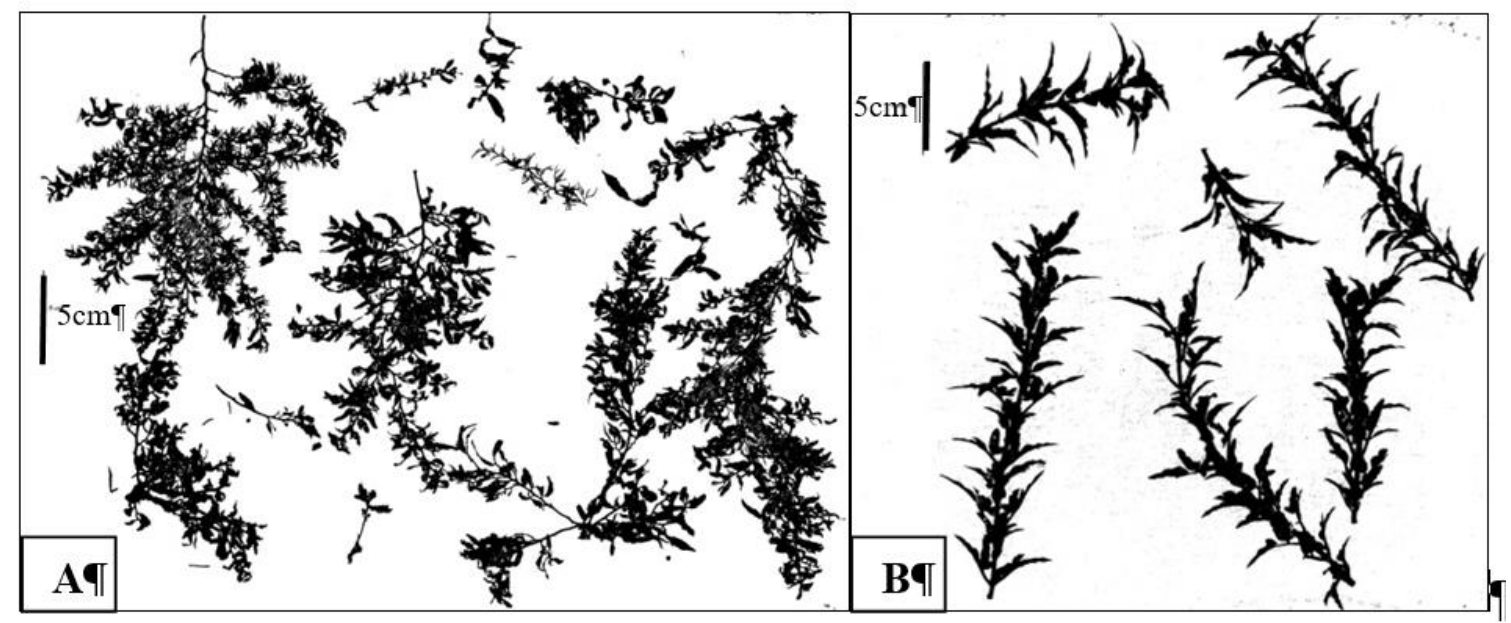

Figura 02 - Exemplos das imagens analisadas pelo software ImageJ 1.51: A - Sargassum filipendula - Naturale B - Alga Artificial. 


\subsection{Análises Estatísticas}

A abundância total $(\mathrm{N})$, a riqueza de espécies (S), o índice de diversidade de Shannon-Wiener (H'), o índice de equitabilidade de Pielou ( $\left.J^{\prime}\right)$ foram calculados para cada substrato. As análises de variância (ANOVAs) foram feitas para testar diferenças entre os tipos de substrato na quantidade de habitat (AS), complexidade morfoló gica (Da e Dp), e descritores de comunidade - N, S e H' dos anfípodes. Para essas análises, considerou-se um modelo bidirecional, incluindo os fatores: tipo de substrato (Fixo em dois níveis: natural e artificial) e período (Fixo com oito níveis: $1^{\circ}, 2^{\circ}, 3^{\circ}, 6^{\circ}, 15^{\circ}, 30^{\circ}, 45^{\circ}$ e $90^{\circ}$ dias). Antes de cada ANOVA, o teste de Kolmogorov-Smirnov foi feito para verificar a homogeneidade das variâncias. Os dados foram transformados para remover a heterogeneidade das variâncias e quando isto não era possível, os dados não transformados foram analisados e os resultados considerados robustos se significativos em $\mathrm{P}<0,01$ (UNDERWOOD, 1997). No caso de diferenças significativas encontradas, um teste post-hoc Tukey HSD foi utilizado entre todos os pares de níveis do fator selecionado.

Para explorar a relação entre as variáveis (N e S) e medidas de complexidade de cada tipo de substrato (AS, Da e Dp), foram realizadas análises de correlação. Devido à distribuição não normal dos dados, a correlação de Spearman foi utilizada. Os dados foram transformados em logaritmos para facilitar a visualização.

A estrutura da comunidade de anfípodes em escala espacial foi analisada seguindo Clarke \& Warwick (2001), com o software PRIMER 6. As ordenações de escala multidimensional não métricas (nMDS) foram realizadas para cada data de amostragem e substrato, a fim de pesquisar semelhanças entre repetições. A semelhança entre repetições foi calculada para cada matriz, aplicando-se o índice de Bray-Curtis e utilizando a densidade de anfípodes transformada em sua raiz quadrada para equilibrar a contribuição de espécies raras e abundantes (CLARKE \& WARWICK, 2001).

Depois disso, foi realizado um second-stage nMDS para visualizar as relações entre as matrizes de similaridade de cada tipo de substrato (natural e artificial) e período (cada dia de amostragem), usando o método de Somerfield \& Clarke (1995). Este método calcula os postos de correlação entre os pares de matrizes de similaridade, tornando-os elementos de uma matriz de similaridade de segundo estágio. Em uma ordenação de second-stage nMDS, cada símbolo representa uma matriz de similaridade e as distâncias relativas entre os símbolos indicam semelhanças. Assim, os padrões em uma série de 
matrizes de similaridade de cada investigação podem ser comparados simultaneamente. Para mais casos de second-stage nMDS aplicados em ecologia ver Bilton et al. (2006).

A análise de dados de similaridade (ANOSIM) foi aplicada para testar a influê nc ia combinada do substrato e período. Para realizar este teste, os três grupos observados no second-stage nMDS foram utilizados. A seguir, a análise da porcentagem de similaridade (SIMPER) foi aplicada aos mesmos três grupos como um complemento. Esta análise calcula a dissimilaridade entre todos os pares de grupos obtidos pelo second-stage nMDS, e depois calcula a contribuição média de cada espécie para a dissimilaridade entre os grupos de amostras separadamente (CLARKE \& WARWICK, 2001). 


\section{RESULTADOS}

Os resultados das ANOVAs mostraram que as medidas de Área Superficial (AS) e da Área Fractal (Da) do Sargassum filipendula e algas artificiais apresentaram diferenças significativas entre o período (dias), e somente AS apresentou diferença significativa entre os substratos (natural e artificial) (Tabela 02). Além disso, as medidas obtidas por ambos os métodos mostraram diferenças significativas na interação entre o período e o substrato (Tabela 02).

Tabela 02 - Resumo das ANOVAs para as medidas de complexidade do Sargassumfilipendula e algas artificiais mímicas (Área Superficial - AS, Área Fractal - Da e Perímetro Fractal- Dp). **, $P<0.01{ }^{\text {s }}$, significativo; ${ }^{\text {ns }}$, não significativo.

\begin{tabular}{|c|c|c|c|c|c|c|c|}
\hline \multirow{2}{*}{ Fonte } & \multirow{2}{*}{$d f$} & \multicolumn{2}{|c|}{ AS } & \multicolumn{2}{|c|}{ Da } & \multicolumn{2}{|c|}{ Dp } \\
\hline & & MS & $\mathrm{F}$ & MS & $\mathrm{F}$ & MS & $\mathrm{F}$ \\
\hline Período & 7 & $1.82 \mathrm{E}+05$ & $3.31 * *$ & 0.02 & $7.55^{* *}$ & 0.07 & 2.11 \\
\hline Substrato & 1 & $2.37 \mathrm{E}+06$ & $43.23 * *$ & 0.003 & 1.52 & 0.08 & 2.40 \\
\hline Período*Substrato & 7 & $2.40 \mathrm{E}+05$ & $4.38 * *$ & 0.01 & $3.00 * *$ & 0.17 & $5.16 * *$ \\
\hline Residual & 63 & 54855.67 & & 0.002 & & 0.03 & \\
\hline Total & 79 & & & & & & \\
\hline Kolmogorov-Smirnov & & \multicolumn{2}{|c|}{$0.260^{\mathrm{ns}}$} & \multicolumn{2}{|c|}{$0.099^{\mathrm{s}}$} & \multicolumn{2}{|c|}{$0.164^{\mathrm{ns}}$} \\
\hline Transformação & & \multicolumn{2}{|c|}{ Não } & \multicolumn{2}{|c|}{ Não } & \multicolumn{2}{|c|}{ Sim } \\
\hline
\end{tabular}

As frondes de $S$. filipendula apresentaram uma diminuição no valor de AS durante o período de amostragem. As comparações post-hoc de Tukey HSD demonstraram que o maior valor obtido no segundo dia foi significativamente diferente daqueles após o $15^{\circ}$ dia (Figura 03). Deste período em diante, as frondes apresentaram alguns sinais de senescência, ou seja, houve perda na força e fragmentação dos ramos laterais primários. Do primeiro ao $15^{\circ}$ dia, houve poucas mudanças nos valores médios de AS dos substratos artificiais. Após esse período, os aumentos foram crescentes, com pico no $30^{\circ}$ dia (Figura 03). Além disso, o valor médio de AS no substrato artificial no $90^{\circ}$ dia apresentou uma alta variabilidade similar às exibidas pelas frondes naturais (Figura 03). 

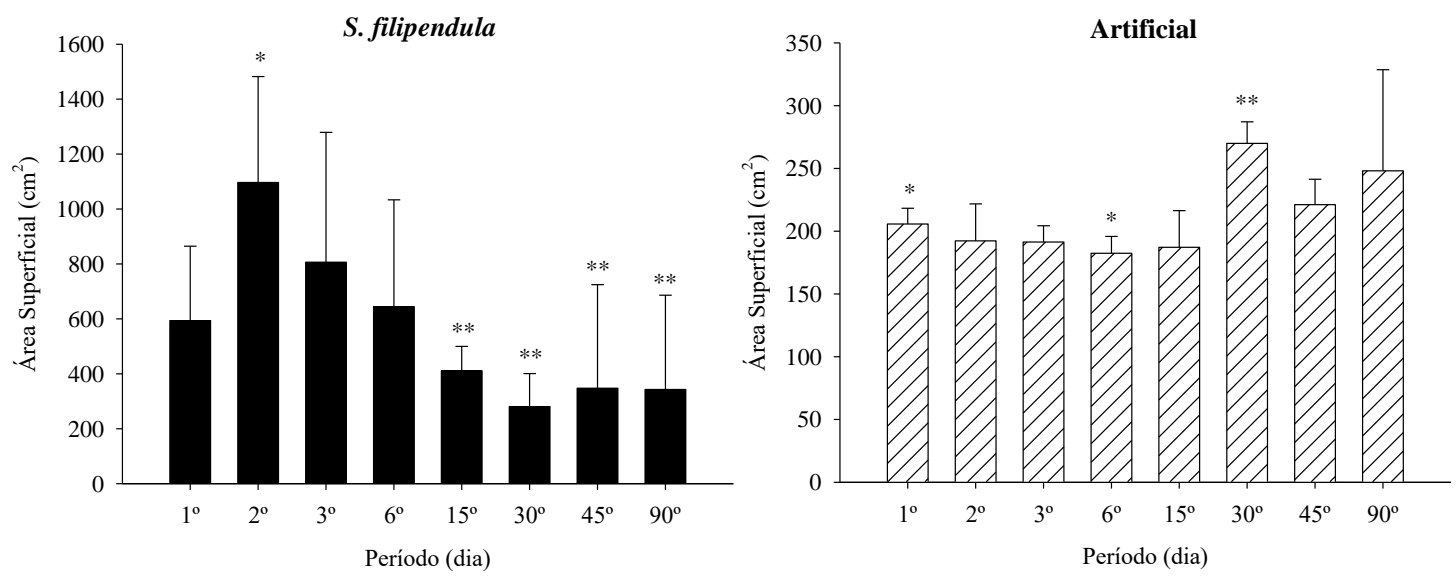

Figura 03 - Área Superficial (AS) do Sargassum filipendula (natural) e algas artificiais mímicas por $\mathrm{cm}^{2}$. Barras com os mesmos asteriscos foram iguais, de acordo com as comparações par a par do teste de Tukey HSD.

A alta variação observada para AS nas frondes de S. filipendula não foram notadas pelos dados de Área Fractal (Da). Apesar disso, as mesmas diferenças entre os dias foram observadas por ambos os métodos, os valores mais altos e mais significativos ocorreram no segundo dia e os valores mais baixos no trigésimo dia (Figura 04). No substrato artificial, os resultados foram semelhantes entre AS e Da, embora o valor de Da não apresentasse diferenças significativas entre os últimos 60 dias, e este período foi significativamente diferente dos dias referentes ao início do experimento (Figura 04). Como esperado, as algas artificiais não apresentaram uma forte variabilidade nos valores de AS e Da no início do experimento e ambos os métodos mostraram um aumento dos valores após o $30^{\circ}$ dia, ocasionado provavelmente pelo crescimento das algas epífitas e/ou presença de outros organismos.
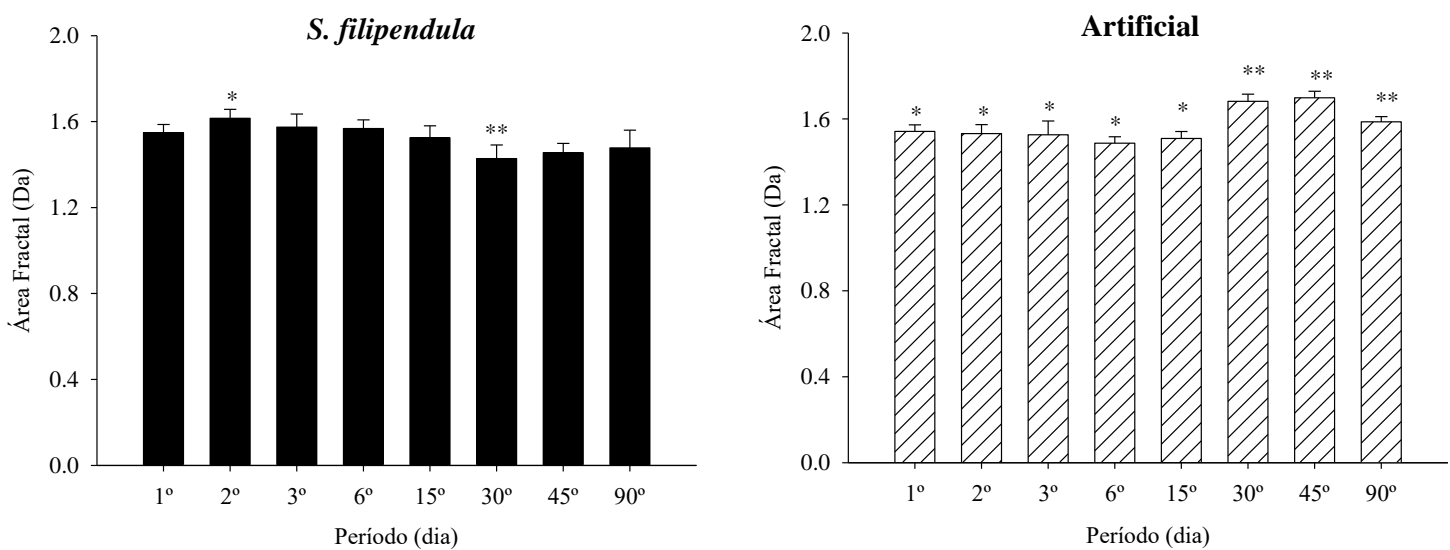

Figura 04 - Área Fractal (Da) do Sargassum filipendula (natural) e algas artificiais mímicas. Barras com os mesmos asteriscos foram iguais, de acordo com as comparações par a par do teste de Tukey HSD. 
Os valores do perímetro fractal (Dp) foram muito diferentes do das outras medidas. Nas frondes do S. filipendula, os valores médios mudaram ao longo do período de amostragem e aumentaram nos seis primeiros dias (Figura 05). Os dados dos três primeiros dias foram significativamente diferentes daqueles do $30^{\circ}$ dia, sendo este o maior valor obtido durante o experimento (Figura 05). Contrariamente, nas algas artificia is ocorreu uma diminuição nos valores de Dp entre os três primeiros dias e diferenças significativas estiveram presentes entre o $1^{\circ}$ e $90^{\circ}$ dias e também entre o $2^{\circ}$ e o $45^{\circ}$ dias (Figura 05).
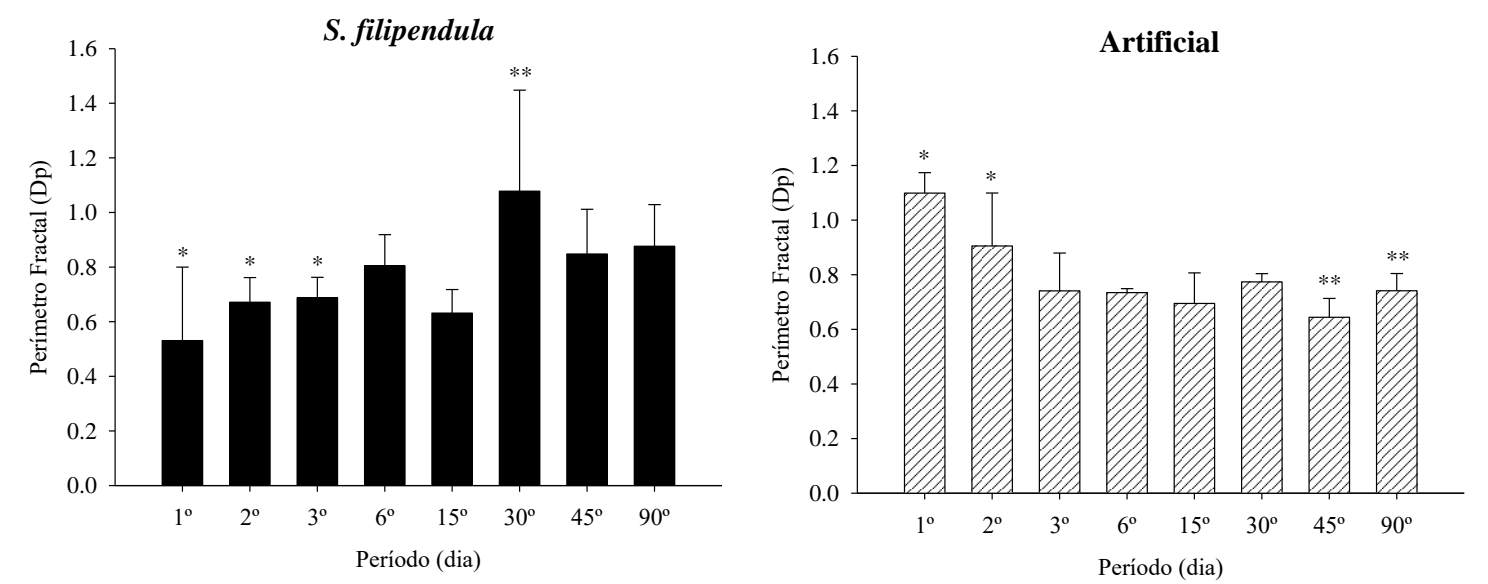

Figura 05-Perímetro Fractal (Dp) do Sargassumfilipendula (natural) e algas artificiais mímicas. Barras com os mesmos asteriscos foram iguais, de acordo com a comparação par a par do teste de Tukey HSD.

Um total de 28.723 organismos foram obtidos e distribuídos em vinte espécies (Tabela 03). Espécies tubícolas foram dominantes na seguinte ordem de importância: (i) detritívoras/herbívoras Cymadusa filosa e Ampithoe ramondi; (ii) suspensívoras Ericthonius punctatus, Photis longicaudata e Laticorophium baconi. Entre as espécies de vida livre as mais abundantes foram (iii) as herbívoras Dulichiella anisochir e Hyale niger, (iv) as detritívoras, Podocerus brasiliensis e (v) as inquilinas Stenothoe valida e Leucothoe spinicarpa. Caprella scaura e Paracaprella pusilla foram as únicas espécies de caprelídeos encontrados. 
Tabela 03 - Espécies encontradas e seu respectivo grupo funcional

\begin{tabular}{lclc}
\hline \multicolumn{1}{c}{ Espécies } & Grupo Funcional & \multicolumn{1}{c}{ Espécies } & Grupo Funcional \\
\hline Ampithoe ramondi & Herbívoro/ Detritívoro & Gammaropsis palmata & Suspensívoro \\
Cymadusa filosa & Herbívoro/ Detritívoro & Photis longicaudata & Suspensívoro \\
Sunamphitoe pelagica & Herbívoro/ Detritívoro & Caprella scaura & Detritívoro \\
Batea catharinensis & Detritívoro & Paracaprella pusilla & Detritívoro \\
Apolochus neapolitanus & Detritívoro/ Carnívoro & Stenothoe valida & Comensal \\
Aora spinicornis & Suspensívoro & Shoemakerella cubensis & Detritívoro/ Carnívoro \\
Jassa slatteryi & Suspensívoro & Leucothoe spinicarpa & Comensal \\
Laticorophiumbaconi & Suspensívoro & Hyale niger & Herbívoro \\
Ericthonius punctatus & Suspensívoro & Elasmopus pectenicrus & Herbívoro/ Detritívoro \\
Podocerus brasiliensis & Suspensívoro & Dulichiella anisochir & Herbivoro \\
\hline
\end{tabular}

As ANOVAs mostraram que o efeito do período teve grande influência sobre todos os descritores da comunidade de anfípodes e a natureza do substrato foi importante para abundância e riqueza de espécies. Além disso, os descritores de comunidade mostraram diferenças significativas na interação entre o período (dias) e os tipos de substratos (natural e artificial) (Tabela 04).

Tabela 04 - Resumo das ANOVAs para os descritores da comunidade analisados (Abundância $\mathrm{N}$; Riqueza - S; Diversidade - H' e Equitabilidade - J). **, $P<0.01$; ${ }^{\text {s }}$, significativo; ${ }^{\text {ns }}$, não significativo.

\begin{tabular}{|c|c|c|c|c|c|c|c|c|c|}
\hline \multirow{2}{*}{ Fonte } & \multirow{2}{*}{$d f$} & \multicolumn{2}{|c|}{$\mathbf{N}$} & \multicolumn{2}{|c|}{$\mathbf{S}$} & \multicolumn{2}{|c|}{$\mathbf{H}^{\prime}$} & \multicolumn{2}{|c|}{$\mathbf{J}$} \\
\hline & & MS & $\mathrm{F}$ & MS & $\mathrm{F}$ & MS & $\mathrm{F}$ & MS & $\mathrm{F}$ \\
\hline Período & 7 & 57.33 & $20.99^{* * *}$ & 5.90 & $67.20^{* * *}$ & 1.06 & $12.58^{* * *}$ & 0.31 & $6.60^{* * *}$ \\
\hline Substrato & 1 & 46.51 & $17.03^{* *}$ & 3.95 & $45.02^{* *}$ & 0.21 & 2.43 & 0.01 & 0.19 \\
\hline Período*Substrato & 7 & 23.05 & $8.44^{* *}$ & 0.83 & $9.44^{* *}$ & 0.59 & $6.94^{* *}$ & 0.14 & $3.00^{* *}$ \\
\hline Residual & 63 & 2.73 & & 0.09 & & 0.08 & & 0.05 & \\
\hline Total & 79 & & & & & & & & \\
\hline Kolmogorov-Smirnov & & \multicolumn{2}{|c|}{$0.001^{\mathrm{ns}}$} & \multicolumn{2}{|c|}{$0.112^{\mathrm{s}}$} & \multicolumn{2}{|c|}{$0.067^{\mathrm{s}}$} & \multicolumn{2}{|c|}{$0.097^{\mathrm{s}}$} \\
\hline Transformação & & \multicolumn{2}{|c|}{ Não } & \multicolumn{2}{|c|}{ Sim } & \multicolumn{2}{|c|}{ Não } & \multicolumn{2}{|c|}{ Não } \\
\hline
\end{tabular}

Os valores médios da abundância diferiram claramente diferentes ao longo do período de amostragem. No geral, houve um aumento na abundância média independentemente do tipo de substrato até o $30^{\circ}$ dia (Figura 06). As comparações par a par para as frondes de S. filipendula mostraram diferenças significativas entre os valores dos seis primeiros dias e $15^{\circ}$ e $30^{\circ}$ dias (Figura 06). Antes do terceiro dia, os valores de abundância foram inferiores a 100 organismos, mais depois, triplicaram, atingindo $914 \pm$ 256 indivíduos no $15^{\circ}$ dia (Figura 06). Para o substrato artificial, de acordo com o teste de Tukey, os primeiros três dias foram significativamente diferentes dos demais, sendo que abundância média passou de menos de 10 indivíduos para valores cerca de 50 e 150 
vezes maiores no $15^{\circ}(514 \pm 81$ indivíduos $)$ e $30^{\circ}$ dias $(1490 \pm 780$ indivíduos $)$, respectivamente (Figura 06). No $30^{\circ}$ dia, a abundância nos substratos artificiais excedeu os valores encontrados nas frondes de S. filipendula, sendo quase 20 vezes maior que a dos primeiros três dias (Figura 06).

$\mathbf{N}$

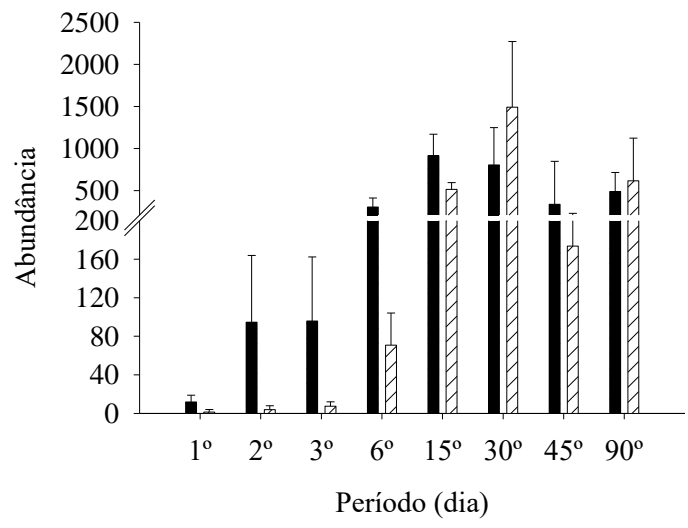

$\mathbf{H}^{\prime}$

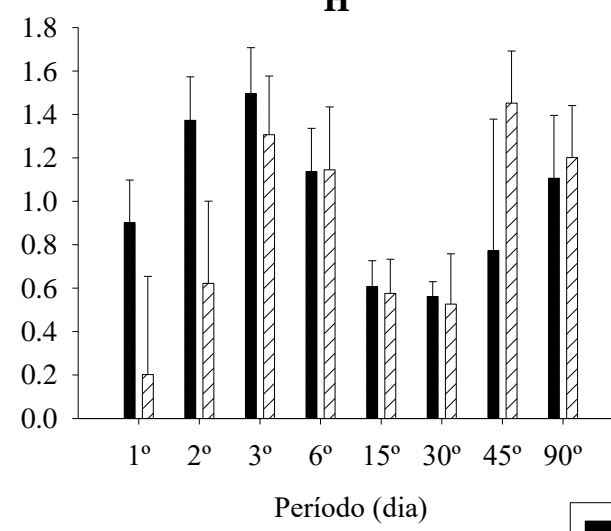

S. filipendula Artificial
$\mathbf{S}$

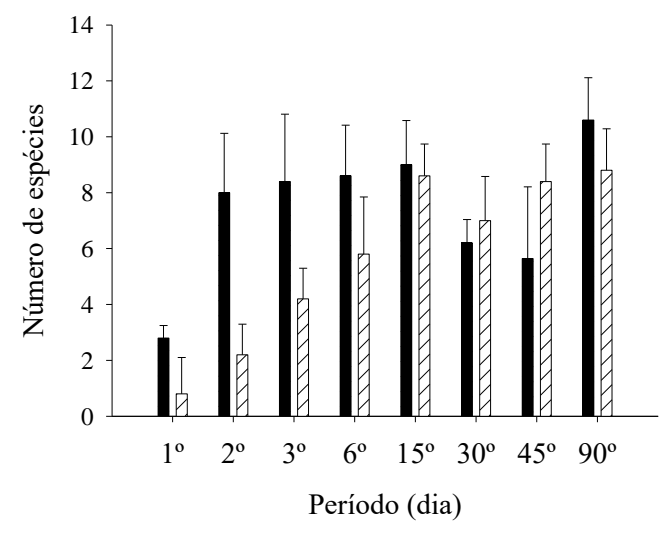

$\mathbf{J}^{\prime}$

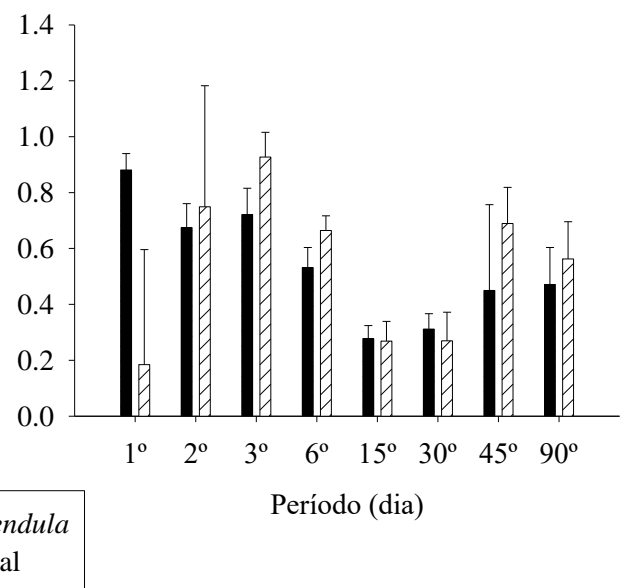

Figura 06 - Valores médios de abundância, riqueza, diversidade e equitabilidade para cada tipo de substrato (natural e artificial) por dia.

A riqueza (S) apresentou padrão de variação semelhante ao descrito para abundância, mas enquanto os altos valores ocorreram já no segundo dia para o substrato natural, para o artificial foi somente no $15^{\circ}$ dia (Figura 6). De acordo com a ANOVA, o tipo de substrato, o período e a interação entre esses dois fatores influenciaram efetivamente os valores de riqueza (Tabela 04). Os picos de riqueza (S. filipendula: $11 \pm$ 2 espécies e Artificial: $9 \pm 1,5$ espécies) foram obtidos no último dia de amostragem $\left(90^{\circ}\right)$ para os dois substratos, em oposição ao ocorrido no primeiro dia, em que as médias foram as mais baixas (S. filipendula: $3 \pm 0,4$ espécies e Artificial: $1 \pm 1$ espécies) (Figura 06).

A diversidade $\left(\mathrm{H}^{\prime}\right)$ e equitabilidade $(\mathrm{J})$ apresentaram diferenças significativas entre o período e a interação do período e dos substratos (Tabela 04). Os valores da 
diversidade diminuíram muito entre os dias $15^{\circ}$ e $30^{\circ}$ e, depois disso, ocorreu outro período de incremento, especialmente no substrato artificial no $45^{\circ}$ dia (Figura 06). No que diz respeito à equitabilidade, ou uniformidade, de modo geral tendeu a decrescer até o $15^{\circ}$ dia, onde alcançou seu valor mínimo, indicando recursos mal repartidos entre as espécies, havendo dominância mais expressiva de poucas espécies (Cymadusa filosa e Ericthonius punctatus) no início do experimento. As comparações par a par mostraram que esses valores foram contrastantes e significativamente diferentes daqueles após o $15^{\circ}$ dia quando a dominância passou a crescer, provavelmente indicando a chegada de novas espécies (Figura 06 e Tabela 04).

Os resultados das correlações entre as variáveis de complexidade e abundância mostraram tendências opostas em Da e Dp para os dois substratos, como mostrado na Figura 07. A AS foi correlacionada significativamente apenas com as algas artificiais e $\mathrm{Da}$ apresentou a mesma tendência positiva para o mesmo substrato. A riqueza foi outro indicador com correlação significativa apenas para o substrato artificial e mostrou a mesma tendência de Da, Dp e AS encontrada para abundância neste mesmo substrato (Figura 07).

Somente nos substratos artificiais, a riqueza apontou para uma correlação positiva e significativa entre AS e $S$ e Da e $S$, além de uma correlação negativa entre Dp e $S$ (Figura 08).

De acordo com o second-stage nMDS, três grupos diferentes puderam ser considerados, separados principalmente pelo período de tempo (Figura 09). Esses grupos representam três etapas distintas na ocupação do habitat pelos anfípodes. O Grupo I diz respeito ao primeiro dia no S. filipendula (natural) e os primeiros três dias no substrato artificial; o Grupo II é representado pelo segundo, terceiro e sexto dias no S. filipendula e o sexto dia no substrato artificial; o Grupo III é representado pelos dias superiores ao $15^{\circ}$ dia, em ambos os substratos. Ao se comparar semelhanças entre as amostras dentro de cada grupo, especialmente Grupos I e II, pode-se observar um atraso na colonização dos anfípodes no substrato artificial. Os valores encontrados nos primeiros três dias nestes substratos foram aos do primeiro dia em S. filipendula. Somente no sexto dia, o número de indivíduos do artificial atingiu igual valor ao do substrato natural no período 2-6 dias. As diferenças encontradas anteriormente entre o substrato/dia para os Grupos I e II não foram observadas para o Grupo III (Figura 09). 


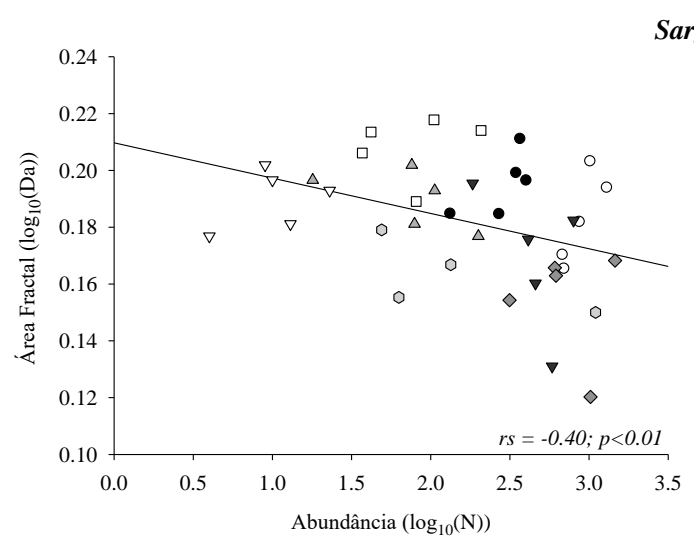

Sargassum filipendula

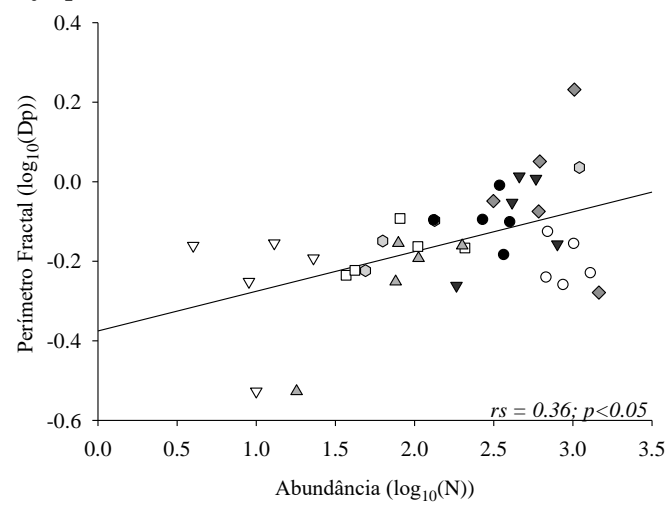

ARTIFICIAL
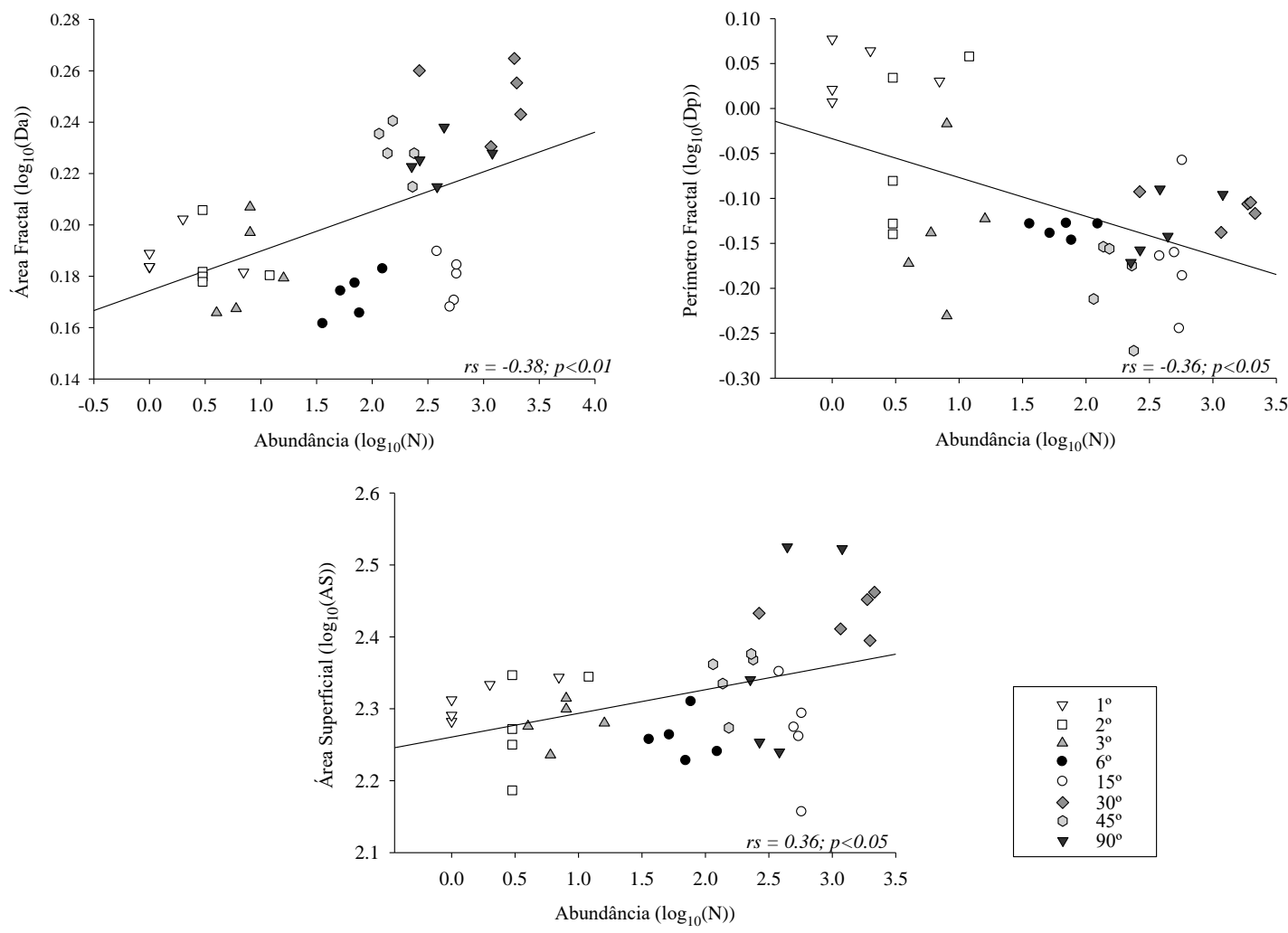

Figura 07 - Correlação de Spearman entre as variáveis de complexidade das frondes de Sargassum filipendula e algas artificiais e a abundância de anfípodes nos oito períodos amostrados. 


\section{ARTIFICIAL}
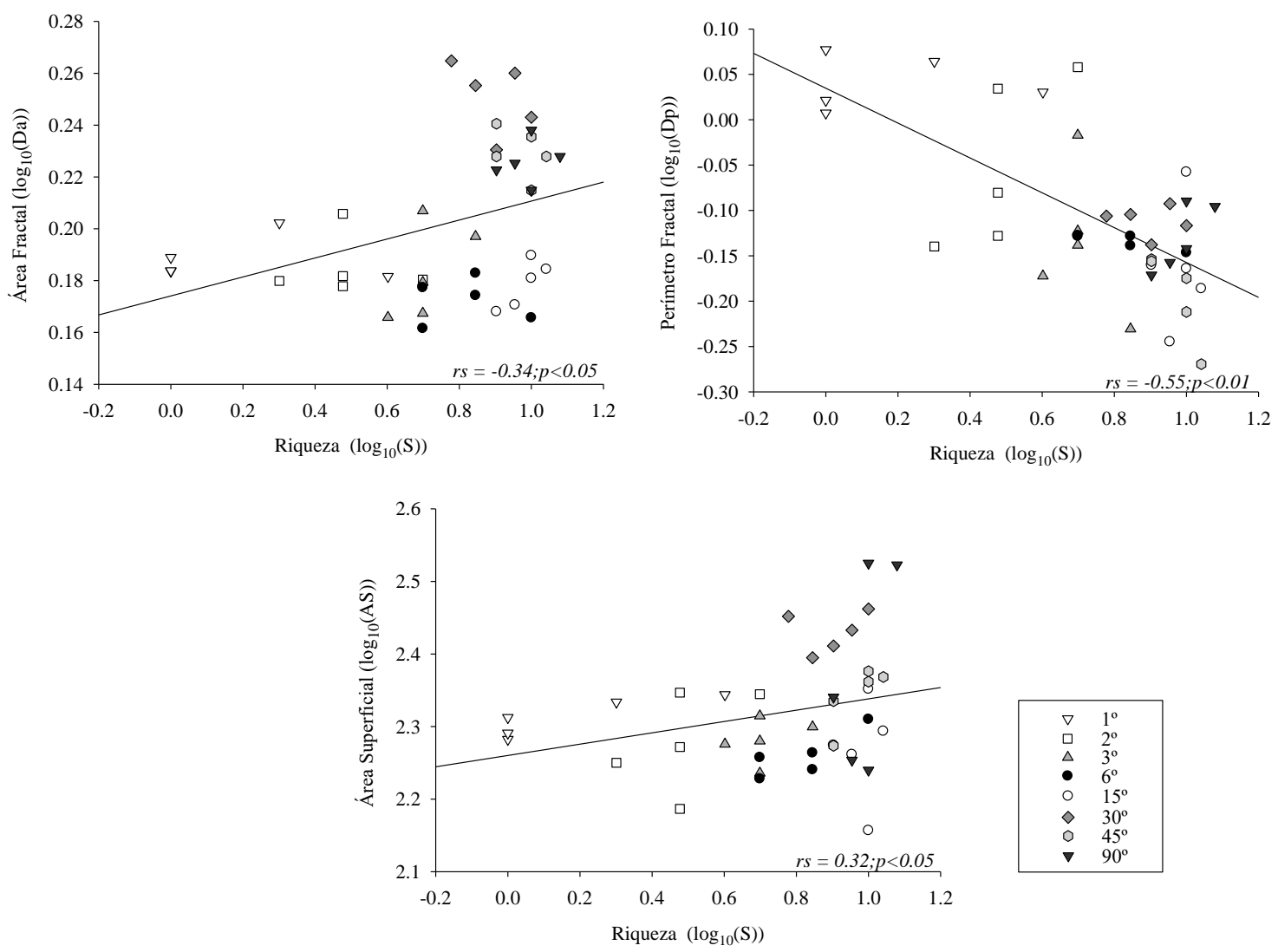

Figura 08 - Correlação de Spearman entre as variáveis de complexidade das algas artificiais mímicas e a abundância de anfípodes nos oito períodos amostrados.

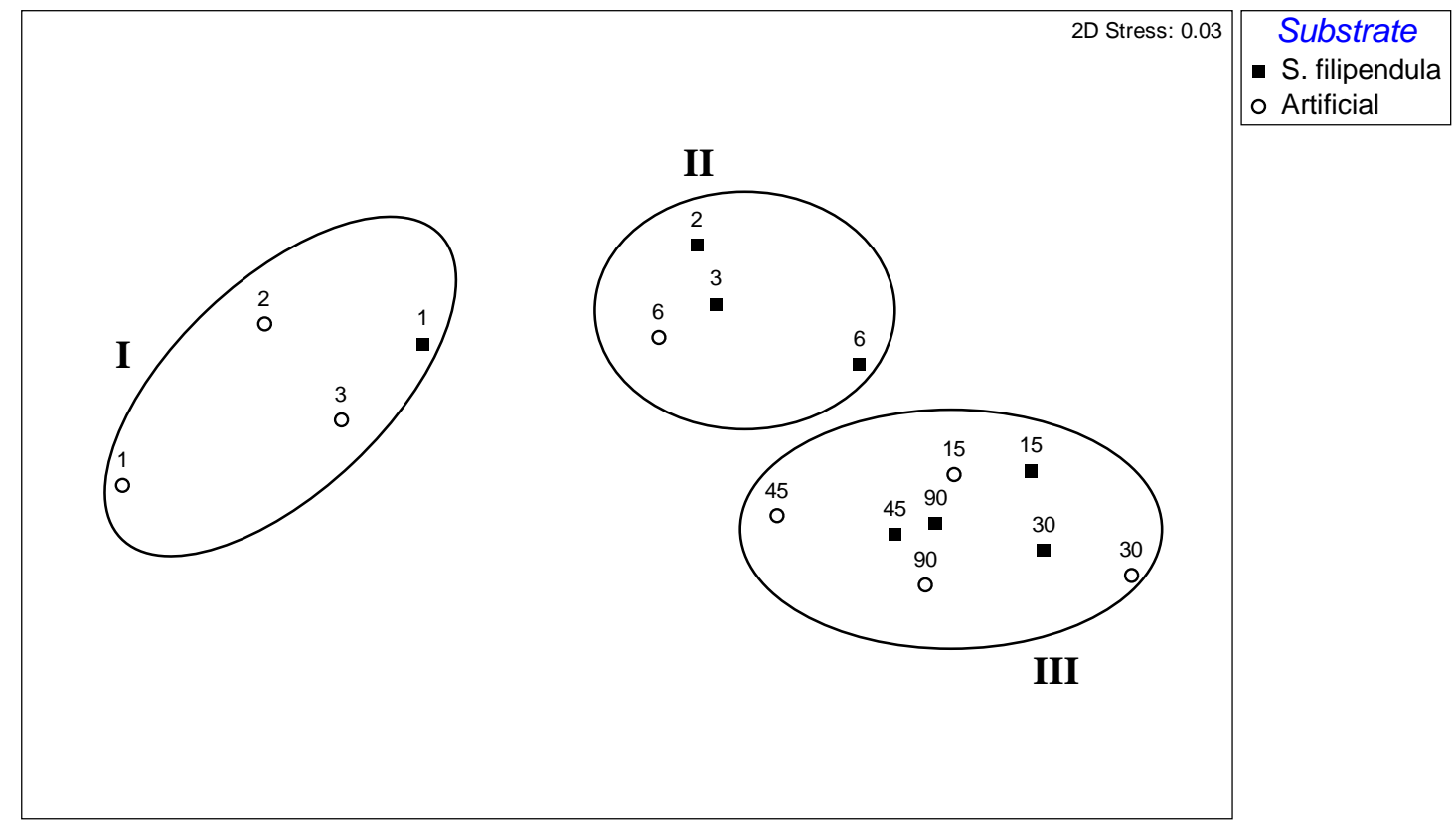

Figura 09 - Second-stage nMDS mostrando os três grupos identificados. Os números representam o dia de amostragem. 
A ANOSIM aplicado aos dados mostrou que os grupos foram muito diferentes um do outro ( $\mathrm{R}$ Global $=0,924 ; \mathrm{sl}=0,1 \%$, sendo a maior diferença observada entre os Grupos I e III (R: 1 p: 0,2\%) seguido pelos Grupos II e III (R: 0,864; p: 0,2\%) (Tabela $05)$.

Tabela 05 - Resultados da ANOSIM aplicada à interação entre período e grupos. Sl = nível de significância.

\begin{tabular}{|c|c|c|}
\hline \multicolumn{3}{|c|}{ ANOSIM } \\
\hline Período: & $\mathrm{al}=0,924$ & $\mathrm{p}=0,1 \%$ \\
\hline Grupos & $\mathbf{R}$ & $\mathrm{sl}(\%)$ \\
\hline$I, I I$ & 0,958 & 2,9 \\
\hline I, III & 1 & 0,2 \\
\hline$I I, I I I$ & 0,864 & 0,2 \\
\hline
\end{tabular}

O SIMPER apontou apenas três espécies tubícolas como as mais comuns durante todo o período estudado: Ericthonius punctatus, Cymadusa filosa e Ampithoe ramondi (Tabela 06). O maior valor médio de dissimilaridade foi observado entre os Grupos I e III $(97,7 \%)$, seguido pelos Grupos I e II $(89,7 \%)$ e Grupos II e III $(78,5 \%)$.

Em geral, o Grupo I pode ser interpretado como o ponto de partida da colonização dos anfípodes devido à presença de seis espécies pioneiras (Tabela 06). Durante os primeiros dias observou-se os valores mais baixos de todos os descritores $(N: 6,1 \pm 4,5$ indivíduos; S: $2 \pm 1$ espécies e $H^{\prime}: 0,76 \pm 0,47$ ), com exceção da equitabilidade com número médio maior $(0,69 \pm 0,34)$. Diferentemente dos outros grupos, houve dominância dos detritívoros/ herbívoros, C. filosa e A. ramondi seguidos pelo suspensívoros $E$. punctatus, todas as espécies sendo tubícolas (Tabela 06).

O Grupo II representou o período de assentamento de novas espécies de anfípodes, bem como a manutenção daquelas previamente estabelecidas, levando a um aumento da de abundância média (141,3 \pm 109,2 indivíduos) e riqueza ( $7 \pm 1$ espécies). Neste grupo, as mesmas espécies tubícolas presentes no Grupo I foram as mais abundantes, seguidas por novas espécies de suspensívoros (Photis longicaudata e Laticorophium baconi) e detritívoros (Batea catharinensis, Caprella scaura e Paracaprella pusilla) (Tabela 06).

O Grupo III pode ser definido pela alta abundância média $(653 \pm 412$ indivíduos), ocasionada primeiramente pela alta dominância de E. punctatus e, em segundo lugar pela chegada de novas espécies. Devido ao forte domínio de E. punctatus, a equitabilidade média foi a menor entre os grupos $(0,42 \pm 0,16)$. Muito provavelmente, no Grupo III começa o início da partição de nicho, uma vez que a maioria das espécies recém-chegadas 
tem diferentes grupos tróficos de E. punctatus (tubícolas suspensívoro). Estas espécies são herbívoras de vida livre, como Dulichiella anisochir e Hyale niger; detritívoras/ herbívoras de vida livre, como Elasmopus pectenicrus; comensais, como Leucothoe spinicarpa e Stenothoe valida e as detritívoras/ carnívoras de vida livre, tal como Apolochus neapolitanus e Shoemakerella cubensis (Tabela 06).

Tabela 06 - Resultados da análise SIMPER aplicada nos três grupos encontrados no second-stage nMDS, mostrando a abundância média (Ab.) e a porcentagem de contribuição de cada espécie. Contribuições maiores que $5 \%$ estão em negrito.

\begin{tabular}{|c|c|c|c|c|c|c|}
\hline \multirow{2}{*}{ Espécies } & \multicolumn{2}{|c|}{$\mathbf{I}$} & \multicolumn{2}{|c|}{ II } & \multicolumn{2}{|c|}{ III } \\
\hline & $\mathrm{Ab}$. & $\%$ & Ab. & $\%$ & Ab. & $\%$ \\
\hline Ericthonius punctatus & 1.60 & 18.20 & 49.60 & 36.14 & 533.29 & 84.43 \\
\hline Cymadusa filosa & 2.85 & 53.90 & 23.15 & 19.51 & 10.10 & 1.90 \\
\hline Ampithoe ramondi & 0.75 & 17.99 & $\mathbf{5 5 . 5 0}$ & 34.76 & 13.89 & 1.16 \\
\hline Dulichiella anisochir & & & & & 25.48 & 2.58 \\
\hline Batea catharinensis & 0.30 & 6.91 & 2.80 & 1.05 & 0.68 & 0.02 \\
\hline Laticorophium baconi & & & 2.15 & 1.30 & 11.69 & 1.75 \\
\hline Photis longicaudata & & & 1.80 & 1.05 & 24.91 & 4.61 \\
\hline Podocerus brasiliensis & & & 0.85 & 0.85 & 1.93 & 0.04 \\
\hline Caprella scaura & 0.15 & 1.50 & 1.45 & 1.93 & 0.28 & 0.02 \\
\hline Paracaprella pusilla & 0.15 & 1.50 & 2.50 & 3.04 & 23.04 & 2.48 \\
\hline Aora spinicornis & & & 0.30 & 0.28 & 0.03 & - \\
\hline Leucothoe spinicarpa & & & & & 5.11 & 0.75 \\
\hline Elasmopus pectenicrus & & & & & 1.53 & 0.21 \\
\hline Stenothoe valida & & & 0.15 & 0.03 & 0.55 & 0.04 \\
\hline Shoemakerella cubensis & & & & & 0.20 & 0.01 \\
\hline Hyale niger & & & & & 0.03 & - \\
\hline Sunamphitoe pelagica & & & 0.45 & 0.03 & & \\
\hline \multicolumn{7}{|l|}{ Gammaropsis palmata } \\
\hline Jassa slatteryi & & & 0.20 & 0.03 & & \\
\hline Apolochus neapolitanus & & & & & 0.03 & - \\
\hline
\end{tabular}




\section{DISCUSSÃO}

Este estudo mostrou que a comunidade de anfípodes apresentou uma resposta semelhante a ambos os substratos investigados, embora um atraso na colonização tenha sido observado nos primeiros dias para as algas artificiais. Esse fato mostra que a primeira hipótese levantada inicialmente foi respondida de modo parcial. Após o $15^{\circ}$ dia, a composição, abundância e diversidade das espécies foram semelhantes nos dois tipos de substrato. $\mathrm{O}$ atraso na colonização de anfípodes observado entre o substrato artificial e as frondes de Sargassum filipendula pode ser explicado pela falta de um biofilme no substrato artificial no início do experimento. A atratividade do biofilme para os organismos epifaunais já foi reportada por vários estudos sobre epifauna vágil (EDGAR, 1991; EDGAR \& KLUMPP, 2003).

Normalmente, o biofilme, bactérias e diatomáceas, estão presentes após 24 horas no início do experimento, dependendo de algumas condições abióticas (YEBRA et al., 2012; CIMA \& BALLARIN, 2013). De acordo com esses autores, deve haver uma adesão de partículas orgânicas (por exemplo, proteínas e polissacarídeos) em primeiro lugar, seguida por bactérias de desenvolvimento rápido e diatomáceas de célula única que se instalam na superfície dos substratos artificiais. No presente estudo, o S. filipendula passou por um procedimento de defaunação pelo qual, provavelmente, apenas os macroinvertebrados foram removidos, mas não o biofilme. Quando ambos os substratos foram submersos novamente, S. filipendula, com substrato mais complexo revestido com o biofilme, conseguiu atrair mais anfípodes que os artificiais (TANIGUCHI et al., 2003; HANSEN et al., 2011). Após três dias na água, as algas artificiais apresentaram composição e abundância semelhantes às do primeiro dia dos naturais, o que indicou a provável presença de biofilme no substrato plástico.

A segunda hipótese postulou que a complexidade do substrato influenciaria a escolha do habitat pela comunidade de anfípodes, uma vez que habitats mais complexos fornecem mais espaço e recursos para os macroinvertebrados (McABENDROTH et al., 2005; HAUSER et al., 2006). Para avaliar melhor a complexidade do habitat, aplicou-se a Área Superficial (AS) e as medidas de dimensão fractal, representadas pela Área Fractal (Da) e Perímetro Fractal (Dp). Por um lado, Da revela a forma como a área é dividida no espaço descrevendo a estrutura do intervalo, portanto, valores mais altos de Da indicam divisões elevadas e menor tamanho médio da lacuna. Por outro lado, Dp indica o grau de 
convoluções de bordas de macroalgas; valores altos mostram divisão adicional do espaço em escalas menores (McABENDROTH et al., 2005). Nossos resultados aceitaram em parte, esta segunda hipótese, considerando que apenas o substrato artificial apresentou o aumento na complexidade durante o experimento (AS e Da), o que teve influência direta tanto na abundância quanto na riqueza da comunidade de anfípodes. Para as frondes de S. filipendula ocorreu o contrário, ou seja, os valores máximos de Da foram relacionados a diminuição dos valores de abundância e AS não apresentou correlação com os valores de abundância. Esses resultados provavelmente estavam relacionados ao declínio dos valores de AS e Da ao final do experimento. Nossos resultados concordam com aqueles de estudos anteriores (HANSEN et al., 2011) que também compararam a colonização de macroinvertebrados em substratos naturais e artificiais. De acordo com essas descobertas, os macroinvertebrados escolheram substratos mais complexos, independentemente do tipo.

Os valores de Dp influenciaram as comunidades de anfípodes de forma diferente considerando os tipos de substratos. Nas frondes de $S$. filipendula, o aumento de Dp resultou em altas abundâncias, enquanto que nos substratos artificiais foi correlacionado com a diminuição da abundância e da riqueza. O resultado obtido para o Sargassum filipendula corroborou o encontrado por estudos anteriores (TANIGUCHI \& TOKESHI, 2004; TOKESHI \& ARAKAKI, 2012), e pode ser explicado pelo fato de que um habitat mais fragmentado proporcionará mais espaços pequenos, resultando em aumento da densidade de pequenos organismos. De fato, no presente estudo observou-se, especialmente no final do experimento, um aumento de espécies de porte pequeno, como Photis longicaudata e Laticorophium baconi. No entanto, no substrato artificial ocorreu o oposto, ou seja, a diminuição nos valores de Dp resultou em um maior número de espaços com dimensões maiores do que aqueles observados para S. filipendula. Com base nisso, pode-se inferir que o habitat artificial permitiria a coexistência entre espécies de tamanhos corporais diferentes, levando a um aumento na abundância e riqueza, como observamos em nossos resultados.

Além do tipo de substrato (natural ou artificial), o comprimento do período experimental foi um fator importante no estudo. Durante esse período, e especialmente após o $30^{\circ}$ dia, os valores dos descritores de comunidade (diversidade, riqueza e abundância) aumentaram significativamente. No caso dos substratos artificiais também 
ocorreu um aumento na Área Superficial (AS). Considerando-se os dois aumentos (abundância e AS), estes provavelmente estariam relacionados ao desenvolvimento de algas epífitas e conteúdo detrital na superfície dos substratos. Foi relatado que a presença de algas epífitas depende da duração do período de submersão dos substratos artificiais, ou seja, se esse tempo é suficiente para o desenvolvimento de algas (EDGAR, 1991). Além disso, a carga epífita pode aumentar a atratividade de um habitat, uma vez que pode fornecer abrigo e/ou alimento para uma quantidade adicional de organismos (CACABELOS et al., 2010). Foi proposto por alguns autores que anfípodes não comem tecidos da macroalga diretamente, mas se alimentam dos recursos associados, tal como detritos (GUERRA-GARCÍA et al., 2014). Por exemplo, caprelídeos (Caprella scaura e Paracaprella pusilla), Photis longicaudata e Laticorophium baconi alimentam-se principalmente de detritos (GUERRA-GARCÍA et al., 2014) e Dulichiella anisochir é considerada herbívora de microalgas (LEE \& BRUNO, 2014). Em conclusão, a maior abundância observada no $15^{\circ}$ e $90^{\circ}$ dias poderia ser ocasionada pelas maiores taxas de imigração e, neste caso, mais organismos conseguiriam detectar e/ou serem atraídos para um substrato com algas epífitas e/ou conteúdo detritivo.

A fauna de anfípodes obtida neste estudo mostrou-se semelhante àquela normalmente descrita para os bancos de Sargassum que cobrem os costões rochosos do Estado de São Paulo, sudeste do Brasil (LEITE et al., 2007; JACOBUCCI et al., 2009b). Embora apresente uma alta diversidade de grupos tróficos e modo de vida, os tubícolas suspensívoros foram os organismos mais numerosos. Esta grande abundância foi resultado do elevado número de Ericthonius punctatus, espécie suspensívora eurihalina/polihalina que habita as águas costeiras quentes em todo o mundo (MYERS \& McGRATH, 1984; MILOSLAVICH et al., 2010).

A elevada abundância observada para E. punctatus neste estudo pode estar relacionada à colonização eficiente que fazem em qualquer tipo de material (eles estão especialmente envolvidos na incrustação de navios e instalações de materiais artificiais), bem como seu estilo de vida e trófico (KEVREKIDIS \& KOUKOURAS, 1988). Embora essa espécie seja encontrada abundantemente em algas pardas e vermelhas, bem como em fanerógamas, hidroides e tunicados, ela não se alimenta do hospedeiro e sim de detritos (DUFFY, 1990; GUERRA-GARCÍA et al., 2014). Vários estudos (TARAMELLI \& PEZZALI, 1986; SEZGIN \& KATAGAN, 2007) mostraram que E. punctatus pode ser 
frequentemente encontrada em áreas de grande acúmulo de detritos e pode suportar agentes poluentes presentes em portos e lagoas, como é o caso da área de estudo. A praia do Lamberto é uma praia protegida, caracterizada por baixa atividade hidrodinâmica e entrada de poluentes de origem antropogênica, como o petróleo proveniente das embarcações do Saco da Ribeira e o esgoto trazido pelo do rio Perequê-Mirim (ALBERGARIA-BARBOSA et al., 2011; STRADIOTTO, 2013; JACOBUCCI \& LEITE, 2014).

De acordo com a dieta baseada em detritos de E. punctatus, a alta abundância observada para substratos artificiais provavelmente está mais relacionada ao espaço disponível para colonização do que ao valor nutricional da própria planta. Além disso, $E$. punctatus vive em tubos simples de muco e detritos que não podem ser destacados e movidos (LOWRY \& BERENTS, 1996). Provavelmente a espécie foi a responsável por construir a maioria dos agrupamentos de tubos descontínuos observados na superfície de ambos os substratos (observação pessoal). À medida que os tubos sésseis reduzem o espaço disponível na superfície das algas, podem impedir o estabelecimento de outras espécies, conferindo, assim, vantagem competitiva a E. punctatus. Para testar esta hipótese, recomenda-se que sejam realizados estudos experimentais específicos.

Duas espécies de Ampithoidae, Cymadusa filosa e Ampithoe ramondi constituíam o segundo grupo mais abundante de tubícolas. Ambas as espécies são cosmopolitas de grande tamanho e detritívoras/herbívoras (APPADOO \& MYERS, 2003; POORE et al., 2008). De forma semelhante a E. punctatus, A. ramondi também é resistente a poluentes orgânicos e pode formar populações monoespecíficas importantes em locais contaminados (SEZGIN \& KATAGAN, 2007). As preferências generalizadas de habitat de Cymadusa spp. (bem como Ampithoe spp.) podem favorecer colonizações bemsucedida (PEART, 2004). No presente estudo, essas características parecem fornecer uma boa explicação para a colonização rápida e eficiente de Cymadusa filosa no início do experimento em ambos os substratos.

A diminuição observada na Área Superficial (AS) do S. filipendula durante o experimento pode ser resultado de uma diminuição da altura do talo e no número total de ramos laterais primários (observação pessoal). A diminuição do desenvolvimento vegetativo poderia ser uma resposta para o estresse fisiológico causado pelo procedimento metodológico empregado (amostragem-defaunação-realocação). No 
entanto, é necessário esclarecer se o declínio envolveu a senescência da planta mediada por variáveis físicas (temperatura ou intensidade de luz) e/ou químicas (nutrientes) ou, se é devido a interações biológicas, como a pastagem por anfípodes ou por mesmo peixes.

Diferentemente da baixa variação que ocorreu entre as réplicas artificias até o $45^{\circ}$ dia, detectou-se uma grande variação nas réplicas naturais durante todo o experimento. Muitos estudos relataram uma alta variabilidade entre réplicas para substratos naturais e argumentaram ser devido a diferenças de tamanho, composição e estrutura do habitat, parâmetros estes que influenciam a distribuição dos organismos (SMITH \& RULE, 2002; RULE \& SMITH, 2005). Ao se usar substratos artificias, todas as réplicas são padronizadas em termos de forma e tamanho, o que minimiza a variação entre repetições e, consequentemente, leva a informações mais uniformes sobre a epifauna. Além disso, com material plástico é de baixo custo e de fácil manipulação, podendo ser utilizada para examinar fatores específicos que afetam a distribuição dos organismos, como profundidade, intensidade de luz, etc.

Para concluir, ao comparar as frondes de S. filipendula com substratos artific iais mímicos em um sistema marinho, este estudo tornou-se pioneiro no Brasil. Trabalhos anteriores com fital foram feitos apenas em ambientes de água doce (DIBBLE \& THOMAZ, 2009). A intenção deste trabalho foi também a de incentivar os pesquisadores a usar substratos artificiais para quantificar e qualificar a comunidade marinha, usando uma abordagem experimental. Como demonstraram os resultados, o substrato artificial apresentou padrões consistentes de riqueza, abundância e diversidade, assemelhando-se ao substrato natural. Este fato é uma descoberta importante quando se considera seu possível emprego em programas de recuperação e gestão ambiental. Com base neste trabalho, também podemos recomendar uma maior atenção tanto no tempo de duração do experimento quanto na manipulação dos substratos naturais. O período de 90 dias mostrou um aumento de AS e Da, bem como a variabilidade entre as réplicas. Em nossa opinião as experiências devem ser feitas em curto prazo, ao redor de 45 dias, para que o formato e o tamanho do substrato (ou seja, AS, volume e Da) não sejam extremamente diferentes do início do experimento. As frondes de Sargassum filipendula experimentaram estresse talvez em resposta à manipulação ou ao posicionamento das frondes na coluna d'água. Esses fatores precisariam ser melhor investigados para que o estresse fosse minimizado, 
a fim de deixas os dois substratos (natural e artificial) em condição o mais próximo possível no ponto inicial do experimento. 


\section{CONSIDERAÇÕES FINAIS}

$\checkmark$ Uma única medida quantitativa para avaliar a complexidade estrutural de Sargassum não é ideal para avaliar a densidade da macrofauna total e pode gerar interpretações errôneas. Recomenda-se empregar um conjunto de medidas quantitativas e morfológicas (como por exemplo, a dimensão fractal) para se ter a real complexidade estrutural das frondes;

$\checkmark$ As frondes mais complexas de Sargassum filipendula foram amostradas na Praia do Lamberto, e esta complexidade influenciou positivamente a abundância da macrofauna total;

$\checkmark$ Tanto as medidas quantitativas, quanto as morfológicas expressaram a complexidade estrutural do Sargassum filipendula coletadas em ambas as praias. Contudo, a medida de Peso Seco Total (PST) apresentou uma maior influência, tanto para a abundância da macrofauna total, como para a de anfípodes;

$\checkmark$ As medidas fractais utilizadas no presente estudo, Área Fractal (Da) e Perímetro Fractal (Dp), apresentaram baixa influência sobre a distribuição e composição da macrofauna total e dos anfípodes nas macroalgas. Entretanto, tais medidas foram eficientes em demonstrar aspectos diferentes na estrutura do Sargassum filipendula;

$\checkmark$ As escalas de resolução - $100 \mathrm{~cm}^{2}, 25 \mathrm{~cm}^{2}, 9 \mathrm{~cm}^{2}$ e $1 \mathrm{~cm}^{2}$ - de Da e Dp empregadas no presente estudo mostraram-se independentes e influíram na classe de tamanho dos anfípodes, Classe I (>2,0 mm), Classe II (1,9-1,0 mm) e Classe III (0,9-0,5 mm);

$\checkmark$ Os valores de Dp influenciaram negativamente a abundância dos anfípodes nas macroalgas em sua menor classe de tamanho, Classe III, comprovando que com o aumento de pequenos espaços entre os ramos há um incremento na abundância de espécies de pequeno porte e jovens;

$\checkmark$ Apesar dos substratos artificiais mímicos terem apresentado um atraso na colonização dos anfípodes, tais substratos exibiram abundância e composição de espécies semelhantes ao substrato natural, Sargassum filipendula. Por esta razão, 
acredita-se que os substratos artificiais podem ser empregados em estudos de monitoramento ambiental;

$\checkmark$ Com base nas medidas quantitativas e morfológicas, Área Superficial da Macroalga (ASM) e Da, observamos um incremento da complexidade estrutural do substrato artificial mímico durante o experimento. Essas medidas influenciaram positivamente a abundância e riqueza de espécies dos anfípodes;

$\checkmark$ Todos os valores dos descritores de comunidade de anfípodes - abundância, riqueza e diversidade - obtidos no presente estudo, estão de acordo com aqueles reportados para as espécies de Sargassum na região de Ubatuba. 


\section{REFERÊNCIAS BIBLIOGRÁFICAS}

AGUILAR-ROSAS, R. \& GALUNDO, A.M. 1990. Ecological aspects of Sargassum muticum (Fucales, Phaeophyta) in Baja California, Mexico: reproductive phenology and epiphytes. Hydrobiologia, 204/205: 185-190.

AIKINS, S. \& KIKUCHI, E. 2001. Studies on habitat selection by amphipods using artificial substrates within an estuarine environment. Hydrobiologia, 457:77-86.

ALBERGARIA-BARBOSA, A.C.R.; ALVES, D.P.V.; BALDASSIN, P.; BÍCEGO, M.C.; CAM ARGO, J.M.; COELHO, L.H.F.; FELIX, C. et al. 2011. Impacts of marina constructions over the depositional conditions in the Saco da Ribeira, Ubatuba - SP. Oceanografia e Políticas Públicas. V Simpósio Brasileiro de Oceanografia.

ALMADA， C.H.B.A.; YONESHIGUE-VALENTIN， Y.; NASSAR， C.A.G. 2008. Aspectos populacionais de Sargassum vulgare C. Agardh (Ochrophyta, Fucales) na Ponta do Arpoador - Rio de Janeiro. Oecol. Bras., 12(2): 291-298.

AMADO-FILHO, G.M.; BARRETO, M.B.B.; MARINS, B.V.; FELIX, C. \& REIS, R.P. 2003. Estrutura das comunidades fitobentônicas do infralitoral da Baía de Sepetiba, RJ, Brasil. Revista Brasileira de Botânica, 26: 329-342.

ANDERSON, M.J. 2001. A new method for non-parametric multivariate analysis of variance. Aust. Ecol, 26: 32-46.

ANDERSON, M.J.; GORLEY, R.N.; CLARKE, K.R. 2008. PERMANOVA+ for PRIMER: Guide to Software and statistical methods. PRIMER-E, Plymouth, UK.

ANG JR, 1985. Phenology of Sargassum siliquosum J. Ag. And S. paniculatum A. Ag. (Sargassaceae, Phaeophyta) in the reef flat of Balibago (Calatagan, Philippines). In: Proceedings of the $5^{\text {th }}$ International Coral Reef Congress. Taiti, Polinésia Francesa. Pp: 51-57.

APPADOO, C. \& MYERS, A.A. 2003. Observations on the tube-building behaviour of the marine amphipod Cymadusa filosa (Crustacea: Ampithoidae). J. Nat. Hist., 37: 2151-2164.

ASSIS, T.A.; MIRANDA, J.G.V.; MOTA, F.B.; ANDRADE, R.F.S. \& CASTILHO, C.M.C. 2008. Geometria fractal: propriedades e características de fractais ideias. Rev. Bras. Ens. Fis., 30(2): 2304-1 - 2304-10. 
ATILLA, N.; FLEEGER, J.W.; FINELLI, C.M. 2005. Effects of habitat complexity and hydrodynamics on the abundance and diversity of small invertebrates colonizing artificial substrates. J. Mar. Res., 63: 1151-1172.

ATTRILL, M.J.; STRONG, J.A. \& ROWDEN, A.A. 2000. Are macroinvertebrate communities influenced by seagrass structural complexity? Ecography 23, 114-121.

AYALA, Y. \& MARTÍN, A. 2003. Relaciones entre 1 ala comunidade de anfípodos y las macroalgas a las que están associados, em uma plataforma rochosa del litoral central de Venezuela. Bol. Inst, Esp. Oceanogr. 19 (1-4): 171-182.

BARNSLEY, F. 1993. Fractals Everywhere. Boston Academic Press, 531pp.

BACCHIOCCHI, F. \& AIROLDI, L. 2003. Distribution and dynamics of epibiota on hard structures for coastal protection. Estuar. Coast Shelf Sci., 56: 1157-1166.

BEERMANN, J. 2014. Spatial and seasonal population dynamics of sympatric Jassa species (Crustacea, Amphipoda). J. Exp. Mar. Biol. Ecol., 459: 8-16.

BECK, M.W. 1998. Comparison of the measurement and effects of habitat structure in gastropods in rocky intertidal and mangrove habitats. Marine Ecology Progress Series, 169: $165-178$.

BIERNBAUM, C.K. 1979. Influence of sedimentary factors on the distribution of benthic amphipods of fishers Island Sound, Connecticut. J. Exp. Mar. Biol. Ecol., 38: 201-223.

BILTON, D.T.; McABENDROTH, L.; BEDFORD, A. \& RAMSAY, P.M. 2006. How wide to cast the net? Cross-taxon congruence of species richness, community similarity and indicator taxa in ponds. Freshwater Biol., 51; 578-590.

BOUMA, T.J.; OLENIN, S.; REISE, K.; YSEBAERT, T. 2009. Ecosystem engineering and biodiversity in coastal sediments: posing hypotheses. Helgol Mar. Res., 63: 95106.

BRADBURY, R.H.; REICHELT, R.E. \& GREEN, D.G. 1984. Fractals in ecology: methods and interpretation. Mar. Ecol. Prog. Ser. 14, 295-296.

BRAWLEY, S.H. \& FEI, X.G. 1987. Studies of mesoherbivory in aquaria and in an unbarricaded mariculture farm in the Chinese coast. J. Phycol., 23: 614-623. 
CACABELOS, E.; OLABARRIA, C.; INCERA, M.; TRONCOSO, J. 2010. Effects of habitat structure and tidal height on epifaunal assemblages associated with macroalgae. Estuar. Coast Shelf Sci., 43-52.

CESAR, R.M. \& COSTA, L.F. 2000. Shape Analysis and Classification: Theory and Practice. Hardcover.

CHEMELLO, R. \& MILAZZO, M. 2002. Effect of algal architecture on associated fauna: some evidence from phytal mollusks. Mar. Biol. 140, 981-990.

CHRISTIE, H.; JØRGENSEN, N.M.; NORDERHAUG, K.M. 2007. Bushy or smooth, high or low; importance of habitat architecture and vertical position for distribution of fauna on kelp. J. Sea Res., 58: 198-208.

CHRISTIE, H; NORDERHAUG, K.M.; FREDRIKSEN, S. 2009. Macrophytes as habitat for fauna. Mar. Ecol. Prog. Ser., 396: 221-233.

CIMA, F. \& BALLARIN, L. 2013. A proposed integrated bioindex for the macrofouling biocoenosis of hard substrata in the lagoon of Venice. Estuar. Coast. Shelf Sci., 130: 190-201.

CLARKE, K.R. \& WARWICK, R.M. 1994. An approach to statistical analysis and interpretation. Change in marine communitites, v.2.

COIMBRA, C.S. 2006. Inferências filogenética na ordem Fucales (Phaeophyceae), com ênfase no gênero Sargassum C. Agardh do Atlântico Sul. Tese (Doutorado), Instituto de Biociências da Universidade de São Paulo, Departamento de Botânica, 71pp.

CORBISIER, T.N. Macrozoobentos da Praia do Codó (Ubatuba, SP) e a presença de Haludule wrightii Acherson. Bolm. Inst. Oceanogr., 42(1/2): 99-111, 1994.

COULL, B.C. \& WELL, J.B.J. 1983. Refuges from fish predation: experiments with phytal meiofauna from the New Zealand rock intertidal. Ecology, 64: 1599-1609.

CREMONA, F.; PLANAS, D.; LUCOTTE. 2008. Biomass and composition of macroinvertebrate communities associated with different types of macrophyte architectures and habitats in a large fluvial lake. Fundam. Appl. Limnol., 171(2): 119130.

CROOKS, J.A. 2002. Characterizing ecosystem-level consequences of biological invasions: the role of ecosystem engineers. Oikos, 97: 153-166. 
CUNHA, F.L.R.; CUNHA, A.F.; JACOBUCCI, G.B. 2010. Is the occurrence of caprellid amphipods associated with Sargassum (Phaeophyta) influenced by algal and hydrozoan epibiosis? Zoociências, 10(3): 257-264.

CÚRDIA, J.; CARVALHO, S.; PEREIRA, F.; GUERRA-GARCÍA, J.M.; SANTOS, M.N.; CUNHA, M.R. 2015. Diversity and abundance of invertebrate epifauna assemblages associated with gorgonians are driven by colony attributes. Coral Reefs, 34:611-624. doi: 10.1007/s00338-015-1283-1.

CYR, H. \& DOWNING, J.A. 1988. The abundance of phytophilous invertebrates on different species of submerged macrophytes. Freshwater Biol. 20, 365-374.

D' ANTONIO, C. 1985. Epiphytes on th rocky intertidal alga, Rhodomela larix (Turner) C. Agardh: negative effects on the host and foof for herbivores? J. Exp. Mar. Biol. Ecol., 86: 197-218.

DAVENPORT, J.; BUTLER, A.; CHESHIRE, A. 1999. Epifaunal composition and fractal dimension of marine plants in relation to emersion. J. Mar. Biol. Ass. UK, 79(2): 351-355.

DAYTON, P.K. 1971. Competition, disturbance, and community organization the provision and subsequent utilization of space in a rocky intertidal community. Ecol. Monogra., 41: 351-389.

DE BROYER, C. \& JAZDZEWSKI, K. 1996. Biodiversity of the Southern Ocean: towards a new synthesis for the Amphipoda (Crustacea). Boll. Mus. Civ. Stor. Nat. Verona, 20: 547-568.

De-la-OSSA-CARRETERO, J.A.; DEL-PILAR-RUSO, Y., GIMÉNEZCASALDURERO, F.; SÁNCHEZ-LIZASO, J.L., DAUVIN, J.C. 2011. Sensitivity of amphipods to sewage pollution. Estuar. Coast. Shelf Sci., 73: 630-638.

DIBBLE, E.D.; THOMAZ, S.M.; PADIAL, A.A. 2006. Spatial complexity measured at multi-scale in three aquatic plant species. Journal of Freshwater Ecology, 21(2): 239247.

DIBBLE, E.D. \& THOMAZ, S.M. 2009. Use of fractal dimension to assess habitat complexity and its influence on dominant invertebrates inhabiting tropical and temperate macrophytes. Journal of Freshwater Ecology, 24(1): 93-102.

DUFFY, J.E. 1990. Amphipods on seaweeds: partners or pests? Oecologia, 83: 267-276. 
DULEBA, W. 1994. Interpretações paleoambientais obtidas a partir das variações na coloração das carapaças de foraminíferos, da Enseada do Flamengo, SP. Bolm. Inst. Oceanogr., 42 (1/2): 63-72.

EDGAR, G.J. 1991. Artificial algae as habitats for mobile epifauna: factors affecting colonization in a Japonese Sargassum bed. Hydrobiologia, 226: 111-118.

EDGAR, G.J. \& KLUMPP, D.W. 2003. Consistencies over regional scales in assemblages of mobile epifauna associated with natural and artificial plants of different shape. Aquat. Bot., 75: 275-291.

EILERTSEN, M.; NORDERHAUG, K.M.; SJØTUN. 2011. Does the amphipod fauna associated with epiphytes on kelp (Laminaria hyperborean) change with depth? Mar. Biol. Res., 7: 224-234.

FERREIRO, N.; FEIJOÓ, C.; GIORGI, A.; LEGGIERI, L.; 2011. Effects of macrophyte heterogeneity and food availability on structural parameters of the macroinvertebrate community in a Pampean stream. Hydrobiologia, 664: 199-211.

FERREIRO, N.; GIORGI, A.; FEIJOÓ, C. 2013. Effects of macrophyte architecture and leaf shape complexity on structural parameters of the epiphytic algal community in a Pampean stream. Aquat. Ecol, 47: 389-401.

FIGUEIREDO, M.A.O.; TREVOR, A.N.; KAIN, J.M. 1997. Settlement and survival of epiphytes on two intertidal crustose coralline alga. J. Exp. Mar. Biol. Ecol., 213: 247260.

FIGUEIREDO, M.A.O.; KAIN-JONES, J.N.; NORTON, J.M. 2000. Responses of crustose coralline to epiphyte and canopy cover. Journal of Phycology, 36: 17-24.

FROST, N.J.; BURROWS, M.T.; JOHNSON, M.P.; HANLEY, M.E.; HAWKINS, S.J. 2005. Measuring surface complexity in ecological studies. Limnol. Oceanogr.: Methods 3: 203-210.

GARCÍA-GÓMEZ, J.C.; LÓPEZ-FÉ, C.M.; ESPINOSA, F.; GUERRA-GARCÍA, J.M.; RIVERA-INGRAHAM，G.A. 2011. Marine artificial micro-reserves: a possibility for the conservation of endangered species living on artificial substrata. Mar. Ecol., 32: 614.

GEE, J.M. \& WARWICK, R.M. 1994a. Metazoan community structure in relation to the fractal dimensions of marine macroalgae. Mar. Ecol. Prog. Ser. 103, 141-150. 
GEE, J.M. \& WARWICK, R.M. 1994b. Body size distribution in a marine metazoan community and the fractal dimensions of macroalgae. J. Exp. Mar. Biol. Ecol., 178: 247-259.

GEE, J.M. \& WARWICK, R.M. 1996. A study of global biodiversity patterns in the marine motile fauna of hard substrata. J. Mar. Biol. Ass. UK, 76: 177-184.

GIBBONS, W.N.; MUNN, M.D.; PAINE, M.D. 1993. Guidelines for monitoring benthos in freshwater environments. Report prepared for Environment Canada, North Vancouver, B.C. by EVS Consultants, North Vancouver, B.C. 81pp.

GODOY, E.A.S. \& COUTINHO, R. 2002. Can artificial beds of plastic mimics compensate for seasonal absence of natural beds of Sargassum furcatum? J. of Marine Science, 59: 111-115.

GUERRA-GARCÍA, J.M.; TIERNO DE FIGUEROA, J.M. 2009. What do caprellids feed on? Mar. Biol., 156: 1881-1890.

GUERRA-GARCÍA, J.M.; FIGUEROA, J.M.T.; NAVARRO-BARRANCO, C.; ROS, M.; SÁNCHEZ-MOYANO, J.E.; MOREIRA, J. 2014. Dietary analysis of the marine Amphipoda (Crustacea: Peracarida) from the Iberian Peninsula. J. Sea Res., 85: 508517.

GUIRY, M.D. \& GUIRY, G.M. 2016. AlgaeBase. World-wide Electronic Publication, National University of Ireland, Galway [WWW Document] AlgaeBase (URL www.algaebase.org, accessed 15.12.16).

GUNNARSSON, B. 1992. Fractal dimension of plants and body size distribution in spiders. Functional Ecology, 6(6): 636-641.

GUNNILL, F.C. 1985. Population fluctuations of seven macroalgae in southern California during 1981-1983 including effects of severe storms and an El Niño. J. Exp. Mar. Biol. Ecol., 85: 149-164.

HACKER, S.D. \& STENECK, R.S. 1990. Habitat architecture and the abundance and body size-dependent habitat selection of a phytal amphipod. Ecology 71, 2269-2285.

HAGERMAN, L. 1966. The macro- and microfauna associated with Fucus serratus L., with some ecological remarks. Ophelia, 3: 1-43. 
HALLEY, J.M.; HARTLEY, S.; KALLIMANIS, A.S.; KUNIN, W.E.; LENNON, J.J.; SGARDELIS, S.P. 2004. Uses and abuses of fractal methodology in ecology. Ecol. Lett., 7: 254-271.

HANSEN, J.P.; SAGERMAN, J.; WIKSTRÖM, S.A. 2010. Effects of plant morphology n small-scale distribution of invertebrates. Mar. Biol., 157: 2143-2155.

HANSEN, J.P.; WIKSTRÖM, S.A.; AXEMAR, H.; KAUTSKY, L. 2011. Distribution differences and active habitat choices of invertebrates between macrophytes of different morphological complexity. Aquat Ecol, 45:11-22.

HARROD, J.J. \& HALL, R.E. 1962. A method for determining the surface areas of various aquatic plants. Hydrobiologia 20(2): 173-178.

HAUSER, A.; ATTRILL, M.J. \& COTTON, P.A. 2006. Effects of habitats complexity on the diversity and abundance of macrofauna colonizing artificial kelp holdfast. Mar. Ecol. Prog. Ser. 325: 93-100.

HOOPER, G.J. \& DAVENPORT, J. 2006. Epifaunal composition and fractal dimensions of intertidal marine macroalgae in relation to emersion. J. Mar. Biol. Ass. U.K., 86: 1297 1304.

HOLMLUND, M.B.; PETERSON, C.H.; HAY, M.E. 1990. Does algal morphology affect amphipod susceptibility to fish predation? J. Exp. Mar. Biol. Ecol., 139: 65-83.

HOWARD, R.K. 1982. Impact of feeding activities of epibenthic amphipods on surfacefouling of eelgrass leaves. Aquat. Bot., 14: 91-97.

HUANG, Y.M.; AMSLER, M.O.; McCLINTOCK, J.B.; AMSLER, C.D.; BAKER, B.J. 2007. Patterns of gammaridean amphipod abundance and species composition associated with dominated subtidal macroalgae from the western Antarctic Peninsula. Polar Biol., 30:1417-1430.

JACOBI, C.M. 1987. Spatial and temporal distribution of Amphipoda associated with mussel beds from the Bay of Santos (Brazil). Mar. Ecol. Prog. Ser., 35: 51-58.

JACOBUCCI, G.B. \& LEITE, F.P.P. 2002. Distribuição vertical e flutuação sazonal da macrofauna vágil associada a Sargassum cymosum C. Agardh, na praia do Lázari, Ubatuba, São Paulo. Brasil.

JACOBUCCI, G.B.; GÜTH, A.Z.; TURRA, A.; MAGALHÃES, C.A.; DENADIR, M.R.; CHAVES, A.M.R.; SOUZA, E.C.F. 2006. Levantamento de Mollusca, 
Crustacea e Echinodermata associados a Sargassum spp. Na Ilha da Queimada Pequena, Estação Ecológica dos Tupiniquins, litoral sul do Estado de São Paulo, Brasil. Biota Neotrop., 6(2): bn02706022006.

JACOBUCCI, G.B.; TANAKA, M.O.; LEITE, F.P.P. 2009a. Temporal variation of amphipod assemblages associated with Sargassum filipendula (Phaeophyta) and its epiphytes in a subtropical shore. Aquat. Ecol., 43: 1031-1040.

JACOBUCCI, G.B.; TANAKA, M.O.; LEITE, F.P.P. 2009b. Factors influencing temporal variation of Sargassum filipendula (Phaeophyta: Fucales) bed in a subtropical shore. J. Mar. Biol. Ass. UK, 89(2): 315-321.

JACOBUCCI, G.B.; GÜTH, A.Z; TURRA, A.; LEITE, F.P.P. 2011. Influence of a narrow depth gradient and season on the morphology, phenology, and epibiosis of the brown alga Sargassum cymosum. J. Mar. Biol. Ass. UK, 91(4): 761-770.

JACOBUCCI, G.B. \& LEITE, F.P.P. 2014. The role of epiphytic algae and different species of Sargassum in the distribution and feeding herbivorous amphipods. Lat. Am. J. Aquat. Res., 42(2): 353-363.

JEFFRIES, M. 1993. Invertebrate colonization of artificial pondweeds of differing fractal dimension. Oikos, 67(1): 142-148.

KARPERIEN, A. 2007-2012. FracLac for ImageJ Version 2.5. Available online at: http://rsb.info.nih.gov/ij/plugins/frcalac/FLHELP/Introduction.htm

KEVREKIDIS, T. \& KOUKOURAS, A. 1988. Bionomy of the amphipods in the Evros Delta (North Aegean Sea). P.S.Z.N.I Mar. Ecol., 9: 199-212.

KLEY, A.; KINZLER, W.; SCHANK, Y.; MAYER, G.; WALOSZEK, D.; MAIER, G. 2009 Influence of substrate preference and complexity on co-existence of two nonnative gammarideans (Crustacea: Amphipoda). Aquat. Ecol., 43: 1047-1059.

KOSTYLEV, V.E.; ERLANDSSON, J.; MING, M.Y.; WILLIAMS, G.A. 2005. The relative importance of habitat complexity and surface area in assessing biodiversity: Fractal application on rocky shores. Ecol. Complex., 2: 272-286.

LEE, S.C. \& BRUNO, J.F. 2014. Propagule supply limits grazer richness equally across a resource gradient. Ecosphere, 5(1):8. http $/ /$ dx.doi.org/10.1890/ES13-00152.1 
LEITE, F.P.P. \& TURRA, A. 2003. Temporal variation in Sargassum biomass, Hypnea epiphytism and associated fauna. Braz. Arch. Biol. Technol., 46(4): 665-671.

LEITE, F.P.P.; TANAKA, M.O.; GEBARA, R.S. 2007. Structural variation in the brown alga Sargassum cymosum and its effects on associated amphipod assemblages. Braz. J. Biol., 67(2): 215-221.

LOWRY, J.K. \& BERENTS, P.B. 1996. The Ericthonius group, a new perspective on an problem (Crustacea: Amphipoda: Corophioidea). Rec. Aust. Mus., 48(1): 75-109.

MACHADO, G.B.O.; SIQUEIRA, S.G.L.; LEITE, F.P.P. 2017. Abundance, performance, and feeding preference of herbivorous amphipods associated with a hostalga-epiphyte system. J. Exp. Mar. Biol. Ecol., 486: 328-335.

MAFRA JR, L.L. \& CUNHA, S.R. 2002. Bancos de Sargassum cymosum (Phaeophyceae) na enseada de Armação do Itapocoroy, Penha, SC: biomassa e rendimento em alginato. Notas Técnicas da FACIMAR, 6: 111- 119.

MAGRUDER, W.H. 1988. Sargassum (Phaeophyta, Fucales, Sargassaceae) in the Hawaiian Islands. In: ABBOTT, I.A., (ed.) Taxonomy of Economic Seaweeds: with reference to some Pacific and Caribbean species. Vol. 2 pp. 65-87. California Sea Grant College Program, University of California, La Jolla, California.

MANDELBROT, B.B. 1967. How long is the coast of Britain? Science, 156 (3775): 636638.

MANDELBROT, B.B. 1983. The fractal geometry of nature. San Francisco: Freeman, 468pp.

MASUNARI, S. 1987. Ecologia das comunidades fitais. In: Simpósio sobre ecossistemas da costa sul e sudeste brasileira: síntese dos conhecimentos Cananéia. Academia de Ciências do Estado de São Paulo.

McABENDROTH, L.; RAMSAY, P.M.; FOGGO, A.; RUNDLE, S.D.; BILTON, D.T. 2005. Does macrophyte fractal complexity drive invertebrate diversity, biomass and body size distributions? Oikos, 111: 279-290.

MENGE, B.A. \& SUTHERLAND, J.P. 1976. Species diversity gradients: synthesis of the roles of predation, competition and temporal heterogeneity. The American Naturalist, 110(973): 351-369. 
MILOSLAVICH, P.; DÍAZ,. J.M.; KLEIN, E.; ALVARADO, J.J.; DÍAS, C.; GOBIN, J.; ESCOBAR-BRIONES, E. et al. 2010. Marine Biodiversity in the Caribbean: Regional Estimates and Distribution Patterns. PLoS ONE. 5(8): e11916.

MONTEIRO, S.M.; CHAPMAN, M.G.; UNDERWOOD, A.J. 2002. Patches of the ascidian Pyura stolonifera (Heller, 1878): structure of habitat and associated intertidal assemblages. J. Exp. Mar. Biol. Ecol., 270(2): 171-189.

MORMUL, R.P.; THOMAZ, S.M.; TAKEDA, A.M.; BEHREND, R.D. 2011. Structural complexity and distance from source habitat determine invertebrate abundance and diversity. Biotropica, 43(6): 738-745.

MORSE, D.R.; LAWTON, J.H.; DODSON, M.M. \& WILLIAMSON, M.H. 1985. Fractal dimension of vegetation and the distribution of arthropod body lengths. Nature, 314: 731-733.

MUKAI, H. 1971. The phytal animals on the thalli of Sargassum serratifolium in the Sargassum region with reference to their seasonal fluctuations. Mar. Biol, 8: 170-182.

MUNIZ, R.A.; GONÇALVES, J.E.A. \& SZÉCHY, M.T.M. 2003. Variação temporal das macroalgas epífitas em Sargassum vulgare C. Agardh (Phaeophyta-Fucales) da Prainha, Arraial do Cabo, Rio de Janeiro, Brazil. Inheringia, 58: 14-24.

MUNIZ, P. \& PIRES-VANIN, A.M.S. 2005. More about taxonomic sufficiency: a case study using polychaete communitites in a subtropical bay moderately affected by urban sewage. Ocean. Sci. J., 40(3): 127-143.

MYERS, A.A. \& McGRATH, D. 1984. A revision of northeast Atlantic species of Ericthonius (Crustacea: Amphipoda). J. Mar. Biol. Ass. UK, 64: 379-400.

NASSAR, C.A.G.; LAVRADO, H.P. \& YONESHIGUE-VALENTIN, Y. 2002. Effects of iron-ore particles on propagule release, growth and photosynthetic performance of Sargassum vulgare C.Agardh (Phaeophyta, Fucales). Revista Brasileira de Botânica, 25(4): 459-468.

NEGREIROS-FRANSOZO, M.L.; FRANSOZO, A.; PINHEIRO, M.A.A.; MANTELATTO, F.L.M. \& SANTOS, S. 1991 Caracterização física e química da Enseada de Fortaleza, Ubatuba, SP. Rev. Bras. Geo. 21(2): 114-120. 
NISHIHIARA, G.N., TERADA, R. \& NORO, T. 2005. Effect of temperature and irradiance on the uptake of ammonium and nitrate by Laurencia brongniartii (Rhodophyta, Ceramiales). Journal of Applied Phycology, 17:371-377.

NORDERHAUG, K.M.; CHRISTIE, H. \& RINDE, E. 2002. Colonization of kelp imitations by epiphyte and holdfast fauna, a study of mobility patterns. Mar. Biol., 141: 965-973.

ORAV-KOTTA, H. \& KOTTA, J. 2004. Food and habitat choice of the isopod Idotea baltica in the northeastern Baltic Sea. Hydrobiologia, 54: 79-85.

ORNELLAS, A.B. \& COUTINHO, R. 1998. Spatial and temporal patterns of distribution and abundance of a tropical fish assemblage in a seasonal Sargassum bed, Cabo Frio Island, Brazil. Journal of Fish Biology, 53(A): 198-208.

PARKER, J.D.; DUFFY, J.E.; ORT, R.J. 2001 Plant species diversity and composition: experimental effects on marine epifaunal assemblages. Mar. Ecol. Prog. Ser., 224: 5567.

PAULA, E.J. 1978 Taxonomia, aspectos biológicos e ecológicos do gênero Sargassum (Phaeophyta - Fucales) no litoral do estado de São Paulo. Dissertação de mestrado, Instituto de Biociências, Universidade de São Paulo, 190p.

PAULA, E.J. 1988. Gênero Sargassum C. Ag. (Phaeophyta-Fucales) no litoral do estado de São Paulo, Brasil. Bol. Bot. Univ. São Paulo, 10: 65-118.

PAULA, E.J. \& OLIVEIRA-FILHO, E.C. 1980. Phenology of two populations of Sargassum cymosum (Phaeophyta - Fucales) of São Paulo state coast, Brazil. Bol. Inst. Bot., 8: 21-39.

PAULA, E.J. \& OLIVEIRA-FILHO, E.C. 1982. Wave exposure and ecotypical differentiation in Sargassum cymosum (Phaeophyta-Fucales). Phycologia, 21: 145153.

PAVIA, H.; CARR, H. \& ÅBERG, P. Habitat and feeding preferences of crustacean mesoherbivores inhabiting the brown seaweed Ascophyllum nodosum (L.) Le Jol. and its epiphytic macroalgae. J. Exp. Mar. Biol. Ecol., 236: 15-32, 1999.

PEART, R.A. 2004. A revision of the Cymadusa filosa complex (Crustacea: Amphipoda: Corophioidea: Ampithoidae). J. Nat. Hist., 38: 301-336. 
PEREIRA, P.H.C.; BIASI, P.C.; JACOBUCCI, G.B. 2010. Dinâmica populacional e distribuição espacial de Tricolia affinis (Mollusca: Gastropoda) associados a Sargassum spp. no litoral norte de São Paulo. Rev. Bras. Zoociênc., 12(1): 7-16.

POORE, A.G.B. 1994. Selective herbivory by amphipods inhabiting the brown alga Zonaria angustata. Mar. Ecol. Prog, Ser., 107: 113-123.

POORE, A.G.B.; HILL, N.A.; SOTKA, E.E. 2008. Phylogenetic and geographic variation in host breadth and composition by herbivorous amphipods in the Family Ampithoidae. Evolution, 62: 21-38.

REIS, R.P.; LEAL, M.C.R.; YONESHIGUE-VALENTIN, Y.; BELLUCO, F. 2003. Efeito de fatores bióticos no crescimento de Hypnea musciformis (Rhodophyta, Gigartinales). Acta Botanica Brasilica, 17: 279-286.

RULE, M.J. \& SMITH, S.D. 2005. Spatial variation in the recruitment of benthic assemblages to artificial substrata. Mar. Ecol. Prog. Ser., 290: 67-78.

RUSSO, A.R. 1990. The role of seaweed complexity in structuring Hawaiian epiphytal amphipod communities. Hydrobiologia, 94: 1-12.

SANCHEZ-JEREZ, P.; BARBERÁ-CEBRIÁN, C.; RAMOS-ESPLÁ, A.A. 2000. Influence of the structure of Posidonia oceanica meadows modified by bottom trawling on crustacean assemblages: comparison of amphipods and decapods. Sci. Mar., 64: 319-326.

SARVALA, J. \& UITTO, A. 1991. Production of the benthic amphipod Pontoporeia affinis and $\mathrm{P}$. femorata in a Baltic archipelago. Ophelia, 34: 71-90.

SASSI, R.; KUTNER, M.B.B. Variação sazonal do fitoplâncton da região do Saco da

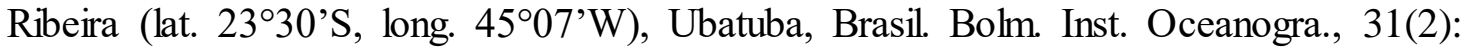
29-42, 1982.

SEZGIN, M. \& KATAGAN, T. 2007. An account of our knowledge of the amphipod fauna of the Black Sea. Crustaceana, 80: 1-11.

SMITH, S.D.A.; SIMPSON, R.D.; CAIRNS, S.C. 1996. The macrofaunal community of Ecklonia radiate holdfasts: description of the faunal assemblage and variation associated with differences in holdfast volume. Aust. J. Ecol., 21: 81-95. 
SMITH, S.D.A. \& RULE, M.J. 2002. Artificial substrata in a shallow sublittoral habitat: do they adequately represent natural habitats or the local species pool? J. Exp. Mar. Biol. Ecol., 277: 25-41.

SOMERFIELD, P.J. \& CLARKE, K.R. 1995. Taxonomic levels, in marine community studies, revisited. Mar. Ecol. Prog. Ser., 127: 113-119.

STENECK, R.S\& DETHIER, M.N. 1994. A functional group approach to the structure of algal-dominated communities. Oikos, 69(3): 476-498.

STEWART, T.; SHUMAKER, T. \& RADZIO, T. 2003. Linear and nonlinear effect of habitat structure on composition and abundance in the macroinvertebrate community of a large river. A, Mid. Nat., 149: 293-305.

STRADIOTTO, G.C. 2013. Densidade e resistência a antimicrobianos de Enterococcus sp e Escherichia coli isoladas de águas, areias e algas do gênero Sargassum de praias recreacionais do Litoral Norte do Estado de São Paulo. Dissertação de Mestrado, Instituto de Biociências, UNESP - Rio Claro, 96pp.

STONER, A.W. \& LEWIS, F.G. 1985. The influence of quantitative and qualitative aspects of habitat complexity in tropical sea-grass meadows. J. Exp. Biol. Eco.., 94: $19-40$.

SUEIRO, M.C.; BORTOLUS, A.; SCHWINDT, E. 2011. Habitat complexity and Community composition: relationships between different ecosystem engineers and the associated macroinvertebrate assemblages. Helgol Mar. Res., 65: 467-477.

SUGIHARA, G. \& MAY, R.M. 1990. Applications of fractal in ecology. Trends Ecol. Evol. 5: 79-86.

SZÉCHY, M.T.M. 1996. Estrutura dos bancos de Sargassum (Phaeophyta - Fucales) do litoral dos Estados do Rio de Janeiro e de São Paulo. São Paulo. Tese de Doutorado. Instituto de Biociências, Universidade de São Paulo, v.1, 186p., v.2, 159p.

SZÉCHY, M.T.M.; GALLIEZ, M.; MARCONI, M.I. 2006. Quantitative variables applied to phenological studies of Sargassum vulgare C. Agardh (Phaeophyceae Fucales) from Ilha Grande Bay, State of Rio de Janeiro. Rev. Bras. Bot., 29(1): 27-37.

SZÉCHY, M.T.M. \& PAULA, E.J. 1997. Macroalgas epífitas em Sargassum (Phaeophyta, Fucales) do litoral dos Estados do Rio de Janeiro e de São Paulo, Brasil. Leandra, 12:1-10. 
SZÉCHY, M.T.M. \& PAULA, E.J. 2000. Padrões estruturais quantitativos em bancos de Sargassum (Phaeophyta, Fucales) do litoral dos estados do Rio de Janeiro e São Paulo, Brasil. Rev. Bras. Bot., 23(2): 121-132.

SZÉCHY, M.T.M. \& PAULA, E.J. 2010. Phaeophyceae. In: Catálogo de plantas e fungos do Brasil. Vol. 1. (Forzza, R.C. Eds), pp. 404-408. Rio de Janeiro: Andrea Jakobsson Estúdio; Instituto de Pesquisas Jardim Botânico do Rio de Janeiro.

SZÉCHY, M.T.M. \& DE SÁ, A.D.F. 2008. Variação sazonal do epifitismo por macroalgas em uma população de Sargassum vulgarae C. Agardh (Phaeophyta, Fucales) da Baía da Ilha Grande, Rio de Janeiro. Oecol. Bras., 12(2): 299-314.

TANAKA, M.O. \& LEITE, F.P.P. 2003. Spatial scaling in the distribution of macrofauna associated with Sargassum stenophyllum (Mertens) Martius: analyses of faunal groups, gammarid life habits, and assemblage structure. Journal of Experimental Marine Biology and Ecology, 293: 1-22.

TANIGUCHI, H.; NAKANO, S.; TOKESHI, M. 2003. Influences of habitat complexity on the diversity and abundance of epiphytic invertebrates on plants. Freshwater Biol. $48,718-728$.

TANIGUCHI, H. \& TOKESHI, M. 2004. Effects of habitat complexity on benthic assemblages in a variable environment. Fresh. Biol., 49:1164-1178.

TARAMELLI, E. \& PEZZALI, S. 1986. Ecologia e distribuzione dei crostacei anfipode nei laghi costieri della provincial di Latina. Boll. Mus. Civ. Stor. Nat. Verona, 13: 295-318.

TARARAM, A.S. \& WAKABARA, Y. (1981). The mobile fauna - especially Gammaridae - of Sargassum cymosum. Mar. Ecol. Prog. Ser., 5: 157-163.

TAYLOR, R.B. \& COYLE, R.G. 1994. Mobile epifauna on subtidal brown seaweeds in northeastern New Zealand. Mar. Ecol. Prog. Ser., 115: 271-282.

THIBAUT, T.; PINEDO, S.; TORRAS, X.; BALLESTEROS, R. 2005. Long-term decline of population of Fucales (Cystoseira spp. and Sargassum spp.) in the Albères coast (France, Northwestern Mediterranean). Mar. Pol. Bull., 50: 1472-1489.

THOMAZ, S.M.; DIBBLE, E.D.; EVANGELISTA, L.R.; HIGUTI, J.; BINI, L.M. 2008. Influence of aquatic macrophyte habitat complexity on invertebrate abundance and richness in tropical lagoons. Freshw. Biol, 53: 358-367. 
THOMAZ, S.M. \& CUNHA, E.R. 2010. The role of macrophytes in habitat structuring in aquatic ecossystems: methods of measurement, causes and consequences on animal assemblages' composition and biodiversity. Acta Limnologica Brasiliensia, 22(2): 218-236.

TILMAN, D. 1994. Competition and biodiversity in spatially structure habitats. Ecology, 75: 2-16, 1994.

TOKESHI, M. \& ARAKAKI, S. 2012. Habitat complexity in aquatic systems: fractals and beyond. Hydrologia, 685:27-47.

TORRES, A.C.; VEIGA, P.; RUBAL, M.; SOUSA-PINTO, I. 2015. The role of annual macroalgal morphology in driving its epifaunal assemblages. J. Exp. Mar. Biol. Ecol., 464: 96-106.

UNDERWOOD, A.J. 1997. Experiments in ecology: their logical design and interpretation using analysis of variance. Cambridge University Press, Cambridge, UK.

VEIGA, P.; RUBAL, M.; SOUSA-PINTO, I. 2014. Structural complexity of macroalgae influences epifaunal assemblages associated with native and invasive species. Marina Environmental Research, 10:115-123.

VELOSO, A.P.A.; SZÉCHY, M.T.M. 2008. Variações espaciais e temporais no desenvolvimento vegetativo e reprodutivo da macroalga Sargassum C. Agardh (Fucales, Phaeophyceae) - Síntese do conhecimento. Oecol. Bras., 12(2): 275-290, 2008.

VENEKEY, V.; FONSÊCA-GENEVOIS, V.; ROCHA, C.M.; SANTOS, P.J.P. 2008. Distribuição espaço-temporal da meiofauna em Sargassum polyceratium Montagne (Fucales, Sargassaceae) de um costão rochoso do nordeste do Brasil. Atlântica, Rio Grande, 30(1): 53-67.

VIEJO, R.M. 1999. Mobile epifauna inhabiting the invasive Sargassum muticum and two local seaweeds in northern Spain. Aquat. Bot., 64: 131-149.

VIDOTTI, E.C. \& ROLLEMBER, M.C.E. 2004. Algas: da economia nos ambientes aquáticos à bioremediação e à química analítica. Quimica Nova, 27(1): 139-145.

WARFE, D.M. \& BARMUTA, L.A. 2006. Habitat structural complexity mediates food web dynamics in freshwater macrophyte community. Oecologia, 150: 141-154. 
WARFE, D.M.; BARMUTA, L.A.; WOTHERSPOON, S. 2008. Quantifying habitat structure convolution and living space for species in complex environments. Oikos, 117: 1764-1773.

WELLS, E.; WILKINSON, M.; WOOD, P.; SCANLAN, C. 2007. The use of macroalgal species richness and composition on intertidal rocky seashores in the assessment of ecological quality under the European Water Framework Directive. Marine Pollution Bulletin, 55(1): 151-161.

WETZEL, M.A.; SCHOLLE, K.; TESCHKE, K. 2014. Artificial structures in sedimentdominated estuaries and their possible influences on the ecosystem. Mar. Environ. Res., 99: 125-135.

WILLIS， S.C.; WINEMILLER， K.O.; LÓPEZ-FERNÁNDEZ， H. 2005. Habitat structural complexity and morphological diversity of fish assemblages in neotropical floodplain river. Oecologia, 142: 284-295.

YEBRA, D.M.; KIIL, S.; DAM-JOHANSEN, K. 2012. Antifouling technology - past, present and future steps towards efficient and environmentally friendly antifouling coatings. Prog. Org. Coat., 50: 75-104.

WAKABARA, Y.; TARARAM, A.S.; TAKEDA, A.M. 1983. Comparative study of the amphipod fauna living on Sargassum of two Itanhaém shores of Brazil. I. Crust. Biol., 3(4): 602-607.

WOODS, C. 2009. Caprellid amphipods: an overlooked marine finfish aquaculture resource? Aquaculture, 289: 199-211.

ZINTZEN, V.; NORRO, A.; MASSIN, C.; MALLEFET, J. 2008. Spatial variability of epifaunal communities from artificial habitat: Shipwrecks in the Southern Bight of the North Sea. Estuar. Coast. Shelf Sci., 76: 327-344. 